Universidade de São Paulo

Instituto de Astronomia, Geofísica e Ciências Atmosféricas

Departamento de Geofísica

Débora dos Santos Cotis

\title{
A gênese dos diques subalcalinos do Enxame da Serra do Mar na Região Serrana do Estado do Rio de Janeiro
}

São Paulo 
Débora dos Santos Cotis

\title{
A gênese dos diques subalcalinos do Enxame
}

\section{da Serra do Mar na Região Serrana do Estado do Rio de Janeiro}

\author{
Versão Corrigida. \\ O original encontra-se disponível na Unidade.

Dissertação apresentada ao
Departamento Geofísica do Instituto de
Astronomia, Geofísica e Ciências \\ Atmosféricas da Universidade de São Paulo \\ como requisito parcial para obtenção do \\ título de Mestre em Ciências.
}

Área de Concentração: Geofísica

Orientador(a): Prof(a). $\operatorname{Dr}(\mathrm{a}) . \quad$ Leila Soares Marques

São Paulo 
À minha mãe e inspiração, Elaine Vitor. 


\section{RESUMO}

Os diques da Região Serrana do Rio de Janeiro, situados nos municípios de Nova Friburgo, Macuco e Bom Jardim, pertencem ao Enxame da Serra do Mar. Parte dessas ocorrências apresenta características geoquímicas e isotópicas distintas daquelas dos demais diques do enxame, sendo principalmente caracterizadas por baixas concentrações de titânio e elementos incompatíveis. Este estudo apresenta os resultados da investigação da gênese dos diques que afloram nessa região, através de análises de elementos maiores, menores, traço e razões isotópicas ( $\mathrm{Sr}$ e $\mathrm{Nd}$ ).

Os diques são de natureza subalcalina e quimicamente representados por basaltos toleíticos e andesitos basálticos. As análises de geoquímica elemental propiciam a distinção de três grupos, o primeiro com os teores de $\mathrm{TiO}_{2} \leq 2 \%$ (BTi) e mais primitivos, o segundo com teores de $3 \% \geq \mathrm{TiO}_{2}>2 \%$ e restritos à região do Distrito de Lumiar (ATiLumiar), e o terceiro com teores de $\mathrm{TiO}_{2}>3 \%$ (ATi) e mais evoluídos. Os dados sugerem a significativa influência de contaminação crustal durante a evolução magmática e apontam similaridades do grupo BTi com os basaltos dos derrames Gramado da Província Magmática do Paraná (PMP). Os grupos ATi-Lumiar e ATi, por sua vez, apresentam semelhanças aos basaltos dos derrames Pitanga da PMP, com os diques ATi apresentando maior enriquecimento em elementos incompatíveis. Os cálculos de balanço de massa usando elementos maiores e menores e também a modelagem de elementos traço apontam a importância do processo de cristalização fracionada na evolução magmática para os três grupos, embora o sistema claramente não tenha sido fechado, principalmente no grupo BTi. As razões isotópicas de Sr e Nd sugerem que os grupos BTi e ATi foram originados por fontes mantélicas com características geoquímicas distintas. Os dados apontam também que os diques BTi foram originados por fontes similares àquelas que originaram os diques dos grupos $A$ e $B$ presentes na Região dos Lagos (RJ). Tal comportamento pode estar relacionado a heterogeneidades do manto litosférico, quimicamente afetado por processos de subducção durante a amalgamação do Gondwana Ocidental.

PALAVRAS CHAVE: Enxame da Serra do Mar, Província Magmática do Paraná, Diques toleíticos do Rio de Janeiro, Enxames Diques Máficos. 


\section{ABSTRACT}

The dykes of the Serrana Region of Rio de Janeiro, located in the municipalities of Nova Friburgo, Macuco, and Bom Jardim, belong to the Serra do Mar Swarm. Some of these intrusive rocks presents geochemical and isotopic characteristics distinct from those of the other dykes of such swarm, being mainly characterized by low concentrations of titanium and incompatible elements. This study presents the results of the investigation of the dyke genesis that outcrop in this region, using analyzes of major, minor, trace elements, and $\mathrm{Sr}$ and $\mathrm{Nd}$ isotopic ratios.

Dykes are subalkaline in nature and chemically represented by tholeiitic basalts and basaltic andesites. Elemental geochemical analyzes allowed the distinction of three groups, the first presents $\mathrm{TiO}_{2} \leq 2 \%(\mathrm{BTi})$ and is more primitive, the second with $3 \% \geq$ $\mathrm{TiO}_{2}>2 \%$ is restricted to the Lumiar District region (ATi-Lumiar), and the third one presenting $\mathrm{TiO}_{2}$ contents $>3 \%(\mathrm{ATi})$ is more differentiated. The data suggest the significant influence of crustal contamination during magmatic evolution and point out similarities of the BTi group with the Gramado basaltic flows of the Paraná Magmatic Province (PMP). The ATi-Lumiar and ATi groups, in turn, show chemical and isotopic similarities to the Pitanga basaltic flows of the PMP, with the ATi dykes showing significant enrichment in incompatible elements. Mass balance calculations using major and minor oxides, along with trace element modelling, point out the importance of the fractional crystallization process during magmatic evolution for the three groups, although the system clearly has not been closed, mainly in the BTi group. The Sr and Nd isotopic ratios suggest that the BTi and ATi groups were originated from mantle sources with distinct geochemical characteristics. The data also indicate that the BTi dykes originated from mantle sources similar to those that originated the dykes belonging to groups $A$ and $B$, which are found in the Lagos Region (RJ). Such behavior may be related to mantle heterogeneities in the lithospheric mantle chemically affected by subduction processes during the amalgamation of Western Gondwana.

KEY-WORDS: Serra do Mar Dyke Swarm, Paraná Magmatic Province, Tholeiitic magmatism of the Rio de Janeiro; Mafic Dyke Swarms. 


\section{AGRADECIMENTOS}

Inicialmente, agradeço ao Programa de Excelência Acadêmica da Coordenação de Aperfeiçoamento de Pessoal de Nível Superior (PROEX/CAPES) pela bolsa concedida, a qual tornou possível a execução do projeto.

Agradeço ao Conselho Nacional de Desenvolvimento Científico e Tecnológico (CNPq) pelo financiamento do trabalho de campo e das análises químicas e isotópicas (processo 303139/2017-0).

Agradeço à minha orientadora, Leila Soares Marques, pelo apoio e dedicação constantes, pela paciência desde a minha decisão de me aventurar entre os diversos diagramas, pelas críticas científicas indispensáveis ao longo da escrita da dissertação e, sobretudo, pelo exemplo de pesquisadora.

Agradeço à minha supervisora no IPEN-CNEN/SP, Ana Maria Graciano Figueiredo, pela orientação nos processos burocráticos e pela disponibilidade e amabilidade em esclarecer dúvidas referentes à ativação neutrônica experimental.

Agradeço ao professor da UFRRJ, Artur Corval, pelas amostras britadas cedidas para o presente estudo e pela disposição para esclarecimentos e discussões científicas.

Agradeço ao laboratório NAP Geoanalítica USP, em especial ao José Sertek, pela realização das análises químicas das amostras por Fluorescência de Raios-X.

Agradeço aos meus queridos colegas no IPEN-CNEN/SP, técnica Regina Beck, professor Guilherme Zahn e a Cláudia Arruda, pelo apoio, generosidade e disponibilidade constantes.

Eu sou muito grata aos meus colegas envolvidos no trabalho de amostragem dos diques, Caio Vicentini, Divanir Conego Junior e Nelson Bardelli dos Santos, pelo companheirismo, dedicação e empenho contínuos na caça ao tesouro, e pelo bom humor, histórias compartilhadas e apoio.

Agradeço à técnica de laboratório, Sonia Alonso, pela imensa ajuda no processo de britagem das amostras, pela simpatia e disposição constantes, pela doçura de seus bolos e pela generosidade.

Eu sou muito grata também aos meus queridos colegas de pós-graduação, em especial ao Pedro Chibane, Ualisson Bellon e Gelson Ferreira, pela sincera amizade, companheirismo, carinho, apoio e descontração essenciais nesta jornada. 
Agradeço também a todo o corpo docente e técnico-administrativo do IAG-USP, em especial ao técnico Roberto Zanon e aos professores Victor Sacek, Yara Marangoni e Fernando Brenha pelas discussões científicas e disciplinas ofertadas essenciais.

Por fim, agradeço às minhas mãe e irmã, de quem eu tenho tanto orgulho e admiração, por todo apoio, dedicação, compreensão e encorajamento, sempre tão imprescindíveis. 
IV. SUMÁRIO

I. RESUMO

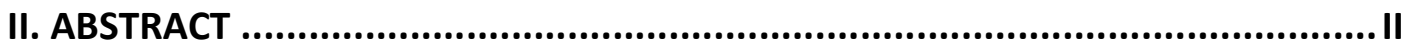

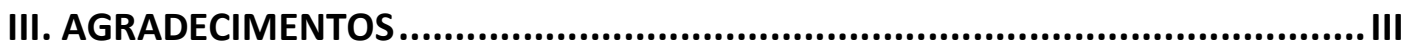

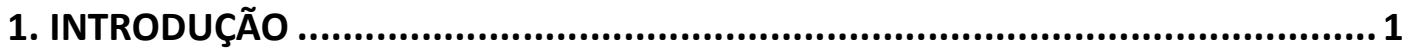

2. CONTEXTO GEOLÓGICO ..................................................................... 5

2.1. Exame da Serra do Mar ................................................................ 11

2.1.1. Diques da Suíte Serrana ............................................................... 17

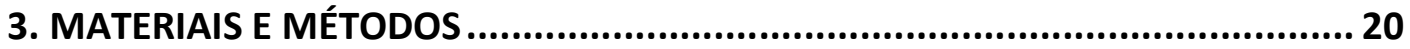

3.1. Trabalhos de amostragem............................................................ 23

3.2. Preparação das amostras ................................................................. 26

3.3. Fluorescência de Raios-X ............................................................. 28

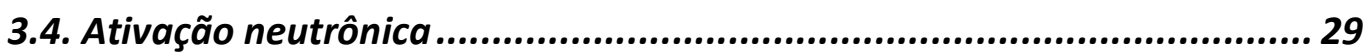

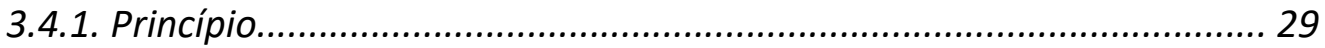

3.4.2. Materiais de referência empregados................................................ 32

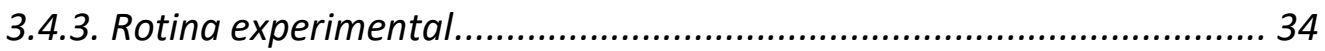

3.5. Espectrometria de massa termoiônica ............................................... 36

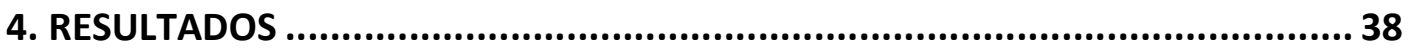

4.1. Fluorescência de Raios X........................................................... 38

4.2. Ativação neutrônica ..................................................................... 42

4.2.1. Critério das incertezas associadas às áreas de pico ........................... 44

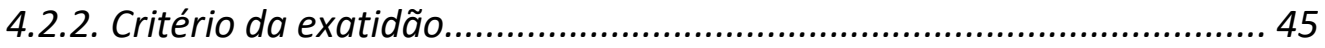

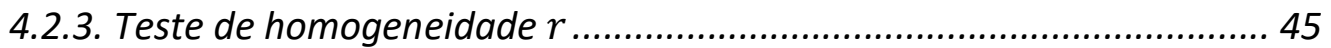

4.2.4. Teste de compatibilidade Zeta-score ............................................... 47

4.2.5. Discussão dos resultados para as amostras ..................................... 49

4.3. Espectrometria de massa termoiônica .............................................. 55

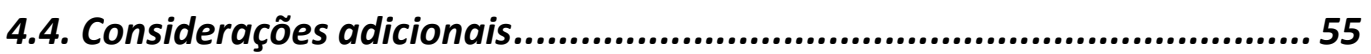

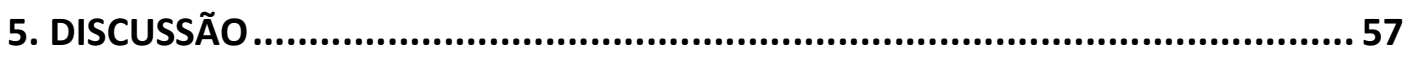

5.1. Caracterização geoquímica dos diques investigados ............................5 57

5.1.1. Classificação e nomenclatura ......................................................... 57 
5.1.2. Óxidos de elementos maiores e menores .......................................... 61

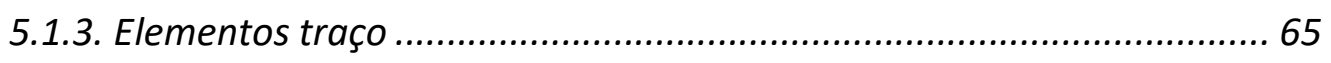

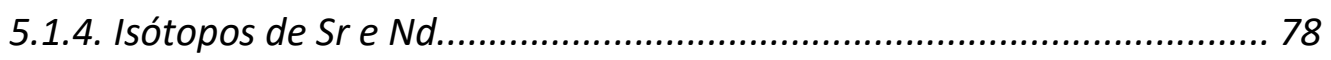

5.2. Processo de cristalização fracionada................................................. 80

5.2.1. Aplicação dos cálculos do balanço de massa aos diques investigados 81

5.3. Contaminação crustal................................................................ 86

5.3.1. Investigação da ocorrência de processos de mistura ........................ 89

5.3.2. Investigação da ocorrência de processos AFC ....................................93

5.4. Comentários gerais ................................................................... 98

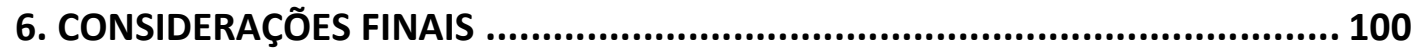

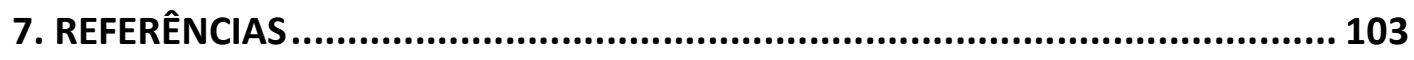

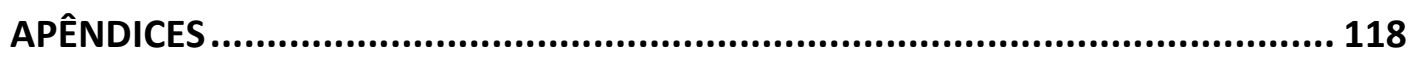

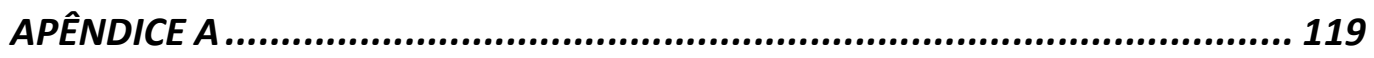

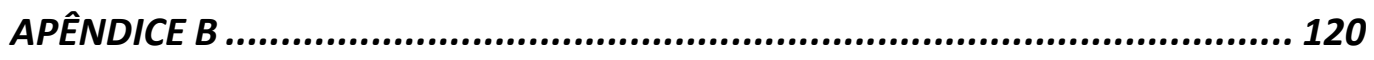

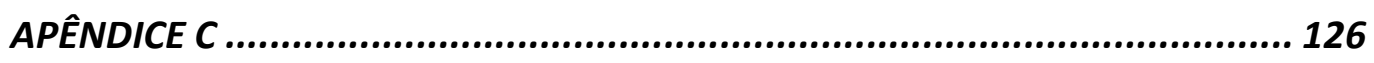

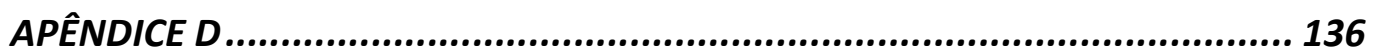

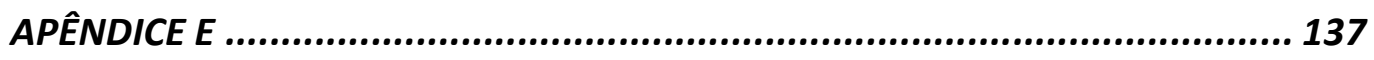

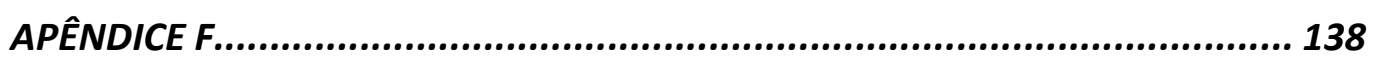




\section{V. ÍNDICE DE FIGURAS}

Figura 2.1 - llustração da Província Magmática Paraná-Etendeka nos primeiros estágios de expansão do Atlântico Sul. FL - Enxame de Florianópolis. PG - Enxame de Ponta Grossa. SM - Enxame da Serra do Mar. MV - Enxame de Morro Vermelho. Baseado em Bellieni et al. (1986), Nardy et al. (2008), Machado et al. (2018) e Carvas et al. (2021).

\section{6}

Figura 2.2 - Mapa do Modelo Digital de Terreno (MDT) com a localização dos diques do Enxame Serra do Mar (Almeida, 1986; Marques, 2001; Corval, 2009).

Figura 3.1 - Mapa geológico simplificado do Enxame Serra do Mar (ESM) com a distribuição dos diques reportado por Almeida (1986), dos diques de conteúdo de $\mathrm{TiO}_{2}$ $<2 \%$ e $\mathrm{TiO}_{2}>2 \%$ de Corval (2009) e das amostras de diques investigados na Região Serrana do Estado do Rio de Janeiro, com os municípios próximos evidenciados (retângulo pontilhado verde). Adaptado de Marques (2001).

Figura 3.2 - Afloramentos sob a forma de blocos rolados com esfoliação esferoidal, na região do Distrito de Lumiar e em torno (A: ponto LMD-RJ-8003; B: ponto LMD-RJ-8000; C: ponto LMD-RJ-8014; D: ponto LMD-RJ-8011). .25

Figura 3.3 - Britador de mandíbulas de aço inoxidável da marca Fritsch (A: destaque para os níveis de britagem e motor; B. destaque para a bandeja e localização das mandíbulas). .26

Figura 3.4 - Esquema de sequência de eventos para a reação de captura de nêutrons seguida de decaimento $\beta^{-}$e emissão de radiação gama para a formação e desexcitação do núcleo irradiado. PGAA: Prompt Gamma Neutron Activation Analysis; DGNAA: Delayed Gamma Neutron Activation Analysis (baseada em TECDOC, 1990).

Figura 4.1 - Valores de Z-score obtidos na análise do material de referência BRP-1 por ativação neutrônica instrumental.

Figura 5.1 - Diagrama TAS (Total Álcalis-Sílica) com nomenclatura química dos 33 diques investigados, com valores em (\%). As amostras do grupo ATi estão representadas pelos círculos cheios de cor laranja, as amostras do grupo ATi-Lumiar estão representadas pelos círculos cheios de cor amarela e as amostras do grupo BTi, círculos cheios de cor verde. A linha pontilhada de cor lilás representa a linha divisória entre os campos alcalino e subalcalino (Irvine $\&$ Baragar, 1971) e a linha tracejada de cor preta, a linha de separação entre os basaltos alcalinos e os basaltos toleíticos (Zanettin, 1984). .58

Figura 5.2 - Diagrama R1-R2 $[\mathrm{R} 1=4 \mathrm{Si}-11(\mathrm{Na}+\mathrm{K})-2(\mathrm{Fe}+\mathrm{Ti})$ e R2 $=6 \mathrm{Ca}+2 \mathrm{Mg}+\mathrm{Al}] \mathrm{de}$ nomenclatura proposta por De La Roche et al. (1980). As amostras do grupo ATi estão representadas pelos círculos cheios de cor laranja, as amostras do grupo ATi-Lumiar estão representadas pelos círculos cheios de cor amarela e as amostras do grupo BTi, círculos cheios de cor verde.

Figura 5.3 - Diagrama AFM de averiguação da tendência magmática. As curvas diferenciam e separam as séries toleíticas das cálcio-alcalinas conforme Kuno (1968) e Irvine \& Baragar (1971). Grupo ATi: círculo cheio laranja; grupo ATi-Lumiar: círculo cheio amarelo; grupo BTi: círculo cheio verde. 60 
Figura 5.4 - Diagrama binário FeOt/MgO vs $\mathrm{SiO}_{2}$ de Myashiro (1994), com valores em (\%). A reta de cor magenta separa a série toleítica da cálcio-alcalina. Grupo ATi: círculo cheio laranja; grupo ATi-Lumiar: círculo cheio amarelo; grupo BTi: círculo cheio verde. A título de comparação, estão representadas amostras de diques da região realizadas por Ludka (1997) e Corval (2008).

Figura 5.5 - Diagramas de variação de óxidos de elementos maiores e menores (\%) em função da concentração de MgO (\%). Grupo ATi: círculo cheio laranja; grupo ATi-Lumiar: círculo cheio amarelo; grupo BTi: círculo cheio verde.

Figura 5.6 - Diagramas de da razão $\mathrm{CaO} / \mathrm{Al}_{2} \mathrm{O}_{3}$ em função das concentrações de $\mathrm{MgO}$ (esquerda) e $\mathrm{SiO}_{2}$ (direita), concentração em (\%). Grupo ATi: círculo cheio laranja; grupo ATi-Lumiar: círculo cheio amarelo; grupo BTi: círculo cheio verde. .64

Figura 5.7 - Diagrama de variação de ETR $(\mathrm{mg} / \mathrm{kg})$ em função da concentração de $\mathrm{MgO}$ (\%). Grupo ATi: círculo cheio laranja; grupo ATi-Lumiar: círculo cheio amarelo; grupo BTi: círculo cheio verde.

Figura 5.8 - Diagrama de variação de ETR $(\mathrm{mg} / \mathrm{kg})$ em função da concentração de $\mathrm{Zr}$ (fortemente incompatível; $\mathrm{mg} / \mathrm{kg}$ ). Grupo ATi: círculo cheio laranja; grupo ATi-Lumiar: círculo cheio amarelo; grupo BTi: círculo cheio verde. .68

Figura 5.9 - Diagrama de variação de elementos traço incompatíveis $(\mathrm{mg} / \mathrm{kg})$ em função da concentração de Zr (fortemente incompatível; mg/kg). Grupo ATi: círculo cheio laranja; grupo ATi-Lumiar: círculo cheio amarelo; grupo BTi: círculo cheio verde. .69

Figura 5.10 - Diagrama de variação de elementos traço incompatíveis $(\mathrm{mg} / \mathrm{kg})$ em função da concentração de MgO (\%). Grupo ATi: círculo cheio laranja; grupo ATi-Lumiar: círculo cheio amarelo; grupo BTi: círculo cheio verde. Para os diques ATi-Lumiar não há determinações de $U$. .70

Figura 5.11 - Padrões de abundância dos elementos terras raras do grupo BTi de acordo com o grau de diferenciação magmática (conteúdo de $\mathrm{MgO}$ ), juntamente com os valores máximos e mínimos dos derrames Esmeralda e Gramado (Marques et al., 1989; Peate, 1997) e com diques do grupo ATi e ATi-Lumiar. Amostra 509 de Marques et al. (1989).

Figura 5.12 - Padrões de abundância dos elementos terras raras do grupo ATi-Lumiar e ATi de acordo com o grau de diferenciação magmática (conteúdo de $\mathrm{MgO}$ em \%), juntamente com os valores máximos e mínimos dos derrames Pitanga e Ribeira (Marques et al., 1989; Peate, 1997; Rocha-Júnior et al., 2013) e com diques do grupo ATi e ATi-Lumiar. Amostras KS-775 de Rocha-Júnior et al. (2013) e B-199 de Marques et al. (1989).

Figura 5.13 - Diagrama de razão dos elementos ETR normalizados pelo condrito $\mathrm{Cl}$ (McDonough \& Sun, 1995) dos grupos BTi, ATi-Lumiar e ATi. Grupo ATi: círculo cheio laranja; grupo ATi-Lumiar: círculo cheio amarelo; grupo BTi: círculo cheio verde. .74 
Figura 5.14 - Padrões de abundância dos elementos incompatíveis do grupo BTi de acordo com a diferenciação magmática (conteúdo de $\mathrm{MgO}$ ), juntamente com os valores máximos e mínimos dos derrames Esmeralda e Gramado (Marques et al., 1989; Peate, 1997) e com diques do grupo ATi e ATi-Lumiar. Análises da amostra 509 foi retirada de Marques et al. (1989). .76

Figura 5.15 - Padrões de abundância dos elementos incompatíveis dos grupos ATi e ATiLumiar de acordo com a diferenciação magmática (conteúdo de $\mathrm{MgO}$ ), juntamente com os valores máximos e mínimos dos derrames Esmeralda e Gramado (Marques et al., 1989; Peate, 1997; Rocha-Júnior et al., 2013) e com diques do grupo BTi. Análises das amostras KS-775 e B-199 foram retiradas de Rocha-Júnior et al. (2013) de Marques et al. (1989), respectivamente.

Figura 5.16 - Diagrama das razões isotópicas iniciais de $\mathrm{Sr}$ e $\mathrm{Nd}$ para os diques dos grupos BTi e ATi. Grupo ATi: círculo cheio laranja; grupo BTi: círculo cheio verde; CRN: média das concentrações e das razões isotópicas de $\mathrm{Sr}$ e $\mathrm{Nd}$ das rochas mais radiogênicas do Complexo Rio Negro (Peixoto et al., 2017) conforme Tabela 5.3. As linhas pontilhadas correspondem às curvas dos modelos de evolução magmática do tipo mistura entre os componentes basálticos [diques do Grupo B de Cabo Frio, os derrames BTi (Ribeira, Esmeralda e Gramado) e ATi (Pitanga) da PMP] e crustais (CRN). Os valores ao lado das linhas de mistura correspondem ao percentual do componente crustal em cada mistura. Os campos referentes aos derrames da PMP e aos diques BTi do Grupo B de Cabo FrioBúzios (Bennio et al., 2003; Carvas, 2016) são também mostrados. Grupo ATi: círculo cheio laranja; grupo BTi: círculo cheio verde.

Figura 5.17 - Diagrama de elementos maiores ( $\mathrm{SiO} 2$ e P2O5/K2O) e alguns traço ( $\mathrm{Rb}, \mathrm{Ba}$, Th, La e Zr) em função da razão isotópica inicial de Sr. Elementos maiores em \% e traço em mg/kg; grupo ATi: círculo cheio laranja; grupo BTi: círculo cheio verde. .88

Figura 5.18 - Diagramas das razões de $\mathrm{Rb} / \mathrm{Ba}$, normalizada pelo manto primitivo (McDonough \& Sun, 1995), e de Th/Nb em função das razões iniciais de Sr. Grupo ATi: círculo cheio laranja; grupo BTi: círculo cheio verde.

Figura 5.19 - Diagramas das razões isotópicas iniciais de $\mathrm{Sr}$ e $\mathrm{Nd}$ em função do inverso das concentrações de $\mathrm{Sr}$ e Nd, respectivamente. Grupo ATi: círculo cheio laranja; grupo BTi: círculo cheio verde. Reta pontilhada se refere ao comportamento esperado no processo de mistura simples entre os dois componentes. .93

Figura 5.20 - Modelos de evolução magmática do tipo AFC para as médias das razões isotópicas dos diques dos grupos B e A na região dos Lagos (Bennio et al., 2003; Carvas, 2016), dos derrames Ribeira (Marques et al., 1999; Rocha-Júnior et al., 2013, 2020) e das rochas mais radiogênicas do Complexo Rio Negro (CRN; Peixoto et al., 2017). Grupo BTi: círculo cheio verde. .96

Figura 5.21 - Modelos de evolução magmática do tipo AFC, com valores da razão entre a massa assimilada e a massa fracionada $(r)$ igual a 0,30, para as médias de diques dos grupos B e A (Bennio et al., 2003; Carvas, 2016), dos derrames Ribeira (Marques et al., 1999; Rocha-Júnior et al., 2013, 2020) e das rochas mais radiogênicas do Complexo Rio Negro (CRN; Peixoto et al., 2017). Grupo BTi: círculo cheio verde. .97 
Figura 5.22 - Modelos de evolução magmática do tipo AFC, com valores da razão entre a massa assimilada e a massa fracionada $(r)$ igual a 0,75 , para as médias de diques dos grupos B e A (Bennio et al., 2003; Carvas, 2016), dos derrames Ribeira (Marques et al., 1999; Rocha-Júnior et al., 2013, 2020) e das rochas mais radiogênicas do Complexo Rio Negro (CRN; Peixoto et al., 2017). Grupo BTi: círculo cheio verde. .98 


\section{VI. ÍNDICE DE TABELAS}

Tabela 3.1 - Etapas do protocolo de manuseio e limpeza do laboratório para o britador da marca Fristsch.

Tabela 3.2 - Elementos analisados e as características principais de seus radioisótopos para reações envolvendo nêutrons térmicos (Adams \& Dams, 1969).

Tabela 3.3 - Valores de concentrações dos materiais de referência utilizados neste trabalho $(\mathrm{mg} / \mathrm{kg})$, os valores de desvio padrão encontram-se entre parênteses (Govindaraju, 1994; Cotta et al., 2008).

Tabela 4.1 - Valores recomendados ( $\mu$, Yurimoto et al., 1989) e de concentrações (x) de elementos maiores, menores e traço obtidos por FRX para os materiais de referência JB1 a e JG-1a e os valores de exatidão $(e)$ para os dois lotes de amostras analisados no IGcUSP. Valores de óxidos e perda ao fogo (Lol) são em \% e os valores de elementos traço em $\mathrm{mg} / \mathrm{kg}$ e valores de exatidão em $\%$.

Tabela 4.2 - Valores de concentrações de elementos maiores, menores e traço para a primeira (A1) e segunda (A2) análises por FRX da amostra QT-SV-2A (primeiro lote de amostras), a média das duas análises $(\bar{x})$ e os desvios padrão $(\sigma)$ em valor percentual (\%). Valores de óxidos e perda ao fogo (Lol) são em \% e de elementos traço em $\mathrm{mg} / \mathrm{kg}$.

Tabela 4.3 - Valores de concentrações de elementos maiores, menores e traço para a primeira (A1) e segunda (A2) análises por FRX das amostras LMD-RJ-8010 e LMD-RJ-8018 (segundo lote de amostras), a média das duas análises $(\bar{x})$ e os desvios padrão $(\sigma)$ em valor percentual (\%). Valores de óxidos e perda ao fogo (Lol) são em \% e de elementos traço em $\mathrm{mg} / \mathrm{kg}$.

Tabela 4.4 - Resultados do teste estatístico $r$ para a avaliação da qualidade e confiabilidade do conjunto de concentrações $(\mathrm{mg} / \mathrm{kg})$ determinadas para o material de referência BRP-1 (Cotta et al., 2008) pelo método INAA. O $\mu$ corresponde ao valor certificado, $\sigma$ ao desvio padrão e $\overline{\mathbf{x}}$ à média das medições.

Tabela 4.5 - Valores percentuais de precisão e exatidão (\%) definidos para as concentrações calculadas pelas análises do material de referência BRP-1 (Cotta et al., 2008).

Tabela 4.6 - Resultados das análises por ativação neutrônica térmica realizadas no Centro do Reator de Pesquisas (CRPq) do Instituto de Pesquisas Energéticas (IPENCNEN/SP), em que $\overline{\mathbf{x}}$ consiste nas médias calculadas, $\boldsymbol{n}$ é o número de determinações e $\sigma^{*}$ é a incerteza associada adotada.

Tabela 4.7 - Resultados das análises isotópicas de Sr e Nd por espectrometria de massa termoiônica realizadas no CPGeo-USP.

Tabela 5.1 - Valores médios e desvio padrão, entre parênteses, das razões entre os ETR leves, intermediários e pesados normalizadas pelo condrito $\mathrm{Cl}$ (McDonough \& Sun, 1995) e anomalias de Eu (Eu/Eu*) calculados para os grupos de diques BTi, ATi-Lumiar e ATi. O símbolo $\mathrm{N}$ corresponde ao número de amostras de diques. 
Tabela 5.2 - Valores médios e desvio padrão, entre parênteses, das razões $\mathrm{Rb} / \mathrm{Ba}$, $\mathrm{La} / \mathrm{Nb}$, $\mathrm{Ti} / \mathrm{Tb}$ e Ti/Y normalizados pelo manto primitivo ((McDonough \& Sun, 1995) para os três grupos de diques. O símbolo $\mathrm{N}$ corresponde ao número de amostras de diques pertencentes a cada conjunto.

Tabela 5.3. - Resultados dos melhores ajustes obtidos na aplicação do modelo de cristalização fracionada para os diques do grupo BTi. Ol: olivina; Cpx: augita; Pig: pigeonita; PI: plagioclásio; Mt: magnetita. Mcristalizada: massa cristalizada; $\overline{E R}$ : erro relativo.

Tabela 5.4 - Resultados dos melhores ajustes obtidos na aplicação do modelo de cristalização fracionada para os diques do grupo ATi-Lumiar. Ol: olivina; Cpx: augita; Pig:

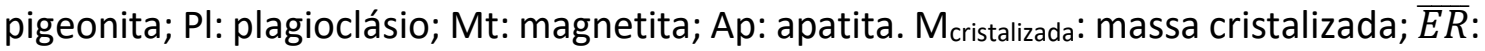
erro relativo.

Tabela 5.5 - Resultados dos melhores ajustes obtidos na aplicação do modelo de cristalização fracionada para os diques do grupo ATi. Ol: olivina; Cpx: augita; Pig: pigeonita; Pl: plagioclásio; Mt: magnetita; Ap: apatita. Mcristalizada: massa cristalizada; $\overline{E R}$ : erro relativo.

Tabela 5.6 - Tabela 5.6 - Valores médios dos end-members basálticos e crustais para as curvas de mistura simples. Grupos B e A de Cabo Frio-Búzios (Bennio et al., 2003; Carvas, 2016), Complexo Rio Negro (CRN; Peixoto et al., 2017) e derrames Pitanga e Ribeira (Piccirillo \& Melfi, 1988; Peate, 1997; Marques, 1999; Rocha-Júnior et al., 2013, 2020). .91

Tabela 5.7 - Valores da média resultado dos coeficientes de partição global dos elementos traço incompatíveis $\mathrm{Sr}, \mathrm{Nd}$, La, Th e $\mathrm{Zr}$ aplicados nos modelos AFC para os diques BTi. 


\section{INTRODUÇÃO}

As Províncias Basálticas Continentais (Continental Flood Basalts; CFB), consideradas um tipo de Grandes Províncias Ígneas (Large Igneous Provinces; LIP; Coffin \& Eldholm, 1994), estão associadas a altos volumes de rochas vulcânicas, comumente relacionados a processos de extensão e ruptura da litosfera continental. Em geral, as CFB caracterizam-se por: a) espessas sequências de derrames básicos com volumes superiores a $10^{6} \mathrm{~km}^{3}$, que podem ser acompanhados por derrames com composição intermediária e ácida em quantidades subordinadas; b) pela duração dos pulsos magmáticos e do magmatismo em si, que são relativamente curtos (5-10 Ma), compreendendo até as fases subsequentes ricas em sílica (Jerram \& Widdowson, 2005); c) pela associação dos derrames a intrusões ígneas (Coffin \& Eldholm, 1994; Jourdan et al., 2007; Machado et al., 2018). Entre as principais CFB, destacam-se as Províncias Karoo, Paraná, Etendeka e Antártica, associadas à ruptura do supercontinente Gondwana durante os períodos Jurássico e Cretáceo (Wilson, 1989).

Estudos geoquímicos, isotópicos e geocronológicos sobre as CFB, sobretudo com idades do Mesozoico e Cenozoico - ou seja, de rochas mais recentes e, portanto, menos afetadas por processos intempéricos - podem fornecer dados precisos sobre a sequência temporal dos processos tectônicos envolvidos e sua evolução, além de fornecer dados acerca das fontes mantélicas responsáveis pelo magmatismo.

Os estudos de corpos intrusivos associados às CFB, por outro lado, fornecem informações complementares e adicionais aos modelos, considerando que uma quantidade significativa dos derrames pode ter sido removida pela erosão. Em particular, os enxames de diques constituem registros magmáticos dos processos de ruptura e separação de massas continentais, contribuindo com dados de caráter estrutural, tais como direções preferenciais, e de caráter composicional, como processos intracrustais que afetaram os magmas basálticos ao longo de sua ascensão. Em outros termos, os enxames de diques preservam informações importantes sobre o sistema de condutos magmáticos durante o processo evolutivo das CFB (Halls, 1982; Marques et al., 2012; Sarmento et al., 2021). 
Uma das maiores manifestações de vulcanismo do mundo, representada pela Província Magmática do Paraná (PMP; Almeida, 1986; Piccirillo \& Melfi, 1988; Peate, 1997), encontra-se majoritariamente nas regiões sul e sudeste do Brasil e precedeu a ruptura da parte ocidental do continente Gondwana e abertura do oceano Atlântico Sul. O vulcanismo apresenta natureza predominantemente básica, e pode ser agrupado em: rochas com alta concentração de $\mathrm{TiO}_{2}\left(\mathrm{TiO}_{2}>2 \%\right)$ e rochas com baixa concentração de $\mathrm{TiO}_{2}\left(\mathrm{TiO}_{2} \leq 2 \%\right)$ e de elementos traço incompatíveis (e.g. $\mathrm{P}, \mathrm{Sr}, \mathrm{Ba}, \mathrm{Zr}$, Ta, $\mathrm{Y}$ e elementos terras raras leves). Alguns estudos, relacionados à gênese da PMP (Gibson et al., 1999; Valente et al., 2007), associam a participação da pluma mantélica Tristão da Cunha como fonte de calor e material para o magmatismo. Porém, dados paleomagnéticos de Ernesto et al. (2002), indicam a localização da pluma a cerca de $1.000 \mathrm{~km}$ ao sul da PMP na época da fase principal do vulcanismo. Entre outros estudos, baseados nos resultados geoquímicos e isotópicos Sr-Nd-Pb (Peate, 1997; Marques et al., 1999; Rocha-Júnior et al., 2020), propõem a contribuição de um manto litosférico subcontinental metassomatizado na geração dos derrames.

O vulcanismo da PMP está associado a corpos intrusivos, na forma sills (e.g. Machado et al., 2007; Lino \& Vlach, 2021) e enxames de diques. Dentre os últimos, destacam-se os de Arco de Ponta Grossa (Piccirillo \& Melfi, 1988; Piccirillo et al., 1990) Florianópolis (Marques et al., 2018) e Serra do Mar (região costeira dos Estados de São Paulo e Rio de Janeiro; Almeida, 1986; Piccirillo \& Melfi, 1988; Peate, 1997; Marques \& Ernesto, 2004; Valente et al., 2007; Corval, 2009; Guedes et al., 2016).

Diversos estudos têm buscado estabelecer as relações entre os diques e os diferentes estágios de abertura do Atlântico Sul, propondo que a colocação dos diques está associada a processos de soerguimento térmico, acomodação tectônica e aos primeiros estágios de desestabilização da litosfera (Chang et al., 1992; Ernst \& Buchan, 1997; Coutinho, 2008; Guedes, 2007). Almeida et al. (2013) discutem aspectos relacionados à colocação dos diques costeiros associados à ruptura continental e vulcanismo da PMP, retratando os estágios que incluem desde a formação do Gondwana, a partir de múltiplos processos de colisão, compostos de blocos com diversas litologias e separados por descontinuidades. Os autores também destacam a ocorrência de mais dois enxames de diques, denominados de Vitória-Colatina e de Resende-Ilha Grande. 
Em particular, o Enxame da Serra do Mar (ESM) possui grande expressão com a intrusão de inúmeros diques, apresentando majoritariamente teores de $\mathrm{TiO}_{2}$ acima de $3 \%$, os quais compreendem litotipos básicos e intermediários (Marques, 2001; Valente et al., 2007; Corval et al., 2008; Vicentini, 2015). Datações K-Ar, ${ }^{40} \mathrm{Ar} /{ }^{39} \mathrm{Ar}$ e dados paleomagnéticos do ESM apresentam idades a cerca de 130, 100 e $50 \mathrm{Ma}$, característica distinta dos demais enxames da PMP (Bennio et al., 2003; Marques et al., 2005; Corval, 2009; Ernesto et al., 2014; Carvas et al., 2021). Idades mais antigas, 193 - $144 \mathrm{Ma}$, foram encontradas na região de Volta Redonda e Resende (Guedes et al., 2016; Almeida et al., 2021). De acordo com esses estudos, os pulsos são decorrentes de eventos tectônicos distintos, relacionados às fases anteriores, concomitantes e posteriores à ruptura continental e à abertura do Atlântico Sul.

Embora de modo bem subordinado e restrito geograficamente, o ESM apresenta diques básicos de teores inferiores a $2 \%$ de $\mathrm{TiO}_{2}(\mathrm{BTi})$, descritos quimicamente como basaltos toleíticos e andesitos basálticos. As intrusões estão situadas na Região dos Lagos (Bennio et al., 2003; Dutra, 2006; Corval, 2009; Carvas, 2016; Almeida et al., 2021; Carvas et al., 2021) e na Região Serrana do Estado do Rio de Janeiro, nas proximidades dos municípios Nova Friburgo, Bom Jardim, Além Paraíba e Macuco, e apresentam características geoquímicas e isotópicas distintas (Ludka, 1997; Marques 2001; Valente et al., 2007; Corval et al., 2008; Corval, 2009).

Os diques BTi da Região Serrana do Rio de Janeiro possuem influências significativas de componentes crustais, com características similares aos derrames do tipo Gramado da PMP, conforme indicam as poucas análises disponíveis na literatura. Na Região Serrana, ocorre também a presença de diques de alto teor de $\mathrm{TiO}_{2}$ (ATi), sem uma separação geográfica nítida (Marques, 2001; Corval et al., 2008).

Diante das particularidades litogeoquímicas dos diques na Região Serrana (BTi e ATi) e da pouca compreensão do papel desse magmatismo no contexto da abertura do Atlântico Sul, o presente estudo visou como objetivo a investigação geoquímica dos diques toleíticos encontrados principalmente na região de Nova Friburgo e Bom Jardim. Os dados obtidos foram utilizados para interpretação petrogenética quantitativa, com a modelagem da evolução magmática (processos de cristalização simples, cristalização fracionada simples ou cristalização fracionada com assimilação crustal) envolvida na gênese dos diques investigados. Além disso, pretendeu-se averiguar se houve a 
participação das mesmas fontes mantélicas na geração das intrusões da Região dos Lagos e das intrusões BTi da Região Serrana, bem como comparar as características geoquímicas dos diques da Região Serrana com aquelas dos derrames basálticos da PMP.

A fim de alcançar os objetivos propostos, foram determinadas as concentrações de elementos maiores, menores e alguns traço $(\mathrm{Cr}, \mathrm{Ni}, \mathrm{Ba}, \mathrm{Rb}, \mathrm{Sr}, \mathrm{Zr}, \mathrm{Y}$ e $\mathrm{Nb})$ através da técnica de Fluorescência de Raios-X. Elementos terra raras ( $\mathrm{La}, \mathrm{Ce}, \mathrm{Sm}, \mathrm{Nd}, \mathrm{Tb}, \mathrm{Eu}, \mathrm{Yb}$ e Lu) e outros traço compatíveis ( $\mathrm{Sc}$ e Co) e incompatíveis (Th, Ta e Hf) foram determinados pelo método de Análise por Ativação Neutrônica Instrumental em um conjunto de 18 amostras. Para as análises das razões isotópicas de $\mathrm{Sr}$ e $\mathrm{Nd}$ em 5 amostras, aplicou-se o método de espectrometria de massa termoiônica, a fim de investigar a natureza das fontes mantélicas envolvidas no magmatismo e os possíveis processos de contaminação crustal. 


\section{CONTEXTO GEOLÓGICO}

A Província Magmática do Paraná (PMP) é resultante de um dos maiores eventos de vulcanismo de caráter dominantemente básico e desenvolveu-se na bacia sedimentar intracratônica do Paraná (Almeida, 1986; Marques \& Ernesto, 2004; Milani et al., 2007) (Figura 2.1). As rochas vulcânicas são de natureza toleítica e recobrem os estados do Rio Grande do Sul, Paraná, Santa Catarina, São Paulo, Sudoeste de Minas Gerais, Sul de Goiás e Sudeste do Mato Grosso, estendendo-se para a região ocidental do Uruguai (Formação Arapey), Nordeste da Argentina (Membro Posadas da Formação Curuzú Cuatiá) e a Leste do Paraguai (Formação Alto Paraná) (Piccirillo \& Melfi, 1988, Nardy et al., 2008). O volume dos sucessivos derrames de lava foi superior a 600.000 $\mathrm{km}^{3}$, visto que ocorreram significativos processos erosivos subsequentes (Gallagher et al., 1994; Frank et al., 2009). Atualmente, a área de cobertura dos derrames é em torno de $917.000 \mathrm{~km}^{2}$ ( $\pm 15.000 \mathrm{~km}^{2}$ ), com $500.000 \mathrm{~km}^{2}$ desta área aflorante (Cabrera, 1971; Frank et al., 2009).

Na estratigrafia da Bacia do Paraná, o vulcanismo é representado pela Formação Serra Geral, majoritariamente ocorrendo sobre os arenitos eólicos juro-cretáceos da Formação Botucatu. Na borda nordeste da província, estados de Minas Gerais e Goiás, os derrames sobrepõem o embasamento cristalino, diretamente sobre rochas metamórficas, enquanto na porção central do estado do Rio Grande do Sul recobrem os depósitos sedimentares lacustres triássicos da Formação Santa Maria (Almeida, 1986; Assine et al., 2004, Milani et al., 2007). Ao norte da bacia, os derrames estão encobertos pelas rochas sedimentares da Sub-bacia Bauru (Basilici et al., 2012; Machado et al., 2018).

$\mathrm{Na}$ costa oeste do continente africano são também registradas, em quantidade minoritária, rochas relacionadas ao vulcanismo da PMP, juntamente com rochas intrusivas associadas, situadas na Bacia de Etendeka na Namíbia, as quais constituem a Província Etendeka (Figura 2.1). Mais ao norte, nas bacias de Cuanza e Namibe em Angola, ocorrem também rochas extrusivas e intrusivas contemporâneas (Marzoli et al., 1999). A Província Etendeka estende-se sobre uma área de $78.000 \mathrm{~km}^{2}$ e, conjuntamente com as rochas vulcânicas da PMP constituem numa das maiores províncias de basaltos continentais conhecidas (Milner \& Le Roex, 1996; Ewart et al., 
2004). A Província Paraná-Etendeka ao todo compreende um volume de no mínimo 1.700 .00 km³ (Frank et al., 2009), antecedeu à abertura do Oceano Atlântico Sul e sua origem está relacionada à ruptura do Gondwana Ocidental.

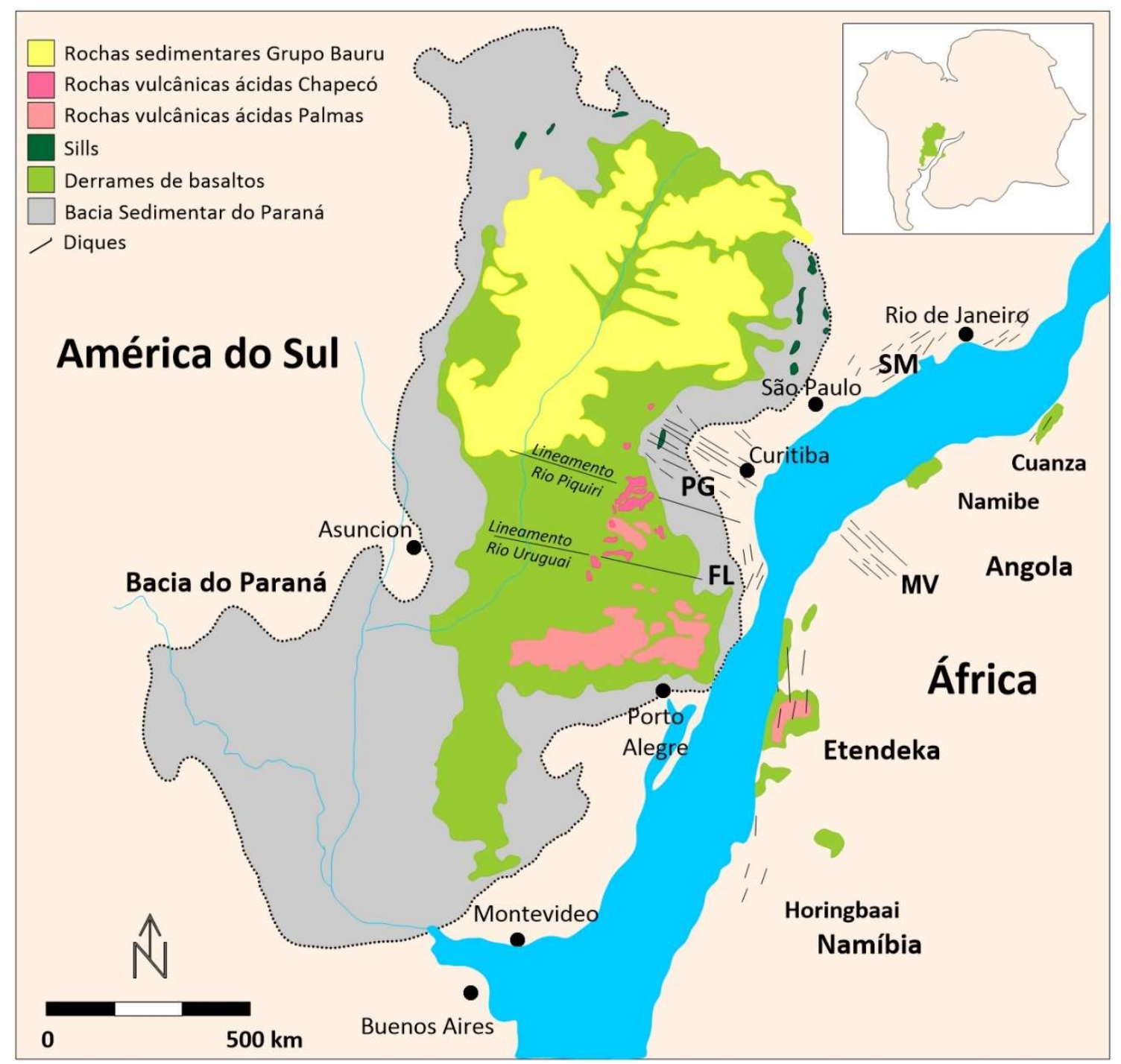

Figura 2.1 - Ilustração da Província Magmática Paraná-Etendeka nos primeiros estágios de expansão do Atlântico Sul. FL - Enxame de Florianópolis. PG - Enxame de Ponta Grossa. SM - Enxame da Serra do Mar. MV - Enxame de Morro Vermelho. Baseado em Bellieni et al. (1986), Nardy et al. (2008), Machado et al. (2018) e Carvas et al. (2021).

O vulcanismo da PMP é constituído principalmente por basaltos toleíticos e andesitos basálticos, os quais representam 90\% das rochas vulcânicas. Enquanto, de modo subordinado, ocorrem andesitos toleíticos, em torno de 7\%, e rochas ácidas, compostas de riodacitos e riolitos, em torno de 3\% (Piccirillo et al., 1988; Peate et al., 1992; Marques \& Ernesto, 2004). Os litotipos ácidos estão concentrados nas porções mais superficiais das sequências de derrames e situados principalmente na borda sul e 
ao longo da margem, representando os estágios finais do magmatismo toleítico (Piccirillo et al., 1988; Nardy et al., 2008).

Estudos geológicos e geoquímicos permitiram dividir os basaltos toleíticos e andesitos basálticos em dois grandes grupos de acordo com seus teores de $\mathrm{TiO}_{2}$ (Bellieni et al., 1984; Mantovani et al., 1985; Piccirillo \& Melfi, 1988; Marques et al., 1989). O grupo com $\mathrm{TiO}_{2}>2 \%$ (ATi) é também caracterizado pelas concentrações relativamente altas de $\mathrm{P}_{2} \mathrm{O}_{5}$ e elementos traço incompatíveis $(\mathrm{Sr}, \mathrm{Zr}, \mathrm{Hf}, \mathrm{Ba}, \mathrm{Ta}, \mathrm{Y}$ e elementos terras raras leves) em comparação ao grupo de $\mathrm{TiO}_{2}<2 \%$ (BTi). 0 primeiro grupo está majoritariamente concentrado no Norte da PMP, enquanto o segundo é mais restrito ao sul da PMP. Essa restrição geográfica permitiu dividir da PMP em duas subprovíncias, a norte e a sul (Piccirillo \& Melfi, 1988). Teores intermediários de $\mathrm{TiO}_{2}$ (2-3\%) foram encontrados principalmente em amostras na região central da PMP, caracterizando a transição entre as subprovíncias norte e sul (Mantovani et al., 1985; Piccirillo et al., 1988).

Conforme Peate et al. (1992), os magmas basálticos são divididos em seis grupos com base nas concentrações de $\mathrm{TiO}_{2}, \mathrm{Sr}, \mathrm{Y}$ e $\mathrm{Zr}$, pois geralmente são elementos imóveis durante os processos de alteração hidrotermal e intemperismo. Os basaltos ATi são decompostos em três magmas-tipo: o Urubici (subprovíncia sul; $\mathrm{TiO}_{2}>3,3 \%$; $\mathrm{Sr}>550$ $\mathrm{mg} / \mathrm{kg} ; \mathrm{Ti} / \mathrm{Y}>500 ; \mathrm{Zr} / \mathrm{Y}>6,5$ ), Pitanga (subprovíncia norte; $\mathrm{TiO}_{2}>2,8 \% ; \mathrm{Sr}>350 \mathrm{mg} / \mathrm{kg}$; $\mathrm{Ti} / \mathrm{Y}>350 ; \mathrm{Zr} / \mathrm{Y}>5,5$ ) e Paranapanema (subprovíncia norte; $1,7<\mathrm{TiO}_{2}<3,2 \% ; 200<\mathrm{Sr}$ $<450 \mathrm{mg} / \mathrm{kg} ; \mathrm{Ti} / \mathrm{Y}>350 ; 4,0<\mathrm{Zr} / \mathrm{Y}<7,0)$. Para os basaltos BTi, nos três magmas-tipo: Gramado (subprovíncia sul; 0,7 < $\mathrm{TiO}_{2}<2,0 \% ; 140<\mathrm{Sr}<400 \mathrm{mg} / \mathrm{kg} ; \mathrm{Ti} / \mathrm{Y}<300 ; 3,5<$ $\mathrm{Zr} / \mathrm{Y}<7,0$ ), Esmeralda (subprovíncia sul; $1,1<\mathrm{TiO}_{2}<2,3 \% ; \mathrm{Sr}<250 \mathrm{mg} / \mathrm{kg}$; Ti/Y $<330$; $2,0<\mathrm{Zr} / \mathrm{Y}<5,0$ ) e Ribeira (subprovíncia norte; $1,5<\mathrm{TiO}_{2}<2,3 \% ; 200<\mathrm{Sr}<375 \mathrm{mg} / \mathrm{kg}$; $\mathrm{Ti} / \mathrm{Y}>300 ; 3,5<\mathrm{Zr} / \mathrm{Y}<7,0)$.

Da mesma forma, observaram-se diferenças geoquímicas nas rochas vulcânicas ácidas da PMP que permitiram dividi-las em dois conjuntos: Chapecó e Palmas, de acordo com os teores de $\mathrm{TiO}_{2}, \mathrm{P}_{2} \mathrm{O}_{5}$ e elementos traço incompatíveis $\mathrm{Rb}, \mathrm{Sr}, \mathrm{Ba}$, $\mathrm{La}$ e $\mathrm{Nb}$. $\mathrm{O}$ tipo Chapecó apresenta alto teor de $\mathrm{TiO}_{2}, \mathrm{P}_{2} \mathrm{O}_{5}, \mathrm{~K}_{2} \mathrm{O}$ e elementos traço incompatíveis ( $\mathrm{Sr}$, Ba, Zr, Hf, Ta e ETR) em comparação ao tipo Palmas e são subgrugadas em: Ourinhos $\left(\mathrm{SiO}_{2}>65 \% ; \mathrm{TiO}_{2}<1,29 \% ; \mathrm{P}_{2} \mathrm{O}_{4}<0,37 \% ; \mathrm{Rb}>120 \mathrm{mg} / \mathrm{kg} ; \mathrm{U}>2,6 \mathrm{mg} / \mathrm{kg} ; \mathrm{Th}>12 \mathrm{mg} / \mathrm{kg}\right)$, Guarapuava $\left(\mathrm{SiO}_{2}>65 \%\right.$; $\mathrm{TiO} 2>1,47 \% ; \mathrm{P}_{2} \mathrm{O}_{4}>0,42 \% ; \mathrm{Rb}<120 \mathrm{mg} / \mathrm{kg} ; \mathrm{U}<9 \mathrm{mg} / \mathrm{kg}$; Th 
$<2 \mathrm{mg} / \mathrm{kg}$ ) e Tamarana (com características intermediárias entre as rochas Ourinhos e Guarapuava: 1,38\% $<\mathrm{TiO}_{2}<1,51 \% ; 0,40 \%<\mathrm{P}_{2} \mathrm{O}_{4}<0,48 \% ; 2 \mathrm{mg} / \mathrm{kg}<\mathrm{U}<2,6 \mathrm{mg} / \mathrm{kg} ; 9,4$ $\mathrm{mg} / \mathrm{kg}<\mathrm{Th}<11 \mathrm{mg} / \mathrm{kg}$ ) (Mantovani et al., 1985; Piccirillo \& Melfi, 1988; Marques, 1988, Garland et al., 1995; Nardy, 1996; Nardy et al., 2008). Por outro lado, as rochas do tipo Palmas, que correspondem a $80 \%$ do volume total das rochas ácidas, são discriminadas em dois grupos de acordo com os teores de $\mathrm{P}_{2} \mathrm{O}_{5}$ e $\mathrm{TiO}_{2}$. O primeiro grupo é composto de riolitos $\left(\mathrm{TiO}_{2} \leq 0,87 \%\right)$ e representado pelas rochas Santa Maria $\left(\mathrm{P}_{2} \mathrm{O}_{5} \leq 0,21 \%\right)$ e Clevelândia $\left(0,21 \%<\mathrm{P}_{2} \mathrm{O}_{5} \leq 0,23 \%\right.$ ) (Nardy et al., 2008). O segundo, composto de dacitos $\left(\mathrm{TiO}_{2} \geq 0,90 \%\right)$, é representado pelos subgrupos: Anita Garibaldi $\left(1,06 \%<\mathrm{TiO}_{2}<1,25 \%\right.$; 0,32\% $\left.<\mathrm{P}_{2} \mathrm{O}_{5}<0,36 \%\right)$, Caxias do Sul $\left(0,91 \%<\mathrm{TiO}_{2}<1,03 \% ; 0,25 \%<\mathrm{P}_{2} \mathrm{O}_{5}<0,28 \%\right)$, Jacuí $\left(1,05 \%<\mathrm{TiO}_{2}<1,16 \% ; 0,28 \%<\mathrm{P}_{2} \mathrm{O}_{5}<0,31 \%\right)$ (Nardy et al., 2008) e Barros Cassal $(1,19 \%$ $<\mathrm{TiO}_{2}<1,21 \% ; 0,35 \%<\mathrm{P}_{2} \mathrm{O}_{5}<$ 0,34\%) (Polo \& Janasi, 2014; Polo et al., 2018a; Polo et al., 2018b).

Sobre as características isotópicas, as rochas básicas ATi da subprovíncia norte (magmas-tipo Pitanga e Paranapanema) contêm pequenas variações nos valores das razões isotópicas iniciais (calculadas para $134 \mathrm{Ma}$ ) de ${ }^{87} \mathrm{Sr} /{ }^{86} \mathrm{Sr} 134$ entre 0,70506 e 0,70689, de ${ }^{143} \mathrm{Nd} /{ }^{144} \mathrm{Nd}_{134}$ entre 0,51218 e 0,51248, de ${ }^{206} \mathrm{~Pb} /{ }^{204} \mathrm{~Pb}_{134}$ entre 17,52 e 17,96 , de ${ }^{207} \mathrm{~Pb} /{ }^{204} \mathrm{~Pb}_{134}$ entre 15,49 e 15,55 e, por fim, de ${ }^{208} \mathrm{~Pb} /{ }^{204} \mathrm{~Pb}_{134}$ entre 37,76 e 38,16. No caso das rochas básicas ATi da subprovíncia sul (magma-tipo Urubici), os valores são levemente dispersos, com ${ }^{87} \mathrm{Sr} /{ }^{86} \mathrm{Sr} 134$ entre 0,70462 e 0,70733, ${ }^{143} \mathrm{Nd} /{ }^{144} \mathrm{Nd}_{134}$ entre 0,51217 e 0,51245, ${ }^{206} \mathrm{~Pb} /{ }^{204} \mathrm{~Pb}_{134}$ entre 16,42 e 17,94, ${ }^{207} \mathrm{~Pb} /{ }^{204} \mathrm{~Pb}_{134}$ entre 15,44 e 15,56 e, por fim, ${ }^{208} \mathrm{~Pb} /{ }^{204} \mathrm{~Pb}_{134}$ entre 36,99 e 38,16 (Cordani et al., 1988; Piccirillo et al, 1989; Peate et al., 1992; Garland et al., 1996; Marques et al., 1999; Peate et al., 1999; Rocha-Júnior et al., 2013). Em suma, os dados isotópicos de Sr, $\mathrm{Nd} \mathrm{e} \mathrm{Pb}$ indicam que a grande maioria dos basaltos ATi sofreu pouca ou nenhuma contaminação crustal no processo evolutivo.

Os basaltos BTi do tipo Ribeira, que ocorrem na parte norte da PMP, são caracterizados por baixas razões iniciais (calculadas para $133 \mathrm{Ma}$ ) ${ }^{87} \mathrm{Sr} /{ }^{86} \mathrm{Sr}_{133}$, situandose entre 0,70546 e 0,70593, enquanto os valores de ${ }^{143} \mathrm{Nd} /{ }^{144} \mathrm{Nd}_{133}$ apresentam pequena dispersão, variando de 0,51223 a 0,51236 . As razões ${ }^{206} \mathrm{~Pb} /{ }^{204} \mathrm{~Pb}_{133}$ situam-se entre 17,63 e 17,81 , as de ${ }^{207} \mathrm{~Pb} /{ }^{204} \mathrm{~Pb}_{133}$ entre 15,50 e 15,54 e as de ${ }^{208} \mathrm{~Pb} /{ }^{204} \mathrm{~Pb}_{133}$ entre 37,86 e 38,15. Cabe destacar que as razões isotópicas iniciais de $\mathrm{Sr}$, $\mathrm{Nd}$ e Pb são bem similares 
às dos basaltos ATi da subprovíncia Norte (Petrini et al., 1987; Marques et al., 1989; Peate, 1997; Marques et al., 1999; Rocha-Júnior et al., 2020).

As características isotópicas das rochas BTi da subprovíncia Sul, em contrapartida, apresentam fortes indícios de assimilação crustal para os litotipos básicos, intermediários e ácidos. Os basaltos e basaltos andesíticos têm valores de razões iniciais (calculadas para $133 \mathrm{Ma}$ ) de ${ }^{87} \mathrm{Sr} /{ }^{86} \mathrm{Sr}_{133}$ entre 0,70492 e 0,71572, de ${ }^{143} \mathrm{Nd} /{ }^{144} \mathrm{Nd}_{133}$ entre 0,51213 e 0,51266 , de ${ }^{206} \mathrm{~Pb} /{ }^{204} \mathrm{~Pb}_{133}$ entre 17,81 e 18,63 , de ${ }^{207} \mathrm{~Pb} /{ }^{204} \mathrm{~Pb}_{133}$ entre 15,57 e 15,67 e, por fim, de ${ }^{208} \mathrm{~Pb} /{ }^{204} \mathrm{~Pb}_{133}$ entre 37,94 e 38,70 (Mantovani et al., 1985; Petrini et al., 1987; Cordani et al., 1988; Peate \& Hawkesworth, 1996; Peate, 1997; Marques et al., 1999; Barreto et al., 2016). As rochas básicas do tipo Esmeralda são caracterizadas pelos menores valores de ${ }^{87} \mathrm{Sr}^{86} \mathrm{Sr}_{133}(0,7046$ - 0,7060) e consideradas não contaminadas ou fracamente contaminadas com material de origem crustal da PMP. Para as rochas do tipo Gramado, os valores de ${ }^{87} \mathrm{Sr} /{ }^{86} \mathrm{Sr}_{133}$ apresentam grande variação, com valores entre 0,70617 e 0,71572 , indicando processos significativos de contaminação crustal (Mantovani et al., 1985; Petrini et al., 1987; Peate, 1997; Marques et al., 1999; Barreto et al., 2016).

As rochas vulcânicas ácidas do tipo Chapecó, associadas em campo às rochas básicas ATi da subprovíncia norte, são caracterizadas por razões isotópicas iniciais de $\mathrm{Sr}$ e de $\mathrm{Nd}$ mais variadas: $0,70488 \leq{ }^{87} \mathrm{Sr} /{ }^{86} \mathrm{Sr}_{133} \leq 0,70806 ; 0,51174 \leq{ }^{143} \mathrm{Nd} /{ }^{144} \mathrm{Nd}_{133} \leq$ 0,51228 , sendo que os valores mais altos das razões isotópicas iniciais de $\mathrm{Sr}\left({ }^{87} \mathrm{Sr} /{ }^{86} \mathrm{Sr}_{133}\right.$ $>0,7070$ ) pertencem às rochas Ourinhos (Piccirillo et al., 1987; Garland et al., 1995; Freitas, 2009). Já as rochas ácidas do tipo Palmas possuem valores de razões iniciais de ${ }^{87} \mathrm{Sr} /{ }^{86} \mathrm{Sr}_{133}$ entre 0,71254 e 0,72633 e de ${ }^{143} \mathrm{Nd} /{ }^{144} \mathrm{Nd}_{133}$ entre 0,51200 e 0,51212, indicativas do aumento de contaminação crustal ao longo do processo de diferenciação, com os maiores valores pertencentes ao subgrupo Santa Maria (Cordani et al., 1988; Garland et al., 1995; Polo, 2014).

A variabilidade do quimismo, associada a mudanças sistemáticas nas razões isotópicas de $\mathrm{Sr}, \mathrm{Nd}$ e $\mathrm{Pb}$, para as rochas BTi básicas e intermediárias da subprovíncia Sul tem sido interpretada (e.g. Mantovani et al., 1985; Petrini et al., 1987; Marques et al., 1989; Peate, 1997; Marques et al., 1999; Barreto et al., 2016) por gênese envolvendo cristalização fracionada com assimilação crustal (AFC; assimilation and fractional crystallization). Este mesmo tipo de processo é proposto para a origem das rochas 
vulcânicas do tipo Palmas (Garland et al., 1995; Polo et al., 2018a). Em contrapartida, a para a gênese das vulcânicas ácidas Chapecó, os modelos envolvendo refusão de rochas básicas ATi aprisionadas na interface crosta-manto (underplating) têm fornecido os resultados mais satisfatórios (Piccirillo et al., 1987; Piccirillo et al., 1988; Garland et al., 1995).

Datações através do método ${ }^{40} \mathrm{Ar} /{ }^{39} \mathrm{Ar}$ indicam que a fase principal do vulcanismo ocorreu em curto intervalo de tempo (1 Ma), com pico em $133( \pm 1)$ Ma (Renne et al., 1992). Os resultados paleomagnéticos, baseados na análise da polaridade das sequências de derrames, evidenciaram também que a atividade ígnea ocorreu num curto intervalo de tempo e destacaram a migração do magmatismo de Sul para o Norte (Ernesto et al., 1999). Concordante com os resultados anteriores, Thiede \& Vasconcelos (2010) propõem a fase principal da extrusão em $134,6( \pm 0,6) \mathrm{Ma}$, com pico de duração de 1,2 Ma e taxa média de erupção magmática em torno de $2,0 \mathrm{~km}^{3} /$ ano, calculada para o volume de 2,35 × $10^{6} \mathrm{~km}^{3}$ da Província Paraná (Gladczenko et al., 1997). Em frações de grãos de zircão e badeleíta pelo método U-Pb, Freitas (2009) e Janasi et al. (2011) obtiveram idades de 134,4 $( \pm 0,9)$ Ma em rochas ácidas Chapecó situadas no município de Ourinhos (SP).

Conforme já mencionado, o vulcanismo da PMP está associado a uma intensa atividade ígnea intrusiva, que abrange sills e enxames de diques. Os sills estão situados, sobretudo, nas regiões leste e nordeste da PMP (Estado de São Paulo e Paraná) e a composição é principalmente de caráter básico e de afinidade toleítica, similares às rochas vulcânicas da PMP. Os sills situados na subprovíncia sul apresentam teores de $\mathrm{TiO}_{2}$ baixo $\left(\mathrm{TIO}_{2}<2 \%\right)$, enquanto as ocorrências na subprovíncia norte caracterizam-se com altos teores de $\mathrm{TiO}_{2}\left(\mathrm{TiO}_{2}>2 \%\right)$ (Marques \& Ernesto, 2004; Rocha-Júnior, 2006; Machado et al., 2007). Sobre os enxames de diques, destacam-se os enxames do Arco de Ponta Grossa (Estado do Paraná), da Serra do Mar (Estados de São Paulo, Rio de Janeiro e Espírito Santo) e de Florianópolis (Estado de Santa Catarina) (Piccirillo \& Melfi, 1988; Piccirillo et al., 1989; Peate, 1997; Marques \& Ernesto, 2004; Corval, 2009, Marques et al., 2018; Florisbal et al., 2018). Segundo alguns pesquisadores (Almeida et al., 2005; Coutinho, 2008), as direções NW-NNW desses diques estão possivelmente relacionadas a braços abortados de uma junção tríplice. 
Em geral, os enxames de diques apresentam características geoquímicas e isotópicas similares aos derrames da PMP, principalmente às rochas vulcânicas ATi da subprovíncia norte (Piccirillo \& Melfi, 1988; Piccirillo et al., 1990; Peate, 1997; Guedes et al., 2005, 2016; Valente et al., 2007; Rosset et al., 2007; Marques et al., 2016; Marques et al., 2018). Estudos geocronológicos nos enxames de diques indicam idades geralmente mais novas em relação aos derrames da PMP. Datações ${ }^{40} \mathrm{Ar} /{ }^{39} \mathrm{Ar}$ em plagioclásios dos diques do Enxame do Arco de Ponta Grossa indicam idades entre o intervalo de 131,4 $( \pm 0,5)$ e 129,2 $( \pm 0,5)$ Ma, corroborado por dados paleomagnéticos (Renne et al., 1996). Dados ${ }^{40} \mathrm{Ar} /{ }^{39} \mathrm{Ar}$ obtidos em diques de Florianópolis indicam duas fases principais de intrusão com idades de 127 e 118 Ma (Raposo et al., 1998), entretanto, uma datação recente de alta precisão efetuada pelo método U-Pb em badeleíta de um dique localizado na área continental, forneceu idade de $134 \mathrm{Ma}$ (Florisbal et al., 2018), indicando que há também intrusões contemporâneas ao vulcanismo na região. Datações ${ }^{40} \mathrm{Ar} /{ }^{39} \mathrm{Ar}$ dos diques ATi do Enxame da Serra Mar apresentaram idades em um amplo intervalo de idades 157 a 129 Ma (Turner et al., 1994; Deckart et al., 1998; Guedes, 2007; Corval, 2009; Guedes et al., 2016), sugerindo episódios intrusivos pré, concomitantes e pós vulcanismo.

\subsection{Exame da Serra do Mar}

O Enxame da Serra do Mar (ESM), composto de diques toleítico-transicionais, encontra-se ao longo de toda região costeira do Sudeste do Brasil, inclusos os Estados de São Paulo, Rio de Janeiro e parte do Espírito Santo, onde se estendem em direção ao continente até alcançar o Vale do Paraíba e o Planalto Sul Mineiro (Figuras 2.1 e 2.2). Os diques são verticais a subverticais com orientações preferencialmente $\mathrm{N} 40^{\circ}-50^{\circ} \mathrm{E}$, coincidentes com a direção do embasamento cristalino, e podem alcançar mais de 15 km de extensão. As espessuras dos corpos variam de centímetros a dezenas de metros, comumente entre 2 e 8 m de espessura (Almeida, 1986; Valente, 1997; Marques, 2001; Marques \& Ernesto, 2004; Guedes, 2005; Corval, 2009; Almeida et al., 2013).

Os afloramentos na região costeira são favorecidos pela topografia com falésias e promontórios, enquanto na região da Serra do Mar, os afloramentos são raros devido ao alto e incessante intemperismo e densa vegetação (Almeida et al., 2013; Almeida \& Carneiro, 2017). De acordo com Gallagher et al. (1994), resultados de traços de fissão 
em apatita e datações ${ }^{40} \mathrm{Ar} /{ }^{39} \mathrm{Ar}$, efetuados ao longo de uma distância de $50 \mathrm{~km}$ a partir da linha costeira, apontam a denudação de mais de $3 \mathrm{~km}$ na planície costeira e possivelmente de $1 \mathrm{~km}$ adentro na Serra do Mar, desde o processo de abertura do Oceano Atlântico Sul. O estudo termocronológico baseado em traços de fissão e (UTh)/He em apatitas na Serra do Mar, Serra da Mantiqueira e das Bacias Terciárias efetuado por Cogné et al. (2012) pontua uma série de eventos soerguimento e reativações tectônicas de grande escala posteriores ao rifteamento, entre cerca de 100 e $70 \mathrm{Ma}$. Destaca-se que há cerca de 80 a $55 \mathrm{Ma}$, são registrados vários episódios magmáticos associados a intrusões alcalinas, principalmente concentradas no lineamento magmático de Cabo Frio (de Cabo Frio a Poços de Caldas), considerado responsável por um soerguimento geral na região e, consequentemente, a rápida denudação neste período (Almeida, 1991; Cogné et al., 2011).

Em geral, os diques do ESM encontram-se encaixados em rochas metamórficas da fácies transicional anfibolito/granulito do Orógeno Ribeira, o qual, por sua vez, compõe um dos blocos que constituem o Segmento Central da Província Mantiqueira, sistema orogênico paralelo à costa Atlântica das regiões Sul e Sudeste do Brasil. Como um todo, o sistema se estende numa área em torno de 700,000 km², do Sul da Bahia ao Uruguai, e é composto pelos orógenos Araçuaí, Ribeira, Dom Feliciano e São Gabriel (Heilbron et al., 2004).

O Orógeno Ribeira é formado pela aglutinação de parte do Gondwana Ocidental, ao longo da Orogênese Brasiliana (entre Neoproterozoico e o Cambriano) e apresenta em grande parte tendências estruturais na direção NE-SW, consequência de vários estágios da colisão das bordas sudeste do Cráton do São Francisco com placas, microplacas e arcos de ilhas. O Orógeno é dividido em cinco terrenos principais, limitados por empurrões ou zona de cisalhamento dúcteis, são estes: Ocidental, Paraíba do Sul, Embu, Cabo Frio e Oriental (Heilbron et al., 2004; Eirado et al., 2016). 

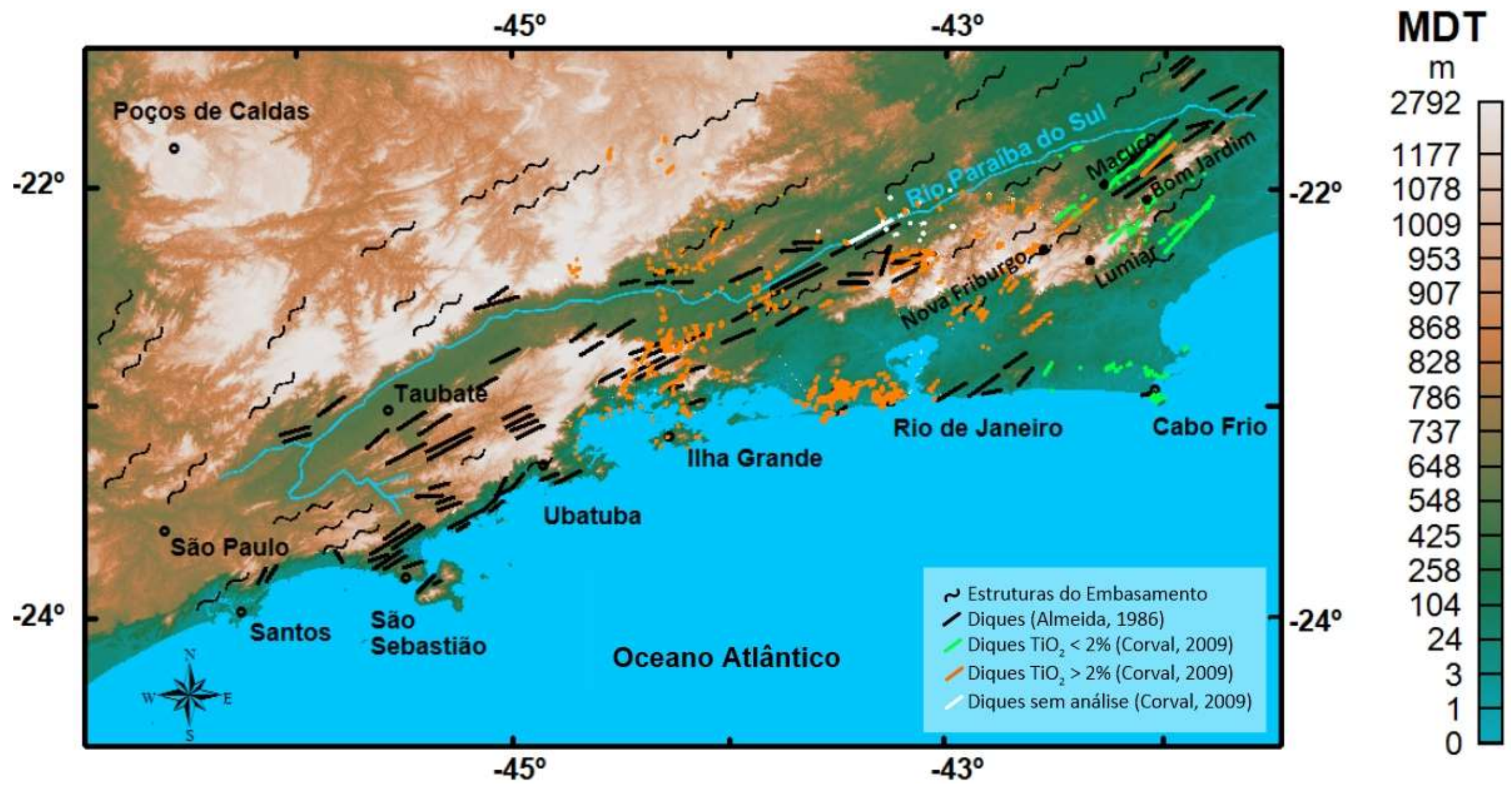

Figura 2.2 - Mapa do Modelo Digital de Terreno (MDT) com a localização dos diques do Enxame Serra do Mar (Almeida, 1986; Marques, 2001; Corval, 2009). 
Estudos petrográficos dos diques do ESM evidenciam texturas holocristalinas e hipocristalinas e matriz preferencialmente inequigranular e, de modo subordinado, equigranular (Garda, 1995; Guedes, 2005; Dutra, 2006; Corval et al., 2008; Carvas, 2016). De acordo com esses autores, a granulometria varia entre fina $(<1 \mathrm{~mm})$ a média $(1-3$ $\mathrm{mm}$ ). A composição mineralógica é pouco variável e essencialmente constituída em plagioclásio e clinopiroxênio (augita) e, em menor quantidade, pigeonita. De modo subordinado, ocorrem os minerais opacos como titanomagnetita e ilmenita. A matriz é composta substancialmente pelos mesmos minerais. Os principais minerais acessórios são apatita e quartzo, os outros minerais acessórios são biotita, uralita e hornblenda. Estes três últimos são os produtos de alteração dos grãos de piroxênios e mais frequentes nas regiões das bordas. Os grãos de apatita ocorrem como inclusões nos grãos de plagioclásios e piroxênios. No centro e borda dos grãos dos feldspatos encontra-se saussurita como resultado de processos de alteração. Ocorrências de fenocristais de olivina alterada são encontradas nas porções oriental e central do enxame (Dutra, 2006; Corval, 2009).

Os diques do ESM são constituídos majoritariamente de litotipos básicos $\mathrm{ATi}\left(\mathrm{TiO}_{2}\right.$ $>3 \%$ ), correspondendo cerca de $85 \%$ dos afloramentos, e quimicamente representados por andesi-basaltos, lati-basaltos e lati-andesitos. De modo subordinado, as ocorrências de litotipos intermediários a ácidos encontram-se na região costeira do Estado de São Paulo, representados por lati-andesitos, dacitos e riodacitos (Comin-Chiaramonti et al.,1983, Piccirillo et al., 1988; Hawkesworth et al., 1992, Garda \& Schorcher, 1996; Marques, 2001; Corval, 2009; Vicentini, 2015). Bem como as rochas vulcânicas da PMP, há a ocorrências de diques contendo baixas concentrações $\left(\mathrm{BTi}^{\mathrm{T}} \mathrm{TiO}_{2}<2 \%\right)$ com cerca de $10 \%$ dos afloramentos, principalmente situados na parte oriental do Estado do Rio de Janeiro. Em comparação aos diques ATi, as rochas BTi apresentam baixas concentrações dos elementos incompatíveis $\mathrm{P}, \mathrm{Zr}$, Ba, Sr e Rb (Marques, 2001; Bennio et al., 2003; Valente et al., 2007; Corval, 2009; Carvas, 2016). As intrusões de concentrações de $\mathrm{TiO}_{2}$ entre 2 -3\% são raras (Marques, 2001; Marques \& Ernesto, 2004; Corval, 2009).

Os diques de natureza básica ATi apresentam teores de MgO entre $6-2 \%$ e, de acordo com Marques (2001), são discriminados em três conjuntos distintos: ATi-P semelhante aos derrames Pitanga ( $\mathrm{Sr}<550 \mathrm{mg} / \mathrm{kg}$ ); ATi-U semelhantes aos derrames 
Urubici ( $\mathrm{Sr}>550 \mathrm{mg} / \mathrm{kg}$; Ti/Y > 500) e ATi-M de características mistas ( $\mathrm{Sr}>550 \mathrm{mg} / \mathrm{kg}$ e $T i / Y<500)$. Os diques ATi-P são constituídos de andesi-basaltos toleíticos e latiandesitos, os ATi-U de andesi-basaltos toleíticos e os diques ATi-M de lati-andesitos.

Os estudos isotópicos indicam que alguns diques ATi sofreram processos de contaminação crustal em diferentes graus, com 0,70531 $\leq{ }^{87} \mathrm{Sr} /{ }^{86} \mathrm{Sr}_{130} \leq 0,70710$; $0,51220 \leq{ }^{143} \mathrm{Nd} /{ }^{144} \mathrm{Nd}_{130} \leq 0,51260 ; 16,6 \leq{ }^{206} \mathrm{~Pb} /{ }^{204} \mathrm{~Pb}_{130} \leq 18,37 ; 15,51 \leq{ }^{207} \mathrm{~Pb} /{ }^{204} \mathrm{~Pb}_{130}$ $\leq 15,60 ; 35,90 \leq{ }^{208} \mathrm{~Pb} /{ }^{204} \mathrm{~Pb}_{130} \leq 38,77$ (Garda, 1995; Marques, 2001; Corval, 2009; Marques et al., 2012; Carvas, 2014). Cabe destacar, que os diques ATi-M se destacam dos demais por mostrar envolvimento de processos de assimilação crustal significativos, evidenciado nas razões isotópicas iniciais calculadas para $130 \mathrm{Ma}\left(0,7062 \leq{ }^{87} \mathrm{Sr} /{ }^{86} \mathrm{Sr}_{130}\right.$ $\leq$ 0,7070; Marques, 2001), que mudaram as características dos magmas iniciais. A natureza levemente mais alcalina desses diques é possivelmente resultante de uma fusão de parcial de menor grau de fonte mantélica semelhante à que originou os derrames Urubici (Marques, 2001).

Os diques BTi do ESM estão situados em duas regiões distintas e restritas, com características geoquímicas e isotópicas próprias. O primeiro grupo situa-se na Região dos Lagos (municípios de Búzios e Cabo Frio) e, o segundo grupo, na Região Serrana do Estado do Rio de Janeiro; denominadas de Suíte Costa Azul e Suíte Serrana, respectivamente (Monteiro \& Valente, 2003; Dutra, 2006; Corval et al., 2008; Corval, 2009).

Os diques da Região dos Lagos são mais empobrecidos em álcalis e em elementos traço incompatíveis. Segundo Bennio et al. (2003), esses diques são subdivididos em dois conjuntos magmáticos (grupos $\mathrm{A}$ e B), conforme as concentrações de $\mathrm{Zr}, \mathrm{Al}_{2} \mathrm{O}_{3}, \mathrm{Fe}_{2} \mathrm{O}_{3}$, $\mathrm{MnO}, \mathrm{V}$ e $\mathrm{Y}$ e, também, pelas razões isotópicas de $\mathrm{Sr}$ e $\mathrm{Nd}$ e padrões de elementos incompatíveis, sendo que não há uma separação geográfica nítida entre os dois conjuntos. O conjunto A é mais primitivo $\left(66 \leq \mathrm{Zr} \leq 114 \mathrm{mg} / \mathrm{kg} ; \mathrm{Al}_{2} \mathrm{O}_{3}<15 \%\right.$; $\mathrm{SiO}_{2}<52 \%$; $145 \leq \mathrm{Sr} \leq 229 \mathrm{mg} / \mathrm{kg} ; \mathrm{MgO}>5,5 \% ; \mathrm{V}<540 \mathrm{mg} / \mathrm{kg} ; 0,70426 \leq{ }^{87} \mathrm{Sr} /{ }^{86} \mathrm{Sr}_{55} \leq 0,70434 \mathrm{e}$ $0,51268 \leq{ }^{143} \mathrm{Nd} /{ }^{144} \mathrm{Nd}_{55} \leq 0,51276$, calculadas para $55 \mathrm{Ma}$ ) e apresenta similaridades geoquímicas com os basaltos do tipo E-MORB (Enriched Mid-ocean Ridge Basalts), bem como, os diques Horingbaai da Namíbia (Província Etendeka). O segundo conjunto, nomeado $\mathrm{B}$, é mais evoluído ( $93 \leq \mathrm{Zr} \leq 154 \mathrm{mg} / \mathrm{kg} ; 14 \leq \mathrm{Al}_{2} \mathrm{O}_{3} \leq 16 \% ; \mathrm{SiO}_{2}>52 \% ; 227 \leq \mathrm{Sr}$ $\leq 264 \mathrm{mg} / \mathrm{kg} ; \mathrm{MgO}<6 \% ; \mathrm{V}<350 \mathrm{mg} / \mathrm{kg} ; 0,70548 \leq{ }^{87} \mathrm{Sr} /{ }^{86} \mathrm{Sr}_{55} \leq 0,70613$ e $0,51245 \leq$ 
${ }^{143} \mathrm{Nd} /{ }^{144} \mathrm{Nd}_{55} \leq 0,51247$, calculadas para $55 \mathrm{Ma}$ ) e possui semelhanças àquelas vistas nos derrames tipo Esmeralda da PMP. Conforme Corval (2009), a evolução das intrusões da Região dos Lagos é devida à cristalização fracionada com assimilação de material crustal (AFC) vista no comportamento das razões La/Y e La/Nb, sem mudanças na assembleia fracionante ao longo da evolução. Com base nos dados isotópicos, Dutra (2006) e Corval (2009) propõem uma componente mantélica empobrecida envolvida na petrogênese dos diques da Região dos Lagos.

Turner et al. (1994) obtiveram idades entre 133,3 $( \pm 1,7)$ e 129,4 ( $\pm 0,6)$ Ma na costa do Estado de São Paulo, região meridional do ESM, através da análise por aquecimento em estágios (step-heating) via laser em grãos de plagioclásio e rocha-total. Conforme a análise de quatro grãos de plagioclásio oriundos de diques toleíticos ATi, Deckart et al. (1998) encontraram idades entre 134,5 ( $\pm 0,4)$ e 129,8 ( $\pm 0,2)$ Ma. Em Janasi et al. (2011), tais datações foram recalculadas conforme a idade de $28,201( \pm 0,046)$ Ma para o padrão internacional em geocronologia ${ }^{40} \mathrm{Ar} /{ }^{39} \mathrm{Ar}$ sanidina Fish Canyon (Kuiper et al., 2008), atingindo valores entre $135,7( \pm 0,6)$ e $131,4( \pm 0,6)$ Ma. Esses estudos, conjuntamente com análises geoquímicas, relacionaram diretamente o ESM ao vulcanismo na porção norte da PMP. Entretanto, estudos paleomagnéticos e geocronológicos ${ }^{40} \mathrm{Ar} /{ }^{39} \mathrm{Ar}$ mais recentes do ESM propõem a extensão, em forma de pulsos, do magmatismo toleítico do período Jurássico ao Paleogeno (Bennio et al., 2003; Corval, 2009; Ernesto et al., 2014; Guedes et al., 2016; Carvas, 2016). Guedes et al. (2016), baseando-se em dados de campo, petrografia e geoquímica, definiram idades entre $155,4( \pm 3,4)$ e $149,8( \pm 3,3)$ Ma em rocha-total de sete diques ATi da região central do ESM. Por outro lado, Corval (2009), obtiveram idades de 142,7 ( \pm 8,3), 138,4 ( \pm 6) e 126,5 ( \pm 3,9) Ma na análise de grãos de plagioclásio de diques BTi do ESM. Datações de intrusões na Região dos Lagos (Bennio et al., 2003) obtiveram idades mais recentes do ESM, cerca de 55,2 Ma, através do valor médio de quatro idades obtidas em grãos de plagioclásio.

Em Ernesto et al. (2014), por meio de dados paleomagnéticos, foram observados que os diques do ESM possuem diferentes polos, que são semelhantes aos de rochas vulcânicas da América do Sul com idades em torno de 50 Ma, 100 Ma e 130 Ma, de polaridade normal, reversa e normal, respectivamente. Em função desses resultados, os autores propõem a existência de pulsos magmáticos decorrentes de eventos tectônicos 
nitidamente distintos, relacionados às fases anteriores, concomitantes e posteriores à ruptura continental e à abertura do Oceano Atlântico Sul.

$\mathrm{Na}$ Região dos Lagos, análises ${ }^{40} \mathrm{Ar} /{ }^{39} \mathrm{Ar}$ de grãos de plagioclásios sericitizados e em rocha-total dos diques BTi forneceram idades de 108 - 106 Ma e 108 Ma, respectivamente, as quais estão sendo interpretadas como registros de grandes eventos hidrotermais, que afetaram esses diques (Carvas, 2016; Carvas et al., 2021). Nesses mesmos estudos, uma fração contendo anfibólio e biotita forneceu idade de $130 \mathrm{Ma}$, a qual foi também, recentemente, corroborada por Almeida et al. (2021) na análise de plagioclásios. Estes últimos autores indicam ainda que um pulso magmático ocorreu há 120 Ma nessa mesma região.

\subsubsection{Diques da Suíte Serrana}

Os diques da Suíte Serrana, caracterizados pelas baixas concentrações de $\mathrm{TiO}_{2}$, estão situados nos arredores dos municípios de Além Paraíba, Nova Friburgo (Distrito de Lumiar), São Pedro da Serra, Macuco e Bom Jardim (Figura 2.2). Diferentemente da Suíte Costa Azul, a Região Serrana do Estado do Rio de Janeiro, onde afloram os diques da Suíte Serrana, também apresenta ocorrências de diques de alto teor de $\mathrm{TiO}_{2}$, sem uma separação geográfica clara (Marques, 2001; Corval et al., 2008; Corval, 2009).

As rochas encaixantes da Suíte Serrana integram o Terreno Oriental, o qual, por sua vez, compõe um dos terrenos no segmento central do Orógeno Ribeira. O Terreno Oriental, conforme descrito por Heilbron \& Machado (2003), corresponde a um arco magmático maduro alojado em cobertura sedimentar de margem passiva e compreende os domínios tectônicos Cambuci (bacia ante-arco), Costeiro (bacia retro-arco) e Klippe Italva (relacionado ao Arco Magmático Rio Negro). O Terreno Oriental é constituído por ortognaisses dos complexos Rio Negro e Serra da Prata e rochas granitoides das fases sin a pós-colisionais (Heilbron et al., 2004; Peixoto \& Heilbron, 2010; do Eirado et al., 2016).

O Complexo Rio Negro (CRN) consiste numa variedade de ortognaisses bandados, migmatíticos e granitoides de idades entre 630 - $600 \mathrm{Ma}$, os quais são produtos de metamorfismo das rochas ígneas mais antigas aflorantes nesta região, e aflora ao longo de 300 km no Terreno Oriental (Tupinambá et al., 1996; Heilbron \& Machado, 2003; 
Tupinambá et al., 2012; Eirado et al., 2016; Peixoto et al., 2017). O Complexo Serra da Prata (CSP) é observado em afloramentos como lentes de ortognaisses nas rochas do CRN e como corpos de ortognaisses de granulação grossa a porfirítica dentro dos mármores do Grupo Italva. Tais observações em campo e análises U-Pb, conforme Peixoto et al. (2017), correspondem a diferentes estágios evolutivos de um único arco magmático. Do ponto de vista geoquímico, os ortognaisses de ambos CRN e CSP são rochas de composição química diorítica, tonalítica e granodiorítica.

Os dados geoquímicos de elementos maiores, menores e traço dos diques BTi mostram grande semelhança tanto com os basaltos do tipo Gramado, quanto Esmeralda, da PMP (Corval, 2009). Em estudos do embasamento cristalino nos municípios de Nova Friburgo e São Pedro da Serra, Ludka (1997) identificou diques BTi com características semelhantes aos derrames Gramado, conforme evidenciado pelas razões Ti/Zr e Ti/Y.

Em geral, as intrusões da Suíte Serrana apresentam razões isotópicas iniciais de $\mathrm{Sr}$ $\left({ }^{87} \mathrm{Sr} /{ }^{86} \mathrm{Sr}_{132} \geq 0,7060\right)$ também similares àquelas dos derrames do tipo Gramado da PMP (Marques, 2001; Dutra et al., 2005; Corval, 2009). Em conjunto com valores das composições isotópicas de Sr mais elevados, os valores mais baixos das razões isotópicas iniciais de $\mathrm{Nd}\left({ }^{143} \mathrm{Nd} /{ }^{144} \mathrm{Nd}_{132} \leq 0,5123\right)$ das rochas foram atribuídos a possíveis e significativos processos de contaminação crustal (Marques \& Ernesto, 2004; Dutra et al., 2006; Corval, 2009). A modelagem petrogenética efetuada por Corval (2009) reafirma a hipótese da contaminação, apontando processo evolutivo AFC para a suíte. As análises dos sistemas isotópicos $\mathrm{Sr}, \mathrm{Nd}$ e $\mathrm{Pb}$ desse estudo indicam que a gênese das intrusões envolveu fontes mantélicas enriquecidas (EM I; Enriched Mantle I) e processos de assimilação crustal. Os valores de $\mathrm{La} / \mathrm{Yb}_{(\mathrm{N})}: 2,7$ e $\mathrm{La} / \mathrm{Nb}_{(\mathrm{N})}: 1,4$, normalizados por condritos (Thompson et al., 1984) dos líquidos parentais, calculados pelo Corval (2009), corroboram com a proposição de envolvimento de manto litosférico subcontinental na gênese desta suíte.

Corval (2009) também sugere, a partir dos modelos de fusão parcial em equilíbrio modal, que os diques ATi e os diques da Suíte Serrana não são cogenéticos, propondo a existência de heterogeneidade mantélica local. 


\subsubsection{Aspectos petrográficos}

De acordo com Ludka (1997), os diques da Suíte Serrana apresentam textura fanerítica inequigranular e granulometria predominantemente fina, com variações de muito fina para média. Ocasionalmente, fenocristais de plagioclásio ou piroxênio são encontrados. As rochas são compostas predominantemente de plagioclásio (33,5 $49,1 \%)$ e clinopiroxênio, augita $(17,1-30,1 \%)$ e pigeonita $(4,0-8,4 \%)$. Seguidamente, de modo subordinado, observam-se minerais opacos (titanomagnetita, ilmenita e pirita), hornblenda e minerais de alteração (principalmente, biotita). Os minerais olivina, biotita, apatita, quartzo e feldspato potássico ocorrem em pequenas quantidades. Os cristais de plagioclásio são majoritariamente sem orientação definida, subedrais a euedrais e semi-tabulares, enquanto os cristais de piroxênio são subedrais a anedrais e em partes anfibolitizados na borda. A olivina presente foi identificada pelo seu formato oval e de bordas arredondadas, pois nas ocorrências ela está totalmente transformada nos minerais de alteração característicos, tais como clorita, serpentina e óxidos de ferro. A apatita encontra-se inclusa nos plagioclásios e na matriz microcristalina intersticial. 0 quartzo encontra-se sempre anedral e associado à textura granofírica, observada frequentemente nos diques mais espessos, ou à sobra de reações. 


\section{MATERIAIS E MÉTODOS}

Para o estudo da petrogênese dos diques da Região Serrana do Estado do Rio de Janeiro, três métodos analíticos distintos foram utilizados. A seguir, são apresentados resumidamente os conceitos teóricos da geoquímica elemental e isotópica aplicados ao presente estudo, o trabalho de amostragem dos diques investigados, a preparação das amostras representativas (cominuição) e, por fim, uma sucinta descrição dos métodos analíticos empregados no estudo de amostras representativas dos diques investigados.

Os elementos maiores são constituídos pelos elementos de alta concentração nas rochas (>1,0\% em peso), são representados na forma de óxidos e consistem nos principais responsáveis pelo comportamento da mineralogia e da cristalização-fusão em sistemas ígneos (Winter, 2014). Os elementos menores, também representados na forma de óxidos, são vistos em concentrações menores (0,1 a 1,0\% em peso) e podem substituir um elemento maior numa fase mineral ou, quando presente em maiores quantidades, formar um mineral acessório (Winter, 2014). Esses elementos estão concentrados em dez principais óxidos e determinam a classificação e nomenclatura química das rochas. A construção de diagramas de duas ou mais variáveis entre diferentes óxidos (diagramas de variação) permite compreender e quantificar processos petrogenéticos, como o fracionamento de minerais na diferenciação magmática, mistura de magmas e contaminação crustal (Wilson, 1989; Rollinson, 1993).

Os elementos traço estão presentes nas rochas em concentrações inferiores a 0,1\% (em peso), mesmo assim, seus comportamentos podem discriminar processos petrogenéticos de modo muito mais eficiente que os elementos maiores e menores (Rollinson, 1993). Conforme a evolução do magma e as condições do sistema, os elementos traço apresentam preferências particulares com relação às fases minerais, segundo as condições de temperatura, pressão, composição, grau de oxidação e estrutura cristalina do sistema (Wilson, 1989). Assim, os elementos podem se concentrar nos líquidos ou sólidos durante os processos de fusão ou de cristalização fracionada, e tal comportamento é quantificado pelo coeficiente de partição $\left(K_{D}\right)$, conforme Equação 3.1. 


$$
K_{D}=\frac{C_{i}^{\text {mineral }}}{C_{i}^{\text {líquido }}}
$$

onde $C_{i}^{\text {mineral }}$ consiste na concentração do elemento $i$ na fase sólida (residual do processo de fusão ou fracionada no processo de cristalização fracionada) e $C_{i}^{\text {líquido é a }}$ concentração do elemento i na fase líquida.

Os elementos traço com valores de $K_{D}$ inferiores a 1 são denominados de incompatíveis e preferencialmente concentrados na fase líquida durante os processos de fusão ou cristalização. Os elementos de valores de $K_{D}$ superiores a 1 , por sua vez, são nomeados de compatíveis e concentram-se na fase sólida (mineral fracionado ou residual no processo de fusão). A compatibilidade ou incompatibilidade relacionam-se à assembleia mineralógica essencial do manto, caracterizada por olivina, piroxênio, espinélio e granada. Com base nos valores de $K_{D}$ de cada um dos minerais presentes na fase sólida no processo de fusão parcial ou de cristalização fracionada, o coeficiente de partição global de um dado elemento $i$ em uma rocha obtida pela Equação 3.2.

$$
D_{i}=x_{1} K_{D_{1}}+x_{2} K_{D_{2}}+x_{3} K_{D_{3}}+\cdots
$$

onde os valores de $x_{1}$ estão relacionados às proporções em peso do mineral 1 na fase sólida e os fatores $K_{D_{1}}$ são os coeficientes de partição do elemento 1 para os minerais envolvidos no processo petrogenético, e assim por diante (Wilson, 1989; Rollinson, 1993).

Usualmente, os elementos incompatíveis são subdivididos em dois grupos com base nos raios iônicos e/ou cargas, associados à mobilidade nos processos de metamorfismo e hidrotermalismo (Rollinson, 1993). Os elementos de alta carga de valência (HFS; High Field Strength; potencial iônico > 2,0) são compostos pelos elementos terras raras, $\mathrm{Th}, \mathrm{U}, \mathrm{Ce}, \mathrm{Pb}^{4+}, \mathrm{Zr}, \mathrm{Hf}, \mathrm{Ti}, \mathrm{Nb}$ e Ta. Enquanto os elementos litófilos de baixa carga de valência (potencial iônico $<2,0$ ) e de grandes íons litófilos (LIL; Large Ion Lithophile), são compostos pelos $\mathrm{K}, \mathrm{Rb}, \mathrm{Cs}, \mathrm{Ba}, \mathrm{Pb}^{2+}, \mathrm{Sr}$ e $\mathrm{Eu}^{2+}$ e considerados mais móveis, principalmente em processos envolvendo fluídos (processos de intemperismo e de alteração hidrotermal). Elementos com raios iônicos pequenos e baixa carga de valência tendem a ser compatíveis, tais Ni, Cr e Cu (Rollinson, 1993; Winter, 2014). 
Tanto a mobilidade, quanto o coeficiente de partição dos elementos são importantes nos estudos de processos petrogenéticos, pois apresentam padrões comportamentais característicos, contribuindo no reconhecimento de diferenciação de suítes magmáticas, de fases minerais fracionadas, de fusão parcial ou cristalização fracionada e de processos de assimilação crustal (Rollinson, 1993).

As razões isotópicas baseadas em isótopos radiogênicos são fundamentais para a compreensão dos processos petrogenéticos em sistemas ígneos, pois, diferentemente das concentrações dos elementos traço, não sofrem fracionamento nos processos de fusão e/ou cristalização magmática. As análises isotópicas possibilitam a caracterização das fontes relacionadas à geração dos magmas e identificação de suítes cogenéticas. Além disso, os isótopos radiogênicos são importantes marcadores e quantificadores de processos metassomáticos e de contaminação crustal (Wilson, 1989).

Dentre as razões isotópicas utilizadas em petrogênese, os mais comuns são as de $\mathrm{Sr}\left({ }^{87} \mathrm{Sr} /{ }^{86} \mathrm{Sr}\right)$ e $\mathrm{Nd}\left({ }^{143} \mathrm{Nd} /{ }^{144} \mathrm{Nd}\right)$, sendo que cautela deve ser tomada no estudo de rochas afetadas por processos hidrotermais e metamórficos, pois pode ocorrer o fracionamento das razões isotópicas de $\mathrm{Sr}$, devido à mobilidade do Rb. Por outro lado, as razões isotópicas de $\mathrm{Nd}$ são bem menos afetadas devido ao fato dos elementos terras raras (ETR) serem praticamente imóveis (Rollinson, 1993).

Neste estudo foram utilizados os sistemas isotópicos $\mathrm{Rb}-\mathrm{Sr}$ e $\mathrm{Sm}-\mathrm{Nd}$. O primeiro baseia-se no isótopo ${ }^{87} \mathrm{Rb}$, que decai para ${ }^{87} \mathrm{Sr}$ por uma emissão beta. O elemento $\mathrm{Rb}$ é um metal alcalino de raio iônico similar ao do K e possui comportamento geoquímico incompatível, enquanto o Sr é um metal alcalino terroso com comportamento mais compatível do que o do Rb. Cabe destacar que embora no decorrer da diferenciação magmática de um sistema fechado, a razão $\mathrm{Rb} / \mathrm{Sr}$ apresenta a tendência de aumentar, as razões isotópicas ${ }^{87} \mathrm{Sr} /{ }^{86} \mathrm{Sr}$, por ocasião da cristalização não apresentam variação, já que não há fracionamento isotópico. O segundo sistema isotópico utilizado foi o $\mathrm{Sm}-\mathrm{Nd}$, onde os dois elementos são pertencentes à família dos lantanídeos e incompatíveis na cristalização fracionada e na fusão parcial, com o Sm apresentando maior grau de compatibilidade do que o $\mathrm{Nd}$, na grande maioria dos sistemas. Deste modo, diferentemente da razão $\mathrm{Rb} / \mathrm{Sr}$, a razão $\mathrm{Sm} / \mathrm{Nd}$ tende a diminuir durante a evolução magmática (Faure \& Mensing, 2005). Neste sistema, são usados o radioisótopo ${ }^{147} \mathrm{Sm}$ e o seu isótopo radiogênico filho ${ }^{144} \mathrm{Nd}$, que é produzido por decaimento alfa. Devido à 
abundância e ao comportamento geoquímico do $\mathrm{Rb}, \mathrm{Sr}$, Sm e $\mathrm{Nd}$ nas rochas da crosta continental, os processos de diferenciação de magmas basálticos tendem a promover aumento das razões ${ }^{87} \mathrm{Sr} /{ }^{86} \mathrm{Sr}$ e diminuição das de ${ }^{143} \mathrm{Nd} /{ }^{144} \mathrm{Nd}$, devido contaminação crustal.

As análises químicas de elementos maiores, menores e alguns traço $(\mathrm{Ni}, \mathrm{Cr}, \mathrm{Ba}$, $\mathrm{Rb}, \mathrm{Y}, \mathrm{Zr}$, Nb e Sr) dos diques investigados foram realizadas pela técnica de Fluorescência de Raios-X. Estas medidas foram efetuadas no Núcleo de Apoio à Pesquisa (NAP) Geoanalítica do Instituto de Geociências da Universidade de São Paulo (IGc-USP). Para as duas amostras QT-SV-2D e QY-SV-6B, as medidas foram efetuadas no Laboratório de Geoquímica do Departamento de Petrologia e Metalogenia (IGCE/UNESP-RC).

As determinações das concentrações de outros elementos traço, incluindo a série dos lantanídeos (elementos terras raras: La, Ce, Nd, Sm, Eu, Tb, Yb e Lu), Ta, Th, Hf, $\mathrm{Ba}$, Sc e Co, foram efetuadas pela técnica de ativação neutrônica instrumental, seguida de espectrometria gama de alta resolução, utilizando detectores de germânio hiperpuro (Figueiredo \& Marques, 1989; Marques, 2001), na Supervisão de Radioquímica do Instituto de Pesquisas Energéticas e Nucleares (CNEN/SP), com a supervisão da Profa. $\mathrm{Dr}^{\mathrm{a}}$. Ana Maria Figueiredo, com o qual é mantido um convênio de colaboração científica.

As análises isotópicas ${ }^{87} \mathrm{Sr} /{ }^{86} \mathrm{Sr}$ e ${ }^{143} \mathrm{Nd} /{ }^{144} \mathrm{Nd}$ foram realizadas via espectrometria de massa termoiônica no Centro de Pesquisas Geocronológicas (CPGeo) do IGc-USP, obedecendo aos procedimentos descritos por Kawashita (1972), Sato et al. (1995) e Rocha-Júnior. et al. (2013) para as separações dos elementos Sr e Nd, utilizando-se o espectrômetro multicoletor Thermo Scientific Triton.

\subsection{Trabalhos de amostragem}

As amostras dos diques estudados estão subgrupadas em: treze diques analisados de Marques (2001) e dados inéditos, coletados na região de Bom Jardim, sete amostras de diques cedidas pelo Prof. Dr. Artur Corval (UFRRJ), situadas no distrito de Lumiar, e dezenove diques amostrados na Região Serrana do Estado do Rio de Janeiro, em trabalho de campo ocorrido no mês de junho de 2019. Ao todo, a pesquisa contou com a análise de trinta e sete amostras de diques, distribuídos nas regiões pertencentes aos municípios de Nova Friburgo, São Pedro da Serra, Bom Jardim, Macuco e Casimiro de Abreu (Figura 3.1). 


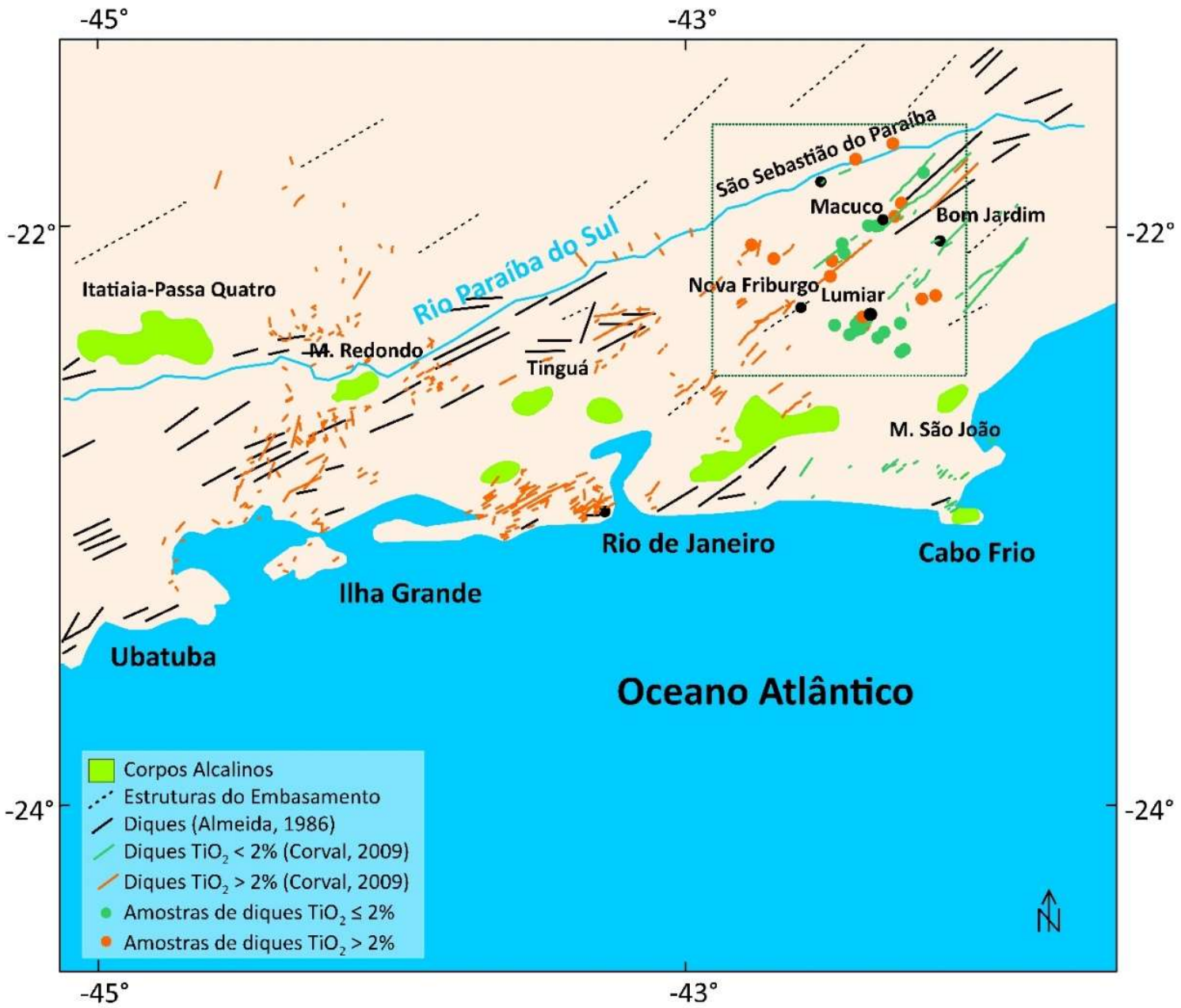

Figura 3.1 - Mapa geológico simplificado do Enxame Serra do Mar (ESM) com a distribuição dos diques reportado por Almeida (1986), dos diques de conteúdo de $\mathrm{TiO}_{2}<2 \%$ e $\mathrm{TiO}_{2}>2 \%$ de Corval (2009) e das amostras de diques investigados na Região Serrana do Estado do Rio de Janeiro, com os municípios próximos evidenciados (retângulo pontilhado verde). Adaptado de Marques (2001).

Dos dezenove diques coletados no trabalho de campo, doze foram selecionados de acordo com o estado das amostras (aquelas sem vestígios de alteração) e melhor representatividade espacial (em vários casos, mais de uma amostra foram coletadas em um mesmo dique). A Figura 3.1 apresenta a localização das amostras de diques selecionadas, conjuntamente com as amostras de diques de Marques (2001) e inéditas. Os afloramentos amostrados ocorrem nas margens das estradas principais e secundárias e apresentam considerável grau de alteração intempérica, principalmente esfoliação esferoidal (Figura 3.2), que pode resultar em blocos rochosos arredondados, com centro muito fresco, imersos no regolito de coloração acastanhada. Os contatos dos diques com as rochas encaixantes não se encontravam expostos devido à densa 
vegetação e ao intemperismo tanto dos diques como das encaixantes. Assim, não foi possível determinar as espessuras e as direções dos diques.
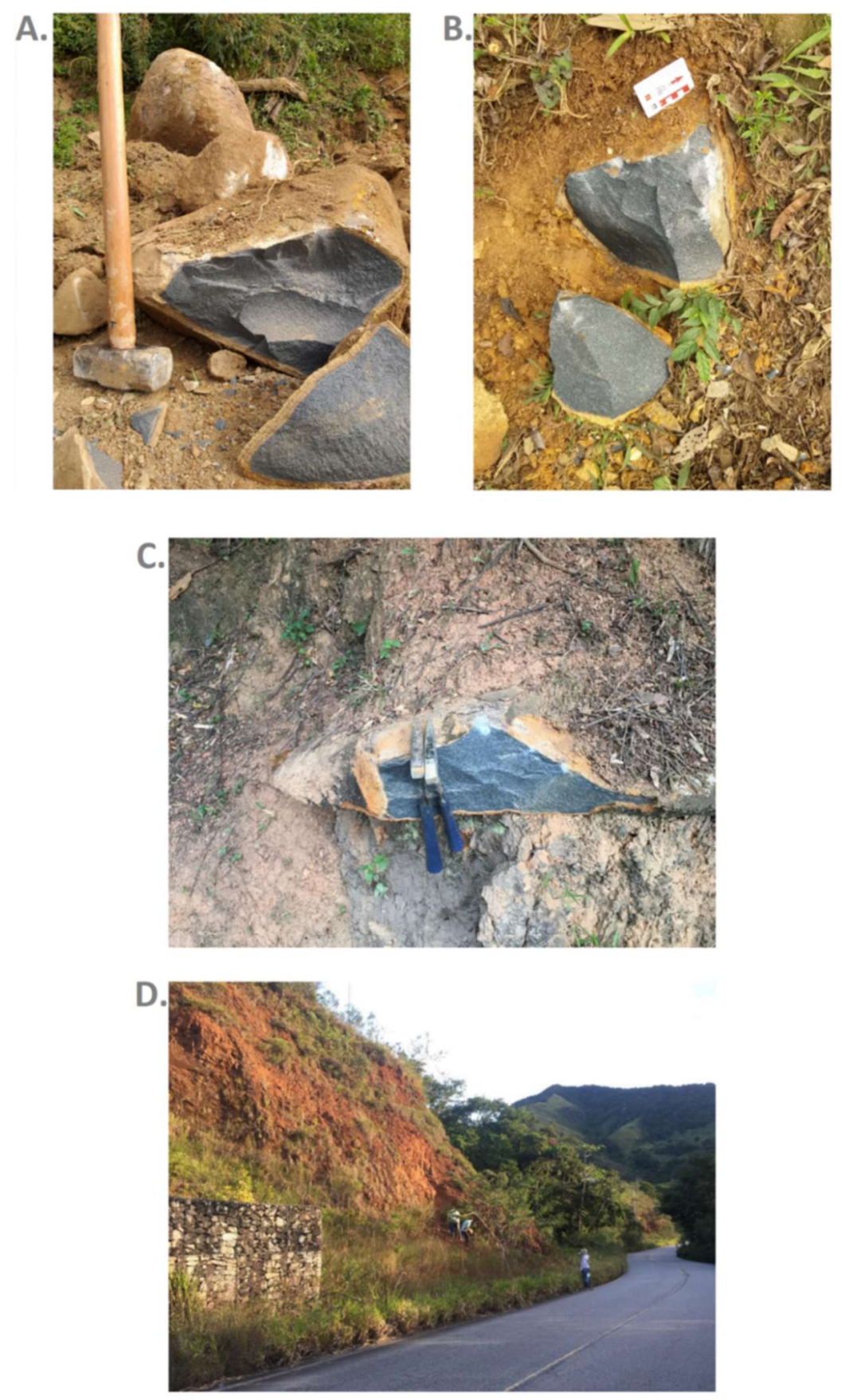

Figura 3.2 - Afloramentos sob a forma de blocos rolados com esfoliação esferoidal, na região do Distrito de Lumiar e em torno (A: ponto LMD-RJ-8003; B: ponto LMD-RJ-8000; C: ponto LMD-RJ-8014; D: ponto LMD-RJ-8011). 


\subsection{Preparação das amostras}

Para a realização das análises geoquímicas, necessita-se que a amostra seja reduzida a uma granulometria inferior a 100 mesh (em torno de 0,149 mm de diâmetro) para a Análise por Ativação Neutrônica Instrumental e a 200 mesh (em torno de 0,074 mm de diâmetro) para a Fluorescência de Raios-X.

Primeiramente, certificou-se de selecionar blocos frescos para cominuição, removendo capas de alteração com o auxílio de um martelo geológico de aço inoxidável. Nesta fase, cerca de $600 \mathrm{~g}$ de cada amostra foram separados. Para a fase da britagem, utilizou-se um britador de mandíbulas de aço inoxidável da marca Fritsch (Figura 3.3), adotando-se os protocolos de manuseio e limpeza do laboratório (Tabela 3.1). Os dois procedimentos descritos acima foram efetuados para o diabásio proveniente de um dique do Enxame do Arco de Ponta Grossa para evitar efeitos de contaminação cruzada e, seguidamente, para alíquotas representativas dos dezenove diques amostrados.
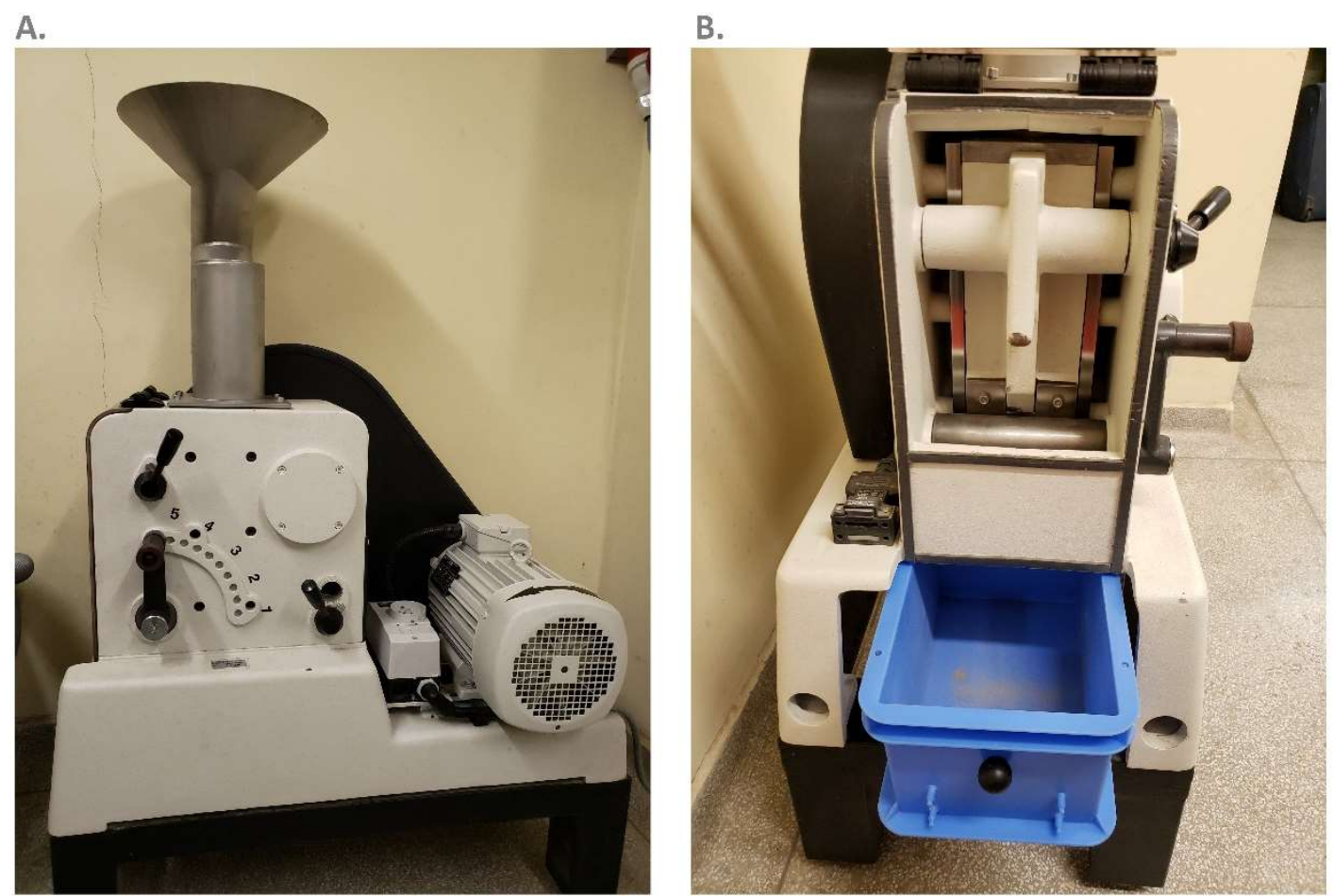

Figura 3.3 - Britador de mandíbulas de aço inoxidável da marca Fritsch (A: destaque para os níveis de britagem e motor; B. destaque para a bandeja e localização das mandíbulas). 
Tabela 3.1 - Etapas do protocolo de manuseio e limpeza do laboratório para o britador da marca Fristsch.

\begin{tabular}{c|c}
\hline Etapa & Descrição \\
\hline I. & $\begin{array}{c}\text { Limpeza da mandíbula de aço inoxidável do britador } \\
\text { com ar comprimido, palha de aço e no final com pano } \\
\text { embebido em álcool. }\end{array}$ \\
\hline$\|$. & $\begin{array}{c}\text { Lavagem da bandeja com água e detergente neutro } \\
\text { e secagem com papel absorvente ou ar comprimido. }\end{array}$ \\
\hline$\|$. & $\begin{array}{c}\text { Britagem com o início na alavanca } \mathrm{n}^{\circ} 5, \text { diminuindo a } \\
\text { numeração até a granulometria desejada (fragmentos } \\
\text { com }<0,5 \text { cm de diâmetro). }\end{array}$ \\
IV. & $\begin{array}{r}\text { Repetição das etapas I e Il a cada nova britagem de } \\
\text { amostra. }\end{array}$ \\
\hline
\end{tabular}

Em seguida, para as doze amostras selecionadas, utilizou-se uma peneira de 80 mesh (em torno de 0,177 mm de diâmetro), da marca Bronzinox, e água deionizada para a lavagem dos fragmentos da fração britada. No processo de lavagem, cada amostra permaneceu 50 minutos na lavadora ultrassônica com água deionizada, que em seguida foi escoada e submetida à secura em estufa por cerca de 4 dias, sob temperatura em torno de $60^{\circ} \mathrm{C}$. A cada nova amostra, a peneira foi lavada com detergente neutro e inserida em lavadora ultrassônica por 20 minutos.

Após a secagem, os fragmentos de cada amostra foram quarteados manualmente com o uso de um papel limpo, de modo que os fragmentos se dispusessem sob a forma de um cone contendo altura bem baixa e com o auxílio de uma espátula limpa de plástico segmentou-se o cone em quatro partes iguais e selecionaram-se e juntaram-se as duas partes diametralmente opostas, até se reduzir a fração homogênea a cerca de $100 \mathrm{~g}$ para a pulverização, sendo que o restante foi armazenado para reserva. A seguir, a fração de cerca de $100 \mathrm{~g}$ foi dividida em 3 partes, em torno de $30 \mathrm{~g}$ por vez, para o uso do moinho mecânico de anéis de ágata. O tempo de pulverização variou de amostra para amostra (em torno de 1 a 2 minutos) e, conforme a necessidade, foram utilizados almofariz e pistilo de ágata até a granulometria atingir a menor possível, em processo manual.

Após a pulverização, as três frações de cada amostra foram homogeneizadas espalhando o pó sobre uma folha de papel limpo, movimentando-se cada ponta da 
borda para o centro, de modo alternado por cerca de 5 minutos. Após a homogeneização, as amostras foram devidamente identificadas e armazenadas.

Para lavagem, os anéis do moinho de ágata, o pistilo e almofariz foram lavados com água e detergente neutro e, em seguida, imersos em água deionizada e colocados na lavadora ultrassônica por 20 minutos, a cada troca de amostra. À parte, a panela e a tampa do moinho de ágata foram lavadas com água e detergente, seguida de água deionizada e álcool 70\%, pois não cabem na lavadora ultrassônica. De modo a prevenir o processo de contaminação cruzada, antes da pulverização de cada amostra foram pulverizados cerca de $25 \mathrm{~g}$ da própria amostra, os quais foram descartados em seguida. Após esse processo, uma nova a lavagem e secagem dos utensílios foram realizadas.

As amostras de diques cedidas pelo Prof. Dr. Artur Corval já se encontravam britadas, dimensões de $0,5 \mathrm{~cm} \mathrm{X} \mathrm{0,5} \mathrm{cm}$ aproximadamente. Para elas, o procedimento de pulverização das amostras e a lavagem dos utensílios foram os mesmos realizados nas amostras coletadas no trabalho de amostragem. Antes da pulverização, os fragmentos foram cuidadosamente observados, para a eliminação daqueles contendo superfícies com alguma alteração ou suspeita de superfícies serradas. Isto é necessário, pois algumas serras podem contaminar com Pb (Marques et al., 2016).

\subsection{Fluorescência de Raios-X}

A espectrometria de Fluorescência de Raios-X (FRX) é uma técnica analítica não destrutiva e vantajosa, devido a sua rapidez, sensibilidade e baixo custo em comparação a outras metodologias para a caracterização química de amostras geológicas (Al-Merey et al., 2005; Sertek, 2010). A FRX determina elementos maiores, menores e alguns traço devido a boa acurácia de análise, tanto para altas concentrações (100\%), quanto para concentrações da ordem $\mathrm{mg} / \mathrm{kg}$. A limitação principal da técnica consiste na impossibilidade de análise para elementos mais leves que o Sódio ( $\mathrm{Na}$; número atômico: 11). A técnica baseia-se no princípio da interação dos átomos de diferentes elementos químicos com os feixes de raios- $X$, causando a emissão de feixes secundários com comprimentos de ondas característicos (Rollinson, 1993; Al-Merey et al., 2005). Para as análises das amostras de diques, usou-se o espectrômetro de dispersão de comprimentos de ondas de Raios-X de modelo PW2400, marca Philips. 
Os raios-X são ondas eletromagnéticas de comprimento entre 0,05 e $1 \AA$. As ondas são capazes de interagir com os elétrons dos níveis mais internos dos átomos (K ou L) e de alterar as propriedades elétricas de materiais sólidos, líquidos e gasosos. A fonte dos feixes de raios-X é externa e precisa emitir fluxos contínuos de fótons energéticos de diversas frequências com razão sinal/ruído pequena. Em geral, as fontes consistem em tubos de raios- $X$ feitos de metais Ródio, Molibdênio, Cobre e Tungstênio. O tipo de metal usado como ânodo, a voltagem de entrada, a tensão entre o ânodo e o cátodo, a corrente no tubo e o grau de interferência do espectro do ânodo são características importantes do tubo e, consequentemente, para as correções aplicadas às medidas finais, por isso necessitam ser bem conhecidas (Al-Merey et al., 2005).

A concentração dos elementos presentes no material analisado é obtida através de cálculos da intensidade de cada elemento. As correções apropriadas do erro instrumental e efeitos da composição da amostra são efetuadas a partir de curvas de calibração com materiais de referência certificados de composições definidas e conhecidas com exatidão (Al-Merey et al., 2005; Sertek et al., 2015). Deste modo, é importante certificar-se da homogeneidade dos materiais em análise, e para isso, estes são fundidos em uma massa vítrea homogênea via borato de lítio para a análise de elementos maiores e menores. No caso de elementos traço, não se faz ataque químico da amostra para geração do vidro, o que diminui a quantidade dos elementos na pastilha (devido à diluição com o borato), assim, efetua-se micronização do pó de 100 mesh para atingir a granulometria de 200 mesh, a fim de minimizar o efeito mineralógico. 0 processo de micronização é realizado em meio líquido (álcool etílico), e, em sequência, foram confeccionadas pastilhas prensadas (Sertek, 2010).

\subsection{Ativação neutrônica}

\subsubsection{Princípio}

A análise por ativação neutrônica é um método não-destrutivo, sensível e apto à determinação das concentrações de diversos elementos químicos presentes em uma amostra de modo independente da forma química em que se encontram. O método usa fluxo de nêutrons, os quais interagem com o núcleo dos isótopos presentes nas amostras. Neste processo de interação, podem ocorrer simples colisões e/ou capturas 
de nêutrons pelos núcleos, formando-se nuclídeos radioativos. Devido ao excesso de energia adquirida na captura, os nuclídeos tornam-se instáveis e podem emitir diferentes partículas e/ou radiações para tornarem-se estáveis novamente. 0 tipo de partícula e radiação emitidos dependem das caraterísticas de cada núcleo atingido e da energia do fluxo dos nêutrons de bombardeio (Vértes et al., 2010).

Várias reações podem ocorrer de acordo com as energias dos nêutrons incidentes, sendo que as principais são:

$$
\begin{aligned}
& \text { - reação }(n, \gamma): X_{Z}^{A}+n \rightarrow X_{Z}^{A+1}+\gamma \\
& \text { - reação }(n, 2 n): X_{Z}^{A}+n \rightarrow X_{Z}^{A-1}+2 n \\
& \text { - reação }(n, p): X_{Z}^{A}+n \rightarrow X_{Z-1}^{A}+p \\
& \text { - reação }(n, \alpha): X_{Z}^{A}+n \rightarrow X_{Z-2}^{A-3}+\alpha
\end{aligned}
$$

onde $\mathrm{A}$ = número de massa; $\mathrm{Z}$ = número atômico; $\mathrm{n}$ = nêutron; $\mathrm{p}=$ próton; $\alpha$ = partícula alfa e $\gamma=$ emissão gama.

Os nêutrons de bombardeio são classificados em três grupos, conforme as suas faixas de energias (Lukens et al., 1974):

- Nêutrons térmicos: são descritos pelas baixas energias, variando de 0 a $0,026 \mathrm{eV}$. Considerando uma fonte de nêutrons de alta energia, estes podem ser produzidos através de uma barreira composta de um material de baixo número atômico (moderador) entre a fonte e alvo. Estes nêutrons favorecem reações do tipo $(n, \gamma)$.

- Nêutrons epitérmicos: são descritos pelas energias intermediárias, entre 0,027 e 1000 eV. Estes são importantes devido ao fato de diversos isótopos de elementos químicos, em particular $Z$ > 30, apresentarem altas secções de choques para esta faixa de energia. Estes nêutrons favorecem reações do tipo $(n, \gamma)$.

- Nêutrons rápidos: são descritos pelas altas energias, acima de 1 keV. Estes são caracterizados pelas seções de choque relativamente baixas. Os tipos de reações induzidas são $(n, 2 n),(n, p)$ e $(n, \alpha)$.

Como as irradiações das amostras ocorrem no reator nuclear, em que há um amplo espectro de energia para o fluxo de nêutrons, todas as reações acima são possíveis de acontecer de modo simultâneo. 
Na Figura 3.4 é representada a sequência de eventos para a formação de um radioisótopo pela reação $(n, \gamma)$, ou captura neutrônica seguida de decaimento $\beta^{-} \mathrm{e}$ emissão de radiação gama. $O$ núcleo alvo $\left({ }_{Z}^{A} X\right)$ ao capturar um nêutron torna-se um núcleo composto ${ }_{Z}^{A+1} X^{*}$ instável e frequentemente perde energia através da emissão de raios gama, com tempo de meia-vida da ordem de $10^{-16}$ a $10^{-14}$ segundos, os quais são denominados de raios gama prontos (Prompt Gamma Neutron Activation Analysis; PGNAA). À medida que o núcleo composto decai emitindo uma partícula $\beta^{-}$, o radioisótopo $\left({ }_{Z}^{A+1} X^{*}\right)$ transforma-se em outro nuclídeo, no esquema visto como ${ }_{Z+1}^{A+1} Y^{*}$. O novo radionuclídeo instável emite, para a estabilidade, radiação gama, a qual é nomeada de emissão de raios gama atrasados. A medição desta emissão gama é denominada de Delayed Gamma Neutron Activation Analysis (DGNAA), ou simplificadamente de Análise por Ativação Neutrônica (Neutron Activation Analysis; NAA), que foi aplicada neste estudo (TECDOC, 1990).

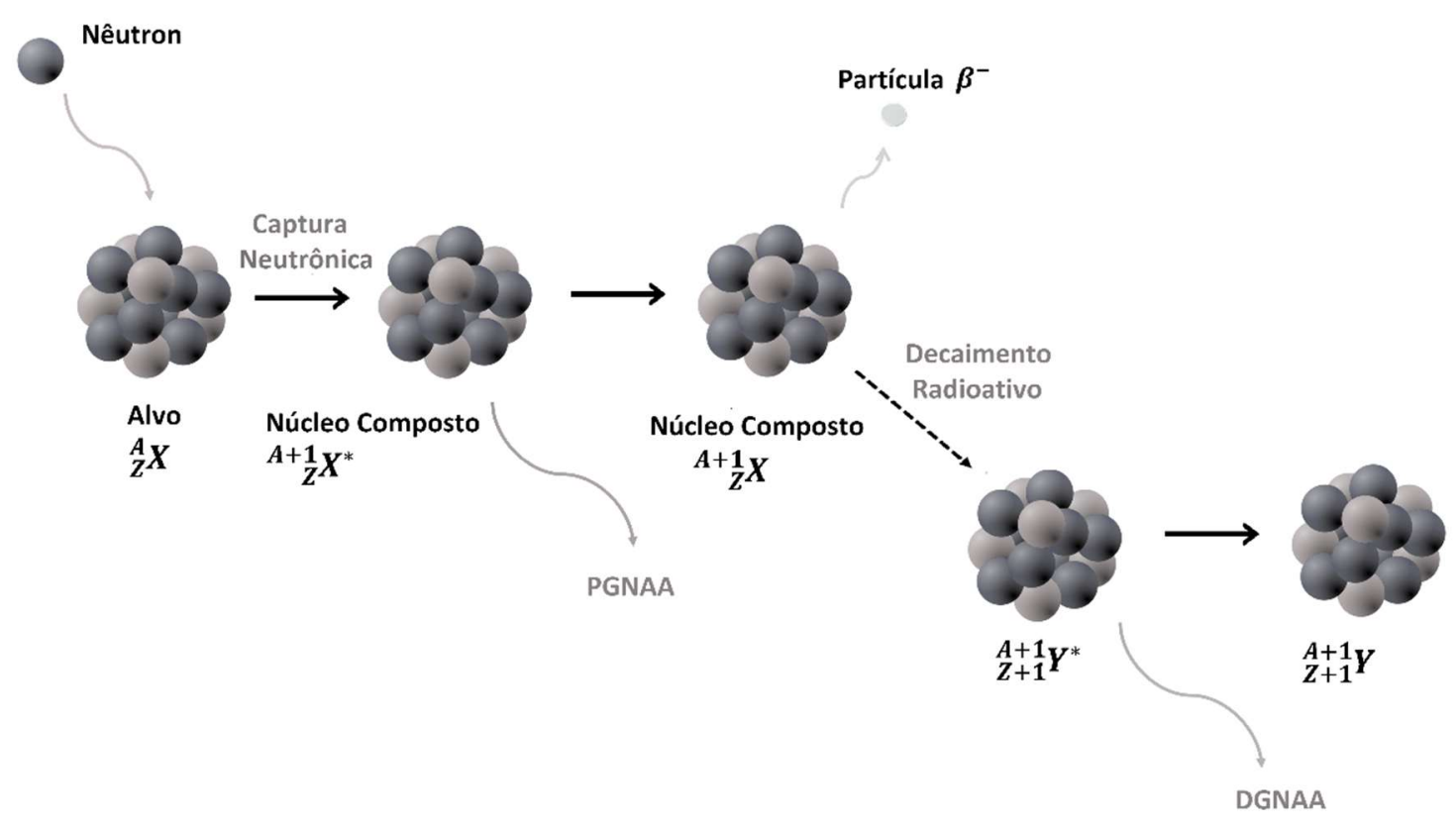

Figura 3.4 - Esquema de sequência de eventos para a reação de captura de nêutrons seguida de decaimento $\beta^{-}$e emissão de radiação gama para a formação e desexcitação do núcleo irradiado. PGAA: Prompt Gamma Neutron Activation Analysis; DGNAA: Delayed Gamma Neutron Activation Analysis (baseada em TECDOC, 1990).

Os radioisótopos resultantes dos processos de ativação neutrônica apresentam características de decaimento particulares, associadas à meia-vida do radioisótopo formado e à energia da emissão gama. De modo que, torna-se viável a determinação 
qualitativa e quantitativa, através de medições das partículas e/ou radiações emitidas após a captura neutrônica. A Tabela 3.2 apresenta algumas características dos elementos analisados com irradiação de nêutrons térmicos.

Tabela 3.2 - Elementos analisados e as características principais de seus radioisótopos para reações envolvendo nêutrons térmicos (Adams \& Dams, 1969).

\begin{tabular}{|c|c|c|c|c|c|}
\hline Elemento & $\begin{array}{l}\text { Radioisótopo } \\
\text { Medido }\end{array}$ & $\begin{array}{c}\text { Nuclídeo } \\
\text { Alvo }\end{array}$ & $\begin{array}{l}\text { Meia- } \\
\text { vida }\end{array}$ & $\begin{array}{c}\text { Energia da } \\
\text { radiação } \\
\text { (keV) }\end{array}$ & $\begin{array}{l}\text { Tempo de } \\
\text { decaimento } \\
\text { antes da } \\
\text { contagem } \\
\text { (d) }\end{array}$ \\
\hline \multirow{3}{*}{ La } & \multirow{3}{*}{${ }^{140} \mathrm{La}$} & \multirow{3}{*}{${ }^{139} \mathrm{La}$} & & 328,6 & \multirow{3}{*}{$04-07$} \\
\hline & & & $47,27 \mathrm{~h}$ & 486,8 & \\
\hline & & & & 1595,4 & \\
\hline $\mathrm{Ce}$ & ${ }^{141} \mathrm{Ce}$ & ${ }^{140} \mathrm{Ce}$ & $32,5 d$ & 145,4 & $15-30$ \\
\hline $\mathrm{Nd}$ & ${ }^{147} \mathrm{Nd}$ & ${ }^{146} \mathrm{Nd}$ & $11,1 d$ & 91,4 & $04-07$ \\
\hline Sm & ${ }^{153} \mathrm{Sm}$ & ${ }^{152} \mathrm{Sm}$ & $47,1 \mathrm{~h}$ & 103,2 & 04-07 \\
\hline \multirow{3}{*}{ Eu } & \multirow{3}{*}{${ }^{152} \mathrm{Eu}$} & \multirow{3}{*}{${ }^{151} \mathrm{Eu}$} & \multirow{3}{*}{$11,1 d$} & 121,8 & \multirow{3}{*}{$15-30$} \\
\hline & & & & 344,2 & \\
\hline & & & & 1407,5 & \\
\hline $\mathrm{Tb}$ & ${ }^{160} \mathrm{~Tb}$ & ${ }^{159} \mathrm{~Tb}$ & $73 d$ & 1177,6 & $15-30$ \\
\hline \multirow{4}{*}{$\mathrm{Yb}$} & \multirow{2}{*}{${ }^{169} \mathrm{Yb}$} & \multirow{2}{*}{${ }^{168} \mathrm{Yb}$} & \multirow{2}{*}{$30,6 d$} & 177,0 & \multirow{2}{*}{$15-30$} \\
\hline & & & & 197,8 & \\
\hline & \multirow[t]{2}{*}{${ }^{175} \mathrm{Yb}$} & \multirow{2}{*}{${ }^{174} \mathrm{Yb}$} & \multirow{2}{*}{$101 \mathrm{~h}$} & 282,6 & \multirow{2}{*}{$04-07$} \\
\hline & & & & 396,1 & \\
\hline Lu & ${ }^{177} \mathrm{Lu}$ & ${ }^{176} \mathrm{Lu}$ & $6,75 d$ & 208,4 & 04-07 \\
\hline Th & ${ }^{233} \mathrm{~Pa}$ & ${ }^{232} \mathrm{Th}$ & $27 d$ & 311,8 & $15-30$ \\
\hline $\mathrm{Ba}$ & ${ }^{131} \mathrm{Ba}$ & ${ }^{130} \mathrm{Ba}$ & $11,5 d$ & 496,3 & $15-30$ \\
\hline $\mathrm{Hf}$ & ${ }^{181} \mathrm{Hf}$ & ${ }^{180} \mathrm{Hf}$ & $44,6 d$ & 482,2 & $15-30$ \\
\hline Sc & ${ }^{46} \mathrm{Sc}$ & ${ }^{45} \mathrm{Sc}$ & $83,9 \mathrm{~d}$ & 889,4 & $15-30$ \\
\hline Co & ${ }^{60} \mathrm{Co}$ & ${ }^{59} \mathrm{Co}$ & $5,24 \mathrm{a}$ & 1173,1 & $15-30$ \\
\hline \multirow{2}{*}{$\mathrm{Ta}$} & \multirow{2}{*}{${ }^{182} \mathrm{Ta}$} & \multirow{2}{*}{${ }^{181} \mathrm{Ta}$} & \multirow{2}{*}{$115,1 \mathrm{~d}$} & 1188,8 & \multirow{2}{*}{$15-30$} \\
\hline & & & & 1221,6 & \\
\hline
\end{tabular}

\subsubsection{Materiais de referência empregados}

Como a abundância isotópica dos elementos químicos na natureza é conhecida, a concentração dos elementos pode ser obtida pelo método comparativo entre os 
isótopos ativados presentes no conjunto de amostras e nos materiais de referência certificados (Figueiredo \& Marques, 1989; TECDOC, 1990).

No método comparativo (Instrumental Neutron Activation Analysis; INAA), é possível a determinação das concentrações dos elementos das amostras utilizando a equação 3.3 , onde $C_{s}^{I}$ é a concentração do elemento $/$ na amostra, $A_{s}^{I}$ e $A_{s t}^{I}$ são as atividades do radioisótopo considerado presente na amostra e no material de referência no tempo $t$, respectivamente, $M_{s}$ e $M_{s t}$ são as massas das amostras e dos materiais de referência, respectivamente, $C_{s t}^{I}$ é a concentração do elemento / no material de referência, $t$ é o tempo decorrido entre a contagem da amostra e do material de referência, e $\lambda$ é a constante de decaimento do elemento I (Equação 3.3).

$$
C_{s}^{I}=\frac{A_{s}^{I} \cdot M_{s t} \cdot C_{s t}^{I} \cdot e^{\lambda t}}{A_{s t}^{I} M_{s}}
$$

Para os estudos dos diques investigados, optou-se pelos seguintes materiais de referência: o basalto BE-N, fornecido pelo International Working Group - Group International de Travail (IWG-GIT) e o granito GS-N, fornecido pela Association Nationale de La Recherche Technique (ARNT) (Govindaraju, 1994). Esses padrões são rochas compostas por silicatos com composições distintas, abrangendo as concentrações de elementos presentes nas rochas investigadas. Como terceiro material de referência, adotou-se o BRP-1 (Basalto Ribeirão Preto - lote 1), certificado pelo Instituto de Geociências da Universidade Estadual de Campinas (Cotta et al., 2008), para aprimorar a qualidade dos dados estatísticos. Esta rocha basáltica provém de um derrame tipo Pitanga da PMP, com características similares aos diques do presente estudo.

A Tabela 3.3 apresenta as concentrações de cada elemento químico analisado para cada um dos materiais de referência. 
Tabela 3.3 - Valores de concentrações dos materiais de referência utilizados neste trabalho $(\mathrm{mg} / \mathrm{kg})$, os valores de desvio padrão encontram-se entre parênteses (Govindaraju, 1994; Cotta et al., 2008).

\begin{tabular}{c|ccc}
\hline Elemento & BRP-1 & GS-N & BE-N \\
\hline La & $42,6(0,5)$ & $75,00(1,3)$ & $82,00(0,75)$ \\
\hline Ce & $93,3(0,6)$ & $135,0(3,5)$ & $152(2)$ \\
\hline $\mathrm{Nd}$ & $51,9(0,45)$ & $49,00(0,75)$ & $67,00(0,75)$ \\
\hline Sm & $11,2(0,1)$ & $7,50(0,11)$ & $12,20(0,15)$ \\
\hline Eu & $3,42(0,04)$ & $1,70(0,03)$ & $3,60(0,09)$ \\
\hline Tb & $1,52(0,03)$ & $0,60(0,02)$ & $1,30(0,05)$ \\
\hline Yb & $3,48(0,05)$ & $1,40(0,08)$ & $1,8(0,1)$ \\
\hline Lu & $0,50(0,01)$ & $0,22(0,02)$ & $0,24(0,02)$ \\
\hline Th & $3,97(0,05)$ & $40,00(1,7)$ & $10,40(0,33)$ \\
\hline Ba & $555,0(3,5)$ & $1400(22)$ & $1025(15)$ \\
\hline Hf & $8,0(0,1)$ & $6,20(0,17)$ & $5,60(0,08)$ \\
\hline Sc & $28,5(0,4)$ & $7,3(0,2)$ & $22,00(0,75)$ \\
\hline Rb & $35,4(0,5)$ & $185,0(2,5)$ & $47(1)$ \\
\hline Co & $37,5(0,7)$ & $65(2)$ & $60(1)$ \\
\hline Ta & $1,96(0,04)$ & $2,6(0,1)$ & $5,7(0,2)$ \\
\hline
\end{tabular}

\subsubsection{Rotina experimental}

Após a redução das amostras a uma granulometria inferior a 100 mesh (em torno de 0,149 $\mathrm{mm}$ de diâmetro), realizou-se a rotina experimental descrita em Figueiredo \& Marques (1989) e Vicentini (2015) no Centro de Reator de Pesquisa (CRPq) do Instituto de Pesquisas Energéticas Nucleares (IPEN-CNEN/SP).

Inicialmente, foram confeccionados os envoltórios plásticos onde o pó é depositado. Os envoltórios são constituídos de invólucros plásticos do tipo ZipLock e para suas preparações usou-se um papel celofane, para envolver o plástico, a fim deste não derreter enquanto foi soldado por uma seladora Selapack, destinada apenas a materiais geológicos. Os invólucros têm dimensões em torno de $2 \mathrm{~cm} \mathrm{X} 3 \mathrm{~cm}$, configurando-se como saquinhos. As amostras em pó foram depositadas nestes saquinhos com o auxílio de pinças sem pontas afiadas e uma espátula, ambas de metal, e pesadas em torno de 0,100 g em uma balança analítica OHAUS de modelo AR2140. Em seguida, a aresta de cada invólucro foi fechada com a seladora, de modo a não apresentar bolhas de ar. Para verificar a presença de eventuais furos, foi esguichado álcool em cada um, observando-se atentamente se houve a mudança na coloração da amostra em pó. Em caso positivo, uma nova alíquota foi preparada. 
Após os envoltórios serem lacrados e devidamente identificados, eles foram embalados com papel alumínio e nomeados com a mesma identificação. O uso do papel alumínio previne uma possível fusão (colagem) entre os saquinhos plásticos durante a irradiação. Logo após, os invólucros das amostras foram alinhados juntamente com os materiais de referência nas posições centrais do conjunto (alternados entre as amostras), organizados de acordo com a numeração descrita acima. O conjunto foi embalado novamente com papel alumínio, de modo que os invólucros permanecessem firmes, e inserido em um cilindro composto de alumínio (nomeado de "coelho"). A ativação do isótopo ${ }^{28} \mathrm{Al}$ produz o radioisótopo ${ }^{27} \mathrm{Al}(1778,9 \mathrm{keV})$ de curta meia-vida, cerca de minutos (2,31 minutos; Adams \& Dams, 1969), consequentemente, a diminuição da atividade é muito rápida após sua ativação, que é um requisito para o manuseio e retirada das amostras do seu interior.

Cada coelho contendo um conjunto de amostras e materiais de referência certificados foram submetidos à irradiação no reator nuclear de pesquisas da CRPq, IEA$\mathrm{R} 1$, sob o período de $8 \mathrm{~h}$ e fluxo de 3 a $5 \times 10^{12} \mathrm{n} / \mathrm{cm}^{2} \mathrm{~s}$. A primeira medida da atividade gama induzida ocorreu entre 5 e 7 dias após o término da irradiação, com o tempo de contagem de 1 hora, enquanto na segunda contagem, ocorreu entre 12 e 15 dias com duração de 1,5 horas.

As contagens das atividades gama induzidas foram realizadas no detector de Ge hiperpuro GX20190, Canberra, de resolução nominal de 1,90 keV para o pico de 1332 keV do ${ }^{60} \mathrm{Co}$ e ligado a uma placa multicanal de 8192 Canberra S-100 e eletrônica associada. O software de análise do espectro de raios gama foi o VISPECT, desenvolvido pelo Laboratório de Análise por Ativação Neutrônica (LAN-IPEN). O sistema de Ge hiperpuro possui a forma cilíndrica com blindagem constituída de chumbo com cerca de $5 \mathrm{~cm}$ de espessura e revestido internamente de cádmio e cobre, os quais reduzem o efeito de espalhamento de raios gama. Uma espécie de prateleira, que permite a realização das contagens em quatro níveis diferentes de distância entre fonte (alíquota irradiada) e detector é acoplada a este último. A escolha do nível de distância a ser empregada é baseada no "tempo morto" fornecido pelo próprio software, sendo que os valores aceitáveis dos níveis devem ficar no máximo entre 5-10\%. O tempo morto é um parâmetro de ajuste do sistema para compensar o tempo do detector de desassociar a leitura de duas emissões gama (Lindstrom \& Fleming, 1995; Knoll, 1999). 


\subsection{Espectrometria de massa termoiônica}

A espectrometria de massa termoiônica (TIMS) é uma técnica analítica usualmente aplicada na geocronologia e geoquímica, que realiza medições precisas das razões isotópicas de elementos possíveis de serem ionizados termicamente. Neste estudo, as razões ${ }^{87} \mathrm{Sr} /{ }^{86} \mathrm{Sr}$ e ${ }^{143} \mathrm{Nd} /{ }^{144} \mathrm{Nd}$ foram medidas pelo espectrômetro de massa de setor magnético da marca Thermo Scientific TRITON (multicoletor).

Para a aplicação do TIMS, as amostras devem estar previamente pulverizadas, a fim de ampliar sua superfície de contato e possibilitar a sua dissolução em meio ácido. Esse procedimento é denominado ataque químico e constitui-se na quebra das estruturas silicáticas dos minerais constituintes da rocha, viabilizando a separação individual dos elementos de interesse, neste caso $\mathrm{Sr}$ e $\mathrm{Nd}$, via cromatografia de troca iônica (Kawashita, 1972; Sato et al., 1995; Rocha-Júnior et al., 2013; Magdaleno et al., 2017). Para esse ataque, cerca de $100 \mathrm{mg}$ de cada amostra foram submetidas ao ataque com $\mathrm{HF}, \mathrm{HNO}_{3}$ e $\mathrm{HCl}$ em béqueres de teflon (Savillex), os quais foram colocados sobre chapa aquecedora a aproximadamente $100^{\circ} \mathrm{C}$ (clean box), em capela com fluxo laminar classe ISO-5 e sala limpa ISO-7. Após cerca de 5 dias, as amostras são então submetidas à secura e em seguida o resíduo foi dissolvido em $6 \mathrm{M} \mathrm{HCl}$ durante 24 horas. Após nova evaporação o resíduo foi diluído com $\mathrm{HNO}_{3}$ concentrado e a solução é percolada em resina de troca iônica Eichrom Sr-Spec, pré-condicionada com $\mathrm{HNO}_{3}$ concentrado. Nessa condição, a resina retém $\mathrm{Sr}$, mas não $\mathrm{Nd}$, sendo que solução que passa pela resina é reservada para posterior purificação de $\mathrm{Nd}$. O Sr retido na resina é, então, eluído com $\mathrm{HNO}_{3}$ 0,05M. Para a separação e purificação de $\mathrm{Nd}$ foram utilizadas as resinas RE-Spec e LN-Spec, respectivamente, em meio $\mathrm{HCl} 0,26 \mathrm{M}$.

As soluções de Sr purificadas foram depositadas em filamentos metálicos simples feitos de $\mathrm{Ta}$, com adição de solução de tântalo $\left(\mathrm{TaCl}_{5}\right)$, enquanto, as soluções de $\mathrm{Nd}$ foram depositadas em filamentos duplos de Re. Os elementos Ta e Re dos filamentos são caracterizados por alto ponto de fusão, sendo que os elétrons não são afetados pelo efeito termoiônico em altas temperaturas. No interior do espectrômetro, ocorre o aquecimento do filamento a altas temperaturas, onde a solução que foi depositada evapora e que, em seguida, sofre ionização. 
No espectrômetro de massa as condições para as medições são de ultra vácuo, pois, assim, evita a perturbação de moléculas externas nas trajetórias das partículas oriundas das soluções das amostras. No tubo do espectrômetro, os íons resultantes do efeito termoiônico são acelerados pela aplicação de uma diferença de potencial e deslocamse para um tubo curvo, no qual um campo magnético é aplicado perpendicularmente à trajetória das partículas. Nesse trajeto, cada íon apresenta seu raio de desvio característico de acordo com a razão massa/carga, descrita pela força de Lorentz (Vanhaecke, 2012).

Para as medidas das razões isotópicas de Sr foram efetuadas para cada amostra 200 medições. As razões isotópicas ${ }^{87} \mathrm{Sr} /{ }^{86} \mathrm{Sr}$ foram normalizadas para o valor de ${ }^{86} \mathrm{Sr} /{ }^{88} \mathrm{Sr}$ igual a 0,1194. No caso das medidas das razões isotópicas de $\mathrm{Nd}$, foram realizadas 120 medições com normalização baseada no valor ${ }^{146} \mathrm{Nd} /{ }^{144} \mathrm{Nd}: 0,7219$. As incertezas das razões ${ }^{86} \mathrm{Sr} /{ }^{88} \mathrm{Sr}$ e ${ }^{146} \mathrm{Nd} /{ }^{144} \mathrm{Nd}$ medidas são de $2 \sigma$ (Magdaleno et al., 2017). 


\section{RESULTADOS}

Conforme descrito anteriormente, analisaram-se 18 amostras de diques da Região Serrana do Rio de Janeiro, situadas na Região de Nova Friburgo (porção nordeste do ESM). A caracterização dos diques iniciou-se com a determinação de óxidos de elementos maiores e menores por Fluorescência de Raios-X e de elementos traço compatíveis e incompatíveis (abrangendo ETR) por esse mesmo método e, também, por análise por ativação neutrônica instrumental. Além disso, a partir dos dados obtidos, 5 das 19 amostras foram selecionadas para as análises das razões isotópicas de Sr e Nd.

\subsection{Fluorescência de Raios $X$}

Para o estudo geoquímico dos diques, foram analisados elementos maiores $\left(\mathrm{SiO}_{2}\right.$, $\mathrm{Al}_{2} \mathrm{O}_{3}, \mathrm{Fe}_{2} \mathrm{O}_{3}, \mathrm{MgO}, \mathrm{CaO}, \mathrm{Na}_{2} \mathrm{O}$ e $\left.\mathrm{K}_{2} \mathrm{O}\right)$, menores $\left(\mathrm{TiO}_{2}\right.$ e $\left.\mathrm{P}_{2} \mathrm{O}_{5}\right)$ e alguns traço $(\mathrm{Cr}, \mathrm{Ni}, \mathrm{Ba}$, $\mathrm{Rb}, \mathrm{Sr}, \mathrm{Zr}, \mathrm{Y}$ e Nb) por espectrometria de Fluorescência de Raios-X, cujos fundamentos teóricos e procedimentos experimentais foram apresentados no capítulo anterior.

As amostras foram agrupadas em dois lotes para as medições, sendo o primeiro composto pelas amostras QT-SV-4A, QT-SV-2A, QT-SV-6A, QT-SV-3 e QT-SV-1B; e o segundo pelas amostras LMD-RJ-8000A, LMD-RJ-8004, LMD-RJ-8005A, LMD-RJ-8006, LMD-RJ-8010, LMD-RJ-8012, LMD-RJ-8013A, LMD-RJ-8014A, LMD-RJ-8017, LMD-RJ8018, LMD-RJ-8019A e LMD-RJ-8019C. Os materiais de referência empregados para determinar a exatidão $e(\%)$ do método (Equação 4.1), nas condições experimentais adotadas, foram o JB-1a e JG-1a, basalto e granodiorito, respectivamente (Yurimoto et al., 1989), cujas concentrações dos elementos analisados e os respectivos valores de exatidão estão apresentados na Tabela 4.1.

$$
e=\frac{\left|x_{\text {cert }, i}-x_{\text {det }, i}\right|}{x_{\text {cert }, i}} x 100
$$

onde $x_{c e r t, i}$ consiste no valor de concentração certificado do elemento $i$ e $x_{\text {det }, i}$ no valor de concentração determinado para o mesmo elemento nos materiais de referência JB-1a e JG-1a. 
Tabela 4.1 - Valores recomendados ( $\mu$, Yurimoto et al., 1989) e de concentrações (x) de elementos maiores, menores e traço obtidos por FRX para os materiais de referência JB-1a e JG-1a e os valores de exatidão $(e)$ para os dois lotes de amostras analisados no IGc-USP. Valores de óxidos e perda ao fogo (Lol) são em \% e os valores de elementos traço em $\mathrm{mg} / \mathrm{kg}$ e valores de exatidão em \%.

\begin{tabular}{|c|c|c|c|c|c|c|c|c|c|c|}
\hline \multirow{3}{*}{$\begin{array}{c}\text { MR } \\
\text { Análise } \\
\end{array}$} & \multicolumn{2}{|c|}{$\mu$} & \multicolumn{4}{|c|}{$\begin{array}{c}\text { QT-SV-4A, QT-SV-2A, QT-SV-6A, } \\
\text { QT-SV-3, QT-SV-1B }\end{array}$} & \multicolumn{4}{|c|}{$\begin{array}{l}\text { LMD-RJ-8000A, LMD-RJ-8004, } \\
\text { LMD-RJ-8005A, LMD-RJ-8006, } \\
\text { LMD-RJ-8010, LMD-RJ-8012, LMD- } \\
\text { RJ-8013A, LMD-RJ-8014A, LMD-RJ- } \\
\text { 8017, LMD-RJ-8018, LMD-RJ- } \\
\text { 8019A, LMD-RJ-8019C }\end{array}$} \\
\hline & \multirow[t]{2}{*}{ JB-1a } & \multirow[t]{2}{*}{ JG-1a } & \multicolumn{2}{|c|}{ JB-1a } & \multicolumn{2}{|c|}{ JG-1a } & \multicolumn{2}{|c|}{ JB-1a } & \multicolumn{2}{|c|}{ JG-1a } \\
\hline & & & $\mathrm{x}$ & e & $x$ & e & $x$ & e & $\mathrm{x}$ & e \\
\hline $\mathrm{SiO}_{2}$ & 52,16 & 72,19 & 52,54 & 0,7 & 71,8 & 0,5 & $52, \varepsilon$ & 1,3 & 71,76 & 0,6 \\
\hline $\mathrm{TiO}_{2}$ & 1,3 & 0,25 & 1,29 & 0,8 & 0,233 & 6,8 & 1,29 & 0,8 & 0,233 & 6,8 \\
\hline $\mathrm{Al}_{2} \mathrm{O}_{3}$ & 14,51 & 14,22 & 14,37 & 1,0 & 14,09 & 0,9 & 14,61 & 0,7 & 14,17 & 0,4 \\
\hline $\mathrm{Fe}_{2} \mathrm{O}_{3}$ & 1 & 205 & 9,04 & 0,7 & 198 & 3,4 & 9,06 & 0,4 & 1,98 & 3,4 \\
\hline MnO & 0,15 & 0,06 & 0,148 & 1,3 & 0,059 & 1,7 & 0,148 & 1,3 & 0,059 & 1,7 \\
\hline $\mathrm{MgO}$ & 7,75 & 0,69 & 7,82 & 0,9 & 0,77 & 11,6 & 7,78 & 0,4 & 0,76 & 10,1 \\
\hline $\mathrm{CaO}$ & 9,23 & 2,13 & 9,39 & 1,7 & 2,13 & 0,0 & 9,39 & 1,7 & 2,12 & 0,5 \\
\hline $\mathrm{Na}_{2} \mathrm{O}$ & 2,74 & 3,41 & 2,68 & 2,2 & 3,49 & 2,4 & 2,87 & 4,7 & 3,5 & 2,6 \\
\hline $\mathrm{K}_{2} \mathrm{O}$ & 1,42 & 4,01 & 1,40 & 1,4 & 3,96 & 1,3 & 1,41 & 0,7 & 3,94 & 1,7 \\
\hline $\mathrm{P}_{2} \mathrm{O}_{5}$ & 0,26 & 0,08 & 0,261 & 0,4 & 0,087 & 8,8 & 0,259 & 0,4 & 0,087 & 8,8 \\
\hline Lol & 1,1 & 0,59 & 1,1 & 0,0 & 0,59 & 0,0 & 1,1 & 0,0 & 0,59 & 0,0 \\
\hline Total & 99,72 & 99,68 & 100,04 & 0,3 & 99,19 & 0,5 & 100,75 & 1,0 & 99,20 & 0,5 \\
\hline $\mathrm{Cr}$ & 415 & 18,6 & 403 & 2,9 & 26 & 39,8 & 406 & 2,2 & 27 & 45,2 \\
\hline $\mathrm{Ni}$ & 140 & 6,4 & 40 & 0,0 & $<5$ & - & 142 & 1,4 & $<5$ & - \\
\hline $\mathrm{Ba}$ & 497 & 458 & 518 & 2,0 & 449 & 2,0 & 518 & 4,2 & 449 & 2,0 \\
\hline $\mathrm{Rb}$ & 41 & 180 & 40 & 2,4 & 178 & 1,1 & 40 & 2,4 & 179 & 0,6 \\
\hline $\mathrm{Sr}$ & 443 & 185 & 439 & 0,9 & 180 & 2,7 & 442 & 0,2 & 182 & 1,6 \\
\hline La & 38,1 & 21,8 & 39 & 2,4 & $<28$ & - & 37 & 2,9 & $<28$ & - \\
\hline $\mathrm{Ce}$ & 45,2 & 45,2 & 56 & 23,9 & 35 & 22,6 & 66 & 46,0 & 49 & 8,4 \\
\hline $\mathrm{Nd}$ & 25,5 & 21 & 28 & 9,8 & 22 & 4,76 & 29 & 13,7 & 30 & 43 \\
\hline $\mathrm{Zr}$ & 146 & 121 & 137 & 6,2 & 117 & 3,3 & 137 & 6,2 & 119 & 1,7 \\
\hline Y & 24 & 31,6 & 22 & 8,3 & 29 & 8,2 & 22 & 8,3 & 30 & 5,1 \\
\hline $\mathrm{Nb}$ & 27 & 12 & 27 & 0,0 & 13 & 8,3 & 28 & 3,7 & 13 & 8,3 \\
\hline
\end{tabular}

Os valores de exatidão para os óxidos estão de acordo com o esperado para a metodologia empregada, sendo na grande maioria dos casos inferiores a $5 \%$. Valores um pouco mais elevados (máximo de 11,6 \%) foram observados para $\mathrm{TiO}_{2}, \mathrm{MgO}_{\text {e }} \mathrm{P}_{2} \mathrm{O}_{5}$ no JG-1a, os quais muito provavelmente estão relacionados às baixas concentrações de tais óxidos (menores do que 1\%) nesse material de referência. Cabe notar, que para o 
material de referência JB-1a, bem mais enriquecido nesses mesmos elementos, os níveis de exatidão são melhores do que $1 \%$.

Para os elementos traço, os valores de exatidão obtidos nos dois materiais de referência também foram plenamente satisfatórios, não ultrapassando 10\%, com exceção do Cr e Ni no JG-1a, que apresentam concentrações muito baixas e, para o caso do $\mathrm{Ni}$, próximo ao limite de detecção do método. Para os elementos Ce (primeiro lote) e $\mathrm{Nd}$ (segundo lote), os valores de exatidão estão acima de 10\%, mostrando que as concentrações para esses dois elementos não são confiáveis, para os níveis de grandeza presentes nas amostras estudadas. Assim, no presente estudo, tais resultados não foram utilizados para investigações petrogenéticas.

Para a averiguação da reprodutibilidade dos resultados, duplicaram-se as análises da amostra QT-SV-2A (Tabela 4.2) relacionada ao primeiro lote de amostras e as análises das amostras LMD-RJ-8010 e LMD-RJ-8018, relacionadas ao segundo lote. Os desvios padrão $(\sigma)$ apresentaram valores percentuais inferiores a $0,4 \%$ para elementos maiores e menores e a $6 \%$ para elementos traço, os quais são concordantes com o esperado para a metodologia, com valores de desvio padrão iguais a zero para os elementos traço $\mathrm{Nb}$ e $\mathrm{Ba}$ (primeiro lote) e $\mathrm{Ni}, \mathrm{Rb}, \mathrm{Sr}, \mathrm{Y}$ e $\mathrm{Zr}$ (segundo lote) e para os óxidos $\mathrm{Na}_{2} \mathrm{O}$ e $\mathrm{K}_{2} \mathrm{O}$ (segundo lote).

Adicionalmente, os óxidos maiores e menores das amostras QT-SV-2D e QT-SV-6B analisados no IGCE/UNESP-RC apresentam valores de exatidão são inferiores a 0,29\% não ultrapassando 5\%, satisfatório para o método (Rocha-Júnior et al., 2020).

De modo geral, a FRX apresentou-se satisfatória na determinação dos óxidos maiores e menores e elementos traços, com precisão e exatidão requeridas em estudos petrogenéticos. Entretanto, para interpretação petrogenética não se utilizaram os elementos $\mathrm{La}$, Ce e $\mathrm{Nd}$, devido à baixa acurácia verificada para a faixa de concentrações dos materiais de referência (tabela 4.1). 
Tabela 4.2 - Valores de concentrações de elementos maiores, menores e traço para a primeira (A1) e segunda (A2) análises por FRX da amostra QT-SV-2A (primeiro lote de amostras), a média das duas análises $(\bar{x})$ e os desvios padrão ( $\boldsymbol{\sigma}$ ) em valor percentual (\%). Valores de óxidos e perda ao fogo (Lol) são em \% e de elementos traço em $\mathrm{mg} / \mathrm{kg}$.

\begin{tabular}{c|cccc}
\hline & \multicolumn{4}{|c}{$\mathrm{QT}-\mathrm{AV}-2 \mathrm{~A}$} \\
& $\mathrm{~A} 1$ & $\mathrm{~A} 2$ & $\bar{x}$ & $\sigma(\%)$ \\
\hline $\mathrm{SiO}_{2}$ & 51,21 & 51,05 & 51,13 & 0,22 \\
\hline $\mathrm{TiO}_{2}$ & 2,542 & 2,529 & 2,536 & 0,363 \\
\hline $\mathrm{Al}_{2} \mathrm{O}_{3}$ & 13,11 & 13,04 & 13,08 & 0,38 \\
\hline $\mathrm{Fe}_{2} \mathrm{O}_{3}$ & 14,39 & 14,30 & 14,35 & 0,44 \\
\hline $\mathrm{MnO}$ & 0,196 & 0,193 & 0,195 & 1,09 \\
\hline $\mathrm{MgO}$ & 4,92 & 4,93 & 4,93 & 0,14 \\
\hline $\mathrm{CaO}$ & 8,48 & 8,41 & 8,45 & 0,59 \\
\hline $\mathrm{Na} \mathrm{O}_{2} \mathrm{O}$ & 2,60 & 2,59 & 2,60 & 0,27 \\
\hline $\mathrm{K} 2 \mathrm{O}$ & 1,31 & 1,30 & 1,31 & 0,54 \\
\hline $\mathrm{P} \mathrm{O}_{5}$ & 0,369 & 0,370 & 0,370 & 0,191 \\
\hline $\mathrm{Lol}$ & 0,50 & 0,50 & 0,50 & 0,00 \\
\hline $\mathrm{Total}$ & 99,63 & 99,21 & 99,42 & 0,30 \\
\hline $\mathrm{Cr}$ & 79 & 75 & 77 & 4 \\
\hline $\mathrm{Ni}$ & 72 & 70 & 71 & 2 \\
\hline $\mathrm{Ba}$ & 395 & 395 & 395 & 0 \\
\hline $\mathrm{Rb}$ & 30 & 29 & 29,5 & 2,4 \\
\hline $\mathrm{Sr}$ & 468 & 461 & 464,5 & 1,1 \\
\hline $\mathrm{Zr}$ & 217 & 214 & 215,5 & 0,9 \\
\hline $\mathrm{Y}$ & 39 & 38 & 38,5 & 1,5 \\
\hline $\mathrm{Nb}$ & 21 & 21 & 21 & 0 \\
\hline & & & &
\end{tabular}


Tabela 4.3 - Valores de concentrações de elementos maiores, menores e traço para a primeira (A1) e segunda (A2) análises por FRX das amostras LMD-RJ-8010 e LMD-RJ-8018 (segundo lote de amostras), a média das duas análises $(\bar{x})$ e os desvios padrão $(\boldsymbol{\sigma})$ em valor percentual (\%). Valores de óxidos e perda ao fogo (Lol) são em \% e de elementos traço em $\mathrm{mg} / \mathrm{kg}$.

\begin{tabular}{|c|c|c|c|c|c|c|c|c|}
\hline & \multicolumn{4}{|c|}{ LMD-RJ-8010 } & \multicolumn{4}{|c|}{ LMD-RJ-8018 } \\
\hline & $\mathrm{A} 1$ & $\mathrm{~A} 2$ & $\bar{x}$ & $\sigma(\%)$ & $\mathrm{A} 1$ & $\mathrm{~A} 2$ & $\bar{x}$ & $\sigma(\%)$ \\
\hline $\mathrm{SiO}_{2}$ & 51,76 & 51,85 & 51,81 & 0,12 & 53,19 & 53,18 & 53,19 & 0,01 \\
\hline $\mathrm{TiO}_{2}$ & 2,057 & 2,051 & 2,054 & 0,21 & 1,164 & 1,158 & 1,161 & 0,37 \\
\hline $\mathrm{Al}_{2} \mathrm{O}_{3}$ & 12,34 & 12,31 & 12,33 & 0,17 & 14,24 & 14,25 & 14,25 & 0,05 \\
\hline $\mathrm{Fe}_{2} \mathrm{O}_{3}$ & 16,15 & 16,21 & 16,18 & 0,26 & 11,56 & 11,57 & 11,57 & 0,06 \\
\hline $\mathrm{MnO}$ & 0,224 & 0,224 & 0,224 & 0,000 & 0,185 & 0,185 & 0,185 & 0,000 \\
\hline $\mathrm{MgO}$ & 3,78 & 3,77 & 3,78 & 0,19 & 6,16 & 6,20 & 6,18 & 0,46 \\
\hline $\mathrm{CaO}$ & 7,91 & 7,90 & 7,91 & 0,19 & 9,74 & 9,75 & 9,75 & 0,07 \\
\hline $\mathrm{Na}_{2} \mathrm{O}$ & 2,59 & 2,59 & 2,59 & 0,09 & 2,35 & 2,36 & 2,36 & 0,30 \\
\hline $\mathrm{K}_{2} \mathrm{O}$ & 1,40 & 1,40 & 1,40 & 0,00 & 1,23 & 1,22 & 1,23 & 0,58 \\
\hline $\mathrm{P}_{2} \mathrm{O}_{5}$ & 0,250 & 0,250 & 0,250 & 0,000 & 0,160 & 0,159 & 0,160 & 0,443 \\
\hline Lol & 0,56 & 0,56 & 0,56 & 0,00 & 0,38 & 0,26 & 0,32 & 26,52 \\
\hline Total & 99,02 & 99,12 & 99,07 & 0,07 & 100,36 & 100,29 & 100,33 & 0,05 \\
\hline $\mathrm{Cr}$ & $<13$ & $<13$ & - & - & 69 & 67 & 68 & 2 \\
\hline $\mathrm{Ni}$ & 38 & 38 & 38 & 0 & 54 & 54 & 54 & 0 \\
\hline $\mathrm{Ba}$ & 319 & 313 & 316 & 1 & 252 & 247 & 249,5 & 1,4 \\
\hline $\mathrm{Rb}$ & 53 & 52 & 52,5 & 1,4 & 46 & 46 & 46 & 0 \\
\hline $\mathrm{Sr}$ & 197 & 198 & 197,5 & 0,4 & 230 & 230 & 230 & 0 \\
\hline $\mathrm{Zr}$ & 173 & 172 & 172,5 & 0,4 & 113 & 113 & 113 & 0 \\
\hline$Y$ & 41 & 41 & 41 & 0 & 25 & 25 & 25 & 0 \\
\hline $\mathrm{Nb}$ & 15 & 15 & 15 & 0 & 13 & 12 & 12,5 & 5,7 \\
\hline
\end{tabular}

\subsection{Ativação neutrônica}

A análise por ativação neutrônica instrumental dispensa a necessidade de separações químicas e depende, sobretudo, dos materiais de referência irradiados conjuntamente com as amostras, ou seja, sob as mesmas condições experimentais. As amostras dos diques investigados foram submetidas à irradiação térmica, conjuntamente com três materiais de referência, BE-N, GS-N e BRP-1, mencionados anteriormente no capítulo 3. Para apenas duas amostras do conjunto (QT-SV-2D e QTSV-6B) houve a possibilidade de análises em duplicatas, a fim de refinamento dos valores de concentração obtidos. 
Para a determinação da precisão e exatidão da metodologia, nas condições experimentais adotadas, utilizaram-se as áreas de picos de emissão gama emitidos pelos radioisótopos do material de referência BRP-1, as quais foram comparadas com aquelas associadas aos materiais de referência GS-N e BE-N, ou seja, considerou-se o BRP-1 como uma amostra de concentração desconhecida. Deste modo, as concentrações calculadas dos elementos traço do BRP-1 foram, então, comparadas àquelas certificadas por Cotta et al. (2008), nos cinco "coelhos" irradiados ao longo deste estudo. Ressaltase que a decisão do uso do BRP-1 baseou-se no fato de tratar-se de um basalto da subprovíncia norte da PMP, região de Ribeirão Preto (SP) e, consequentemente, de composição semelhante aos diques estudados.

Esse processo de comparação, somente entre os materiais de referência, viabiliza a averiguação de uma possível inconsistência em um determinado resultado, pois os valores de concentrações calculados do BRP-1 devem ser iguais aos valores certificados, considerando as incertezas analíticas. Entretanto, por vezes, ocorreram discrepâncias entre tais valores, sendo que as causas prováveis são muitas e diversas, tais como: concentrações inferiores ou muito próximas ao limite de detecção, medições errôneas das massas das alíquotas, posicionamento dos "coelhos" no reator (fluxo menos adequado), tempo de exposição dos "coelhos" ao fluxo de nêutrons, contaminação das alíquotas com a água do reator, tempo de resfriamento para a realização das contagens, sobreposição dos picos de diferentes radioisótopos presentes no espectro gama e interferências devido ao Efeito Compton (espalhamento de fótons).

Assim, buscando verificar se os níveis de precisão e exatidão obtidos são compatíveis com os requisitados para as interpretações petrogenéticas, empregaramse, em uma primeira etapa, critérios de confiabilidade que levam em conta as incertezas associadas às áreas dos picos presentes nos espectros de raios gama. Em uma segunda etapa, foram levados em consideração os valores de exatidão obtidos na análise do material de referência BRP-1 (considerado como amostra), ou seja, os valores de concentrações dos elementos de interesse foram comparados com aqueles certificados, determinados diversas vezes e por meio de diferentes métodos analíticos. Após essas filtragens, aplicaram-se sequencialmente os testes de homogeneidade $r$ (Nalimov, 1963) e de compatibilidade Zeta-score (ISO 13528, 2005). 
A seguir, estão apresentadas descrições detalhadas dos critérios e testes estatísticos adotados neste trabalho, seguidamente, os resultados obtidos para 0 material de referência BRP-1 e para as amostras representativas dos diques da Região Serrana do Estado do Rio de Janeiro.

\subsubsection{Critério das incertezas associadas às áreas de pico}

A área do pico de energia da radiação gama, fornecida pelo software VISPECT (Piccot, 1989; Silva \& Figueiredo, 1996), está associada a uma incerteza. Esta área consiste no número de contagem das emissões gama por unidade de tempo, descontando o background, registradas pelo espectrômetro, em um dado intervalo de energia. Para o cálculo da incerteza são considerados o ajuste do pico (em relação a uma gaussiana) e a estatística de contagem, regida pelo processo de decaimento radioativo.

Em uma primeira etapa, os valores das áreas de picos presentes no espectro de raios gama apresentando incertezas associadas superiores a $15 \%$ foram descartados. Incertezas dessa magnitude foram observadas nos picos do ${ }^{239} \mathrm{~Np}$ com energias de 228,2 keV e 277,5 keV e no pico de $795,8 \mathrm{keV}$ do ${ }^{134} \mathrm{Cs}$, inviabilizando a determinação das concentrações de U (através do ${ }^{239} \mathrm{~Np}$ ) e do Cs.

No caso do U, as incertezas nas áreas dos picos foram da ordem de $20 \%$ e causadas pelas baixas concentrações de U no material de referência BRP-1 (U: 0,82 $\pm 0,03 \mathrm{mg} / \mathrm{kg}$ ). $\mathrm{O}$ mesmo ocorreu na análise do material de referência $\mathrm{BE}-\mathrm{N}$, que também é uma rocha básica empobrecida em $\mathrm{U}(2,40 \pm 0,18 \mathrm{mg} / \mathrm{kg})$. Cabe destacar, que em alguns espectros gama desses dois materiais de referência, o programa VISPECT sequer conseguiu identificar os picos de $228,2 \mathrm{keV}$ e $277,5 \mathrm{keV}$ emitidos ${ }^{239} \mathrm{~Np}$, pois além das baixas concentrações de $U$, essa região espectral é muito afetada pelo efeito Compton e por outras emissões gama produzidas por vários outros radioisótopos com energias em torno de $200-350 \mathrm{keV}\left({ }^{140} \mathrm{La},{ }^{233} \mathrm{~Pa},{ }^{152} \mathrm{Eu},{ }^{151} \mathrm{Nd},{ }^{133} \mathrm{Ba}\right.$, entre outros) que causam interferências.

Devido também às baixas concentrações de Cs em rochas básicas, as incertezas na determinação da área do pico de energia $795,8 \mathrm{keV}$ emitido radioisótopo ${ }^{134} \mathrm{Cs}$ foram 
acima de $15 \%$. Em alguns casos o pico também não foi identificado pelo software VISPECT.

\subsubsection{Critério da exatidão}

Após aplicação do critério das incertezas associadas às áreas de pico, calcularam-se as concentrações dos elementos traço presentes no material de referência BRP-1, de modo a considerá-lo como uma amostra desconhecida, utilizando para os cálculos os materiais de referência BE-N e GS-N. As concentrações resultantes foram inseridas na equação 4.1 para a obtenção dos valores de exatidão $(e)$ em relação às concentrações certificadas (Cotta et al., 2008), para cada elemento traço.

As concentrações resultantes cujos valores de exatidão ultrapassaram $15 \%$ foram desconsideradas, pois são indicativos de alguma perturbação naquela análise. Nesta filtragem, os elementos $\mathrm{Gd}\left({ }^{153} \mathrm{Gd}\right.$ de energias 69,7 keV e 97,5 keV) e $\mathrm{Cr}\left({ }^{57} \mathrm{Cr}\right.$ de energia $320 \mathrm{KeV}$ ) foram descartados. Quando presentes em baixas concentrações, esses dois elementos são de difícil determinação por ativação neutrônica instrumental, pois os picos localizam-se em regiões complexas do espectro, já que além do efeito Compton, muitos dos radioisótopos produzidos na irradiação emitem gama (e raios- $\mathrm{X}$ ) nessa faixa de energia.

\subsubsection{Teste de homogeneidade $r$}

Todos os experimentos que envolvem medidas, como foi realizado neste estudo, estão susceptíveis a erros acidentais não percebidos pelo pesquisador no decorrer do processo. Esses erros geram resultados que podem apresentar distorção significativa, afetando as interpretações petrogenéticas e suas implicações.

O teste $r$ consiste em um critério estatístico robusto na investigação da homogeneidade dos dados para poucos graus de liberdade (f), ou seja, para número de medições inferiores a $25(\mathrm{f}=n-2, \operatorname{com} n \leq 25)$. Este critério depende apenas do conjunto de dados provenientes das medições e baseia-se na distribuição normal (gaussiana), a qual admite um número pequeno de ocorrência de resultados anômalos (Nalimov, 1963). Para a aplicação deste critério, analisa-se um conjunto de $n$ dados $\left(x_{1}, x_{2}, \ldots, x_{n}\right)$ referentes às medições de uma certa grandeza e, se por alguma razão, suspeita-se que 
os valores mais distantes da média $(\bar{x})$ do conjunto são incompatíveis com as medições restantes. Com isto, após o cálculo da média e do desvio padrão $\left(S_{x}\right)$ do conjunto pelas equações (4.2) e (4.3), respectivamente, determinam-se as distribuições do desvio máximo $\left(r_{m i ́ n}\right.$ e $\left.r_{m a ́ x}\right)$, usando os valores mais distantes do conjunto de medidas, com as equações (4.4) e (4.5).

$$
\begin{gathered}
\bar{x}=\frac{\sum_{1}^{n} x_{i}}{n} \\
S_{x}=\sqrt{\frac{\sum_{1}^{n}\left(x_{i}-\bar{x}\right)^{2}}{n-1}} \\
r_{\text {mín }}=\frac{\left|x_{\text {mín }}-\bar{x}\right|}{S_{x \sqrt{\frac{n-1}{n}}}} \\
r_{\text {máx }}=\frac{x_{\text {máx }}-\bar{x}}{S_{x} \sqrt{\frac{n-1}{n}}}
\end{gathered}
$$

onde $x_{i}$ é um valor de concentração determinado do conjunto de dados, $x_{\operatorname{mí}}$ é o menor valor de concentração determinado do conjunto e $x_{\text {máx }}$, o maior.

Os valores dos fatores $r_{\text {máx }}$ e $r_{\text {mín }}$ são comparados com os tabelados (Apêndice A) para um determinado nível de significância, considerando o número de graus de liberdade até $23(n=25)$. Se os valores de $r_{\text {máx }}$ e $r_{\text {mín }}$ forem menores que o tabelado, os valores de concentração determinados são aceitos. Caso contrário, rejeita-se o valor de concentração determinado e calculam-se novamente a média e o desvio padrão para determinar novamente a distribuição do desvio máximo. Para o número de medidas $\mathrm{n}$ superior a 25, adota-se o critério do $3 \sigma$ para o teste de homogeneidade (Nalimov, 1963). Desse modo, é verificado se a diferença entre um valor do conjunto de dados e a média

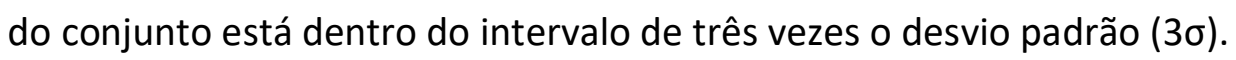

Os resultados da aplicação do teste de homogeneidade $r$ para o material de referência BRP-1 encontram-se na Tabela 4.2, bem como, os valores de concentrações certificados e suas incertezas associadas (Cotta et al., 2008) para comparação. Os valores calculados $r_{\text {máx }}$ e $r_{\text {mín }}$ para o BRP-1 ficaram abaixo dos tabelados para o nível de significância 0,05 (intervalo de confiança de 95\%) adotado neste estudo, sem a 
necessidade de rejeição de qualquer resultado, após a aplicação dos dois primeiros critérios descritos acima. Para os elementos La e Eu $(n>25)$, verificou-se que a diferença entre a média determinada e o valor do certificado está dentro do intervalo de $3 \sigma$.

Tabela 4.4 - Resultados do teste estatístico $r$ para a avaliação da qualidade e confiabilidade do conjunto de concentrações $(\mathrm{mg} / \mathrm{kg}$ ) determinadas para o material de referência BRP-1 (Cotta et al., 2008) pelo método INAA. $O \boldsymbol{\mu}$ corresponde ao valor certificado, $\boldsymbol{\sigma}$ ao desvio padrão, $\overline{\mathbf{x}}$ à média das medições e $\boldsymbol{n}$ ao número de concentrações adquiridas (medições) .

\begin{tabular}{|c|c|c|c|c|c|c|c|c|c|}
\hline & \multicolumn{3}{|c|}{$\begin{array}{c}\text { Certificado (Cotta et alo, } \\
\text { 2008) }\end{array}$} & \multicolumn{6}{|c|}{ Teste r (Nalimov, 1963) } \\
\hline & $\mu$ & $1 \sigma$ & $1 \sigma(\%)$ & $\bar{x}$ & $1 \sigma$ & $1 \sigma(\%)$ & $n$ & $r_{\min }$ & $r_{\text {máx }}$ \\
\hline Th & 3,97 & 0,05 & 1,3 & 3,82 & 0,10 & 2,7 & 10 & 1,239 & 2,286 \\
\hline $\mathrm{Sc}$ & 28,5 & 0,4 & 1,4 & 28,5 & 0,9 & 3,3 & 9 & 1,585 & 1,982 \\
\hline $\mathrm{Ba}$ & 555 & 3,5 & 0,6 & 533 & 34 & 6,4 & 9 & 1,863 & 1,767 \\
\hline Co & 37,5 & 0,7 & 1,9 & 38,5 & 1,3 & 3,3 & 10 & 1,549 & 1,255 \\
\hline$H f$ & 8,0 & 0,1 & 1,3 & 7,6 & 0,3 & 4,6 & 20 & 2,112 & 1,547 \\
\hline La & 42,6 & 0,5 & 1,2 & 42,2 & 3,0 & 7,2 & 30 & - & - \\
\hline $\mathrm{Ce}$ & 93,3 & 0,6 & 0,6 & 91,2 & 3,1 & 3,3 & 10 & 1,900 & 1,794 \\
\hline $\mathrm{Nd}$ & 51,9 & 0,5 & 0,9 & 50,5 & 3,2 & 6,3 & 8 & 1,515 & 1,540 \\
\hline $\mathrm{Sm}$ & 11,2 & 0,1 & 0,9 & 10,9 & 0,5 & 4,7 & 10 & 1,505 & 1,489 \\
\hline Eu & 3,42 & 0,04 & 1,2 & 3,39 & 0,22 & 6,4 & 37 & - & - \\
\hline $\mathrm{Tb}$ & 1,52 & 0,03 & 1,6 & 1,53 & 0,11 & 7,5 & 9 & 1,746 & 1,296 \\
\hline $\mathrm{Yb}$ & 3,48 & 0,05 & 1,3 & 3,37 & 0,27 & 7,9 & 24 & 2,393 & 1,426 \\
\hline Lu & 0,50 & 0,01 & 2,0 & 0,47 & 0,04 & 8,6 & 18 & 2,128 & 1,943 \\
\hline $\mathrm{Ta}$ & 1,96 & 0,04 & 2,0 & 2,03 & 0,11 & 5,5 & 10 & 1,965 & 1,681 \\
\hline
\end{tabular}

\subsubsection{Teste de compatibilidade Zeta-score}

O teste de compatibilidade Zeta-score (ISO 13528, 2005) foi usado para averiguar a qualidade das medições pelo método INAA, ou seja, para verificar a exatidão das concentrações dos elementos traço presentes no material de referência BRP-1. Os valores de Zeta-score são obtidos pela equação 4.6, a seguir.

$$
Z=\frac{x_{c e r t, i}-x_{\mathrm{det}, i}}{\sqrt{S_{c e r t, i}^{2}+S_{\mathrm{det}, i}^{2}}}
$$


onde $x_{c e r t, i}$ e $x_{\mathrm{det}, i}$ são os valores de concentração certificado e determinado para o elemento $i$, respectivamente, e $S_{c e r t, i}$ e $S_{\text {det }, i}$ são os erros associados ao valor certificado e ao valor de concentração determinado.

Para valores de $Z$ entre -2 e 2 , as concentrações determinadas são consideradas satisfatórias em relação às concentrações certificadas, para o nível de significância de 0,05 .

Os valores de Zeta-score para o material de referência BRP-1, obtidos pelas cinco irradiações, são apresentados na Figura 4.1. Para todos os elementos determinados, os valores de $Z$ indicam exatidão muito boa dos resultados.

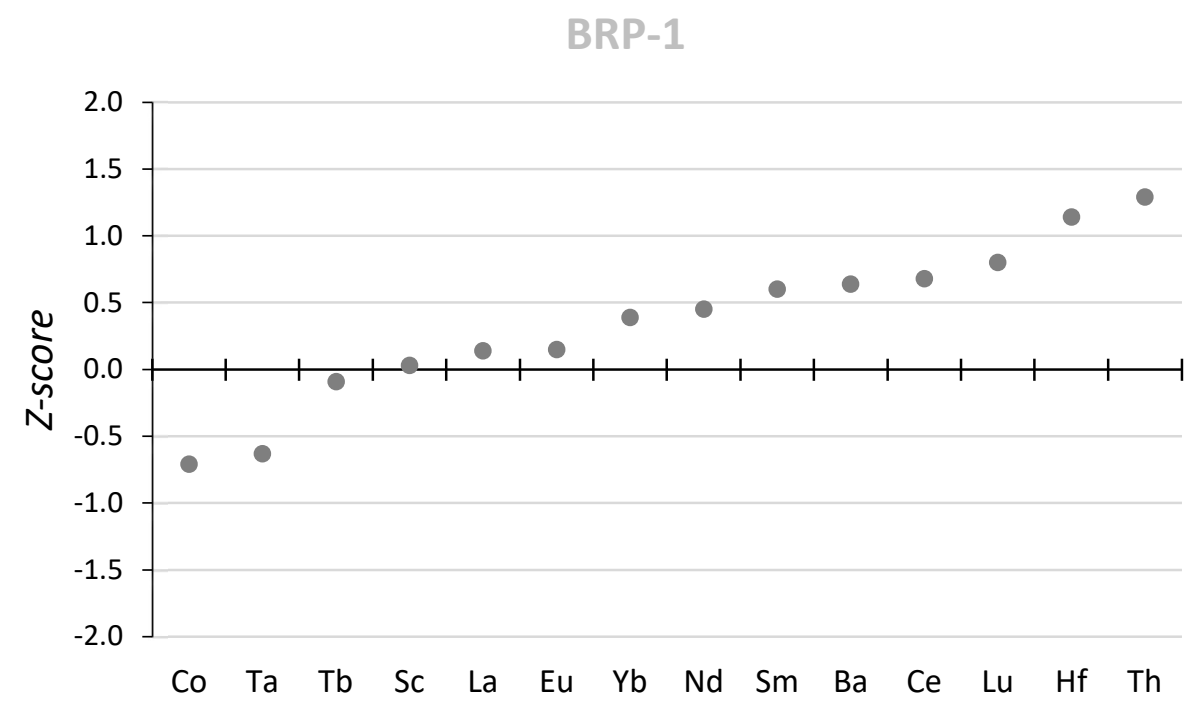

Figura 4.1 - Valores de Zeta-score obtidos na análise do material de referência BRP-1 por ativação neutrônica instrumental.

\subsubsection{Discussão dos resultados para BRP-1}

Após todo o processo de filtragem dos resultados foi possível determinar a exatidão e a reprodutibilidade da técnica analítica adotada, nas condições experimentais aplicadas, independentemente da amostra de interesse. Visto que os materiais de referência foram analisados em medidas totalmente independentes entre si, desde o processo de confecção das alíquotas para serem submetidas à irradiação, irradiação, fluxo de nêutrons, tempo de resfriamento e contagem da emissão gama dos radioisótopos formados, as variações observadas correspondem aos erros das medidas. 
Os valores de precisão e exatidão resultantes das análises do BRP-1 estão apresentados a seguir (Tabela 4.3). Estatisticamente, os resultados correspondem a probabilidade de que uma nova análise para esse material de referência, nessas condições experimentais, apresente concentração dentro do intervalo de confiança adotado neste estudo (95\%).

Tabela 4.5 - Valores percentuais de precisão e exatidão (\%) definidos para as concentrações calculadas pelas análises do material de referência BRP-1 (Cotta et al., 2008).

\begin{tabular}{c|cccccccccccccc}
\hline$(\%)$ & Th & Sc & Ba & Co & Hf & La & Ce & Nd & Sm & Eu & Tb & Yb & Lu & Ta \\
\hline Exatidão & 3,7 & 0,1 & 3,9 & 2,8 & 5,2 & 1,0 & 2,3 & 2,8 & 2,8 & 1,0 & 0,7 & 3,1 & 6,7 & 3,8 \\
\hline Precisão & 2,7 & 3,3 & 6,4 & 3,3 & 4,6 & 7,2 & 3,3 & 6,3 & 4,7 & 6,4 & 7,5 & 7,9 & 8,6 & 5,5 \\
\hline
\end{tabular}

Como pode ser observado na Tabela 4.5, os resultados mostram que os níveis de precisão e a exatidão são melhores do que $5 \%$ para a grande maioria das determinações e em nenhum caso ficou acima de $9 \%$, mostrando que a qualidade dos resultados é compatível com as requeridas para as interpretações geoquímicas e petrogenéticas. Os resultados do teste de homogeneidade $r$ mostram que, para todos os elementos, as concentrações determinadas estão dentro da faixa dos valores recomendados, considerando as incertezas em um nível de 95\% de confiança. Como, da mesma forma, pode ser observado na Figura 4.1, os valores de Z estão entre -0,71 e 1,29.

Nota-se que a flutuação estatística dos resultados é maior para elementos cuja determinação é associada a radioisótopos que possuem poucos picos de emissão gama, emitem raios gama em zonas complexas do espectro e/ou que estão presentes em concentrações muito baixas. Os resultados obtidos para Lu, que apresentou exatidão de $6,7 \%$ e precisão de $8,6 \%$, é um exemplo desse tipo de dificuldade, pois apresenta essas três características que dificultam sua determinação (emissão de apenas 1 pico detectável, com energia de $208,4 \mathrm{keV}$ em área fortemente afetada por efeito Compton e concentração de $0,50 \mathrm{mg} / \mathrm{kg}$ ).

\subsubsection{Discussão dos resultados para as amostras}

Para a análise das amostras dos diques, adotaram-se os mesmos critérios de filtragens aplicados na análise do material de referência BRP-1, com a análise das incertezas das áreas dos picos dos espectros gama de cada amostra. Em seguida, 
verificou-se a coerência dos resultados de concentrações calculadas pelos três materiais de referência (BRP-1, BE-N e GS-N) para cada análise e aplicou-se o teste $r$ para verificar a homogeneidade do conjunto. Os valores de incertezas associados às concentrações determinadas são bastante satisfatórios (Apêndice B) e estão de acordo com os critérios para o uso da técnica comparativa $(<15 \%)$. Entretanto, o número baixo de determinações $(n)$ para alguns elementos (Sc, Ba, Co, $\mathrm{Nd}$ e Sm; $n=2$ ) em poucas amostras, não permitiu assegurar a confiabilidade desses resultados de modo efetivo. Em vista disso, decidiu-se utilizar os valores de precisão obtidos para material de referência BRP-1, adicionalmente aos desvios padrões determinados na análise das amostras, selecionando, dentre eles, os valores mais altos para representar a incerteza da determinação. Por exemplo, o elemento Nd para a amostra LMD-RJ-8017 apresenta apenas duas análises, inviabilizando a aplicação do teste de homogeneidade r e o cálculo de incerteza confiável (2,5\%). Com isso, empregou-se para este elemento o valor de precisão relacionado ao do material de referência BRP-1 $(6,4 \%)$.

A Tabela 4.4 apresenta os resultados dos cálculos das médias das $n$ determinações das concentrações para cada elemento investigado de cada amostra de dique, com as incertezas associadas adotadas com base no processo mencionado acima $\left(1 \sigma^{*}\right)$. Em relação ao elemento Ta, mesmo os conjuntos de medidas sendo homogêneos, conforme o teste $r$, as incertezas associadas para as amostras QT-SV-2D e QT-SV-6B estão acima de $15 \%$ (17,5 \% e 19,0\%; respectivamente). Entretanto, ao invés de desconsiderar de imediato os valores, utilizaram-se essas concentrações com cautela nas interpretações petrogenéticas.

De modo geral, os procedimentos experimentais adotados e o uso de critérios estatísticos permitiram obter os valores mais representativos das grandezas medidas, para as 18 amostras de diques, com os níveis de precisão e exatidão desejados. 0 uso da ativação neutrônica propiciou a integração das análises aqui obtidas com os resultados de 13 diques da mesma região investigados por Marques (2001 e dados inéditos), cujas determinações de elementos traço foram realizadas pelo mesmo método e, portanto, sem problemas de viés analítico. Desta forma, com um maior número de amostras, variações composicionais foram mais bem evidenciadas, permitindo um maior aprofundamento das interpretações petrogenéticas. 
Tabela 4.6 - Resultados das análises por ativação neutrônica térmica realizadas no Centro do Reator de Pesquisas (CRPq) do Instituto de Pesquisas Energéticas (IPEN-CNEN/SP), em que $\overline{\mathbf{x}}$ consiste nas médias calculadas, $\boldsymbol{n}$ é o número de determinações e $\boldsymbol{\sigma}^{*}$ é a incerteza associada adotada.

\begin{tabular}{|c|c|c|c|c|c|c|c|c|c|c|c|c|c|c|c|c|c|c|c|c|}
\hline \multirow{2}{*}{$\begin{array}{c}\text { Amostra } \\
\text { Elemento }\end{array}$} & \multicolumn{4}{|c|}{ LMD-RJ-8018 } & \multicolumn{4}{|c|}{ LMD-RJ-8017 } & \multicolumn{4}{|c|}{ QT-SV-2D } & \multicolumn{4}{|c|}{ LMD-RJ-8019C } & \multicolumn{4}{|c|}{ LMD-RJ-8019A } \\
\hline & $\bar{x}$ & $1 \sigma^{*}(\%)$ & $1 \sigma$ & n & $\bar{x}$ & $1 \sigma^{*}(\%)$ & $1 \sigma$ & $n$ & $\bar{x}$ & $1 \sigma^{*}(\%)$ & $1 \sigma$ & $n$ & $\bar{x}$ & $1 \sigma^{*}(\%)$ & $1 \sigma$ & $n$ & $\bar{x}$ & $1 \sigma^{*}(\%)$ & $1 \sigma$ & $n$ \\
\hline Th & 3,64 & 3,3 & 0,12 & 3 & 4,23 & 3,3 & 0,14 & 3 & 2,83 & 3,2 & 0,09 & 6 & 4,69 & 3,2 & 0,15 & 3 & 5,21 & 3,3 & 0,17 & 3 \\
\hline Sc & 38,0 & 3,3 & 1,3 & 3 & 36,8 & 3,3 & 1,2 & 3 & 31,8 & 4,6 & 1,5 & 6 & 35,7 & 3,3 & 1,2 & 3 & 37,0 & 3,3 & 1,2 & 3 \\
\hline $\mathrm{Ba}$ & 321 & 6,4 & 20 & 2 & 207 & 6,4 & 13 & 2 & 325 & 12,2 & 40 & 6 & 263 & 6,4 & 17 & 2 & 313 & 6,4 & 20 & 2 \\
\hline Co & 42,0 & 3,3 & 1,4 & 2 & 41,5 & 3,3 & 1,4 & 2 & 45,8 & 4,1 & 1,9 & 6 & 41,1 & 3,3 & 1,4 & 2 & 42,3 & 3,3 & 1,4 & 3 \\
\hline $\mathrm{Hf}$ & 2,96 & 5,7 & 0,17 & 6 & 3,46 & 4,9 & 0,17 & 6 & 3,17 & 5,7 & 0,18 & 12 & 3,67 & 4,6 & 0,17 & 6 & 3,87 & 4,9 & 0,19 & 6 \\
\hline La & 16,3 & 7,2 & 1,2 & 9 & 19,9 & 7,2 & 1,4 & 9 & 18,5 & 7,2 & 1,3 & 18 & 19,5 & 7,2 & 1,4 & 9 & 20,8 & 7,2 & 1,5 & 9 \\
\hline $\mathrm{Ce}$ & 33,7 & 3,3 & 1,1 & 3 & 41,0 & 3,3 & 1,4 & 3 & 38,6 & 5,6 & 2,2 & 6 & 40,4 & 3,3 & 1,4 & 3 & 42,1 & 3,3 & 1,4 & 3 \\
\hline $\mathrm{Nd}$ & 21,2 & 6,3 & 1,3 & 2 & 30,9 & 6,3 & 2,0 & 2 & 14,5 & 8,5 & 1,2 & 5 & 22,6 & 6,3 & 1,4 & 2 & 28,7 & 6,3 & 1,8 & 2 \\
\hline $\mathrm{Sm}$ & 4,19 & 4,7 & 0,20 & 3 & 4,96 & 4,7 & 0,23 & 3 & 4,55 & 6,4 & 0,29 & 6 & 5,11 & 4,7 & 0,24 & 3 & 5,37 & 4,7 & 0,25 & 3 \\
\hline $\mathrm{Eu}$ & 1,28 & 6,4 & 0,08 & 12 & 1,39 & 7,9 & 0,11 & 12 & 1,55 & 7,1 & 0,11 & 22 & 1,51 & 6,4 & 0,10 & 11 & 1,55 & 7,7 & 0,12 & 12 \\
\hline Tb & 1,03 & 7,5 & 0,08 & 2 & 0,99 & 7,5 & 0,07 & 2 & 0,90 & 12,2 & 0,11 & 6 & 1,16 & 7,5 & 0,09 & 2 & 1,37 & 7,5 & 0,10 & 2 \\
\hline $\mathrm{Yb}$ & 2,22 & 7,9 & 0,18 & 8 & 2,54 & 7,9 & 0,20 & 7 & 2,78 & 12,6 & 0,35 & 18 & 2,71 & 14,0 & 0,38 & 7 & 2,96 & 11,1 & 0,33 & 7 \\
\hline Lu & 0,35 & 8,6 & 0,03 & 5 & 0,38 & 8,6 & 0,03 & 5 & 0,46 & 8,7 & 0,04 & 11 & 0,44 & 9,1 & 0,04 & 5 & 0,48 & 10,4 & 0,05 & 5 \\
\hline $\mathrm{Ta}$ & 0,66 & 5,5 & 0,04 & 2 & 0,74 & 5,5 & 0,04 & 2 & 0,80 & 17,5 & 0,14 & 8 & 0,72 & 5,5 & 0,04 & 4 & 0,73 & 5,5 & 0,04 & 4 \\
\hline
\end{tabular}


Tabela 4.6 (continuação) - Resultados das análises por ativação neutrônica térmica realizadas no Centro do Reator de Pesquisas (CRPq) do Instituto de Pesquisas Energéticas (IPEN-CNEN/SP), em que $\overline{\mathbf{x}}$ consiste nas médias calculadas, $\boldsymbol{n}$ é o número de determinações e $\boldsymbol{\sigma}^{*}$ é a incerteza associada adotada.

\begin{tabular}{|c|c|c|c|c|c|c|c|c|c|c|c|c|c|c|c|c|c|c|c|c|}
\hline \multirow{2}{*}{$\begin{array}{l}\text { Amostra } \\
\text { Elemento }\end{array}$} & \multirow[b]{2}{*}{$\bar{x}$} & \multicolumn{3}{|c|}{ QT-SV-1B } & \multicolumn{4}{|c|}{ QT-SV-6A } & \multicolumn{4}{|c|}{ LMD-RJ-8005A } & \multicolumn{4}{|c|}{ LMD-RJ-8012 } & \multicolumn{4}{|c|}{ LMD-8004 } \\
\hline & & $1 \sigma^{*}(\%)$ & $1 \sigma$ & n & $\bar{x}$ & $1 \sigma^{*}(\%)$ & $1 \sigma$ & $n$ & $\bar{x}$ & $1 \sigma^{*}(\%)$ & $1 \sigma$ & $n$ & $\bar{x}$ & $1 \sigma^{*}(\%)$ & $1 \sigma$ & $n$ & $\bar{x}$ & $1 \sigma^{*}(\%)$ & $1 \sigma$ & $n$ \\
\hline Th & 2,81 & 2,7 & 0,08 & 3 & 3,04 & 2,7 & 0,08 & 3 & 5,37 & 2,7 & 0,14 & 3 & 5,17 & 2,7 & 0,14 & 3 & 5,14 & 2,7 & 0,14 & 3 \\
\hline Sc & 30,0 & 3,3 & 1,0 & 3 & 41,8 & 3,3 & 1,4 & 3 & 35,4 & 3,3 & 1,2 & 3 & 37,4 & 3,3 & 1,2 & 3 & 35,7 & 3,3 & 1,2 & 3 \\
\hline $\mathrm{Ba}$ & 376 & 6,4 & 24 & 2 & 79 & 9,2 & 35 & 2 & 379 & 6,4 & 24 & 3 & 380 & 4 & 24 & 2 & 13 & 4 & 26 & 3 \\
\hline Co & 43,0 & 4,5 & 1,9 & 3 & 49,9 & 4,5 & 2,3 & 3 & 40,7 & 3,7 & 1,5 & 3 & 44,1 & 3,3 & 1,5 & 2 & 42,4 & 3,7 & 1,6 & 3 \\
\hline $\mathrm{Hf}$ & 5,6 & 4,6 & 0,3 & 6 & ,34 & 4,6 & 0,15 & 6 & 4,52 & 4,6 & 0,21 & 6 & 4,54 & 4,6 & 0,21 & 6 & 4,39 & 4,6 & 0,20 & 6 \\
\hline La & 28,0 & 7,2 & 2,0 & 9 & 20,3 & 7,2 & 1,5 & 9 & 26,8 & 7,2 & 1,9 & 9 & 27,3 & 7,2 & 2,0 & 9 & 26,1 & 7,2 & 1,9 & 9 \\
\hline $\mathrm{Ce}$ & 60,4 & 3,3 & 2,0 & 3 & 42,5 & 3,3 & 1,4 & 3 & 55,4 & 3,3 & 1,9 & 3 & 54,9 & 3,3 & 1,8 & 3 & 53,1 & 3,3 & 1,8 & 3 \\
\hline $\mathrm{Nd}$ & 30,8 & 7,5 & 2,3 & 3 & 20,8 & 7,5 & 1,6 & 3 & 26,5 & 6,3 & 1,7 & 2 & 32,1 & 6,3 & 2,0 & 2 & 31,5 & 6,3 & 2,0 & 2 \\
\hline $\mathrm{Sm}$ & 8,15 & 4,7 & 0,38 & 3 & 5,01 & 4,7 & 0,23 & 3 & 6,14 & 4,7 & 0,29 & 2 & 6,28 & 4,7 & 0,29 & 3 & 6,07 & 4,7 & 0,28 & 2 \\
\hline Eu & 2,59 & 6,4 & 0,17 & 11 & 1,59 & 6,4 & 0,10 & 11 & 1,76 & 6,4 & 0,11 & 12 & 1,82 & 6,4 & 0,12 & 12 & 1,76 & 6,4 & 0,11 & 12 \\
\hline Tb & 1,20 & 7,5 & 0,09 & 3 & 0,82 & 7,5 & 0,06 & 3 & 0,92 & 7,5 & 0,07 & 3 & 1,47 & 7,5 & 0,11 & 2 & 0,79 & 7,5 & 0,06 & 3 \\
\hline $\mathrm{Yb}$ & 3,11 & 7,9 & 0,25 & 5 & 2,99 & 7,9 & 0,24 & 5 & 3,10 & 11,3 & 0,35 & 10 & 3,22 & 8,0 & 0,26 & 7 & 3,01 & 12,0 & 0,36 & 10 \\
\hline Lu & 0,47 & 8,6 & 0,04 & 5 & 0,45 & 8,6 & 0,04 & 5 & 0,46 & 10,9 & 0,05 & 6 & 0,58 & 13,8 & 0,08 & 4 & 0,45 & 8,6 & 0,04 & 5 \\
\hline $\mathrm{Ta}$ & 1,36 & 9,6 & 0,13 & 4 & 0,84 & 14,3 & 0,12 & 4 & 0,97 & 8,2 & 0,08 & 4 & 1,03 & 5,5 & 0,06 & 4 & 1,08 & 9,3 & 0,10 & 4 \\
\hline
\end{tabular}


Tabela 4.6 (continuação) - Resultados das análises por ativação neutrônica térmica realizadas no Centro do Reator de Pesquisas (CRPq) do Instituto de Pesquisas Energéticas (IPEN-CNEN/SP), em que $\overline{\mathbf{x}}$ consiste nas médias calculadas, $\boldsymbol{n}$ é o número de determinações e $\boldsymbol{\sigma}^{*}$ é a incerteza associada adotada.

\begin{tabular}{|c|c|c|c|c|c|c|c|c|c|c|c|c|c|c|c|c|c|c|c|c|}
\hline \multirow{2}{*}{$\begin{array}{l}\text { Amostra } \\
\text { Elemento }\end{array}$} & \multirow[b]{2}{*}{$\bar{x}$} & \multicolumn{3}{|c|}{ QT-SV-6B } & \multicolumn{4}{|c|}{ LMD-RJ-8010 } & \multicolumn{4}{|c|}{ QT-SV-2A } & \multicolumn{4}{|c|}{ LMD-RJ-8000A } & \multicolumn{4}{|c|}{ LMD-RJ-8014A } \\
\hline & & $1 \sigma^{*}(\%)$ & $1 \sigma$ & n & $\bar{x}$ & $1 \sigma^{*}(\%)$ & $1 \sigma$ & $n$ & $\bar{x}$ & $1 \sigma^{*}(\%)$ & $1 \sigma$ & $n$ & $\bar{x}$ & $1 \sigma^{*}(\%)$ & $1 \sigma$ & $n$ & $\bar{x}$ & $1 \sigma^{*}(\%)$ & $1 \sigma$ & n \\
\hline Th & 3,55 & 5,1 & 0,18 & 6 & 4,57 & 2,7 & 0,12 & 3 & 3,02 & 2,7 & 0,08 & 3 & 2,82 & 2,7 & 0,08 & 3 & 2,77 & 2,7 & 0,07 & 3 \\
\hline Sc & 39,5 & 3,7 & 1,5 & 6 & 37,0 & 3,3 & 1,2 & 3 & 30,5 & 3,3 & 1,0 & 3 & 33,5 & 3,3 & 1,1 & 2 & 32,5 & 3,3 & 1,1 & 3 \\
\hline $\mathrm{Ba}$ & 341 & 6,4 & 22 & 6 & 250 & 6,4 & 16 & 3 & 366 & 9,2 & 34 & 2 & 386 & 6,4 & 25 & 3 & 52 & 4 & 22 & 2 \\
\hline Co & 54,5 & 3,3 & 1,8 & 6 & 41,6 & 3,7 & 1,5 & 3 & 44,5 & 4,5 & 2,0 & 3 & 47,1 & 3,7 & 1,7 & 3 & 43,7 & 3,7 & 1,6 & 3 \\
\hline $\mathrm{Hf}$ & 3,71 & 6,5 & 0,2 & 12 & 4,76 & 4,6 & 0,2 & 6 & 5,83 & 4,6 & 0,3 & 6 & 5,76 & 4,6 & 0,3 & 6 & 5,60 & 4,6 & 0,3 & 5 \\
\hline La & 22,5 & 7,2 & 1,6 & 18 & 21,4 & 7,2 & 1,5 & 9 & 29,6 & 7,2 & 2,1 & 9 & 28,3 & 7,2 & 2,0 & 9 & 28,3 & 7,2 & 2,0 & 9 \\
\hline $\mathrm{Ce}$ & 47,0 & 7,6 & 3,6 & 6 & 46,3 & 3,3 & 1,5 & 3 & 65,3 & 3,3 & 2,2 & 3 & 62,8 & 3,3 & 2,1 & 3 & 62,1 & 3,3 & 2,1 & 3 \\
\hline $\mathrm{Nd}$ & 18,6 & 11,4 & 2,1 & 5 & 34,6 & 7,5 & 2,6 & 2 & 38,9 & 7,5 & 2,9 & 3 & 37,8 & 6,3 & 2,4 & 2 & 38,4 & 6,3 & 2,4 & 2 \\
\hline $\mathrm{Sm}$ & 5,67 & 4,7 & 0,26 & 6 & 6,45 & 4,7 & 0,30 & 2 & 8,63 & 4,7 & 0,40 & 3 & 8,40 & 4,7 & 0,39 & 2 & 8,38 & 4,7 & 0,39 & 2 \\
\hline Eu & 1,78 & 6,4 & 0,11 & 22 & 1,98 & 6,4 & 0,13 & 12 & 2,75 & 6,4 & 0,18 & 11 & 2,71 & 6,4 & 0,17 & 12 & 2,63 & 6,4 & 0,17 & 12 \\
\hline $\mathrm{Tb}$ & 0,91 & 9,9 & 0,09 & 6 & 0,97 & 7,5 & 0,07 & 3 & 1,24 & 7,5 & 0,09 & 3 & 1,18 & 7,5 & 0,09 & 3 & 0,97 & 7,5 & 0,07 & 3 \\
\hline $\mathrm{Yb}$ & 3,29 & 12,8 & 0,42 & 18 & 3,74 & 9,9 & 0,37 & 10 & 3,23 & 7,9 & 0,26 & 5 & 2,86 & 10,5 & 0,30 & 10 & 2,91 & 7,9 & 0,23 & 7 \\
\hline Lu & 0,52 & 9,6 & 0,05 & 11 & 0,56 & 8,9 & 0,05 & 6 & 0,51 & 9,8 & 0,05 & 5 & 0,42 & 8,6 & 0,04 & 6 & 0,40 & 8,6 & 0,03 & 5 \\
\hline $\mathrm{Ta}$ & 1,00 & 19,0 & 0,19 & 8 & 0,72 & 5,5 & 0,04 & 2 & 1,35 & 9,6 & 0,13 & 4 & 1,26 & 5,56 & 0,07 & 4 & 1,33 & 5,5 & 0,07 & 4 \\
\hline
\end{tabular}


Tabela 4.6 (continuação) - Resultados das análises por ativação neutrônica térmica realizadas no Centro do Reator de Pesquisas (CRPq) do Instituto de Pesquisas Energéticas (IPEN-CNEN/SP), em que $\overline{\mathbf{x}}$ consiste nas médias calculadas, $\boldsymbol{n}$ é o número de determinações e $\boldsymbol{\sigma}^{*}$ é a incerteza associada adotada.

\begin{tabular}{|c|c|c|c|c|c|c|c|c|c|c|c|c|}
\hline \multirow{2}{*}{$\begin{array}{c}\text { Amostra } \\
\text { Elemento }\end{array}$} & \multicolumn{4}{|c|}{ QT-SV-3 } & \multicolumn{4}{|c|}{ LMD-RJ-8013A } & \multicolumn{4}{|c|}{ QT-SV-4A } \\
\hline & $\bar{x}$ & $1 \sigma^{*}(\%)$ & $1 \sigma$ & $n$ & $\bar{x}$ & $1 \sigma^{*}(\%)$ & $1 \sigma$ & $n$ & $\bar{x}$ & $1 \sigma^{*}(\%)$ & $1 \sigma$ & $n$ \\
\hline Th & 4,63 & 2,7 & 0,13 & 3 & 2,09 & 3,3 & 0,07 & 3 & 2,82 & 2,7 & 0,08 & 3 \\
\hline Sc & 36,0 & 3,3 & 1,2 & 3 & 22,2 & 3,3 & 0,7 & 3 & 31,2 & 3,3 & 1,0 & 3 \\
\hline $\mathrm{Ba}$ & 364 & 9,2 & 33 & 2 & 245 & 6,4 & 16 & 2 & 367 & 9,2 & 34 & 2 \\
\hline Co & 44,3 & 4,5 & 2,0 & 3 & 30,6 & 3,3 & 1,0 & 2 & 48,5 & 1,5 & 2,2 & 3 \\
\hline Hf & 3,91 & 4,6 & 0,18 & 6 & 4,11 & 4,6 & 0,19 & 6 & 5,53 & 4,6 & 0,25 & 6 \\
\hline La & 25,0 & 7,2 & 1,8 & 9 & 21,1 & 7,2 & 1,5 & 9 & 30,5 & 7,2 & 2,2 & 8 \\
\hline $\mathrm{Ce}$ & 51,5 & 3,3 & 1,7 & 3 & 45,5 & 3,3 & 1,5 & 3 & 64,6 & 3,3 & 2,2 & 3 \\
\hline $\mathrm{Nd}$ & 22,5 & 7,5 & 1,7 & 3 & 28,5 & 6,3 & 1,8 & 3 & 37,3 & 7,5 & 2,8 & 3 \\
\hline $\mathrm{Sm}$ & 5,97 & 4,7 & 0,28 & 3 & 6,02 & 4,7 & 0,28 & 3 & 8,98 & 4,7 & 0,42 & 3 \\
\hline $\mathrm{Eu}$ & 1,78 & 6,4 & 0,11 & 11 & 1,89 & 6,4 & 0,12 & 11 & 2,79 & 6,4 & 0,18 & 11 \\
\hline $\mathrm{Tb}$ & 1,13 & 7,5 & 0,08 & 3 & 1,19 & 7,5 & 0,09 & 2 & 1,44 & 7,5 & 0,11 & 3 \\
\hline $\mathrm{Yb}$ & 3,55 & 7,9 & 0,28 & 5 & 2,13 & 8,5 & 0,18 & 7 & 3,41 & 7,9 & 0,27 & 5 \\
\hline Lu & 0,59 & 8,6 & 0,05 & 5 & 0,35 & 8,6 & 0,03 & 5 & 0,49 & 8,6 & 0,04 & 5 \\
\hline $\mathrm{Ta}$ & 0,91 & 12,1 & 0,11 & 3 & 0,96 & 7,3 & 0,07 & 4 & 1,44 & 11,1 & 0,16 & 4 \\
\hline
\end{tabular}




\subsection{Espectrometria de massa termoiônica}

Cinco alíquotas de diques da Suíte Serrana $\left(\mathrm{TiO}_{2} \leq 2 \%\right)$, selecionadas com base nos dados de elementos maiores, menores e traço, foram destinadas ao CPGeo-USP para realização das análises dos isótopos $\mathrm{Sr}$ e $\mathrm{Nd}$. As composições isotópicas encontram-se apresentadas na Tabela 4.7, juntamente com as razões recalculadas para $130 \mathrm{Ma}$. As incertezas associadas às determinações correspondem a $2 \sigma$ (número médio de medidas igual a 100).

Tabela 4.7 - Resultados das análises isotópicas de Sr e Nd por espectrometria de massa termoiônica realizadas no CPGeo-USP.

\begin{tabular}{c|ccccc}
\hline Amostra & ${ }^{87} \mathrm{Sr} /{ }^{86} \mathrm{Sr}$ & ${ }^{87} \mathrm{Sr} /{ }^{86} \mathrm{Sr}_{130}$ & ${ }^{143} \mathrm{Nd} /{ }^{144} \mathrm{Nd}$ & ${ }^{143} \mathrm{Nd} /{ }^{144} \mathrm{Nd}_{130}$ & $\varepsilon \mathrm{Nd}(0)$ \\
\hline LMD-RJ-8018 & $0,708016(19)$ & 0,706947 & $0,512311(4)$ & 0,512210 & $-6,37$ \\
\hline LMD-RJ-8017 & $0,710432(16)$ & 0,709413 & $0,512307(4)$ & 0,512225 & $-6,46$ \\
\hline LMD-RJ-8019A & $0,710819(31)$ & 0,709331 & $0,512329(4)$ & 0,512233 & $-6,03$ \\
\hline LMD-RJ-8005A & $0,711598(16)$ & 0,710273 & $0,512218(3)$ & 0,512099 & $-8,19$ \\
\hline LMD-RJ-8010 & $0,710045(09)$ & 0,708624 & $0,512393(4)$ & 0,512300 & $-4,78$ \\
\hline
\end{tabular}

Para as razões isotópicas ${ }^{87} \mathrm{Sr} /{ }^{86} \mathrm{Sr}$, o valor médio do padrão NBS-987, determinado no período de análise das amostras (abril/2019 e março/2020), foi de 0,710268 ( \pm 0,000016). No caso das razões isotópicas ${ }^{143} \mathrm{Nd} /{ }^{144} \mathrm{Nd}$, o valor médio obtido para o padrão Jndi-1, no período em que foram realizadas as medidas (março/2020 a dezembro de 2020), foi de 0,512103 ( $\pm 0,000008)$.

Os brancos $\mathrm{Sr}$ e $\mathrm{Nd}$ durante as análises das amostras foram de 63 e $17 \mathrm{pg}$, respectivamente, os quais são desprezíveis em comparação com as concentrações desses dois elementos nas amostras.

\subsection{Considerações adicionais}

Considerando a verificação dos resultados obtidos pelas diversas técnicas analíticas, pode-se concluir a confiabilidade das análises geoquímicas e isotópicas das amostras de diques situadas na Região Serrana (RJ). Considerando as precisão e exatidão dos resultados, optou-se pela aplicação dos valores dos elementos La, Ce e Nd obtidos pela INAA na interpretação petrogenética. Em contrapartida, para o elemento Ba, optou-se pela FRX, pois para diversas amostras analisadas pela INAA o elemento 
apresentou apenas duas análises, inviabilizando a aplicações dos testes descritos anteriormente.

Os resultados de todas as análises químicas e isotópicas obtidos para cada amostra analisada e empregadas nos diagramas e modelos petrogenéticos, os quais serão discutidos no capítulo a seguir, estão apresentados no Apêndice $C$. 


\section{DISCUSSÃO}

As análises obtidas possibilitaram investigar algumas características geoquímicas e aspectos da origem e evolução dos diques toleíticos que ocorrem na região de Nova Friburgo. Além disso, foram incorporados ao conjunto de dados, 13 análises de diques situados na região de Bom Jardim, reportados por Marques (2001) e dados inéditos. Para elementos maiores, menores e alguns traço ( $\mathrm{Cr}, \mathrm{Ni}, \mathrm{Ba}, \mathrm{Rb}, \mathrm{Sr}, \mathrm{Zr}, \mathrm{Y}$ e $\mathrm{Nb}$ ), as análises dos diques de Bom Jardim e arredores foram realizadas no Instituto de Ciências da Terra na Universidade de Trieste por FRX, com o espectrômetro Philips PW 1404. Para as análises dos elementos traço (ETR, U, Th, Ta, Hf, Cs, Co e Sc), empregou-se a INAA com irradiações térmicas e epitérmicas na Supervisão de Radioquímica do Instituto de Pesquisas Energéticas e Nucleares (CNEN/SP). As análises isotópicas de Sr e de Nd foram realizadas principalmente no Centro de Pesquisas Geocronológicas do Instituto de Geociências da Universidade de São Paulo (dez amostras) e na Universidade de Trieste, para as separações químicas, e na Universidade de Pisa, para medições por espectrometria de massa (três amostras).

\subsection{Caracterização geoquímica dos diques investigados}

\subsubsection{Classificação e nomenclatura}

Em função de seus teores de $\mathrm{SiO}_{2}$ e álcalis $\left(\mathrm{Na}_{2} \mathrm{O}\right.$ e $\left.\mathrm{K}_{2} \mathrm{O}\right)$, as rochas são quimicamente classificadas, através do diagrama TAS, como basaltos (11) e andesitos basálticos (21), conforme observado na Figura 5.1 (Le Bas et al., 1986). Todas as amostras são de natureza subalcalina, situando-se abaixo da linha de separação entre os campos alcalino e subalcalino definido por Irvine \& Baragar (1971). Neste e nos subsequentes diagramas apresentados, os diques foram distinguidos em três grupos conforme o teor de $\mathrm{TiO}_{2}$, o qual corresponde a um importante marcador petrogenético nas rochas da PMP. As amostras em laranja têm teores de $\mathrm{TiO}_{2}$ acima de 3\% (grupo ATi; $\mathrm{TiO}_{2}$ : 3,14 - 3,93\%), com exceção da amostra RJ-7507 ( $\mathrm{TiO}_{2}$ : 2,92\%); os diques em amarelo correspondem àquelas que ocorrem especificamente no Distrito de Lumiar (grupo ATi-Lumiar; $\mathrm{TiO}_{2}$ : 2,60 - 3,19\%); e os diques em verde têm teores inferiores a 2\% (grupo $\mathrm{BTi} ; \mathrm{TiO}_{2}: 1,10$ 1,98\%), excetuando a amostra LMD-RJ-8010 ( $\left.\mathrm{TiO}_{2}: 2,12 \%\right)$. 
O grupo BTi apresenta valores de $\mathrm{MgO}$ entre $6,3 \%$ e 3,2 \% e de sílica $\left(\mathrm{SiO}_{2}\right)$ entre $51,3 \%$ e 55,0\%. O grupo ATi-Lumiar exibe pouca variabilidade composicional, contendo valores de $\mathrm{MgO}$ entre 5,5\% e 4,9\% e de sílica entre 50,7\% e 51,7\%. Com relação ao grupo ATi, os valores de MgO estão entre 5,1 \% e 2,7 \% e os de sílica entre 50,9\% e 54,5\%. Este último grupo apresenta uma maior quantidade de álcalis em relação às demais, com a amostra RJ-7502, proveniente de São Sebastião do Paraíba (Figura 3.1, localização das amostras de diques), situando-se muito pouco acima da linha divisória entre basaltos toleíticos e basaltos alcalinos (Figura 5.1) definida por Zanettin (1984).

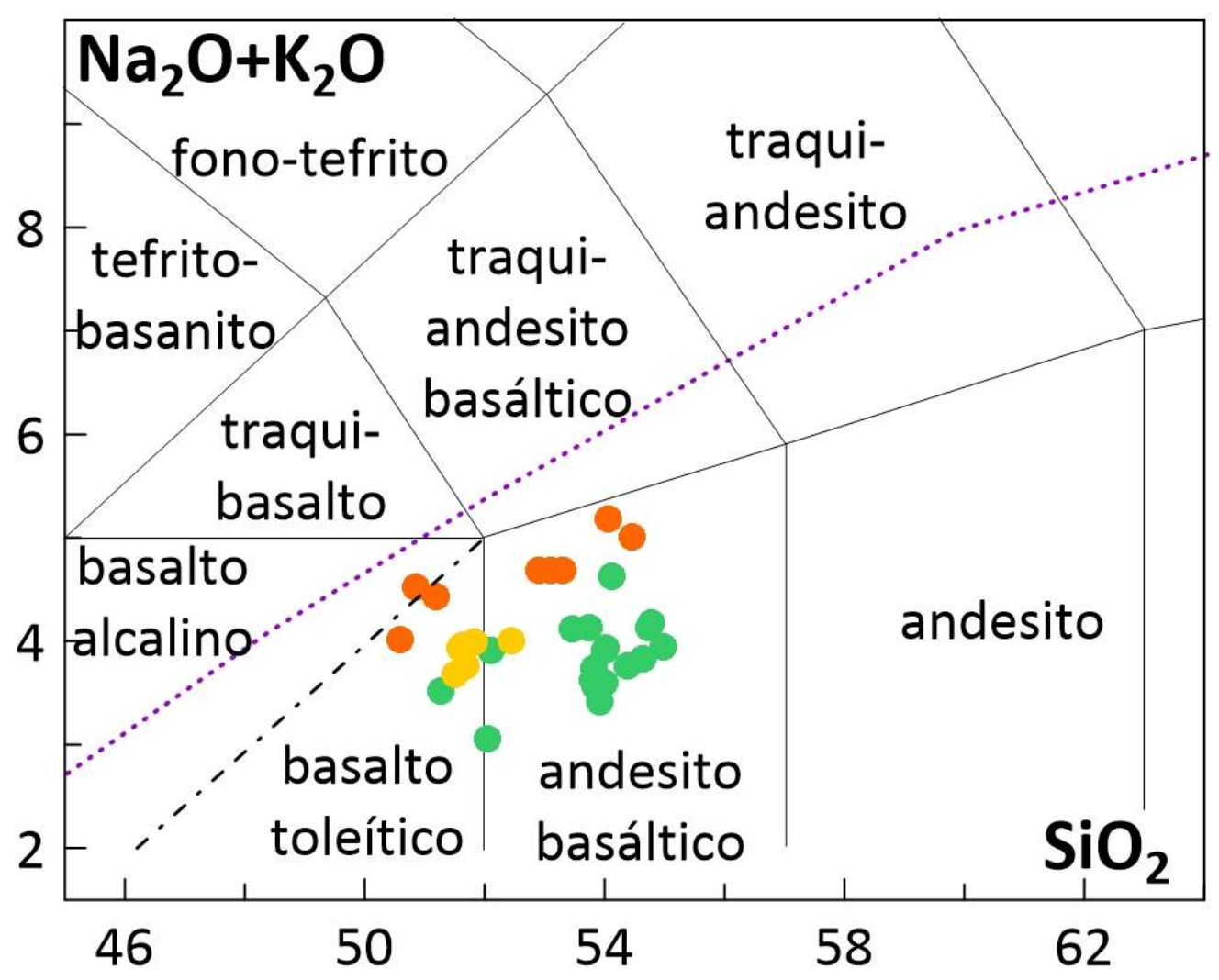

Figura 5.1 - Diagrama TAS (Total Álcalis-Sílica) com nomenclatura química dos 33 diques investigados, com valores em (\%). As amostras do grupo ATi estão representadas pelos círculos cheios de cor laranja, as amostras do grupo ATi-Lumiar estão representadas pelos círculos cheios de cor amarela e as amostras do grupo BTi, círculos cheios de cor verde. A linha pontilhada de cor lilás representa a linha divisória entre os campos alcalino e subalcalino (Irvine \& Baragar, 1971) e a linha tracejada de cor preta, a linha de separação entre os basaltos alcalinos e os basaltos toleíticos (Zanettin, 1984).

Neste estudo considerou-se a nomenclatura do diagrama TAS, conforme estabelecido pela Subcomissão de Sistemática de Rochas Ígneas e recomendado para rochas vulcânicas e subvulcânicas, com os valores dos óxidos normalizados a $100 \%$, eliminando o valor de perda ao fogo, condição exigida para a aplicação dessa 
nomenclatura. Cabe destacar que, a nomenclatura química R1-R2 (Figura 5.2), proposta por De La Roche et al. (1980), e que tem sido muito utilizada no estudo das rochas da PMP, está substancialmente de acordo com a TAS. Observa-se que 25 amostras são andesi-basaltos toleíticos, 2 são basaltos toleíticos (mas praticamente situando-se sobre a linha divisória dos andesi-basaltos toleíticos) e 5 são lati-andesitos. Estas últimas amostras são todas pertencentes ao grupo ATi, incluindo a amostra RJ7502 (MgO: 5,1\%; $\mathrm{SiO}_{2}:$ 50,9\%), que no diagrama TAS são andesitos basálticos.

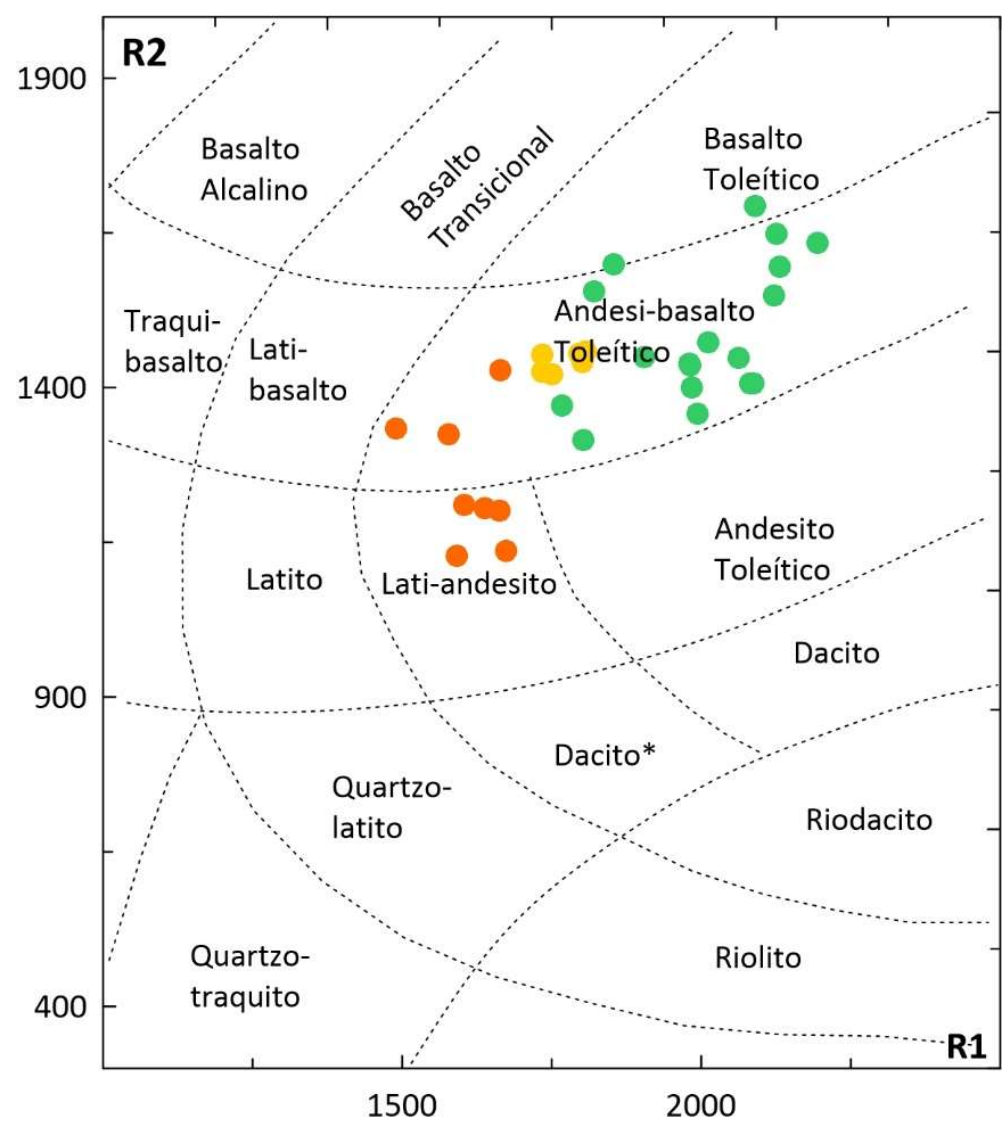

Figura 5.2 - Diagrama R1-R2 $[\mathrm{R} 1=4 \mathrm{Si}-11(\mathrm{Na}+\mathrm{K})-2(\mathrm{Fe}+\mathrm{Ti})$ e $\mathrm{R} 2=6 \mathrm{Ca}+2 \mathrm{Mg}+\mathrm{Al}]$ de nomenclatura proposta por De La Roche et al. (1980). As amostras do grupo ATi estão representadas pelos círculos cheios de cor laranja, as amostras do grupo ATi-Lumiar estão representadas pelos círculos cheios de cor amarela e as amostras do grupo BTi, círculos cheios de cor verde.

Para estudo da verificação das séries magmáticas às quais pertencem as rochas investigadas, aplicou-se o diagrama triangular AFM que subdivide as séries subalcalinas em suítes cálcio-alcalinas e toleíticas, conforme o comportamento das tendências de diferenciação (Wilson, 1989). No diagrama AFM (Figura 5.3), os diques mostram evolução compatível com aquele das suítes toleíticas, de acordo com as divisões 
definidas por Kuno (1968) e Irvine \& Baragar (1971), evidenciado pelo leve aumento dos teores de óxidos de Fe (F) durante a evolução (diminuição de $\mathrm{MgO}$ ), principalmente para os diques BTi.

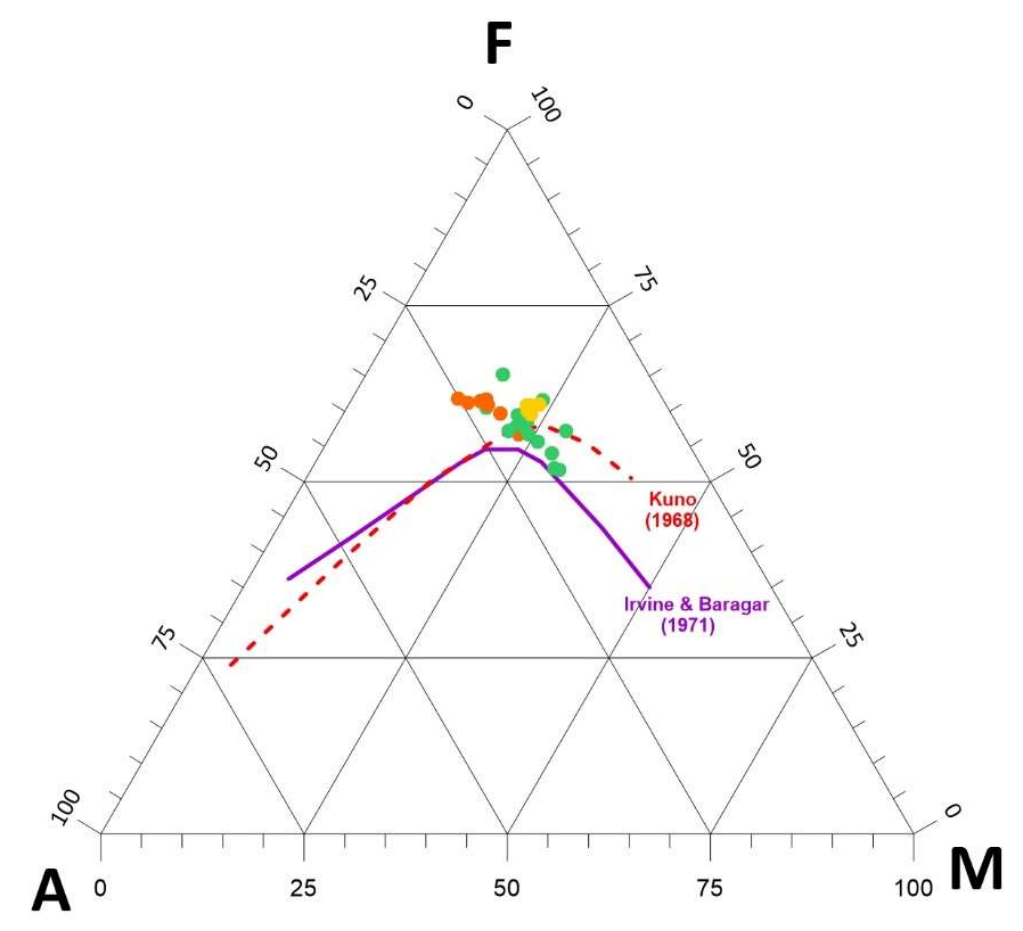

Figura 5.3 - Diagrama AFM de averiguação da tendência magmática. As curvas diferenciam e separam as séries toleíticas das cálcio-alcalinas conforme Kuno (1968) e Irvine \& Baragar (1971). Grupo ATi: círculo cheio laranja; grupo ATi-Lumiar: círculo cheio amarelo; grupo BTi: círculo cheio verde.

O caráter toleítico dos três grupos é reforçado no diagrama binário $\mathrm{FeO}_{\mathrm{t}} / \mathrm{MgO}$ vs. Sílica de Myashiro (1974), o qual subdivide as séries em toleítica e cálcio-alcalina (Figura 5.4). As amostras do grupo $\mathrm{BTi}$ se assemelham tanto aos diques amostrados com $\mathrm{TiO}_{2} \leq$ 2\% reportados por Ludka (1997), os quais são marcados por concentrações levemente mais baixas de $\mathrm{SiO}_{2}$, e aos diques da Suíte Serrana amostrados de Corval et al. (2008), com concentrações de $\mathrm{SiO}_{2}$ similares (amostras SMM-SV-1; CO-SV-1; CM-SV-2; CM-SV1A; CM-SV-1B). Os diques amostrados de Ludka (1997) com $\mathrm{TiO}_{2}>2 \%$ apresentam relação com o grupo ATi-Lumiar e com as amostras menos evoluídas do grupo ATi $\left(\mathrm{SiO}_{2}\right.$ $<53 \%)$. 


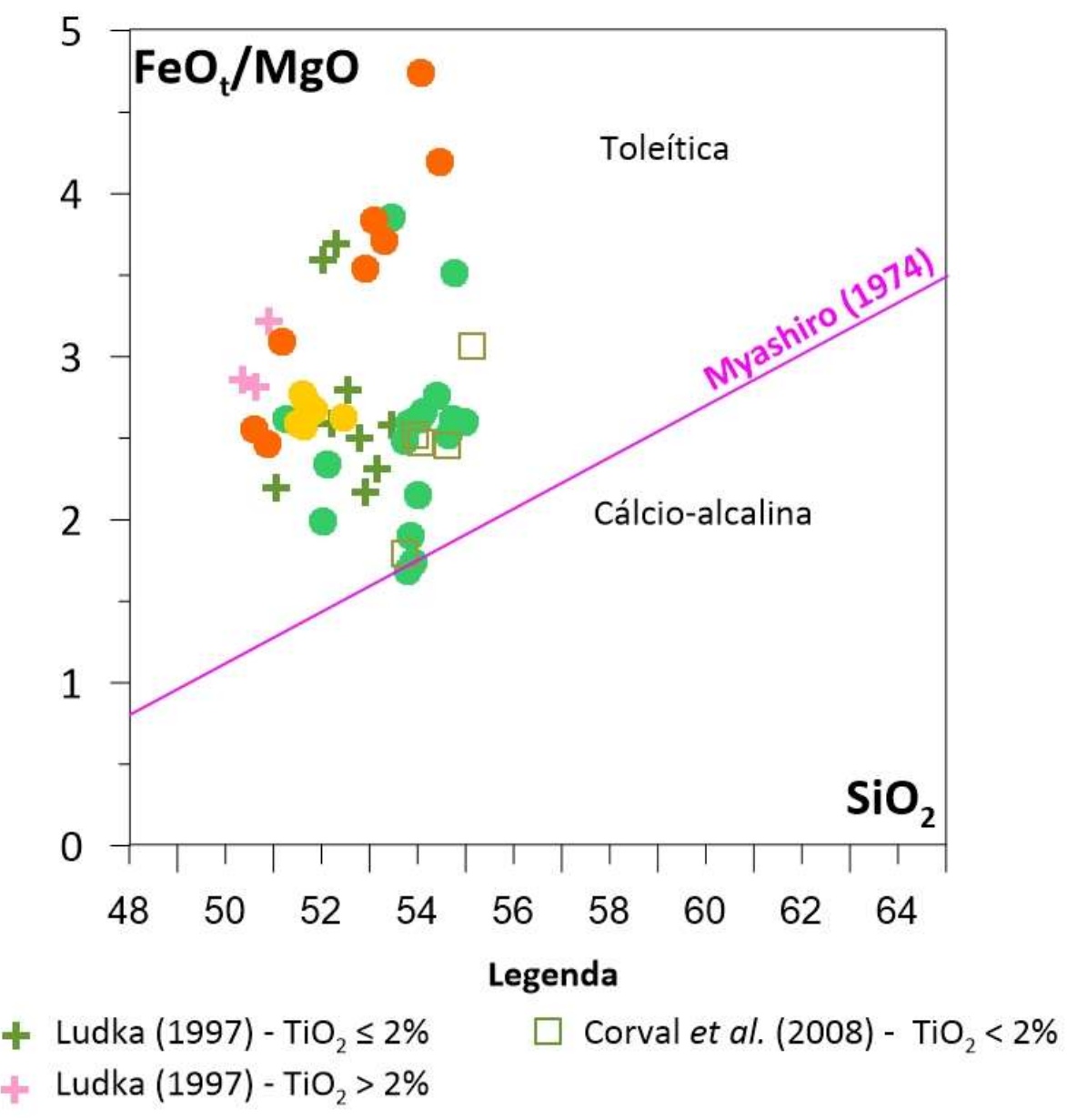

Figura 5.4 - Diagrama binário FeOt/MgO vs $\mathrm{SiO}_{2}$ de Myashiro (1994), com valores em (\%). A reta de cor magenta separa a série toleítica da cálcio-alcalina. Grupo ATi: círculo cheio laranja; grupo ATi-Lumiar: círculo cheio amarelo; grupo BTi: círculo cheio verde. A título de comparação, estão representadas amostras de diques da região realizadas por Ludka (1997) e Corval (2008).

\subsection{2. Óxidos de elementos maiores e menores}

O comportamento dos óxidos maiores e menores nas amostras estudadas foi investigado através de diagramas de variação, considerando o óxido $\mathrm{MgO}$ como índice de evolução magmática (Figura 5.5), cujas concentrações diminuem com a diferenciação das suítes basálticas. Essa variação composicional nos magmas pode ser causada por vários processos, sendo que a mais importante é consequência do fracionamento de fases cristalinas formadas pela diminuição de temperatura, causando evolução química dos líquidos magmáticos (Wilson, 1989).

De modo geral, conforme ocorre a diferenciação magmática, ou seja, com a diminuição da concentração de $\mathrm{MgO}$, observa-se o aumento dos teores de $\mathrm{SiO}_{2}, \mathrm{~K}_{2} \mathrm{O}$ e $\mathrm{Na}_{2} \mathrm{O}$, bem como diminuição de $\mathrm{CaO}$ (Figura 5.5). Em destaque, o teor mais alto de $\mathrm{Na}_{2} \mathrm{O}$ 
do grupo ATi corresponde à amostra RJ-7502. A diminuição dos teores de $\mathrm{CaO}$, à medida que a evolução magmática procede, é indicativa de cristalização fracionada de clinopiroxênio cálcico. Em relação ao $\mathrm{Al}_{2} \mathrm{O}_{3}$ observa-se uma considerável dispersão, especialmente para as rochas do grupo $\mathrm{BTi}$, que pode indicar acumulação de plagioclásio. $\mathrm{O}$ comportamento observado no $\mathrm{FeO}_{\mathrm{t}}$ mostra também uma dispersão significativa para o grupo BTi e diminuição bem leve para o grupo ATi e considerável para o grupo ATi-Lumiar. Isto sugere pouco envolvimento de magnetita na evolução dessas rochas.

Em relação ao $\mathrm{TiO}_{2}$, os três grupos são claramente distinguidos, quando se considera o mesmo conteúdo de $\mathrm{MgO}$, ou seja, o mesmo grau de evolução. Para os diques $\mathrm{BTi}$, ocorre leve aumento nas concentrações conforme aumenta o grau de evolução magmática, reforçando pouco ou nenhum fracionamento de titanomagnetita. Porém, para o grupo ATi, se observa uma possível inflexão entre os teores $5-4 \%$ de $\mathrm{MgO}$ e 3,5-4,0\% de $\mathrm{TiO}_{2}$, indicando fracionamento de titanomagnetita. Em relação ao grupo ATi-Lumiar, a variação de $\mathrm{TiO}_{2}$ não é nítida, devido aos teores restritos de $\mathrm{MgO}$ em torno de $5 \%$.

$\mathrm{O}$ comportamento das concentrações de $\mathrm{P}_{2} \mathrm{O}_{5}$ mostra também a distinção dos mesmos 3 grupos, sendo que no BTi ocorre leve aumento da concentração com a diminuição de $\mathrm{MgO}$, enquanto no grupo ATi-Lumiar os valores são praticamente constantes, indicando que não houve fracionamento de apatita. Por outro lado, parece haver uma leve diminuição de $\mathrm{P}_{2} \mathrm{O}_{5}$ no caso do grupo ATi, embora observe-se uma certa dispersão, apontando para possível fracionamento de apatita, mas em baixa proporção. 

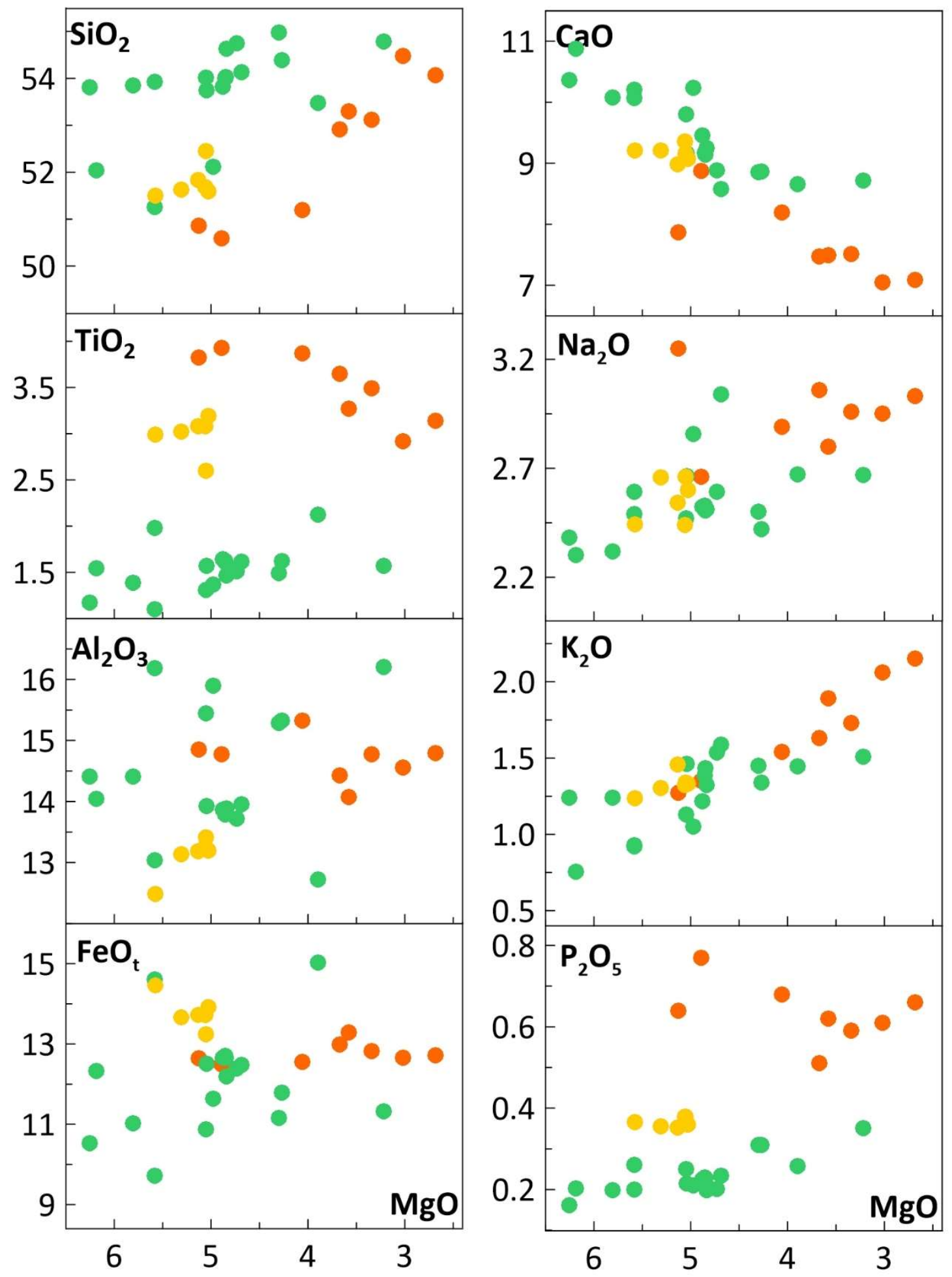

Figura 5.5 - Diagramas de variação de óxidos de elementos maiores e menores (\%) em função da concentração de MgO (\%). Grupo ATi: círculo cheio laranja; grupo ATi-Lumiar: círculo cheio amarelo; grupo BTi: círculo cheio verde.

Nos diagramas de variação da Figura 5.5 observa-se também que o $\mathrm{Na}_{2} \mathrm{O}$ tende a apresentar enriquecimento no grupo ATi em comparação com os demais diques. Em 
contrapartida, nos diagramas de $\mathrm{SiO}_{2}$ e $\mathrm{CaO}$, verifica-se enriquecimento nos respectivos teores no grupo BTi. No caso do grupo ATi-Lumiar, observa-se enriquecimento nos teores de $\mathrm{FeO}_{\mathrm{t}}$ e o empobrecimento nos teores de $\mathrm{Al}_{2} \mathrm{O}_{3}$ e $\mathrm{SiO}_{2}$ em relação aos outros grupos. Nos demais diagramas, o grupo ATi-Lumiar apresenta valores intermediários nos teores dos óxidos. Destacando os comportamentos dos óxidos $\mathrm{TiO}_{2}$ e $\mathrm{P}_{2} \mathrm{O}_{5}$, importantes divisores das séries basálticas da PMP, a separação das rochas do grupo ATi-Lumiar em relação ao grupo ATi está bem evidenciada.

Ao longo da diferenciação magmática, a razão $\mathrm{CaO} / \mathrm{Al}_{2} \mathrm{O}_{3}$ diminui para os três grupos (Figura 5.6), indicando significativo fracionamento de clinopiroxênio cálcico. A razão $\mathrm{CaO} / \mathrm{Al}_{2} \mathrm{O}_{3}$ é indiferente ao fracionamento de olivina, porém sensível nos fracionamentos de plagioclásio e, principalmente, de clinopiroxênio cálcico. Embora os diques ATi tenham conteúdos de MgO menores do que os $\mathrm{BTi}$, ou seja, são mais diferenciados, observa-se que o diagrama $\mathrm{CaO} / \mathrm{Al}_{2} \mathrm{O}_{3}$ em função de $\mathrm{SiO}_{2}$ distingue muito bem esses dois grupos.

De modo geral, o comportamento geoquímico observado nos óxidos maiores e menores dos diques estudados corresponde ao processo de cristalização fracionada a partir de magmas parentais distintos, envolvendo clinopiroxênio cálcico, £plagioclásio, \pm titanomagnetita e \pm apatita.
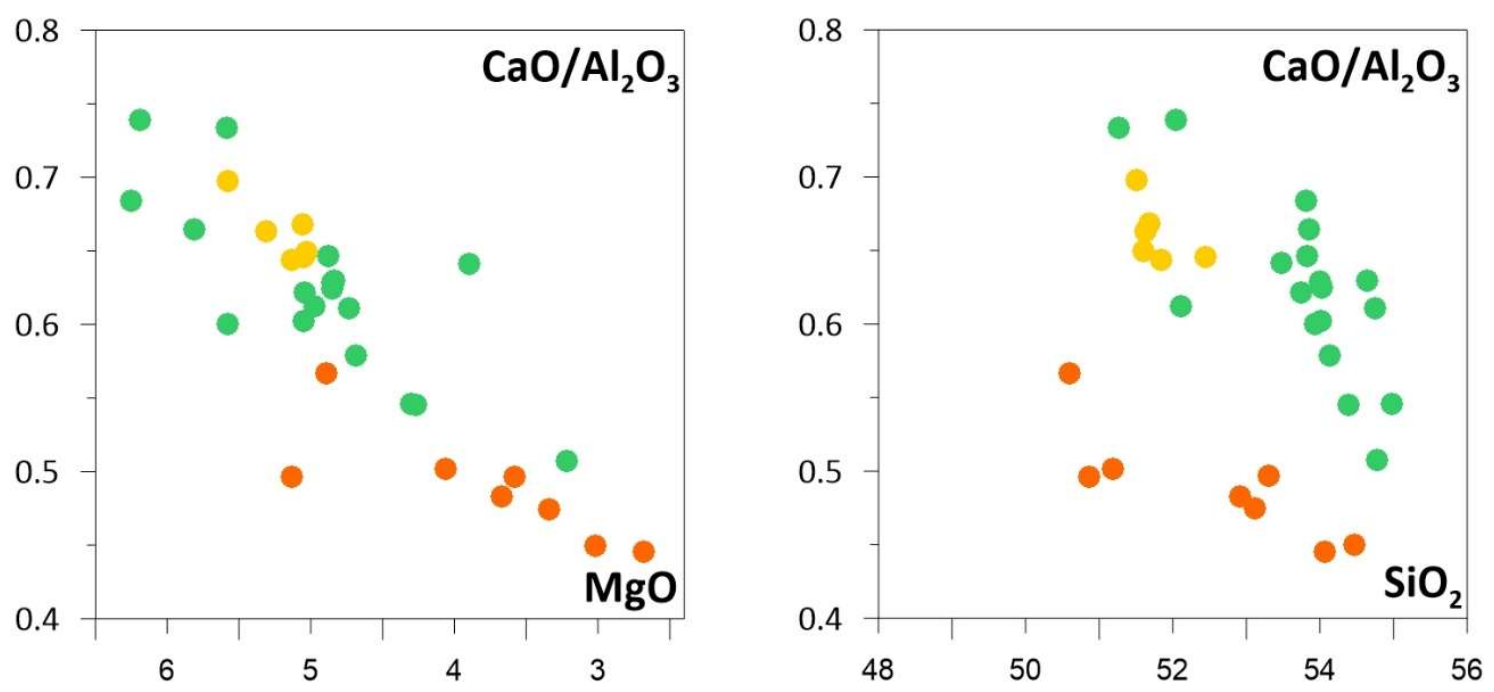

Figura 5.6 - Diagramas de da razão $\mathrm{CaO} / \mathrm{Al}_{2} \mathrm{O}_{3}$ em função das concentrações de $\mathrm{MgO}$ (esquerda) e $\mathrm{SiO}_{2}$ (direita), concentração em (\%). Grupo ATi: círculo cheio laranja; grupo ATi-Lumiar: círculo cheio amarelo; grupo BTi: círculo cheio verde. 


\subsubsection{Elementos traço}

A presença de três conjuntos distintos de rochas neste estudo é ainda mais evidenciada no comportamento dos elementos traço fortemente incompatíveis, usados como índices de evolução magmática, em particular o Zr (o mais incompatível observado nas análises). O grupo ATi apresenta o intervalo de concentração de Zr entre 245 - 296 $\mathrm{mg} / \mathrm{kg}$ (com duas amostras com $213 \mathrm{mg} / \mathrm{kg}$ ), o grupo ATi-Lumiar entre $211-223 \mathrm{mg} / \mathrm{kg}$ e o grupo BTi entre 107 - $189 \mathrm{mg} / \mathrm{kg}$. Tais valores estão concordantes com as observações de Corval et al. (2008) para diques da Suíte Serrana (123 - 183 mg/kg).

Elementos traço fortemente incompatíveis $\left(K_{D} \ll 1\right.$; Rollinson, 1993) são bons indicadores de processos de diferenciação magmática, como a cristalização fracionada (Equação 5.1) Dentro de uma mesma suíte, os diagramas de elementos traço fortemente incompatíveis ajustam-se a uma reta com coeficiente linear igual ou muito próximo de zero, desde que o sistema seja o sistema fechado.

$$
C_{L}^{i}=C_{0}^{i} F^{\left(D_{i}-1\right)}
$$

onde $C_{L}^{i}$ corresponde à concentração do elemento $i$ no líquido, $C_{0}^{i}$ à concentração inicial do elemento $i, F$ à fração líquida remanescente após o fracionamento e $D_{i}$ ao coeficiente de partição global do elemento $i$.

Deste modo, em conjunto com os diagramas binários dos elementos traço em função de $\mathrm{MgO}$, construíram-se também diagramas em função de Zr para interpretação petrogenética da evolução magmática em função de dois índices. A Figura 5.7 apresenta os ETR leves em função de MgO, enquanto a Figura 5.8, os ETR em função de Zr. Para os elementos traço incompatíveis, a Figura 5.9 apresenta os elementos $\mathrm{Th}, \mathrm{Ta}, \mathrm{Hf}, \mathrm{Ba}, \mathrm{Rb}$, U, Y e Sr em função de Zr e a Figura 5.10, os elementos Th, Rb, U e Sr em função de MgO.

Nos diagramas das Figuras 5.7 e 5.8, os três grupos apresentam concentrações diferentes de La, Ce e Nd, porém, como também visto na Figura 5.8, similares de Tb, Yb e Lu indicando fracionamento significativo dos ETR leves em relação aos ETR pesados na diferenciação magmática. Em relação ao grupo BTi (Figura 5.8), os diques ATi são enriquecidos em La, Ce, Nd, Sm e Eu e empobrecidos em Lu. O grupo ATi-Lumiar apresenta valores de concentração intermediários aos dois grupos. O comportamento geral dos ETR sugere que os três grupos de diques foram originados em pelo menos duas 
fontes mantélicas distintas, já que os ETR leves, que são os mais incompatíveis da família, não se ajustam a uma reta que passa que pela origem, como observado na Figura 5.8.

Considerando também todo o conjunto de amostras, nos diagramas das Figuras 5.9, as tendências das concentrações dos elementos fortemente incompatíveis, tais como Ta, U e Th, também não se ajustam em retas passando pela origem, o que também reforça que os diques não são cogenéticos. Cabe ressaltar que o significativo enriquecimento dos elementos $\mathrm{Th}, \mathrm{U}$ e Rb com a evolução magmática no grupo BTi (Figuras 5.9 e 5.10) sugere ainda que a cristalização fracionada não ocorreu em sistema fechado, com significativa assimilação crustal.

O comportamento do Sr também reforça que os diques não são cogenéticos (Figuras 5.9 e 5.10). Os diques BTi apresentam concentrações menores e praticamente constantes, enquanto para diques ATi-Lumiar e ATi os valores são bem mais elevados, com diminuição na concentração desse elemento, em função do aumento de Zr e diminuição de $\mathrm{MgO}$, o que indica maior fracionamento de plagioclásio na diferenciação magmática. 

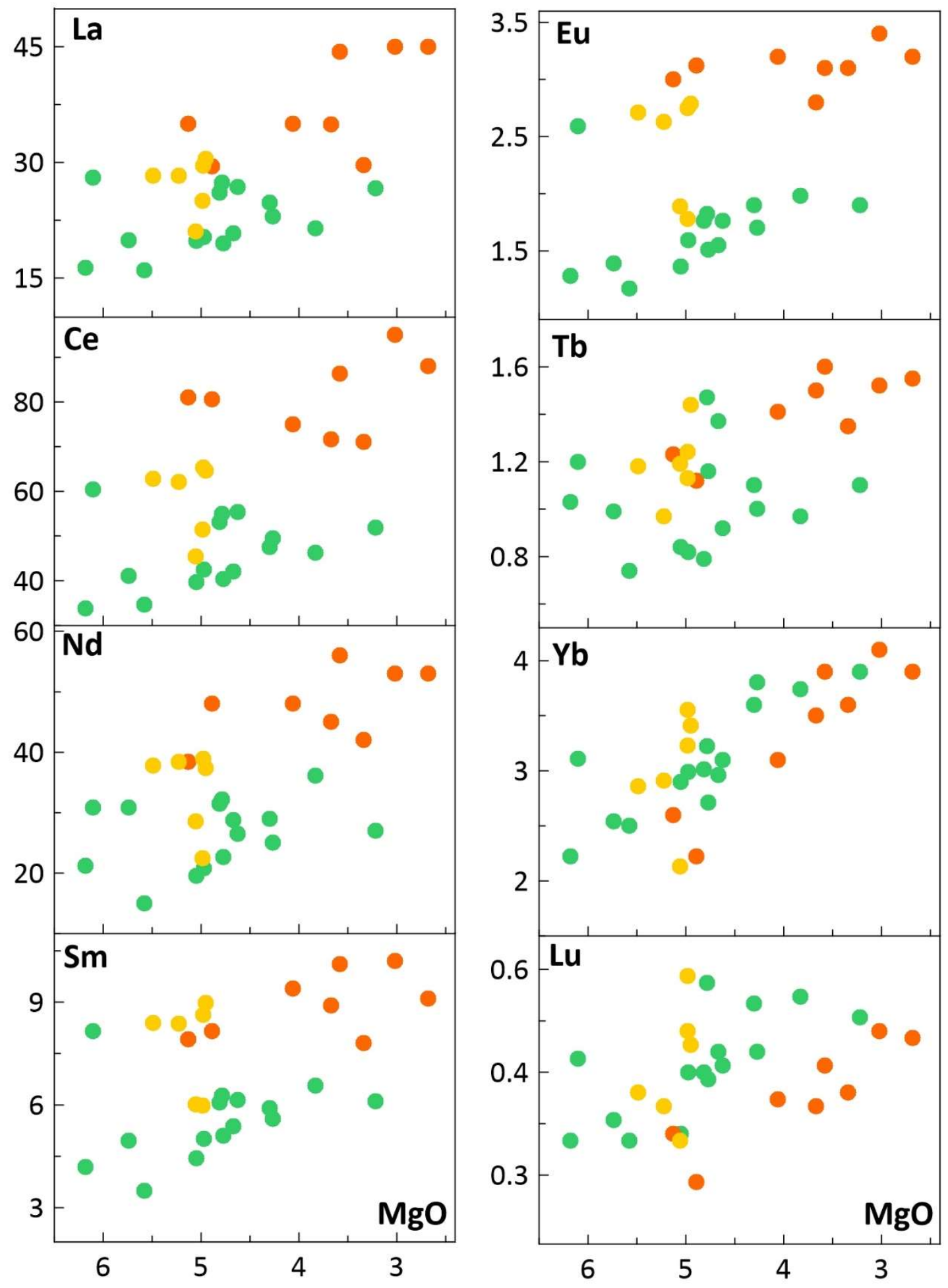

Figura 5.7 - Diagrama de variação de ETR (mg/kg) em função da concentração de $\mathrm{MgO}$ (\%). Grupo ATi: círculo cheio laranja; grupo ATi-Lumiar: círculo cheio amarelo; grupo BTi: círculo cheio verde. 

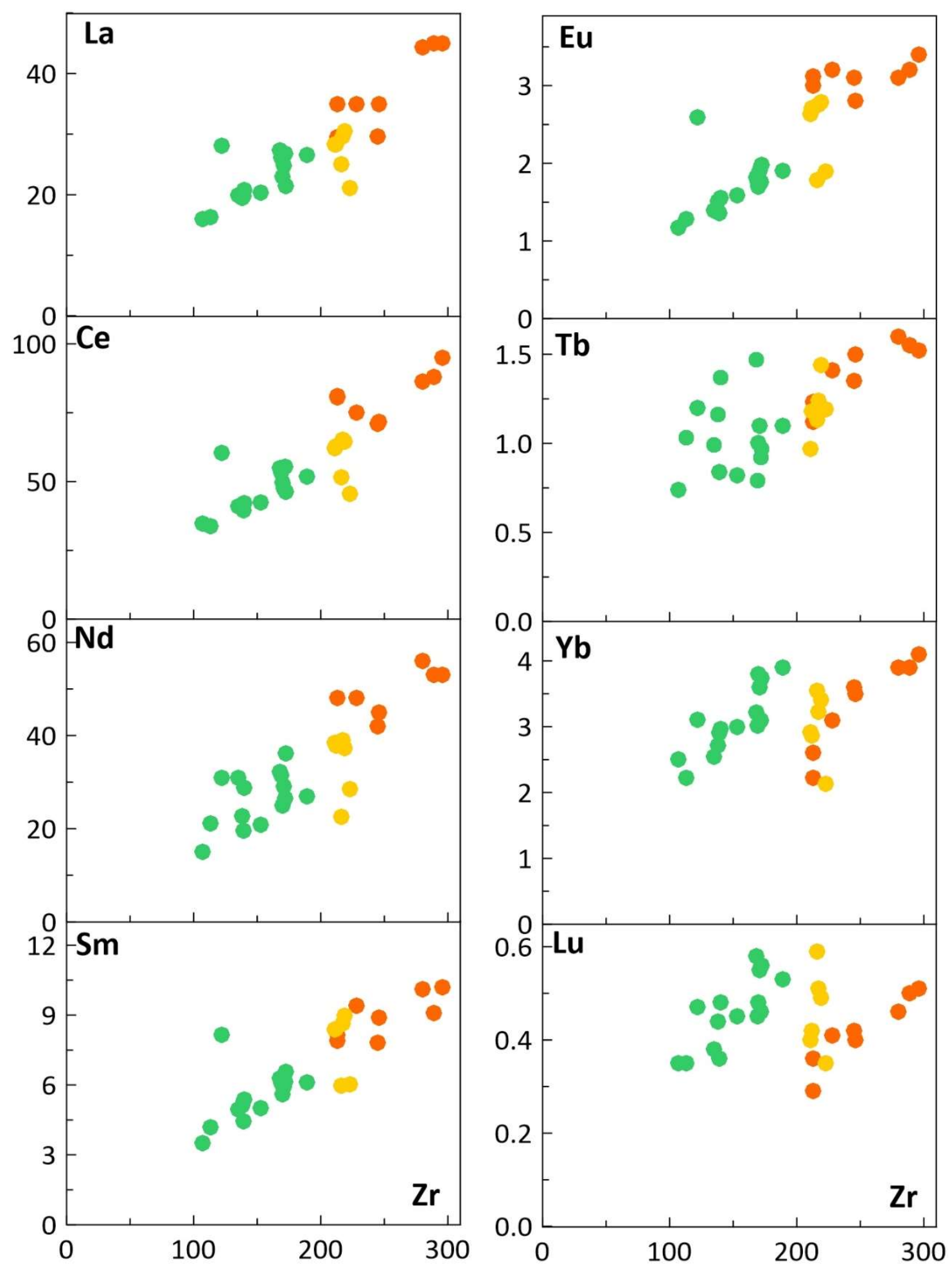

Figura 5.8 - Diagrama de variação de ETR $(\mathrm{mg} / \mathrm{kg}$ ) em função da concentração de $\mathrm{Zr}$ (fortemente incompatível; $\mathrm{mg} / \mathrm{kg}$ ). Grupo ATi: círculo cheio laranja; grupo ATi-Lumiar: círculo cheio amarelo; grupo BTi: círculo cheio verde. 

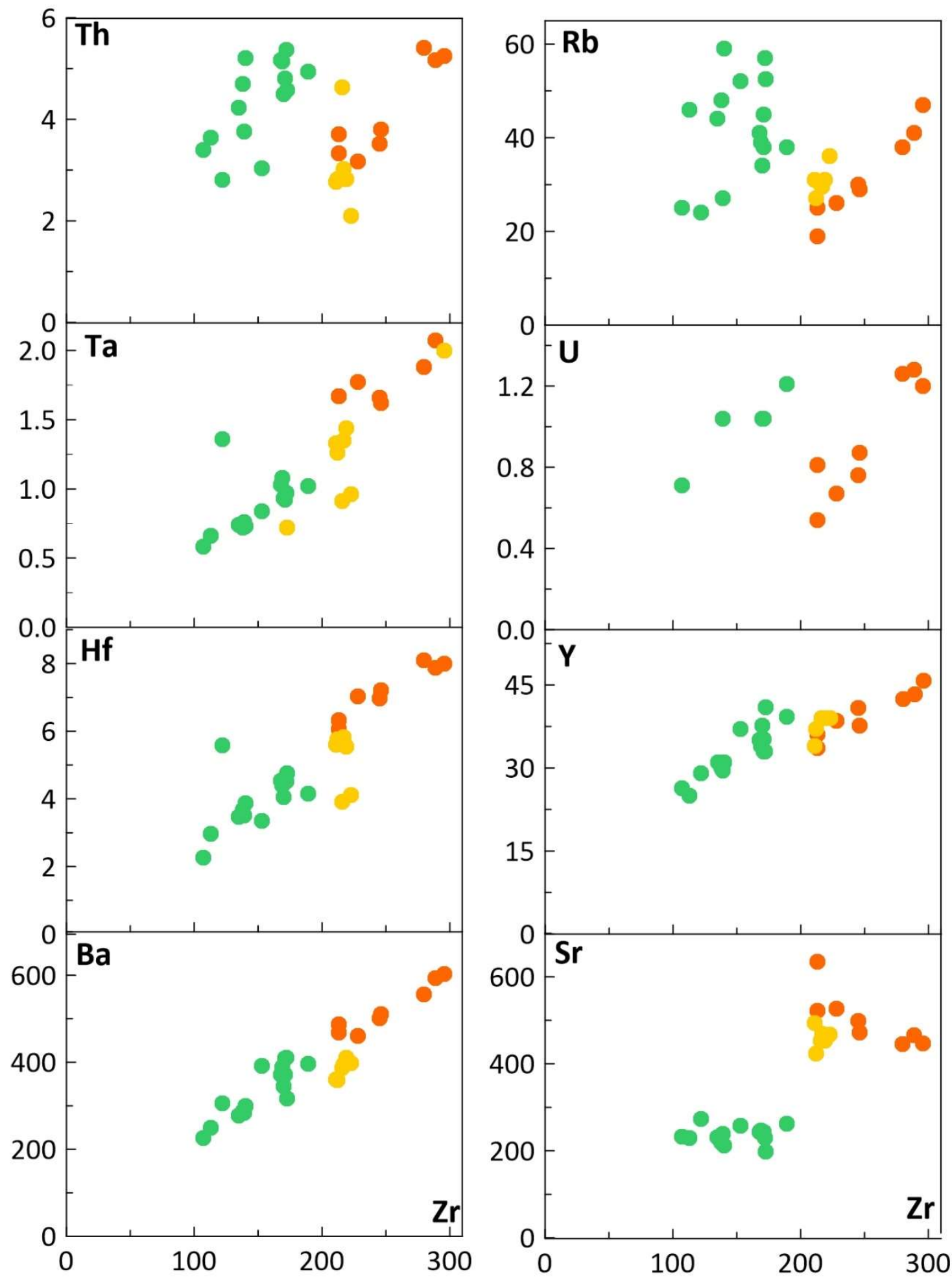

Figura 5.9 - Diagrama de variação de elementos traço incompatíveis $(\mathrm{mg} / \mathrm{kg})$ em função da concentração de Zr (fortemente incompatível; mg/kg). Grupo ATi: círculo cheio laranja; grupo ATi-Lumiar: círculo cheio amarelo; grupo BTi: círculo cheio verde. 

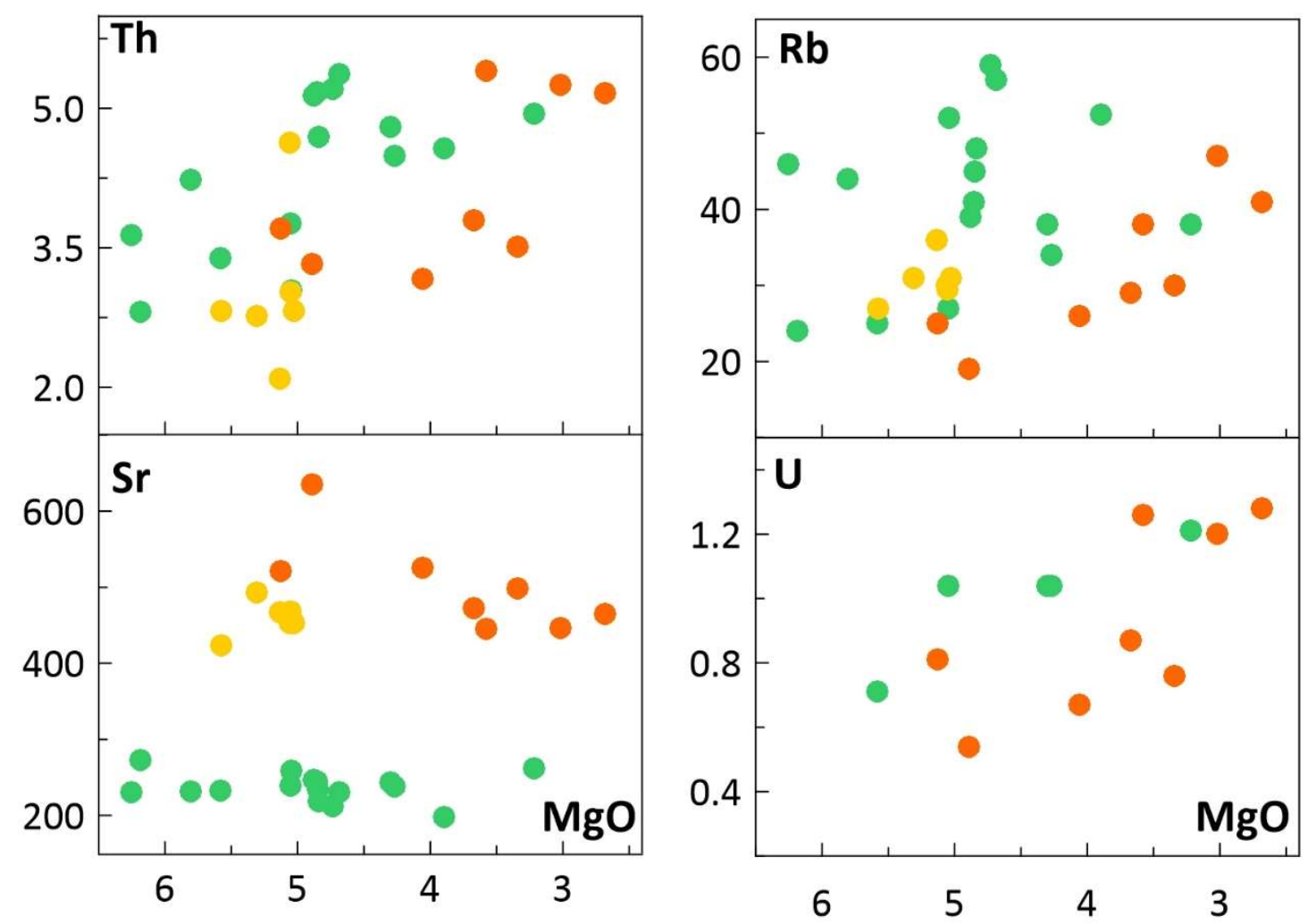

Figura 5.10 - Diagrama de variação de elementos traço incompatíveis $(\mathrm{mg} / \mathrm{kg})$ em função da concentração de MgO (\%). Grupo ATi: círculo cheio laranja; grupo ATi-Lumiar: círculo cheio amarelo; grupo BTi: círculo cheio verde. Para os diques ATi-Lumiar não há determinações de U.

Os três grupos também apresentam diferenças importantes nos padrões de abundância de ETR do grupo BTi e dos grupos ATi e ATi-Lumiar, normalizados pelo condrito $\mathrm{Cl}$ (McDonough \& Sun, 1995), conforme visto nas Figuras 5.11 e 5.12, respectivamente. Em todos os grupos se nota o fracionamento de ETR leves, mais incompatíveis, em relação aos ETR pesados, principalmente nos diques evoluídos do grupo ATi (MgO < 4\%), comportamento esperado para evolução de magmas toleíticos envolvendo cristalização fracionada de piroxênios (Wilson, 1989). Os diques do grupo BTi apresentam-se mais empobrecidos em ETR leves do que os dos grupos ATi-Lumiar e ATi, como observado nas razões dos elementos ETR normalizados (Tabela 5.1) e no diagrama da razão $(\mathrm{La} / \mathrm{Sm})_{\mathrm{Cl}}$ vs. $(\mathrm{Sm} / \mathrm{Yb})_{\mathrm{Cl}}$ (Figura 5.13).

Em comparação aos derrames basálticos da PMP ( $\mathrm{TiO}_{2} \leq 2 \%$; Figura 5.11), os diques do grupo BTi apresentam semelhanças principalmente com o tipo Gramado, acentuadamente contaminados pela crosta continental, apresentando 0 
comportamento e conteúdos normalizados de ETR leves dentro dos intervalos dos valores máximos e mínimos, principalmente nos diques com teores de $\mathrm{MgO}$ entre $4 \%$ e $5 \%$ e inferiores a $4 \%$. Nos diques menos evoluídos ( $6 \% \leq \mathrm{MgO} \leq 5 \%$ ), a amostra QT-SV$1 B$ exibe enriquecimento alto nos ETR leves e Eu em comparação aos derrames e às demais amostras analisadas.

Ambos os grupos, ATi e ATi-Lumiar, são mais semelhantes ao comportamento dos derrames tipo Pitanga (Figura 5.12) para os três intervalos de diferenciação magmática, mesmo para $\mathrm{MgO}<4 \%$, onde são comparados apenas com a amostra KS-775 (RochaJúnior et al., 2013). É interessante notar que as cinco amostras mais evoluídas do grupo ATi são enriquecidas significativamente em ETR leves (Figura 5.13), o que está de acordo com a tendência toleítica-transicional dessas rochas.

O elemento $\mathrm{Eu}$, em particular quando no estado de oxidação $\mathrm{Eu}^{2+}$, distingue-se dos demais ETR pelo comportamento compatível durante a cristalização fracionada de feldspato potássico e plagioclásio. O Eu ${ }^{2+}$ apresenta raio iônico semelhante aos de Ca e $\mathrm{Sr}$, podendo participar da substituição isomórfica com o $\mathrm{Sr}^{2+}$ e/ou $\mathrm{Ca}^{2+}$ nesses minerais (Wilson, 1989; Abdalla, 2012). Os diques dos grupos BTi e ATi-Lumiar apresentam leves anomalias negativas de Eu (Tabela 5.1), sendo que os valores de Eu/Eu* tendem a ser maiores no primeiro grupo. Nota-se ainda que, quando se observa separadamente cada um desses dois grupos, verifica-se que praticamente não há variação das razões Eu/Eu* com o grau de evolução, sugerindo pouco fracionamento de plagioclásio, o que é também corroborado pela falta de correlação entre $\mathrm{Al}_{2} \mathrm{O}_{3}$ e $\mathrm{MgO}$ (Figura 5.5) e de $\mathrm{Sr}$ com Zr e MgO (Figuras 5.9 e 5.10).

Por outro lado, as rochas do grupo ATi são caracterizadas por apresentarem leves anomalias positivas de Eu (com exceção das amostras RJ-7504, Eu/Eu*: 0,93, e RJ-7506, $\mathrm{Eu} / \mathrm{Eu}^{*}:$ 0,92), sendo que os valores de $\mathrm{Eu} / \mathrm{Eu}^{*}$ tendem a diminuir com o grau de diferenciação, sugerindo fracionamento mais significativo de plagioclásio, também indicado pela diminuição da concentração de Sr em função de $\mathrm{Zr}$ e de $\mathrm{MgO}$, considerado como um índice de evolução magmática (Figura 5.11 e 5.10). Cabe ainda destacar que os derrames ATi do tipo Pitanga são também caracterizados por anomalias levemente positivas de Eu (Marques et al., 1989; Rocha-Júnior et al., 2013), indicando ser esta uma característica da fonte mantélica que originou as rochas basálticas do norte da PMP. 


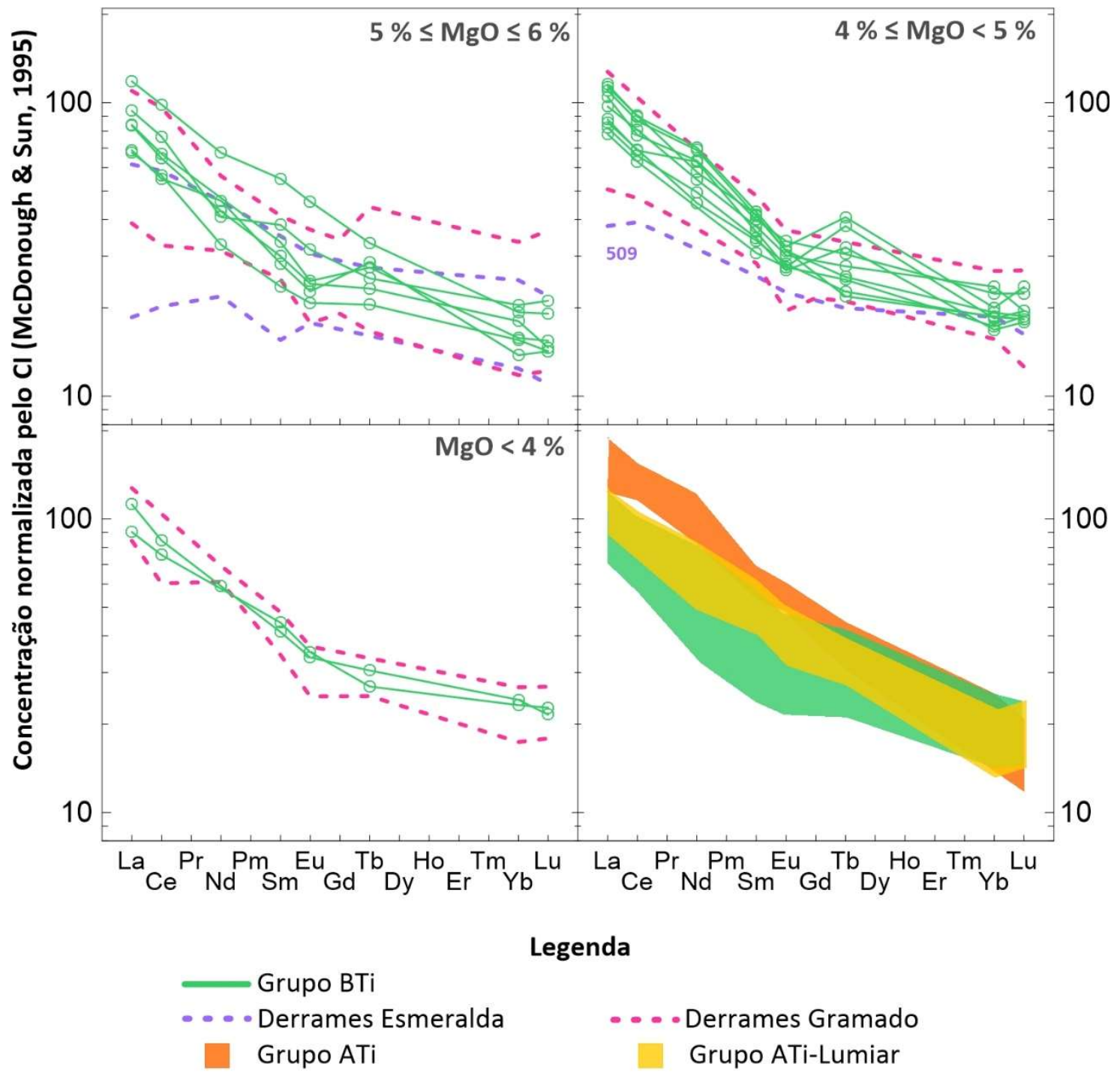

Figura 5.11 - Padrões de abundância dos elementos terras raras do grupo BTi de acordo com o grau de diferenciação magmática (conteúdo de $\mathrm{MgO}$ ), juntamente com os valores máximos e mínimos dos derrames Esmeralda e Gramado (Marques et al., 1989; Peate, 1997) e com diques do grupo ATi e ATiLumiar. Amostra 509 de Marques et al. (1989). 


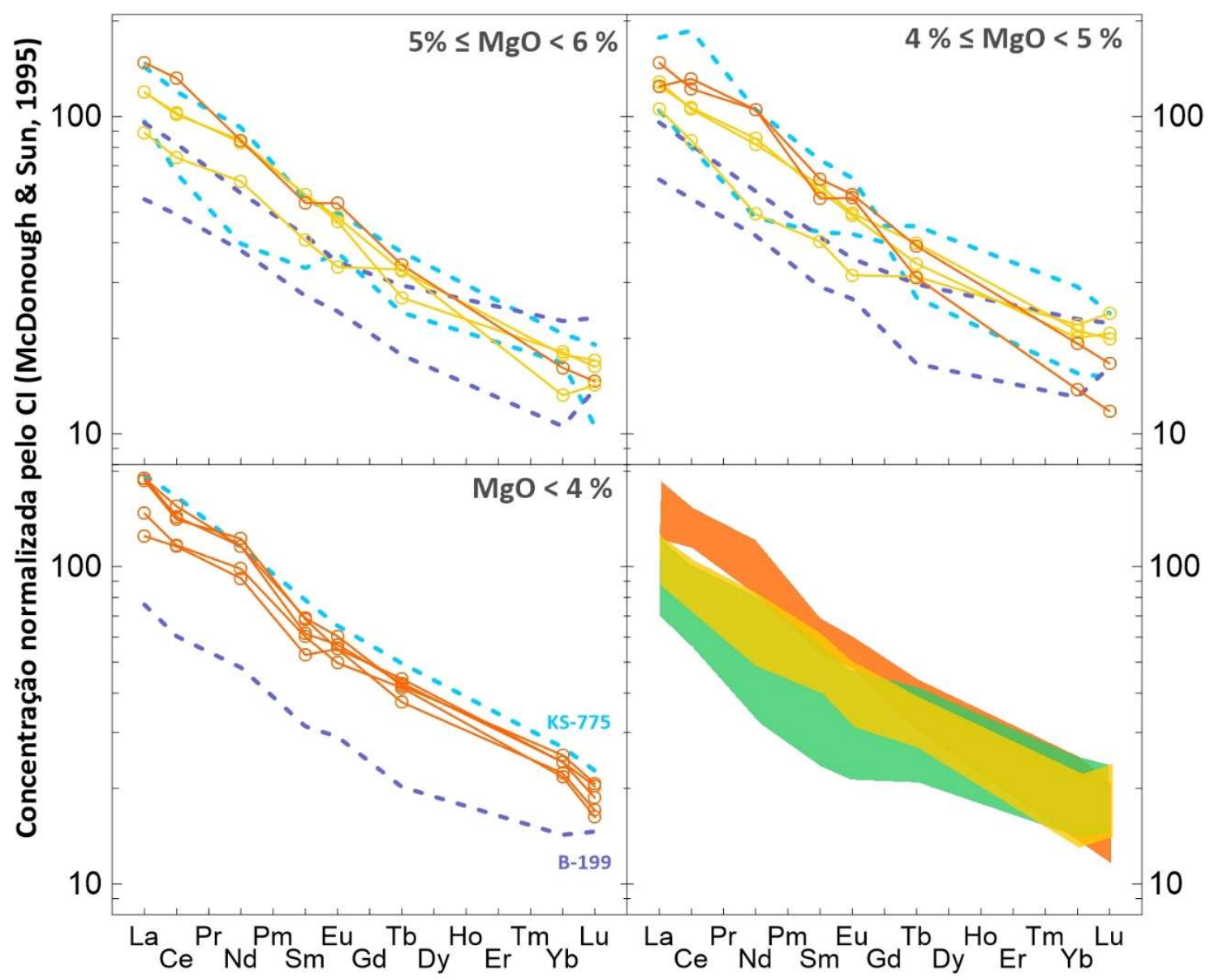

Legenda
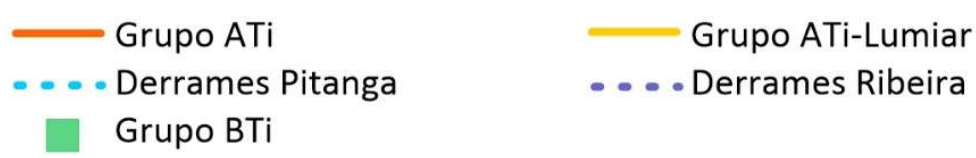

Figura 5.12 - Padrões de abundância dos elementos terras raras do grupo ATi-Lumiar e ATi de acordo com o grau de diferenciação magmática (conteúdo de $\mathrm{MgO}$ em \%), juntamente com os valores máximos e mínimos dos derrames Pitanga e Ribeira (Marques et al., 1989; Peate, 1997; Rocha-Júnior et al., 2013) e com diques do grupo ATi e ATi-Lumiar. Amostras KS-775 de Rocha-Júnior et al. (2013) e B-199 de Marques et al. (1989). 
Tabela 5.1 - Valores médios e desvio padrão, entre parênteses, das razões entre os ETR leves, intermediários e pesados normalizadas pelo condrito $\mathrm{Cl}$ (McDonough \& Sun, 1995) e anomalias de Eu (Eu/Eu*) calculados para os grupos de diques BTi, ATi-Lumiar e ATi. O símbolo $\mathrm{N}$ corresponde ao número de amostras de diques.

\begin{tabular}{|c|c|c|c|c|c|c|c|}
\hline Grupos & $\mathrm{N}$ & MgO (\%) & $(\mathrm{La} / \mathrm{Lu})_{\mathrm{cl}}$ & $(\mathrm{La} / \mathrm{Yb})_{\mathrm{cl}}$ & $(\mathrm{La} / \mathrm{Sm})_{\mathrm{Cl}}$ & $(\mathrm{Sm} / \mathrm{Yb})_{\mathrm{cl}}$ & Eu/Eu* \\
\hline \multirow{4}{*}{ BTi } & 17 & Todas & $5,0(0,7)$ & $4,9(0,7)$ & $2,5(0,2)$ & $2,0(0,3)$ & $0,88(0,07)$ \\
\hline & 6 & $6-5$ & $5,2(0,7)$ & $5,0(0,6)$ & $2,5(0,3)$ & $2,0(0,5)$ & $0,89(0,07)$ \\
\hline & 9 & $5-4$ & $5,0(0,7)$ & $5,0(0,7)$ & $2,6(0,1)$ & $1,9(0,2)$ & $0,87(0,08)$ \\
\hline & 2 & $<4$ & $5,0(0,9)$ & $4,3(0,5)$ & $2,4(0,5)$ & $1,8(0,2)$ & $0,91(0,01)$ \\
\hline \multirow{3}{*}{$\begin{array}{c}\text { ATi- } \\
\text { Lumiar }\end{array}$} & 6 & Todas & $6,2(1,0)$ & $6,2(0,7)$ & $2,2(0,2)$ & $2,8(0,5)$ & $0,94(0,06)$ \\
\hline & 3 & $5-4$ & $6,9(0,6)$ & $6,7(0,1)$ & $2,1(0,1)$ & $3,1(0,1)$ & $0,96(0,07)$ \\
\hline & 3 & $<4$ & $5,6(1,1)$ & $5,7(1,1)$ & $2,3(0,3)$ & $2,5(6)$ & $0,92(0,06)$ \\
\hline \multirow{4}{*}{ ATi } & 8 & Todas & $9,3(1,0)$ & $7,7(1,1)$ & $2,6(1,3)$ & $3,0(1,2)$ & $1,05(0,47)$ \\
\hline & 1 & $6-5^{*}$ & 10,1 & 9,1 & 2,8 & 3,3 & 1,14 \\
\hline & 2 & $5-4$ & $9,7(1,2)$ & $8,3(1,0)$ & $2,3(0,1)$ & $3,7(0,5)$ & $1,11(0,11)$ \\
\hline & 5 & $<4$ & $9,0(1,0)$ & $7,1(0,9)$ & $2,7(0,3)$ & $2,6(0,2)$ & $1,01(0,10)$ \\
\hline
\end{tabular}

*valores corresponde à amostra RJ-7502

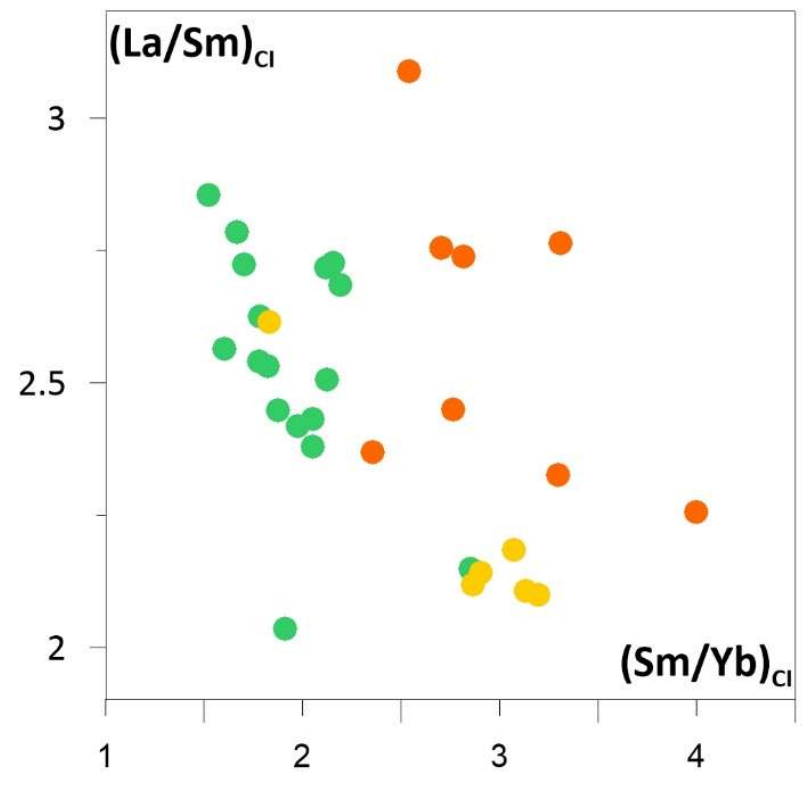

Figura 5.13 - Diagrama de razão dos elementos ETR normalizados pelo condrito Cl (McDonough \& Sun, 1995) dos grupos BTi, ATi-Lumiar e ATi. Grupo ATi: círculo cheio laranja; grupo ATi-Lumiar: círculo cheio amarelo; grupo BTi: círculo cheio verde. 
As Figuras 5.14 e 5.15 apresentam os diagramas multielementares de elementos incompatíveis (spiderdiagrams), normalizados em relação ao manto primordial (McDonough \& Sun, 1995), para os diques do grupo BTi e dos grupos ATi e ATi-Lumiar, respectivamente.

O grupo BTi (Figura 5.14) destaca-se por apresentar razões elevadas e bem variadas de $(\mathrm{Rb} / \mathrm{Ba})_{\mathrm{MP}}$ (entre 1,05 - 2,17; Tabela 5.2), com exceção da amostra QT-SV-1B $\left((\mathrm{Rb} / \mathrm{Ba})_{\mathrm{MP}}: 0,86\right)$, as quais indicam um significativo processo de assimilação crustal na evolução magmática (Marques et al., 2018). Esses diques exibem também anomalias negativas de $\mathrm{Nb}$ e Ta bastante significativas com as razões de (La/Nb) MP próximas a 2 (entre 1,15-2,32; Tabela 5.2) e destacadas anomalias negativas de Ti, [(Ti/Tb) ${ }_{M P}$, entre 0,54-1,08; (Ti/Y) MP entre 0,89-1,12] e de Sr. As diferenças nos padrões de abundância observadas para diferentes graus de evolução magmática reforçam que o processo foi dominantemente controlado pelo fracionamento de clinopiroxênio cálcico, acompanhado subordinadamente por plagioclásio e titanomagnetita. Considerando que o fracionamento mineral parece ter ocorrido simultaneamente ao processo de assimilação crustal, o processo evolutivo dos magmas que originaram esses diques foi provavelmente o AFC (Assimilation And Fractional Crystallization; DePaolo, 1981).

No geral, o comportamento das amostras do grupo BTi é condizente com os valores máximos e mínimos dos derrames Gramado, significativamente afetados por processos de contaminação crustal, para os três intervalos de evolução magmática considerados, apresentando poucas diferenças significativas, com exceção da amostra QT-SV-1B (Figura 5.14). As anomalias negativas de $\mathrm{Nb}$ e Ta observadas nos diques, como também nos derrames BTi da PMP, indicam uma possível contribuição de manto litosférico subcontinental metassomatizado, devido a antigos processos de subducção na gênese dessas rochas BTi (e.g. Rocha-Júnior et al., 2013).

Em relação aos grupos ATi-Lumiar e ATi (Figura 5.15 e Tabela 5.2), as razões $(\mathrm{Rb} / \mathrm{Ba})_{P M}$ (valores entre 0,82 - 1,00 para ATi-Lumiar e 0,45-0,86 para ATi) não sugerem uma assimilação crustal significativa na evolução magmática. Para a razão $(\mathrm{La} / \mathrm{Nb})_{\mathrm{MP}}$ (valores entre 1,02-1,42 para ATi-Lumiar e 1,36-1,87 para ATi), os valores apresentam-se levemente elevados, indicando, assim como no grupo BTi, uma contribuição de manto litosférico metassomatizado na origem destes grupos. Os diques do grupo ATi e ATi-Lumiar apresentam anomalias levemente negativas de Sr, sendo que 
no primeiro grupo, elas tendem a aumentar em função do grau de evolução magmática, reforçando o fracionamento de plagioclásio no processo. Diferentemente dos grupos BTi e ATi-Lumiar, anomalias levemente positivas de P são observadas nos diques ATi, especialmente para as amostras mais primitivas, sendo que a diminuição da concentração desse elemento, com a evolução magmática, indica o fracionamento de apatita.

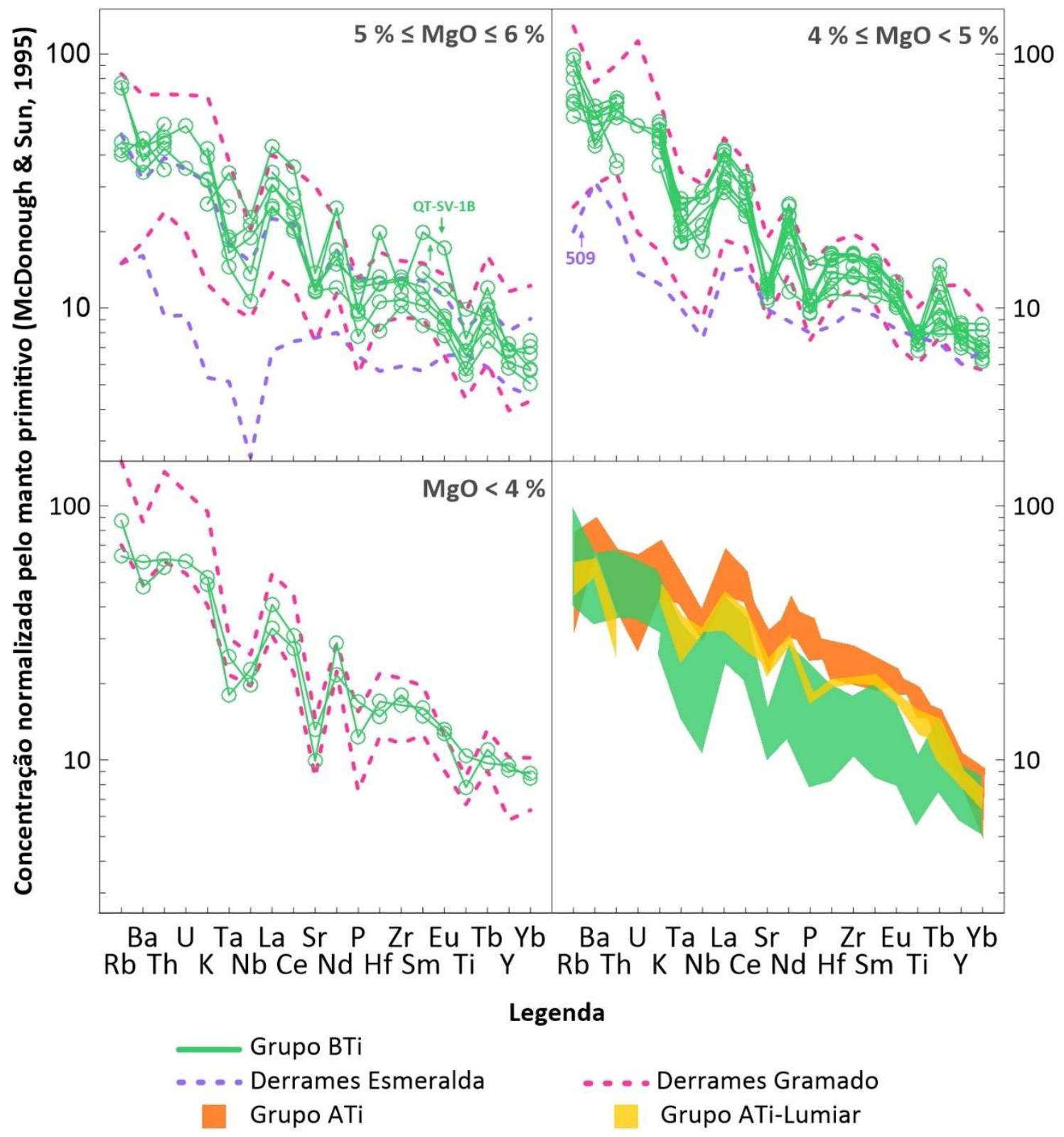

Figura 5.14 - Padrões de abundância dos elementos incompatíveis do grupo BTi de acordo com a diferenciação magmática (conteúdo de $\mathrm{MgO}$ ), juntamente com os valores máximos e mínimos dos derrames Esmeralda e Gramado (Marques et al., 1989; Peate, 1997) e com diques do grupo ATi e ATiLumiar. Análises da amostra 509 foi retirada de Marques et al. (1989). 
$\mathrm{Na}$ comparação com os derrames da PMP, observa-se forte similaridade nos padrões de abundância de elementos incompatíveis dos diques ATi com os derrames Pitanga, indicando origem em fonte mantélica com características geoquímicas similares. Os diques ATi-Lumiar, embora menos enriquecidos em elementos mais incompatíveis do que os ATi, apresentam também semelhanças com os derrames Pitanga, especialmente para os elementos HFS.

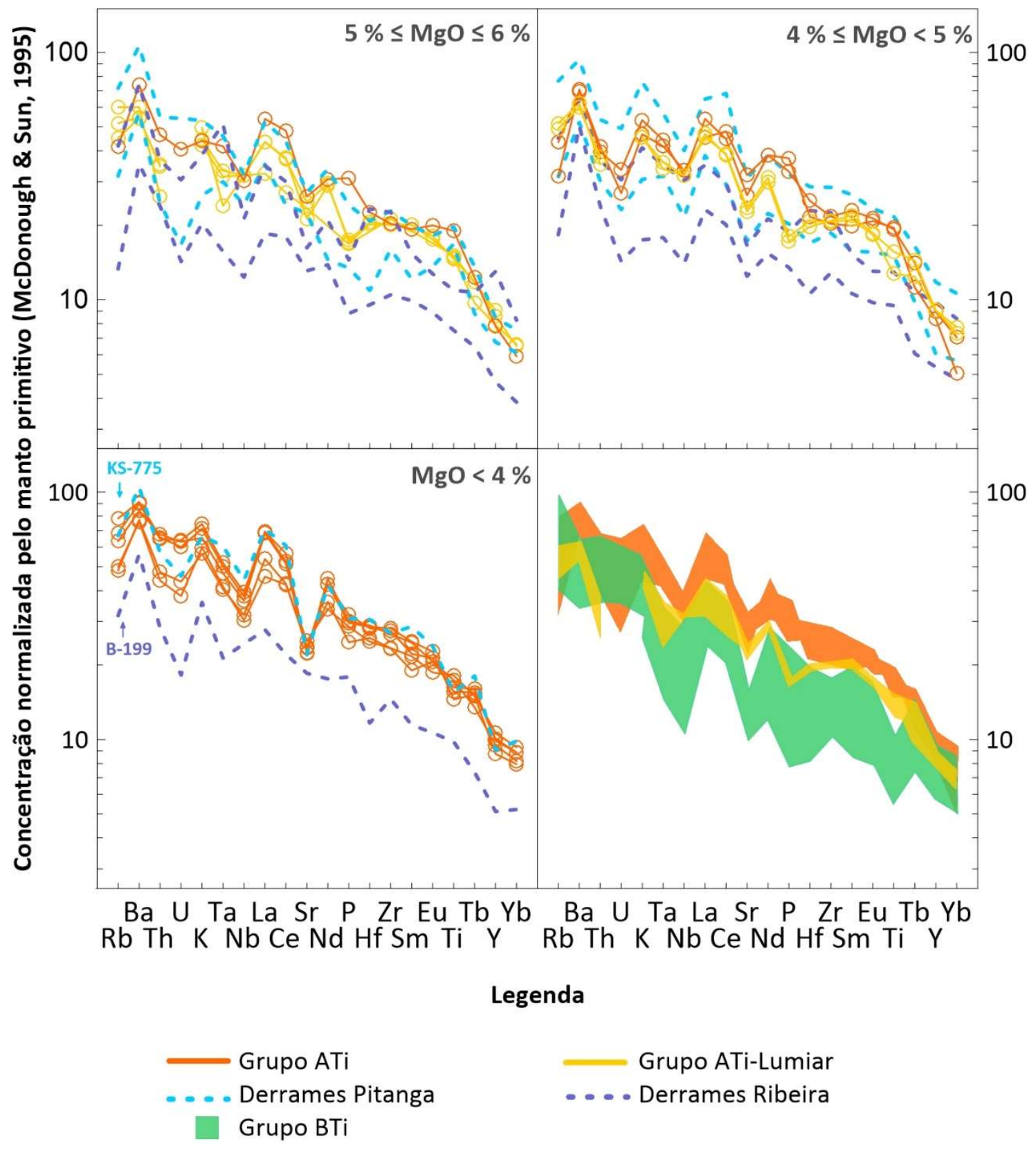

Figura 5.15 - Padrões de abundância dos elementos incompatíveis dos grupos ATi e ATi-Lumiar de acordo com a diferenciação magmática (conteúdo de $\mathrm{MgO}$ ), juntamente com os valores máximos e mínimos dos derrames Esmeralda e Gramado (Marques et al., 1989; Peate, 1997; Rocha-Júnior et al., 2013) e com diques do grupo BTi. Análises das amostras KS-775 e B-199 foram retiradas de Rocha-Júnior et al. (2013) de Marques et al. (1989), respectivamente. 
Tabela 5.2 - Valores médios e desvio padrão, entre parênteses, das razões $\mathrm{Rb} / \mathrm{Ba}, \mathrm{La} / \mathrm{Nb}, \mathrm{Ti} / \mathrm{Tb}$ e Ti/Y normalizados pelo manto primitivo ((McDonough \& Sun, 1995) para os três grupos de diques. O símbolo $\mathrm{N}$ corresponde ao número de amostras de diques pertencentes a cada conjunto.

\begin{tabular}{c|c|ccccc}
\hline Grupos & $\mathrm{N}$ & MgO $(\%)$ & $(\mathrm{Rb} / \mathrm{Ba})_{\mathrm{MP}}$ & $(\mathrm{La} / \mathrm{Nb})_{\mathrm{MP}}$ & $(\mathrm{Ti} / \mathrm{Tb})_{\mathrm{MP}}$ & $(\mathrm{Ti} / \mathrm{Y})_{\mathrm{MP}}$ \\
\hline \multirow{4}{*}{$\mathrm{BTi}$} & 17 & Todas & $1,4(0,4)$ & $1,7(0,4)$ & $0,77(0,18)$ & $0,98(0,07)$ \\
\cline { 2 - 7 } & 6 & $6-5$ & $1,4(0,5)$ & $1,8(0,5)$ & $0,75(0,18)$ & $0,98(0,09)$ \\
\cline { 2 - 7 } & 9 & $5-4$ & $1,4(0,4)$ & $1,6(0,4)$ & $0,75(0,17)$ & $0,97(0,07)$ \\
\cline { 2 - 7 } & 2 & $<4$ & $1,4(0,5)$ & $1,8(0,4)$ & $0,89(0,25)$ & $1,03(0,01)$ \\
\hline \multirow{3}{*}{ ATi- } & 6 & Todas & $0,88(0,07)$ & $1,3(0,2)$ & $1,3(0,2)$ & $1,7(0,2)$ \\
\cline { 2 - 7 } & 3 & $5-4$ & $0,92(0,09)$ & $1,3(0,2)$ & $1,4(0,2)$ & $1,8(0,2)$ \\
\hline \multirow{4}{*}{ ATi } & 3 & $<4$ & $0,84(0,02)$ & $1,4(0,2)$ & $1,2(0,2)$ & $1,6(0,2)$ \\
\hline & 8 & Todas & $0,66(0,13)$ & $1,7(0,2)$ & $1,3(0,3)$ & $1,9(0,4)$ \\
\cline { 2 - 7 } & 1 & $6-5 *$ & 0,56 & 1,8 & 1,5 & 2,4 \\
\cline { 2 - 7 } & 2 & $5-4$ & $0,53(0,12)$ & $1,5(0,2)$ & $1,6(0,3)$ & $2,2(0,1)$ \\
\hline
\end{tabular}

*valores corresponde à amostra RJ-7502

\subsubsection{Isótopos de Sr e Nd}

Em conjunto com as cinco amostras de diques da Suíte Serrana, estão inclusas nas análises isotópicas oito amostras de Marques (2001) e dados inéditos de diques coletados na mesma região (Figura 3.1). Com isso, ao todo são treze amostras com determinações de isótopos de $\mathrm{Sr}$ e $\mathrm{Nd}$, sendo oito pertencentes ao grupo BTi e cinco, ao grupo ATi. Na análise dos resultados, foram também incorporados, para comparação e discussão petrogenética, os resultados das análises de diques BTi e ATi reportados por Corval (2009), situados na Região Serrana do Rio de Janeiro.

Para o grupo BTi, os resultados variam no intervalo $0,706947 \leq{ }^{87} \mathrm{Sr}^{86} \mathrm{Sr}_{130} \leq$ 0,710273 (média: 0,7098 $\pm 0,0010$ ), e para o ATi, concentram-se no intervalo 0,705666 $\leq{ }^{87} \mathrm{Sr}^{86}{ }^{\mathrm{S}} \mathrm{r}_{130} \leq 0,706255$ (média: 0,70590 $\pm 0,00029$ ). Em relação às análises isotópicas de $\mathrm{Nd}$, para o grupo BTi os resultados estão nos intervalos $0,512099 \leq{ }^{143} \mathrm{Nd} /{ }^{144} \mathrm{Nd}_{130} \leq$ 0,512300 (média: 0,512214 $\pm 0,000055$ ), e para ATi, no intervalo 0,512281 $\leq$ ${ }^{143} \mathrm{Nd} /{ }^{144} \mathrm{Nd}_{130} \leq 0,512351$ (média: 0,512281 $\pm 0,000032$ ). O diagrama ${ }^{143} \mathrm{Nd} /{ }^{144} \mathrm{Nd}_{130}$ vs. ${ }^{87} \mathrm{Sr} /{ }^{86} \mathrm{Sr}_{130}$ (Figura 5.16) apresenta como as razões isotópicas iniciais de $\mathrm{Sr}$ do grupo BTi são bem mais radiogênicas e apresentam variação bem maior do que aquelas dos diques do ATi, cujos valores não ultrapassam 0,706255. 


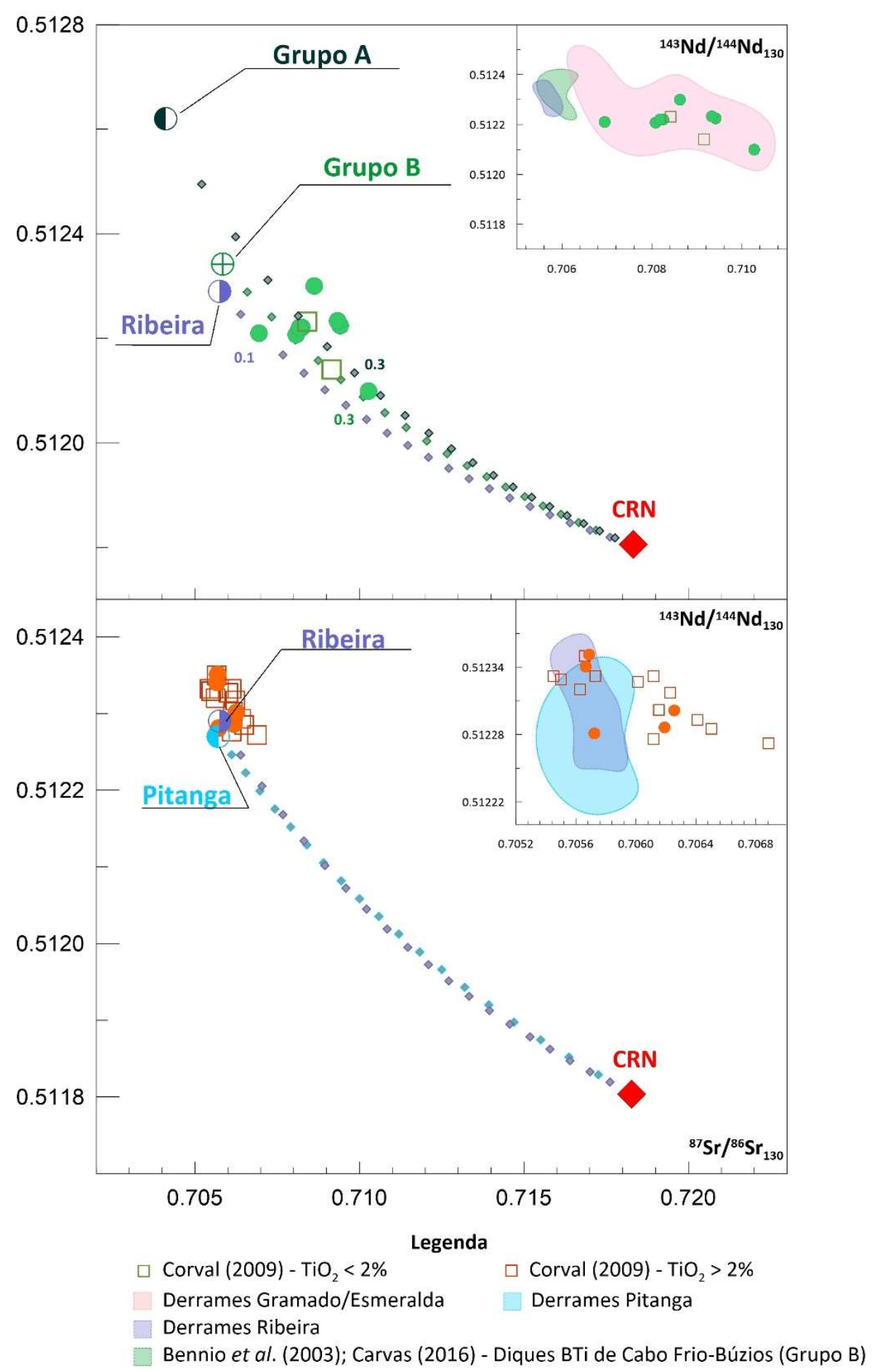

Figura 5.16 - Diagrama das razões isotópicas iniciais de Sr e Nd para os diques dos grupos BTi e ATi. Grupo ATi: círculo cheio laranja; grupo BTi: círculo cheio verde; CRN: média das concentrações e das razões isotópicas de Sr e Nd das rochas mais radiogênicas do Complexo Rio Negro (Peixoto et al., 2017) conforme Tabela 5.3. As linhas pontilhadas correspondem às curvas dos modelos de evolução magmática do tipo mistura entre os componentes basálticos [diques do Grupo B de Cabo Frio, os derrames BTi (Ribeira, Esmeralda e Gramado) e ATi (Pitanga) da PMP] e crustais (CRN). Os valores ao lado das linhas de mistura correspondem ao percentual do componente crustal em cada mistura. Os campos referentes aos derrames da PMP e aos diques BTi do Grupo B de Cabo Frio-Búzios (Bennio et al., 2003; Carvas, 2016) são também mostrados. Grupo ATi: círculo cheio laranja; grupo BTi: círculo cheio verde. 
As razões isotópicas iniciais de $\mathrm{Nd}$ dos grupos BTi e ATi são inversamente correlacionadas com as de Sr e concordantes com os resultados obtidos por Corval (2009), conforme pode ser observado na Figura 5.16. Este comportamento é compatível com um processo de evolução envolvendo contaminação crustal, especialmente nos diques $\mathrm{BTi}$, como também sugerido na análise de elementos incompatíveis. Nota-se também que os diques BTi caem no campo dos derrames Esmeralda/Gramado, sendo que o dique menos evoluído (LMD-RJ-8018; MgO: 6,25\%) plota próximo ao campo dos derrames Ribeira (Marques et al., 1999; Rocha-Júnior et al., 2020) da PMP e aos diques BTi de Cabo Frio-Búzios (Grupo B; Bennio et al., 2003; Carvas, 2016) da Região dos Lagos, cujo local de ocorrência não é muito distante dos diques investigados. Por outro lado, o grupo ATi situa-se no campo dos derrames Pitanga (Piccirillo \& Melfi, 1988; Marques et al., 1999), exceto por uma amostra analisada Corval (2009), que cai no campo Esmeralda/Gramado $\left({ }^{87} \mathrm{Sr} /{ }^{86} \mathrm{Sr}_{130}>0,7068\right)$.

Os dados isotópicos mostram que os grupos BTi e ATi possuem assinaturas bem distintas e foram originados em fontes mantélicas similares aos diques do Grupo B e Pitanga, respectivamente, e afetados por processos de diferenciação distintos, principalmente no que se refere ao grau de envolvimento da crosta continental.

\subsection{Processo de cristalização fracionada}

O modelo de balanço de massa pode contribuir na averiguação da ocorrência de processos como cristalização fracionada, assimilação crustal, fusão parcial e misturas simples na evolução magmática de um conjunto de rochas ígneas. Para a determinação dos percentuais de cada fase mineral fracionada para o conjunto de diques BTi, utilizouse a equação do balanço de massa aplicada para os elementos maiores e menores, na forma de óxidos (Stormer Jr. \& Nicholls, 1978; Albarède, 1996).

O cálculo do balanço de massa baseia-se na equação que envolve a fase fracionada (sólida) e a fase remanescente (líquida) em um sistema conservativo e fechado. Considerando que a soma das frações líquida $\left(f_{L}\right)$ e sólida $\left(f_{S}\right)$ são iguais a 1 e as fases representadas como porcentagem dos minerais fracionados, tem-se a equação 5.2.

$$
\frac{C_{0}^{i}-C_{L}^{i}\left(1-f_{S}\right)}{f_{S}}=C_{1}^{i} X_{1}+C_{2}^{i} X_{2}+\cdots
$$


onde $C_{0}^{i}$ consiste na concentração do óxido $i$ no magma inicial, $C_{L}^{i}$ na concentração do óxido $i$ no magma final, $C_{1}^{i}$ na concentração do óxido $i$ no mineral fracionado 1 e $X_{1}$ na fração do mineral 1 fracionado (sólido fracionado). $O$ valor de $f_{S}$ é obtido pelo método de mínimos quadrados (Stormer Jr. \& Nicholls, 1978).

Em conclusão, a concentração de cada óxido no magma final $\left(C_{L}^{i}\right)$, normalizada a $100 \%$, é obtida pela subtração do magma inicial $\left(C_{0}^{i}\right)$ apresentado na equação 5.3 , com $m$ correspondendo ao número de óxidos presentes nas rochas ígneas (Albarède, 1996).

$$
C_{L}^{i *}=\frac{C_{0}^{i}-\sum_{j=1}^{n} C_{j}^{i} X_{j} f_{S}}{\sum_{i=1}^{m} C_{L}^{i}} 100
$$

Os cálculos do balanço de massa realizados neste estudo basearam-se no software XLFRAC de Stormer Jr. \& Nichols (1978).

Para averiguar a viabilidade do processo de cristalização fracionada indicado pelo balanço de massa dos óxidos, usam-se as concentrações de elementos traços, sensíveis nos processos de cristalização fracionada, conforme descrito na Lei de Fracionamento de Rayleigh (Albarède, 1996), dada pela equação 5.1.

Os valores $C_{L}^{i}$ calculados são comparados com os valores das concentrações observadas através da determinação dos erros relativos para os elementos traço determinados neste estudo. As médias dos valores absolutos dos erros relativos $(\overline{E R})$ foram consideradas como índices para averiguação da qualidade dos ajustes dos elementos traço no processo de cristalização fracionada.

\subsubsection{Aplicação dos cálculos do balanço de massa aos diques investigados}

A possibilidade de diferenciação por cristalização fracionada nos diques investigados foi testada empregando os cálculos de balanço de massa, conforme anteriormente descrito. Para a composição das fases minerais fracionadas, utilizaramse análises representativas de óxidos de elementos maiores e menores, as quais foram determinadas por microssonda eletrônica em fenocristais e microfenocristais de augita, pigeonita, plagioclásio e magnetita, que ocorrem em diques BTi e ATi desse mesmo enxame (Bellieni, dados não publicados; Apêndice D). Os valores de coeficientes de partição $\left(K_{D}\right)$ utilizados foram retirados de Marques (1988; Apêndice E). Para a 
composição de olivina, foram utilizadas análises de Fo-80 (diques com MgO > 6\%) e Fo75 (diques com 4\% < MgO < 6\%), cujos dados foram retirados de Deer et al. (1982). A composição de apatita foi retirada de Deer et al. (1982).

Nas tabelas 5.3, 5.4 e 5.5 estão apresentados os resultados que forneceram os melhores ajustes, ou seja, aqueles com baixa somatória dos quadrados dos resíduos $(\Sigma$ res $^{2}$ ) e com porcentagens das fases cristalizadas compatíveis ao que foi observado nos estudos petrográficos (Ludka, 1997; Corval et al., 2008; Corval, 2009) para os grupos BTi ATi-Lumiar e ATi, respectivamente.

Como pode ser observado na tabela 5.3, para os diques BTi bons resultados foram obtidos na diferenciação entre as rochas mais primitivas $\left(\Sigma \operatorname{res}^{2}<0,67\right)$. No entanto, as passagens para as rochas mais evoluídas o ajuste foi bem pior $\left(\Sigma \mathrm{res}^{2}>1\right)$, e em algumas delas, a quantidade fracionada de pigeonita foi muito alta, sendo incompatível com petrografia. Cabe ainda destacar, que muitos testes apresentaram ótimos valores de $\Sigma$ res $^{2}$, mas foram descartados devido ao fato de ocorrer adição, ao invés de subtração, de plagioclásio ao sistema. Esses resultados são indicativos de que embora a cristalização fracionada tenha sido importante na diferenciação magmática, o processo não ocorreu em sistema fechado, como evidenciado nos diagramas que mostram o comportamento de elementos traço incompatíveis.

Diferentemente dos diques $\mathrm{BTi}$, ajustes muito bons foram obtidos nos cálculos de balanço de massa para a evolução diques e ATi-Lumiar e ATi, conforme pode ser observado nas Tabelas 5.4 e 5.5, respectivamente. Os baixos valores de $\Sigma$ res $^{2}$, que somente em duas passagens ficaram acima de 0,5, indicam que a cristalização fracionada pode ser considerada como o mecanismo principal na diferenciação desses diques, com pouca influência de processos de contaminação crustal. 
Tabela 5.3. - Resultados dos melhores ajustes obtidos na aplicação do modelo de cristalização fracionada para os diques do grupo BTi. Ol: olivina; Cpx: augita; Pig: pigeonita; PI: plagioclásio; Mt: magnetita. Mcristalizada: massa cristalizada; $\overline{E R}$ : erro relativo.

\begin{tabular}{|c|c|c|c|c|c|c|c|c|c|}
\hline \multicolumn{2}{|c|}{ Diferenciação } & \multicolumn{5}{|c|}{ Fases fracionadas } & \multirow{2}{*}{ M $_{\text {cristalizada }}(\%)$} & \multirow{2}{*}{$\sum \operatorname{res}^{2}$} & \multirow{2}{*}{$\overline{E R}(\%$} \\
\hline Magma inicial & Magma final & Ol (\%) & Cpx (\%) & Pig (\%) & PI (\%) & $\mathrm{Mt}(\%)$ & & & \\
\hline $\begin{array}{l}\text { LMD-RJ-8018 } \\
\text { (MgO: 6,25\%) }\end{array}$ & $\begin{array}{l}\text { LMD-RJ-8004 } \\
\text { (MgO: 4,88\%) }\end{array}$ & 0,000 & 28,384 & 19,902 & 51,713 & 0,000 & 35,092 & 0,387 & 19,5 \\
\hline $\begin{array}{l}\text { LMD-RJ-8004 } \\
\text { (MgO: 4,88\%) }\end{array}$ & $\begin{array}{l}\text { LMD-RJ-8019A } \\
\text { (MgO: 4,73\%) }\end{array}$ & 0,000 & 41,250 & 0,000 & 47,196 & 11,553 & 11,872 & 0,039 & 23,2 \\
\hline $\begin{array}{l}\text { LMD-RJ-8019A } \\
\text { (MgO: 4,73\%) }\end{array}$ & $\begin{array}{c}\mathrm{RJ}-7510 \\
(\mathrm{MgO}: 3,22 \%)^{*}\end{array}$ & 0,000 & 45,882 & 50,434 & 0,000 & 3,684 & 12,830 & 1,038 & 16,8 \\
\hline $\begin{array}{l}\text { LMD-RJ-8018 } \\
\text { (MgO: 6,25\%) }\end{array}$ & $\begin{array}{c}\text { QT-SV-6A } \\
\text { (MgO: 5,04\%) }\end{array}$ & 0,000 & 33,089 & 16,084 & 50,827 & 0,000 & 33,675 & 0,306 & 21,0 \\
\hline $\begin{array}{c}\text { QT-SV-6A } \\
\text { (MgO: 5,04\%) }\end{array}$ & $\begin{array}{l}\text { LMD-RJ-8005A } \\
\text { (MgO: 4,69\%) }\end{array}$ & 0,000 & 51,661 & 2,702 & 39,506 & 6,130 & 9,138 & 0,111 & 11,6 \\
\hline $\begin{array}{l}\text { LMD-RJ-8005A } \\
\text { (MgO: 4,69\%) }\end{array}$ & $\begin{array}{c}\mathrm{RJ}-7511 \\
(\mathrm{MgO}-4,27 \%)^{* *}\end{array}$ & 0,000 & 20,759 & 66,885 & 0,000 & 12,356 & 5,514 & 1,242 & 16,4 \\
\hline $\begin{array}{c}\text { RJ-7511 } \\
\text { (MgO: } 4,27 \%)\end{array}$ & $\begin{array}{c}\mathrm{RJ}-7510 \\
(\mathrm{MgO}: 3,22)^{* * *}\end{array}$ & 0,000 & 37,164 & 42,947 & 14,261 & 5,628 & 8,373 & 0,015 & 3,6 \\
\hline
\end{tabular}

*resíduo alto, sem fracionamento de plagioclásio e muito fracionamento de pigeonita

** resíduo alto e muito fracionamento de pigeonita

*** muito fracionamento de pigeonita 
Tabela 5.3 (Continuação) - Resultados dos melhores ajustes obtidos na aplicação do modelo de cristalização fracionada para os diques do grupo BTi. Ol: olivina; Cpx: augita; Pig: pigeonita; PI: plagioclásio; Mt: magnetita. Mcristalizada: massa cristalizada; $\overline{E R}$ : erro relativo.

\begin{tabular}{|c|c|c|c|c|c|c|c|c|c|}
\hline \multicolumn{2}{|c|}{ Diferenciação } & \multicolumn{5}{|c|}{ Fases fracionadas } & \multirow{2}{*}{$\mathbf{M}_{\text {cristalizada }}(\%)$} & \multirow{2}{*}{ Sres $^{2}$} & \multirow{2}{*}{$\overline{E R}(\%)$} \\
\hline Magma inicial & Magma final & Ol (\%) & Cpx (\%) & Pig (\%) & $\mathrm{PI}(\%)$ & Mt (\%) & & & \\
\hline $\begin{array}{l}\text { LMD-RJ-8018 } \\
\text { (MgO: 6,25\%) }\end{array}$ & $\begin{array}{l}\text { LMD-RJ-8006 } \\
\text { (MgO: 4,85\%) }\end{array}$ & 6,642 & 41,062 & 0,000 & 52,296 & 0,000 & 29,915 & 0,481 & $-* *$ \\
\hline $\begin{array}{l}\text { LMD-RJ-8006 } \\
\text { (MgO: 4,85\%) }\end{array}$ & $\begin{array}{c}\text { LMD-RJ-8019A } \\
\text { (MgO: 4,73\%) }\end{array}$ & 0,000 & 32,251 & 5,655 & 48,515 & 13,579 & 7,932 & 0,007 & $-* *$ \\
\hline $\begin{array}{l}\text { LMD-RJ-8019A } \\
\text { (MgO: 4,73\%) }\end{array}$ & $\begin{array}{l}\text { LMD-RJ-8005A } \\
\text { (MgO: 4,69\%) }\end{array}$ & 0,000 & 89,747 & 0,000 & 10,253 & 0,000 & 1,911 & 0,666 & 10,4 \\
\hline $\begin{array}{l}\text { LMD-RJ-8018 } \\
\text { (MgO: 6,25\%) }\end{array}$ & $\begin{array}{l}\text { LMD-RJ-8017 } \\
\text { (MgO: 5,81\%) }\end{array}$ & 7,741 & 43,637 & 0,000 & 48,633 & 0,000 & 9,386 & 0,091 & 8,1 \\
\hline $\begin{array}{l}\text { LMD-RJ-8017 } \\
\text { (MgO: 5,81\%) }\end{array}$ & $\begin{array}{l}\text { LMD-RJ-8004 } \\
\text { (MgO: 4,88\%) }\end{array}$ & 7,672 & 36,458 & 0,000 & 55,870 & 0,000 & 20,430 & 0,522 & 9,1 \\
\hline $\begin{array}{l}\text { LMD-RJ-8004 } \\
\text { (MgO: 4,88\%) }\end{array}$ & $\begin{array}{l}\text { LMD-RJ-8006 } \\
\text { (MgO: 4,85\%) }\end{array}$ & 0,000 & 46,426 & 0,000 & 46,176 & 7,398 & 4,852 & 0,042 & $-* *$ \\
\hline $\begin{array}{c}\text { QT-SV-1B } \\
\text { (MgO: 6,19\%) }\end{array}$ & $\begin{array}{c}\text { QT-SV-2D } \\
\text { (MgO: } 4,98 \%)^{*}\end{array}$ & 0,000 & 80,320 & 15,194 & 0,000 & 4,486 & 12,705 & 0,223 & 58,1 \\
\hline $\begin{array}{c}\text { QT-SV-2D } \\
\text { (MgO: 4,98\%) }\end{array}$ & $\begin{array}{c}\text { RJ-7510 } \\
\text { (MgO: 3,22\%) }\end{array}$ & 0,000 & 30,282 & 11,505 & 50,636 & 7,576 & 43,694 & 0,203 & 19,5 \\
\hline
\end{tabular}

*sem fracionamento de plagioclásio

** não analisada por INAA 
Tabela 5.4 - Resultados dos melhores ajustes obtidos na aplicação do modelo de cristalização fracionada para os diques do grupo ATi-Lumiar. Ol: olivina; Cpx: augita; Pig: pigeonita; PI: plagioclásio; Mt: magnetita; Ap: apatita. Mcristalizada: massa cristalizada; $\overline{E R}$ : erro relativo.

\begin{tabular}{|c|c|c|c|c|c|c|c|c|c|c|}
\hline \multicolumn{2}{|c|}{ Diferenciação } & \multicolumn{6}{|c|}{ Fases fracionadas } & \multirow{2}{*}{ M cristalizada (\%) } & \multirow{2}{*}{$\sum$ res $^{2}$} & \multirow{2}{*}{$\overline{E R}(\%)$} \\
\hline Magma inicial & Magma final & OI (\%) & Cpx (\%) & Pig (\%) & $\mathrm{PI}(\%)$ & $\mathrm{Mt}(\%)$ & Ap (\%) & & & \\
\hline $\begin{array}{l}\text { LMD-8014A } \\
\text { (MgO: 5,31\%) }\end{array}$ & $\begin{array}{c}\text { QT-SV-2A } \\
\text { (MgO: } 5,05 \%)\end{array}$ & 0,000 & 31,707 & 13,338 & 38,482 & 16,473 & 0,000 & 10,665 & 0,069 & 8,2 \\
\hline $\begin{array}{c}\text { QT-SV-2A } \\
\text { (MgO: } 5,05 \%)\end{array}$ & $\begin{array}{c}\text { QT-SV-4A } \\
\text { (MgO: 5,03\%) }\end{array}$ & 0,000 & 36,489 & 0,000 & 63,511 & 0,000 & 0,000 & 8,318 & 0,579 & 10,4 \\
\hline
\end{tabular}

Tabela 5.5 - Resultados dos melhores ajustes obtidos na aplicação do modelo de cristalização fracionada para os diques do grupo ATi. Ol: olivina; Cpx: augita; Pig: pigeonita; PI: plagioclásio; Mt: magnetita; Ap: apatita. Mcristalizada: massa cristalizada; $\overline{E R}$ : erro relativo.

\begin{tabular}{|c|c|c|c|c|c|c|c|c|c|c|}
\hline \multicolumn{2}{|c|}{ Diferenciação } & \multicolumn{6}{|c|}{ Fases fracionadas } & \multirow{2}{*}{ M cristalizada $(\%)$} & \multirow{2}{*}{ Lres ${ }^{2}$} & \multirow{2}{*}{$\overline{E R}(\%)$} \\
\hline Magma inicial & Magma final & OI (\%) & Cpx (\%) & Pig (\%) & $\mathrm{PI}(\%)$ & $\mathrm{Mt}(\%)$ & Ap (\%) & & & \\
\hline $\begin{array}{c}\text { RJ-7500 } \\
\text { (MgO: } 4,89 \%)\end{array}$ & $\begin{array}{c}\text { RJ-7508 } \\
\text { (MgO: } 4,06 \%)\end{array}$ & 0,000 & 46,646 & 7,731 & 34,647 & 8,751 & 2,225 & 13,701 & 0,253 & 14,2 \\
\hline $\begin{array}{c}\text { RJ-7508 } \\
\text { (MgO: } 4,06 \%)\end{array}$ & $\begin{array}{c}\text { RJ-7506 } \\
\text { (MgO: } 3,58 \%)\end{array}$ & 0,000 & 17,451 & 7,774 & 62,175 & 11,905 & 0,695 & 38,610 & 0,868 & 9,9 \\
\hline $\begin{array}{c}\text { RJ-7506 } \\
\text { (MgO: } 3,58 \%)\end{array}$ & $\begin{array}{c}\text { RJ-7509 } \\
\text { (MgO: } 2,68 \%)\end{array}$ & 0,000 & 50,302 & 18,900 & 21,581 & 9,217 & 0,000 & 9,949 & 0,125 & 11,1 \\
\hline
\end{tabular}


Em geral, as passagens apresentadas indicam ajustes de traço bons $(\overline{E R}<15 \%)$ e razoáveis $(15 \%<\overline{E R}<20 \%)$ para os três grupos de diques. Apenas três ajustes para o grupo BTi foram considerados ruins $(\overline{E R}>20 \%)$, destacando a passagem da QT-SV-1B para QT-SV-2D sem o fracionamento de plagioclásio. Para os cálculos dos ajustes, desconsideram as concentrações calculadas para $\mathrm{Cr}$, Ni e Ta, pois afastaram-se bastante dos valores observados. Tal comportamento dos dois primeiros pode ser devido a possível presença de sulfetos. Enquanto o do Ta, pode estar associado as incertezas altas (duas amostras) na determinação desse elemento, conforme mencionado no capítulo 4.

\subsection{Contaminação crustal}

O processo de contaminação crustal refere-se a diversos mecanismos possíveis de interação entre as rochas crustais e os magmas derivados das fontes mantélicas, dependentes da quantidade de calor disponível na câmara magmática (Sparks, 1986). A ascensão do magma em condutos semelhantes a diques, usualmente, é controlada pela natureza do fluxo. Para fluxo laminar, o magma solidifica nas paredes da rocha crustal encaixante, prevenindo uma contaminação significativa. Entretanto, caso o fluxo seja turbulento, os produtos da fusão parcial de rochas encaixantes são continuamente carregados pelo movimento convectivo, propiciando a assimilação ao longo da ascensão. Para o movimento convectivo, estima-se que a largura do dique deve ser de pelo menos 3 metros (Campbell, 1985; Wilson, 1989).

Em geral, o processo de contaminação envolve rochas crustais com temperaturas de fusão baixa, ou seja, preferencialmente rochas com proporções altas de feldspato alcalino ou plagioclásio sódico (Wilson, 1989). Para magmas basálticos, as características gerais da assimilação crustal consistem no enriquecimento do magma em $\mathrm{SiO}_{2}$, elementos traço incompatíveis de grande raio iônico e nas razões ${ }^{87} \mathrm{Sr} /{ }^{86} \mathrm{Sr}$ e no empobrecimento nas razões ${ }^{143} \mathrm{Nd} /{ }^{144} \mathrm{Nd}$ (Campbell, 1985).

A Figura 5.17 apresenta as correlações significativas entre $\mathrm{SiO}_{2}, \mathrm{~K}_{2} \mathrm{O}, \mathrm{Rb}, \mathrm{Ba}$, Th, $\mathrm{La}$ e Zr em função das razões isotópicas iniciais de Sr. Para os dois grupos, especialmente BTi, ocorreu processo de contaminação crustal, cujo grau aumentou progressivamente com a diferenciação magmática, promovendo enriquecimento acentuado das concentrações dos elementos Th e Rb. Embora os elementos maiores e menores sejam menos sensíveis aos processos de assimilação, nota-se aumento de $\mathrm{SiO}_{2}$ e $\mathrm{K}_{2} \mathrm{O}$, além de 
forte diminuição das razões $\mathrm{P}_{2} \mathrm{O}_{5} / \mathrm{K}_{2} \mathrm{O}$ para o grupo $\mathrm{BTi}$, com o aumento das razões isotópicas iniciais de Sr. Os grupos BTi e ATi permanecem distinguíveis e, em comparação aos derrames da PMP, apresentam comportamentos similares ao Gramado e Pitanga, respectivamente. Os dados reportados por Corval (2009) dos diques da Região Serrana apresentam comportamentos semelhantes aos grupos correspondentes aos das amostras investigadas, porém os diques ATi, embora possuam certo espalhamento, são mais enriquecidos em elementos traço incompatíveis, como por exemplo Rb e La, do que os diques do grupo ATi aqui investigados. Desta forma, diferentemente dos derrames Pitanga, os dados de Corval (2009), juntamente com os do presente estudo, constituem uma evidência de que os diques ATi do ESM também foram afetados por processos de contaminação crustal.

Apesar do certo grau de espalhamento nos diagramas da Figura 5.18, observa-se o aumento das razões ( $\mathrm{Rb} / \mathrm{Ba})_{\mathrm{PM}}$ e Th/Nb em função do aumento das razões isotópicas iniciais de Sr em cada um dos grupos investigados. Ressalta-se, ainda, que todos os diques do grupo BTi apresentam razões $(\mathrm{Rb} / \mathrm{Ba})_{\mathrm{PM}}$ superiores 1 , similares àquelas dos derrames Gramado, fortemente afetados pela contaminação crustal. Em contrapartida, a grande maioria dos diques ATi apresenta as razões inferiores a 1, caraterística associada também aos derrames Ribeira e Pitanga, presentes na subprovíncia norte da PMP, os quais não mostram evidências de contaminação da crosta continental (Marques et al., 1989, 2018; Peate, 1997; Rocha-Júnior et al., 2013, 2020). 

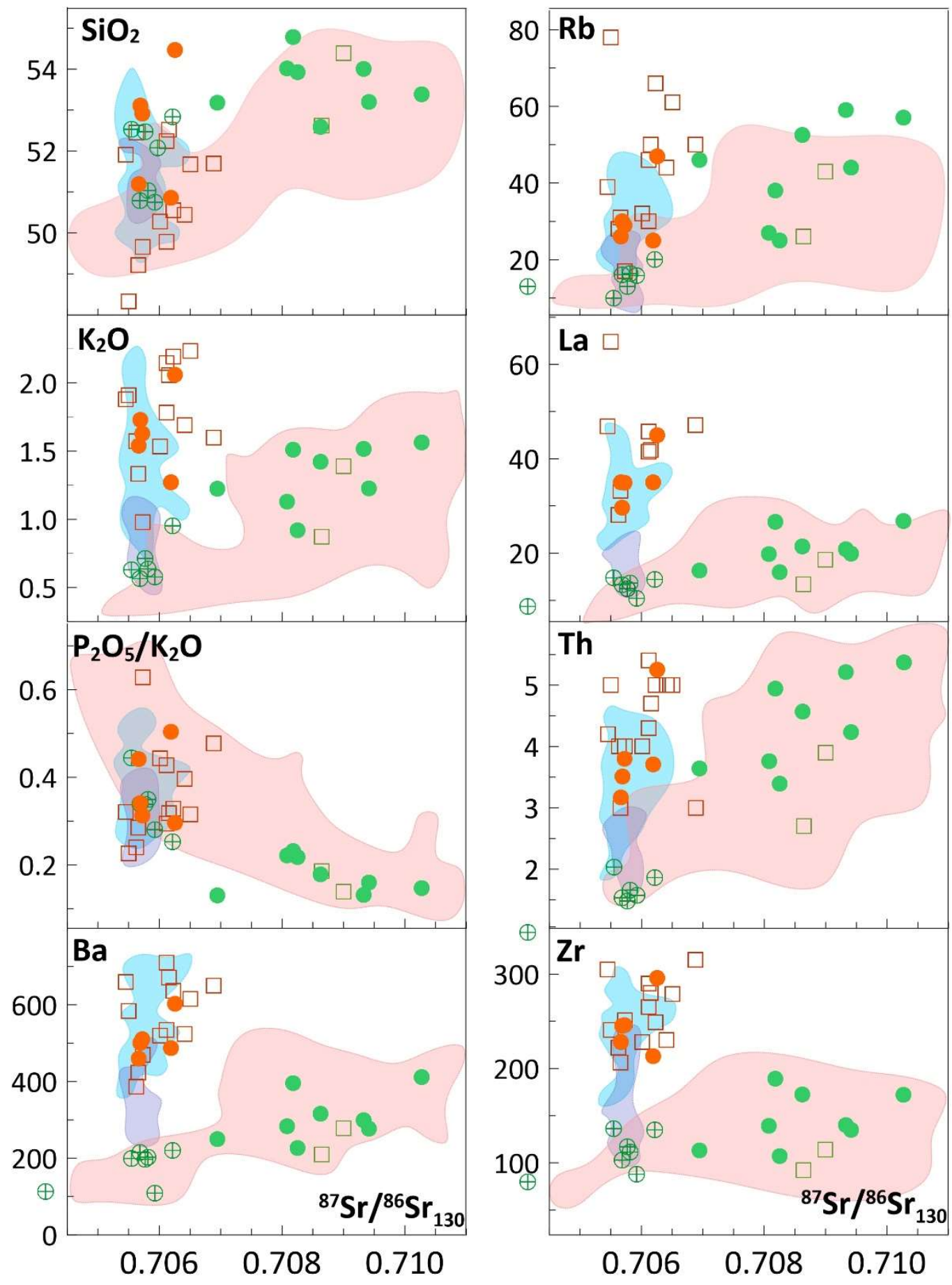

Corval (2009) - $\mathrm{TiO}_{2}<2 \%$

Corval (2009) - $\mathrm{TiO}_{2}>2 \%$

$\oplus$ Bennio et al. (2003); Carvas (2016)- Diques BTi de Cabo Frio-Búzios (Grupo B) Derrames Gramado/Esmeralda Derrames Ribeira

Figura 5.17 - Diagrama de elementos maiores $\left(\mathrm{SiO}_{2}\right.$ e $\left.\mathrm{P}_{2} \mathrm{O}_{5} / \mathrm{K}_{2} \mathrm{O}\right)$ e alguns traço $(\mathrm{Rb}, \mathrm{Ba}$, Th, $\mathrm{La}$ e $\mathrm{Zr}$ ) em função da razão isotópica inicial de Sr. Elementos maiores em \% e traço em $\mathrm{mg} / \mathrm{kg}$; grupo ATi: círculo cheio laranja; grupo BTi: círculo cheio verde. 

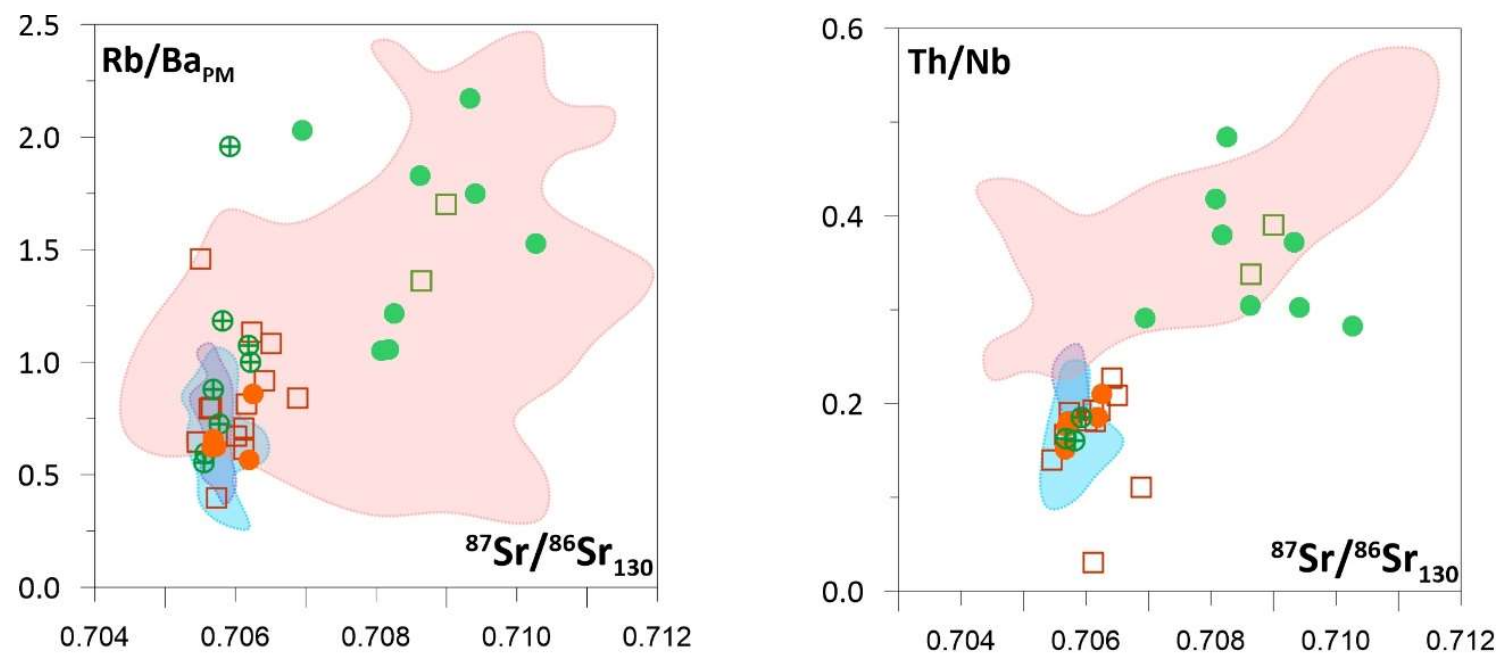

Legenda

Corval (2009) - $\mathrm{TiO}_{2}<2 \%$

Corval (2009) - $\mathrm{TiO}_{2}>2 \%$

$\oplus$ Bennio et al. (2003); Carvas (2016) - Diques BTi de Cabo Frio-Búzios (Grupo B)

Derrames Gramado/Esmeralda

Derrames Pitanga

Derrames Ribeira

Figura 5.18 - Diagramas das razões de Rb/Ba, normalizada pelo manto primitivo (McDonough \& Sun, 1995), e de Th/Nb em função das razões iniciais de Sr. Grupo ATi: círculo cheio laranja; grupo BTi: círculo cheio verde.

\subsubsection{Investigação da ocorrência de processos de mistura}

Em alguns processos geológicos, as concentrações geoquímicas e isotópicas resultantes de uma contaminação podem estar relacionadas a modelos simples de mistura (mixing), onde o processo é considerado conservativo, como exemplo a mistura do magma derivado de fonte mantélica com rochas da crosta continental. O processo de mistura simples envolvendo dois componentes (end-members) é representado pelo parâmetro de mistura $f$, definido como proporção de peso entre os dois componentes, por exemplo A e B, e calculado pelas equações 5.4 e 5.5 (Faure \& Mensing, 2005).

$$
\begin{gathered}
f_{A}=\frac{A}{A+B} \\
f_{B}=\frac{B}{A+B}
\end{gathered}
$$


onde $f_{A} r$ à refere-se à fração de massa do componente $A$ na mistura, $f_{B}$ refere-se à abundância do componente $\mathrm{B}$ na mistura e, por fim, $A$ e $B$ consistem nas concentrações componentes A e B, respectivamente, para um determinado elemento e/ou razão isotópica. A soma de $f_{A}$ e $f_{B}$ corresponde a 1.

Deste modo, quando o sistema é conservativo para um elemento $i$ de concentração $C_{i}$, a mistura resultante é obtida pela equação 5.6 (Faure \& Mensing, 2005).

$$
C_{i, M}=C_{i, A} f_{A}+C_{i, B}\left(1-f_{A}\right)
$$

onde $C_{i, M}$ corresponde à concentração do elemento $i$ na mistura $M, C_{i, A}$ e $C_{i, B}$ correspondem às concentrações do elemento $i$ nos componentes $A$ e $B$, respectivamente. Nos diagramas binários de elementos, os processos de mistura simples alinham-se a retas unindo os pares de end-members.

Para a mistura isotópica $\mathrm{Sr}-\mathrm{Nd}$, as concentrações e razões isotópicas de Sr e $\mathrm{Nd}$ dos componentes A e B são relacionadas pela equação 5.7, para valores selecionados de $f_{A}$ $(0 ; 0,05 ; 0,10 ; 0,15 \ldots)$ (Faure \& Mensing, 2005).

$$
\varepsilon_{M}=\frac{\varepsilon_{A} f_{A} C_{A}+\varepsilon_{B}\left(1-f_{A}\right) C_{B}}{S r_{A} f_{A}+S r_{B}\left(1-f_{A}\right)}
$$

onde $\varepsilon_{M}$ refere-se à razão isotópica $\left({ }^{87} \mathrm{Sr} /{ }^{86} \mathrm{Sr},{ }^{143} \mathrm{Nd} /{ }^{144} \mathrm{Nd}\right)$ da mistura $\mathrm{M}, \varepsilon_{A}$ e $\varepsilon_{B}$ referem-se às razões isotópicas $\left({ }^{87} \mathrm{Sr} /{ }^{86} \mathrm{Sr},{ }^{143} \mathrm{Nd} /{ }^{144} \mathrm{Nd}\right)$ dos componentes $\mathrm{A}$ e $\mathrm{B}$ e, por fim, $C_{A}$ e $C_{B}$ correspondem às concentrações de elemento ( $\left.\mathrm{Sr}, \mathrm{Nd}\right)$ dos componentes $\mathrm{A}$ e B, respectivamente. Os processos de mistura simples das razões isotópicas de Sr e Nd, no diagrama binário, alinham-se a hipérboles com curvaturas dependentes das concentrações dos elementos Sr e Nd.

\subsubsection{Aplicação aos diques investigados}

Devido à grande similaridade geoquímica e isotópica das amostras dos diques ATi com os basaltos do tipo Pitanga (Piccirillo \& Melfi, 1988; Peate, 1997; Marques, 1999) e das amostras dos diques BTi menos contaminadas (menor Sr radiogênico) com aqueles do Grupo B da região dos Lagos (Bennio et al., 2003; Carvas, 2016), calcularam-se linhas de mistura simples com as suas médias pela equação 5.7 , no diagrama ${ }^{143} \mathrm{Nd} /{ }^{144} \mathrm{Nd}_{130}$ vs. 
${ }^{87} \mathrm{Sr} /{ }^{86} \mathrm{Sr}_{130}$ (Figura 5.16), para estimar o grau de envolvimento da crosta continental nesse processo petrogenético. Consideraram-se, também, a média dos derrames Ribeira (Marques et al., 1999; Rocha-Júnior et al., 2013, 2020) e do Grupo A da região dos Lagos (Bennio et al., 2003; Carvas, 2016) como possíveis end-members basálticos, devido a similaridades isotópicas dos diques do Grupo B com os basaltos Ribeira e a possibilidade de influência da mesma fonte mantélica do Grupo A na Região Serrana. O end-member crustal para as curvas de mistura corresponde à média das rochas do Complexo Rio Negro mais radiogênicas (CRN; Peixoto et al., 2017), pois afloram na área de estudo, podendo ser uma importante fonte de contaminação. Os valores médios dos end-members basálticos e crustal para a obtenção das curvas de misturas simples entre eles estão apresentados na Tabela 5.6.

Tabela 5.6 - Valores médios dos end-members basálticos e crustais para as curvas de mistura simples. Grupos B e A de Cabo Frio-Búzios (Bennio et al., 2003; Carvas, 2016), Complexo Rio Negro (CRN; Peixoto et al., 2017) e derrames Pitanga e Ribeira (Piccirillo \& Melfi, 1988; Peate, 1997; Marques, 1999; RochaJúnior et al., 2013, 2020).

\begin{tabular}{c|cccc}
\hline End-members & $\begin{array}{c}\mathrm{Sr} \\
(\mathrm{mg} / \mathrm{kg})\end{array}$ & ${ }^{87} \mathrm{Sr}^{86} \mathrm{Sr}_{130}$ & $\begin{array}{c}\mathrm{Nd} \\
(\mathrm{mg} / \mathrm{kg})\end{array}$ & ${ }^{143} \mathrm{Nd} /{ }^{144} \mathrm{Nd}_{130}$ \\
\hline CRN 4 & 300,0 & 0,71822 & 39,78 & 0,51181 \\
\hline Grupo B & 243,8 & 0,70584 & 18,93 & 0,51234 \\
\hline Grupo A & 187,3 & 0,70411 & 11,50 & 0,51262 \\
\hline Ribeira & 289,3 & 0,70575 & 20,81 & 0,51228 \\
\hline Pitanga & 468,5 & 0,70571 & 38,81 & 0,51227 \\
\hline
\end{tabular}

* valores correspondem a média das 4 amostras mais radiogênicas

Em relação aos diques $\mathrm{BTi}$, nenhuma das curvas ajustou-se satisfatoriamente a todas as amostras analisadas, no sentido de definir uma mistura simples entre um dos os end-members basálticos e o CRN. Entretanto, as três curvas de misturas ajustam-se parcialmente às razões isotópicas destes diques. As amostras de diques LMD-RJ-8018 e LMD-RJ-8004 adequam-se à curva Ribeira-CRN, LMD-RJ-8017, LMD-RJ-8019A e LMD-RJ8010 à curva Grupo A-CRN e RJ-7511, RJ-7510, RJ-7513, RJ-7505 e RJ-7512 à curva Grupo B-CRN. Deste modo, os modelos de mistura simples sugerem a participação de mais de uma fonte mantélica na Região Serrana, assim como na Região dos Lagos, conforme Bennio et al. (2003) e Carvas (2016). O grau de participação máximo observado nos modelos encontra-se em torno de $30 \%(0,3)$. Já para o grupo ATi, o envolvimento crustal 
não se apresenta significativo, envolvendo menos de 5\% de CRN. As análises de Corval (2009) apresentam-se consistentes com o comportamento observado para os dois grupos.

Embora as razões isotópicas de Sr e $\mathrm{Nd}$ dos diques do Grupo B e os basaltos do tipo Ribeira da PMP sejam muito similares, os diagramas da Figura 5.19 mostram que o envolvimento deste último componente não se ajusta aos dados, uma vez que as concentrações de Sr e de Nd são mais altas nesses derrames. Não se pode descartar, no entanto, que o aumento nas concentrações desses elementos pode ter sido causado por diferenças de grau de fusão parcial de uma mesma fonte (grau de fusão parcial levemente maior para a geração dos magmas que originaram os diques).

Os diagramas de razões isotópicas iniciais de $\mathrm{Sr}$ e $\mathrm{Nd}$ em função do inverso das concentrações desses mesmos elementos (Figura 5.19), mesmo apresentando certa dispersão, reforçam o processo de contaminação por rochas enriquecidas e empobrecidas em $\mathrm{Sr}$ e $\mathrm{Nd}$ radiogênicos, respectivamente, pois o comportamento esperado para uma mistura simples é de uma reta que une o par de componentes basálticos e crustais. Cabe ressaltar que o comportamento dispersivo do $\mathrm{Nd}$ pode estar relacionado às análises não muito precisas pela técnica INAA. 

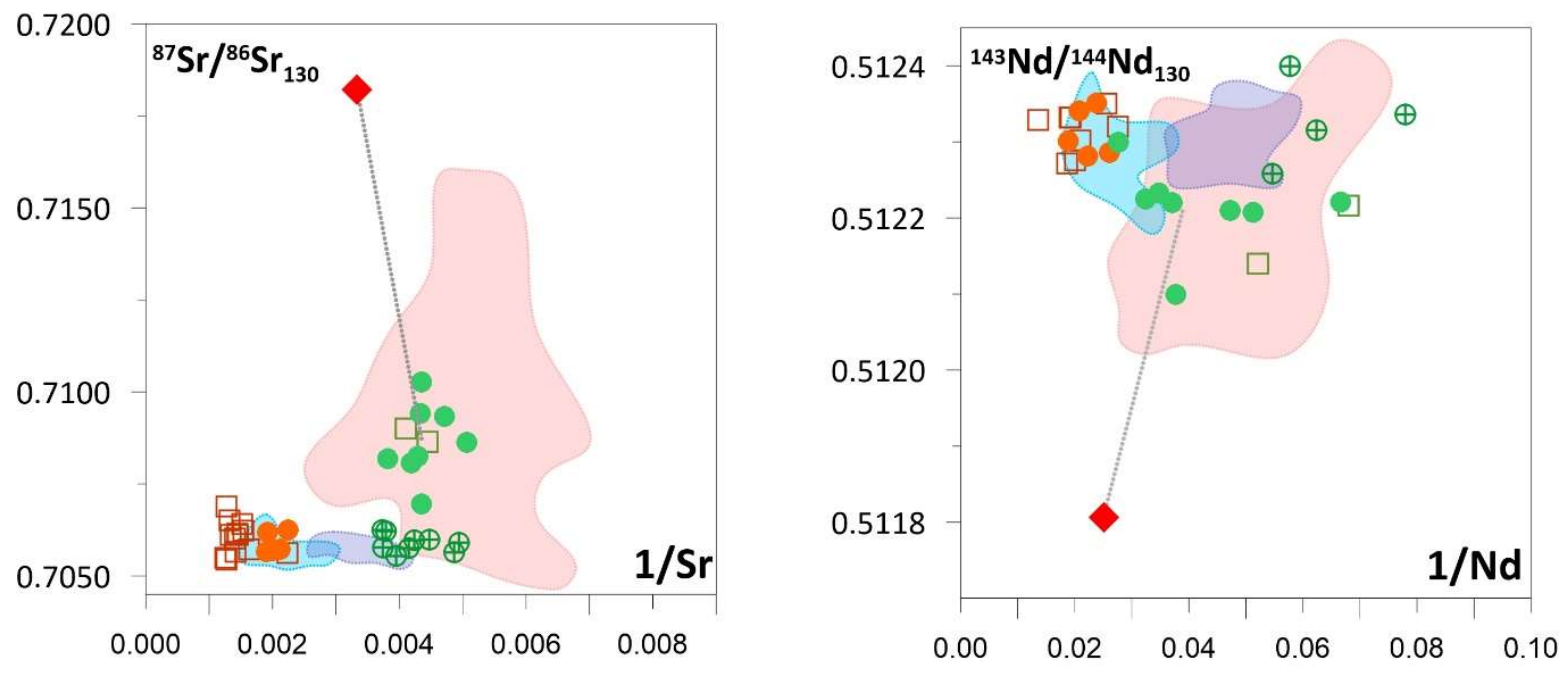

Legenda

Corval (2009) - $\mathrm{TiO}_{2}<2 \%$

Corval (2009) - $\mathrm{TiO}_{2}>2 \%$

$\oplus$ Bennio et al. (2003); Carvas (2016); Almeida et al. (2021) - Diques BTi de Cabo Frio-Búzios (Grupo B)

Derrames Gramado/Esmeralda

CRN - Peixoto et al. (2017)

Derrames Pitanga

Derrames Ribeira

........ Reta entre as médias do grupo BTi e CRN

Figura 5.19 - Diagramas das razões isotópicas iniciais de Sr e $\mathrm{Nd}$ em função do inverso das concentrações de $\mathrm{Sr}$ e Nd, respectivamente. Grupo ATi: círculo cheio laranja; grupo BTi: círculo cheio verde. Reta pontilhada se refere ao comportamento esperado no processo de mistura simples entre os dois componentes.

\subsubsection{Investigação da ocorrência de processos AFC}

O processo de assimilação crustal com cristalização fracionada concomitante (assimilation and fractional crystallization; AFC; DePaolo, 1981) considera a modificação composicional do magma enquanto está em resfriamento (com cristalização fracionada) e ascensão e contato (contaminação) com a crosta continental. Para a interpretação do comportamento dos elementos traço e das razões isotópicas nessa evolução composicional do magma, DePaolo (1981) e Powell (1984) desenvolveram as equações 5.8 e 5.9 , respectivamente.

$$
C_{i}=C_{i, A} f+\frac{r}{r-1+K_{D}} C_{i, B}\left(1-f_{i}\right)
$$

onde $C_{i}$ refere-se à concentração do elemento $i$ no processo $\mathrm{AFC}, C_{i, A}$ e $C_{i, B}$ referem-se às concentrações do elemento $i$ no magma $(A)$ e no contaminante $(B), r$ refere-se à razão entre a taxa de assimilação e a taxa de cristalização fracionada, $D_{i}$ 
corresponde ao coeficiente de partição global do elemento $i$ e, por fim, $f$ é igual $F^{-\left(r-1+D_{i}\right) /(r-1)}$, com $F$ sendo a proporção de magma remanescente.

$$
\varepsilon_{i}=\varepsilon_{i, A}+\left(\varepsilon_{i, B}-\varepsilon_{i, A}\right)\left(1-\frac{C_{i, A}}{C_{i}} f_{i}\right)
$$

onde $\varepsilon_{i}$ refere-se à razão isotópica $i$ no processo $\mathrm{AFC}, \varepsilon_{i, A}$ e $\varepsilon_{i, B}$ referem-se às razões isotópicas $i$ do magma inicial $(A)$ e do contaminante $(B)$, respectivamente.

Para a confecção dos modelos AFC, em relação aos diques do grupo BTi, utilizou-se o software de petrologia magmática Petrogram desenvolvido por Gündüz \& Asan (2021), baseado em ExcelC.

\subsubsection{Aplicação aos diques BTi investigados}

Para testar o processo AFC nos diques $\mathrm{BTi}$, uma série de curvas de evolução magmática do tipo AFC foram calculadas pelas equações 5.8 e 5.9, utilizando como endmembers os diques dos grupos B e A da Região dos Lagos (Bennio et al., 2003; Carvas, 2016), os derrames Ribeira (Marques et al., 1999; Rocha-Júnior et al., 2013, 2020) e as rochas mais radiogênicas do Complexo Rio Negro (CRN; Peixoto et al., 2017), conforme apresentado na Tabela 5.6.

Os coeficientes de partição global dos elementos $\mathrm{Sr}, \mathrm{Nd}$, La, Th e $\operatorname{Zr}\left(D_{i}\right)$ estão apresentados na Tabela 5.7. Os valores foram calculados a partir da equação 3.2, com os coeficientes de partição para as fases minerais $\left(K_{D}\right)$ retirados de Marques (1988; Apêndice E) e as proporções em peso dos minerais cristalizados $(x)$ obtidas através da média dos resultados dos ajustes dos modelos de cristalização fracionados referentes às trajetórias das amostras mais primitivas para as mais evoluídas, do conjunto de diques BTi (Apêndice F). O coeficiente de partição global calculado do Sr encontra-se de acordo com o comportamento desse elemento nos diagramas apresentados nas Figuras 5.9 e 5.10 .

Ressalta-se que as equações 5.8 e 5.9, para a modelagem dos processos AFC, desconsideram as mudanças dos valores dos coeficientes de partição global e da razão entre a massa assimilada e a massa fracionada $(r)$ ao longo do processo de diferenciação magmática, limitando o alcance de descrição dos modelos. Porém, atentando-se ao 
intervalo de $\mathrm{MgO}$ dos diques investigados (6,3\% $\leq \mathrm{MgO} \leq 3,2 \%)$, as mudanças no $D_{i}$ e $r$ devem não ser muito significativas.

Tabela 5.7 - Valores da média resultado dos coeficientes de partição global dos elementos traço incompatíveis Sr, Nd, La, Th e Zr aplicados nos modelos AFC para os diques BTi.

\begin{tabular}{c|ccccc}
\hline Elementos & $\mathrm{Sr}$ & $\mathrm{Nd}$ & La & $\mathrm{Th}$ & $\mathrm{Zr}$ \\
\hline$D_{i}$ & 0,955 & 0,199 & 0,130 & 0,034 & 0,146 \\
\hline
\end{tabular}

A Figura 5.20 apresenta as curvas de evolução magmática do tipo AFC para os diques $\mathrm{BTi}$, considerando dois valores de $r: 0,30$, concordante com o intervalo proposto por Marques (1988) para as rochas básicas da PM, e 0,75 para averiguação da hipótese de massa assimilada em torno de 30\% (Figura 5.16) e de massa fracionada em torno de $40 \%$ (estimada a partir do resultado do balanço de massa calculado para evolução direta da amostra mais primitiva para a mais evoluída; Apêndice F). Assim como nos processos de misturas simples, as curvas do tipo AFC não se ajustaram a todas as razões isotópicas, ou seja, não definindo um caminho evolutivo único entre um dos end-members básicos e o crustal. Novamente, cada uma das três curvas do tipo AFC ajustam-se parcialmente às razões isotópicas dos diques BTi. Com isso, os modelos sugerem a participação de mais de uma fonte mantélica com diferentes características na Suíte Serrana, com ajustes bons para o valor de $r$ igual a 0,3.

Cabe ressaltar a limitação do modelo ao considerar apenas um contaminante (CRN) de características geoquímicas constantes ao longo do processo de ascensão e diferenciação na câmara magmática. Como no trabalho de campo, descrito anteriormente, não foi possível observar os contatos entre os diques e as rochas encaixantes, logo, não se consideraram encaixantes contaminantes locais presentes.

As Figuras 5.21 e 5.22 apresentam os resultados da modelagem AFC para os elementos traço incompatíveis Zr, La, Th em função de razão isotópica inicial de Sr para os valores de $r$ iguais a 0,3 e 0,75, respectivamente. Os diagramas da razão isotópica inicial de Sr em função de Sr também são mostrados. Em geral, o aumento da concentração dos elementos traço fortemente incompatíveis estão associados a mudança gradativa da razão ${ }^{87} \mathrm{Sr} /{ }^{86} \mathrm{Sr}_{130}$, sendo que tal comportamento adequa-se mais favorável às curvas de $r$ igual a 0,75 , ressaltando o fracionamento destes elementos ao longo do processo de diferenciação. As curvas Grupo A-CRN ajusta melhor nas análises 
para os dois valores de $r$, enquanto as curvas Grupo B-CRN principalmente para o valor de $r$ igual a 0,75 . Apenas para o elemento Th, bastante enriquecido no processo de assimilação crustal, apresenta correlação satisfatória para as três curvas AFC para $r$ igual a 0,75 .

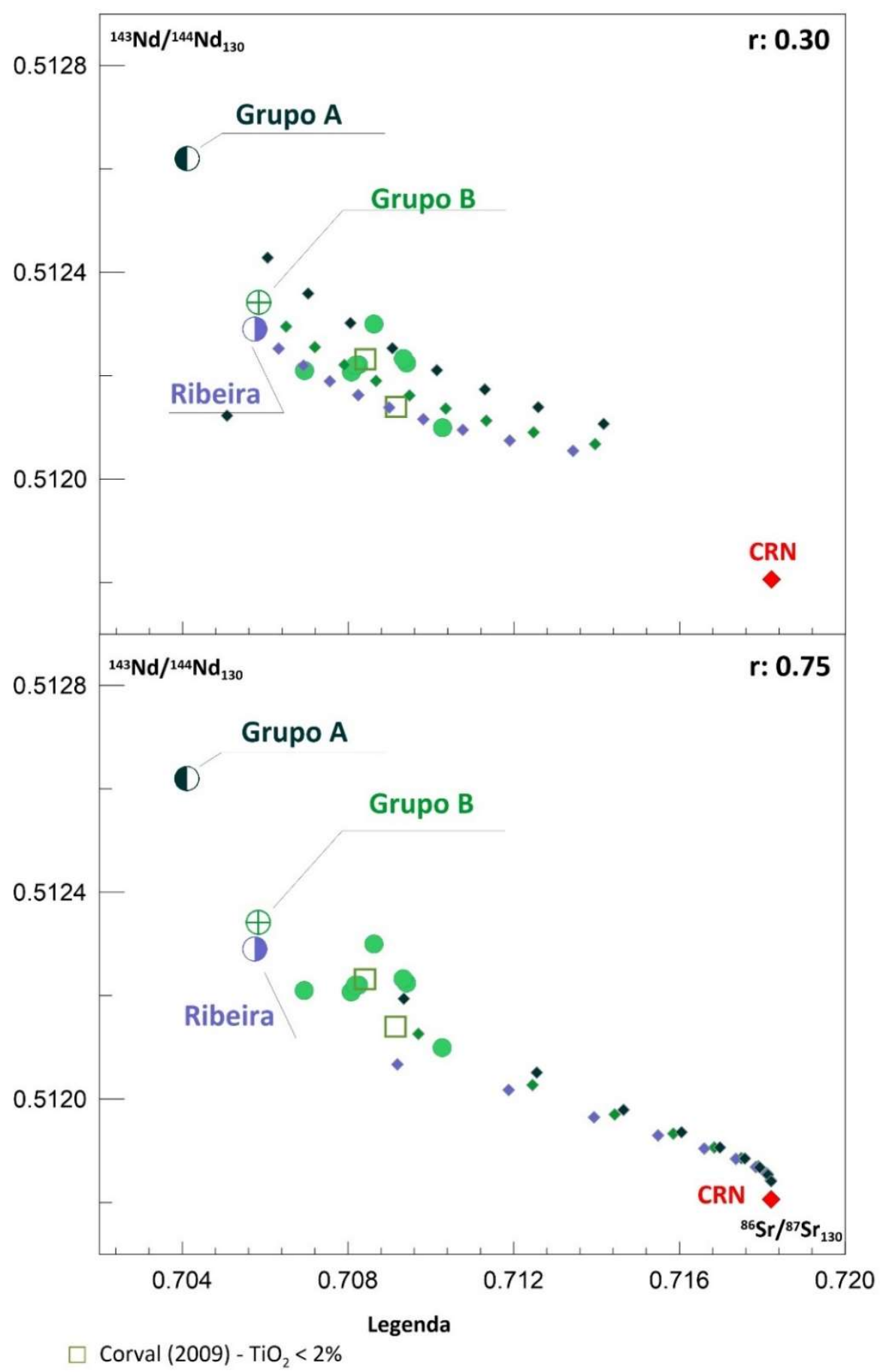

Figura 5.20 - Modelos de evolução magmática do tipo AFC para as médias das razões isotópicas dos diques dos grupos B e A na região dos Lagos (Bennio et al., 2003; Carvas, 2016), dos derrames Ribeira (Marques et al., 1999; Rocha-Júnior et al., 2013, 2020) e das rochas mais radiogênicas do Complexo Rio Negro (CRN; Peixoto et al., 2017). Grupo BTi: círculo cheio verde. 

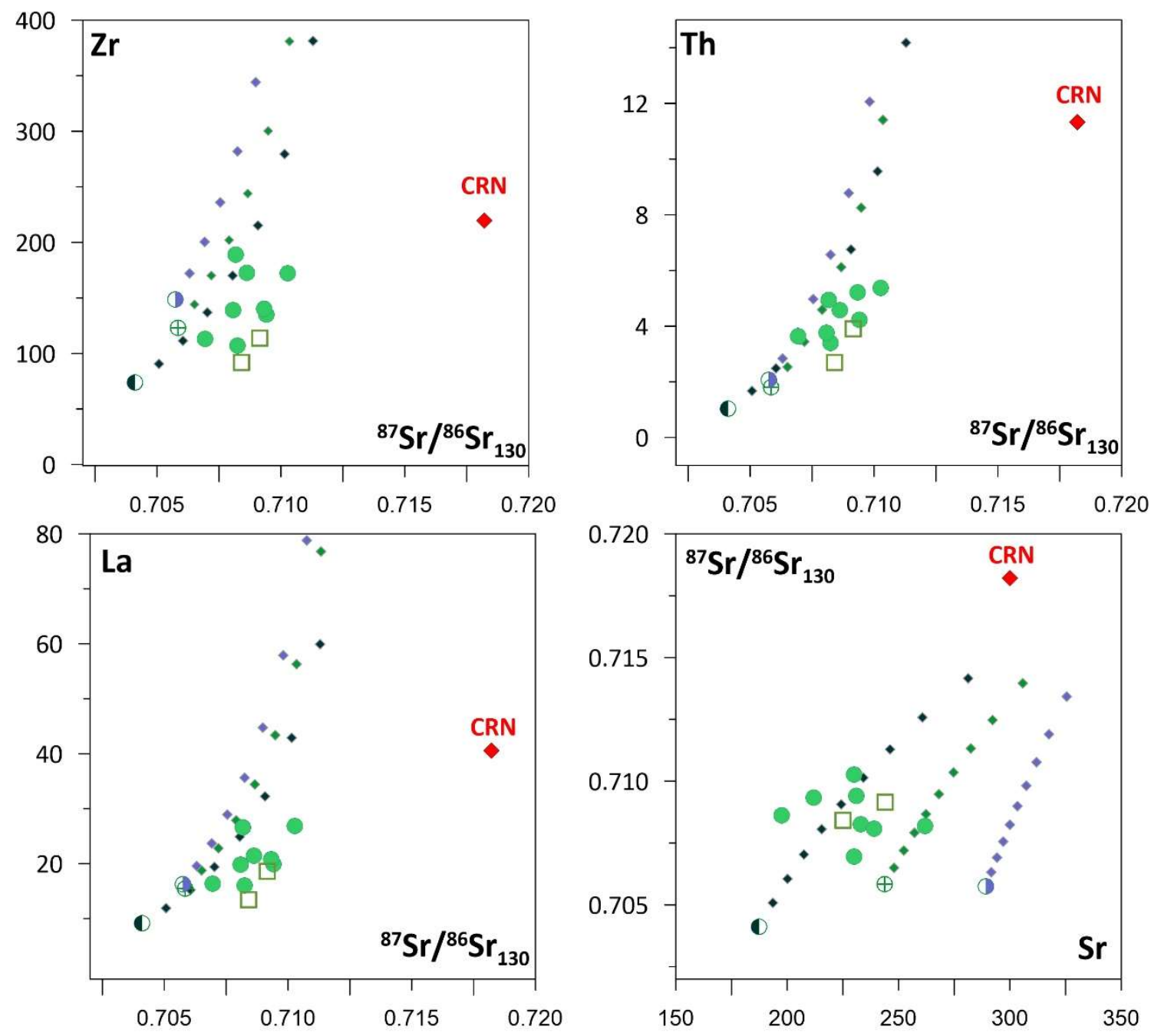

\section{Legenda}

Corval (2009) - $\mathrm{TiO}_{2}<2 \%$

$\oplus$ Bennio et al., 2003; Carvas 2016 - Grupo B

- Bennio et al., 2003; Carvas 2016 - Grupo A

Derrames Ribeira

Figura 5.21 - Modelos de evolução magmática do tipo AFC, com valores da razão entre a massa assimilada e a massa fracionada $(r)$ igual a 0,30, para as médias de diques dos grupos B e A (Bennio et al., 2003; Carvas, 2016), dos derrames Ribeira (Marques et al., 1999; Rocha-Júnior et al., 2013, 2020) e das rochas mais radiogênicas do Complexo Rio Negro (CRN; Peixoto et al., 2017). Grupo BTi: círculo cheio verde. 

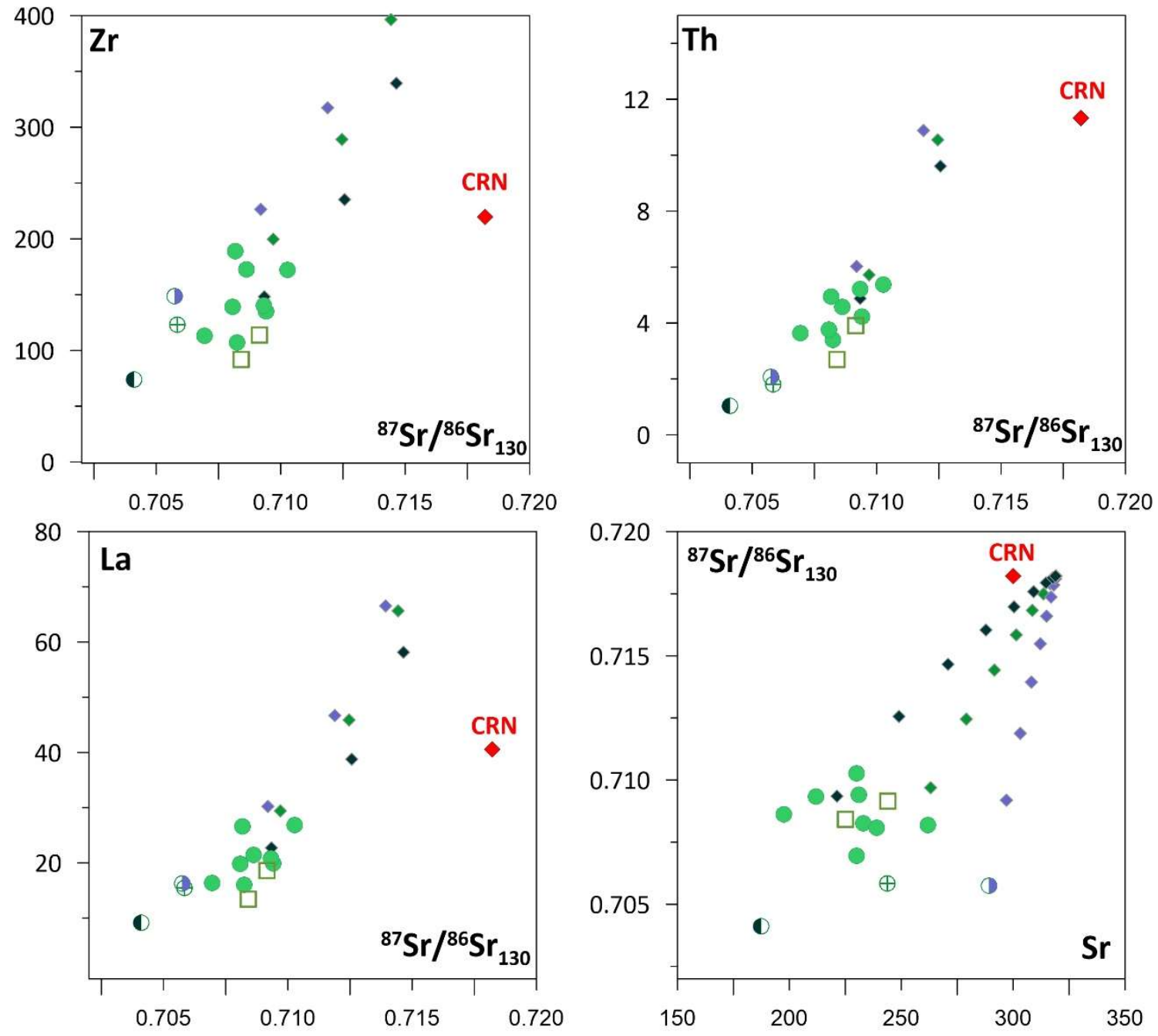

Legenda

Corval (2009) - $\mathrm{TiO}_{2}<2 \%$

$\oplus$ Bennio et al., 2003; Carvas 2016 - Grupo B

- Bennio et al., 2003; Carvas 2016 - Grupo A

Derrames Ribeira

Figura 5.22 - Modelos de evolução magmática do tipo AFC, com valores da razão entre a massa assimilada e a massa fracionada $(r)$ igual a 0,75, para as médias de diques dos grupos B e A (Bennio et al., 2003; Carvas, 2016), dos derrames Ribeira (Marques et al., 1999; Rocha-Júnior et al., 2013, 2020) e das rochas mais radiogênicas do Complexo Rio Negro (CRN; Peixoto et al., 2017). Grupo BTi: círculo cheio verde.

\subsection{Comentários gerais}

Os dados geoquímicos e isotópicos obtidos neste estudo evidenciam claramente que a gênese dos diques BTi envolveu cristalização fracionada concomitante com assimilação crustal. Esse processo de evolução provavelmente ocorreu a partir de magmas com composição similar àqueles que originaram os diques dos grupos $A$ e $B$ 
aflorantes na Região dos Lagos (Bennio et al., 2003; Carvas, 2016). Entretanto, os valores de $r$ (razão entre a massa cristalizada e a cristalizada) obtidos na modelagem isotópica $(r: 0,3)$ e na modelagem elemental $(r: 0,75)$ foram significativamente diferentes. Considerando que dados isotópicos são mais sensíveis para identificar quantitativamente processos de contaminação crustal, valores de $r$ mais baixos parecem ser os mais representativos para o processo evolutivo. Para aprimorar esse modelo, são ainda necessários dados químicos, isotópicos e de química mineral desses diques, com detalhamento da amostragem, como também análises geoquímicas das rochas encaixantes.

Para os diques do grupo ATi, os processos de contaminação foram bem menos expressivos, não afetando significativamente a composição química original dos magmas, ou seja, a diversidade composicional desses diques ocorreu principalmente por cristalização fracionada. 


\section{CONSIDERAÇÕES FINAIS}

O estudo geoquímico nas amostras dos 32 diques situados na Região Serrana do Rio de Janeiro permitiu obter as seguintes informações:

- $\quad$ Os diques são quimicamente representados por basaltos (11) e andesitos basálticos (21) e apresentam natureza subalcalina, em função de sílica e álcalis (TAS), situando-se abaixo da linha de separação entre os campos alcalinos e subalcalinos. As amostras de diques são distinguíveis em três grupos: os diques com teores de $\mathrm{TiO}_{2}>3 \%$ (ATi; 5,1\% > MgO > 2,7\%), alguns deles com tendência toleítica-transicional; os diques com teores de $3 \% \geq \mathrm{TiO}_{2}>2 \%$ e restritos a região do Distrito de Lumiar (ATi-Lumiar; 5,5\% $>\mathrm{MgO}>4,9 \%$ ); e os diques com teores de $\mathrm{TiO} 2 \leq 2 \%$ ( $\mathrm{BTi} ; 6,3 \%>\mathrm{MgO}>3,2 \%$ ). No diagrama AFM, os três grupos exibem comportamento compatível a evolução de suítes toleíticas, com leve aumento de $\mathrm{FeO}_{\mathrm{t}}$.

- $\quad$ Em geral, os padrões de elementos maiores e menores nos diagramas de variação indicam o fracionamento de clinopiroxênio cálcico (augita), plagioclásio, titanomagnetita e apatita. O comportamento dispersivo de $\mathrm{Al}_{2} \mathrm{O}_{3}$, em função de $\mathrm{MgO}$, pode indicar acumulação de plagioclásio na diferenciação magmática, principalmente para o grupo BTi.

- $\quad$ Os três conjuntos de diques são mais evidenciados no comportamento dos ETR e elementos traço fortemente incompatíveis nos diagramas de variação com Zr, como índice de evolução magmática. Os três grupos apresentam concentrações diferentes de $\mathrm{La}$, Ce e $\mathrm{Nd}$ e similares de $\mathrm{Tb}, \mathrm{Yb}$ e $\mathrm{Lu}$, indicando fracionamento significativo de ETR leves em relação os ETR pesados na diferenciação magmática. O comportamento geral dos ETR indica que os três grupos de diques não são cogenéticos, pois os ETR leves não se ajustam em retas passando pela origem. O grupo ATi apresentase mais evoluído e enriquecido em elementos incompatíveis, enquanto o grupo ATiLumiar tem valores de concentrações intermediários aos dois grupos. O grupo BTi é o mais primitivo e empobrecido nesses elementos, com exceção para $\mathrm{Th}, \mathrm{Rb}$ e $\mathrm{U} . \mathrm{O}$ enriquecimento destes elementos indica que o processo de cristalização fracionada, para o grupo BTi, não ocorreu em sistema fechado, com significativa influência de processos de assimilação crustal. 
- $\quad$ O comportamento encontrado nos padrões de abundância dos grupos ATi, ATi-Lumiar e BTi normalizados pelo condrito Cl (McDonough \& Sun, 1995) apresenta maior fracionamento de ETR leves, principalmente para os diques evoluídos do grupo ATi, comportamento esperado na evolução de séries toleíticas envolvendo cristalização fracionada de piroxênios. Leves anomalias negativas de Eu ocorrem apenas nos grupos BTi e ATi-Lumiar, não apresentando variação com o grau de evolução, o que indica o pouco fracionamento de plagioclásio. Comparados aos derrames da PMP, o comportamento dos padrões dos grupos ATi e ATi-Lumiar apresentam similaridades com derrames Pitanga, enquanto o comportamento dos diques BTi são semelhantes principalmente aos dos derrames Gramado, acentuadamente contaminados pela crosta continental.

- As análises dos padrões de elementos traço incompatíveis normalizados pelo manto primitivo (McDonough \& Sun, 1995) possibilitaram a identificação de uma possível contribuição de manto litosférico subcontinental metassomatizado para os três grupos, a partir das anomalias negativas de $\mathrm{Nb}$ e Ta, conforme também observado nos derrames da PMP. Em relação aos diques $\mathrm{BTi}$, as razões elevadas de ( $\mathrm{Rb} / \mathrm{Ba})_{\mathrm{PM}}$ indicam um significativo processo de contaminação crustal, e as anomalias negativas de $\mathrm{Ti}$ e $\mathrm{Sr}$ sugerem um significativo fracionamento de clinopiroxênio cálcico e, de modo subordinado, plagioclásio e titanomagnetita. Já, para os diques dos grupos ATi e ATiLumiar, as razões de (Rb/Ba) PM não sugerem assimilação crustal significativa ao longo da evolução magmática. Anomalias positivas de P são observadas para o grupo ATi, indicando leve fracionamento de apatita. Comparados aos derrames da PMP, o comportamento dos padrões dos grupos ATi e ATi-Lumiar assemelham-se aos derrames do tipo Pitanga e, no caso do grupo BTi, aos derrames do tipo Gramado.

- As análises isotópicas de Sr e $\mathrm{Nd}$ apontam assinaturas ainda mais distintas entre os grupos BTi e ATi. O primeiro, mais radiogênico em Sr, apresenta comportamento similar aos derrames do tipo Gramado, enquanto os diques ATi são semelhantes aos derrames do tipo Pitanga da PMP. As razões iniciais de Sr do grupo BTi apresentam comportamento compatível com um processo de evolução envolvendo assimilação crustal significativa, com as amostras mais primitivas próximas ao campo dos diques do grupo B de Cabo Frio-Búzios (Bennio et al., 2003; Carvas, 2016). 
- Os modelos de cristalização fracionada para evolução, obtidos pelo cálculo do balanço de massa dos óxidos, apresentaram ajustes bons principalmente para os diques ATi-Lumiar e ATi. Em relação aos diques BTi, as passagens para as rochas mais evoluídas obtiveram $\Sigma$ res $^{2}$ acima de 1 e quantidade fracionada de pigeonita alta, incompatível com a petrografia. Tais resultados são indicativos que, embora a cristalização fracionada tenha sido importante na diferenciação magmática, o processo não ocorreu em sistema fechado. A modelagem traços, em geral, indicam bons ajustes para os três grupos de diques, excetuando três ajustes para o grupo BTi.

- Os modelos de misturas simples indicaram significativo grau de envolvimento da crosta continental para os diques do grupo BTi. As curvas entre os endmembers basálticos, grupos B e A (Bennio et al., 2003; Carvas, 2016) e derrames do tipo Ribeira, e o end-member crustal, Complexo Rio Negro (Peixoto et al., 2017), ajustam-se parcialmente às análises isotópicas dos diques BTi, com grau de participação máximo de contaminante em torno de $30 \%$. Já para o grupo ATi, o envolvimento crustal não se apresenta significativo, de grau de participação máximo inferior a 5\%.

- Os modelos do processo de AFC apresentaram ajustes parciais às análises isotópicas e elementais ( $\mathrm{La}, \mathrm{Zr}$, Th e $\mathrm{Sr}$ ) para os diques BTi, com end-members basálticos grupos B e A e derrames do tipo Ribeira e o end-member crustal, Complexo Rio Negro. Tais comportamentos sugerem a participação de mais de uma fonte mantélica com diferentes características geoquímicas, assim como proposto por Bennio et al. (2003) e Carvas (2016) para os diques situados na Região dos Lagos. A variação dos valores de $r$ $(0,3$ e 0,75) para a obtenção dos melhores ajustes é bastante acentuada, mas considerando que os dados isotópicos são muito mais robustos na identificação de processos de contaminação crustal, os menores valores provavelmente representam melhor a razão entre a massa assimilada e a cristalizada durante a gênese dos magmas que originaram esses diques. Desta forma, dados químicos, isotópicos e de química mineral, além de maior detalhamento de trabalhos de amostragem de diques e das encaixantes, são ainda necessários para aprimorar os modelos petrogenéticos 


\section{REFERÊNCIAS}

Abdalla, R. S. M., Albasheer, A. A., El-Hussein, A. R. M. \& Gadkariem, E. A. (2012). Physico-chemical characteristics of date seed oil grown in Sudan. American Journal of Applied Sciences, 9(7), 993-999.

Adams, F. \& Dams, R. (1969). A compilation of precisely determined gammatransition energies of radionuclides produced by reactor irradiation. Journal of Radioanalytical and Nuclear Chemistry, 3(1-2), 99-125.

Albarède, F. (1996). Introduction to geochemical modeling. Cambridge University Press.

Almeida, F. F. M. (1986). Distribuição regional e relações tectônicas do magmatismo pós-paleozóico no Brasil. Revista Brasileira de Geociências, 16(4), 325-349.

Almeida, F. F. M. D. (1991). O alinhamento magmático de Cabo Frio. Simpósio de Geologia do Sudeste, 2, 423-428.

Almeida, F. F. M. \& Carneiro, C. D. R. (2017). Origem e evolução da Serra do Mar. Revista Brasileira de Geociências, 28(2), 135-150.

Almeida, J., Dios, F., Mohriak, W. U., Valeriano, C. D. M., Heilbron, M., Eirado, L. G., \& Tomazzoli, E. (2013). Pre-rift tectonic scenario of the Eo-Cretaceous Gondwana breakup along SE Brazil-SW Africa: insights from tholeiitic mafic dyke swarms. Geological Society, London, Special Publications, 369(1), 11-40.

Almeida, J., Heilbron, M., Guedes, E., Neubauer, F., Manfred, B., Klausen, M. B. \& Tetzner, W. (2021). Pre-to-syn-rift tholeiitic magmatism in a transtensive hyperextended continental margin: Onshore and offshore magmatism of the Campos Basin, SE Brazil. Journal of South American Earth Sciences, 108, 103-218.

Al-Merey, R., Karajou, J. \& Issa, H. (2005). X-ray fluorescence analysis of geological samples: exploring the effect of sample thickness on the accuracy of results. Applied Radiation and Isotopes, 62, 501-508.

Assine, M. L., Piranha, J. M. \& Carneiro, C. D. R. (2004). Os paleodesertos Pirambóia e Botucatu. Geologia do Continente Sul-Americano: Evolução da obra de Fernando Flávio Marques de Almeida, Editora Beca, São Paulo. 
Barreto, C. J. S., Lafon, J. M., de Lima, E. F. \& Sommer, C. A. (2016). Geochemical and $\mathrm{Sr}-\mathrm{Nd}-\mathrm{Pb}$ isotopic insight into the low-Ti basalts from southern Paraná Igneous Province, Brazil: the role of crustal contamination. International Geology Review, 58(11), 1324-1349.

Basilici G., Sgarbi G. N. \& Führ Dal' Bó (2012). A sub-bacia Bauru: um sistema continental entre deserto e cerrado. In: Hasui Y., Carneiro C.D.R., Almeida F.F.M., Bartorelli A. (Eds.). Geologia do Brasil. São Paulo, Beca, 520-543.

Bellieni, G., Comin-Chiaramonti, P., Marques, L. S., Melfi, A. J., Piccirillo, E. M., Nardy, A. J. R. \& Roisenberg, A. (1984). High-and low-TiO2 flood basalts from the Paraná plateau (Brazil), petrology and geochemical aspects bearing on their mantle origin. Neues Jahrbuch für Mineralogie Abhandlungen, 150(3), 273-306.

Bellieni, G., Comin-Chiaramonti, P., Marques, L. S., Melfi, A. J., Nardy, A. J. R., Papatrechas, C., Piccirillo, E. M., Roisenberg, A. \& Stolfa, D. (1986). Petrogenetic aspects of acid and basaltic lavas from the Paraná plateau (Brazil), mineralogical and petrochemical relationships. Journal of Petrology, 27(4), 915-944.

Bennio, L., Brotzu, P., D’Antonio, M., Feraud, G., Gomes, C. B., Marzoli, A., Melluso L., Morbidelli, L., Morra, V., Rapaille, C. \& Ruberti, E. (2003). The tholeiitic dyke swarm of the Arraial do Cabo peninsula (SE Brazil), 39Ar/40Ar ages, petrogenesis, and regional significance. Journal of South American Earth Sciences, 16(2), 163-176.

Cabrera, J. G. (1971). Geological and Engineering Properties of Basaltic Flows and Interbeds throughout the Upper Paraná Basin, Brazil. 208p. PhD Thesis. Faculty of the Graduate School of Cornell University. Ann Arbor, Michigan.

Campbell, I. H. (1985). The difference between oceanic and continental tholeiites: a fluid dynamic explanation. Contributions to Mineralogy and Petrology, 91(1), 37-43.

Carvas, K. Z. (2014). Determinação de razões isotópicas de $\mathrm{Sr}, \mathrm{Nd}$ e $\mathrm{Pb}$ de diques do Cretáceo Inferior do Enxame da Serra do Mar (SP-RJ). Trabalho de Conclusão de Curso, Universidade de São Paulo.

Carvas, K. Z. (2016). Diques mesozoicos subalcalinos de baixo titânio da Região dos Lagos (RJ), geoquímica e geocronologia 40Ar/39Ar. Dissertação de Mestrado, Universidade de São Paulo. 
Carvas, K. Z., Vasconcelos, P. M. P., Marques, L. S., Ubide, T., Carmo, I. O. \& Babinski M. (2021). Geochronology and geochemistry of mafic magmatism and hydrothermal alteration during early stages of South Atlantic opening.

Chang, H. K., Kowsman, R. O., Figueiredo, A. M. \& Bender A. A. (1992). Tectonics and stratigraphy of the East Brazil Rift System - An overview. Tectonophysics, 213, 97138.

Coffin, M. F. \& Eldholm, O. (1994). Large igneous provinces: crustal structure, dimensions, and external consequences. Reviews of Geophysics, 32(1), 1- 36.

Cogné, N., Gallagher, K. \& Cobbold, P. R. (2011). Post-rift reactivation of the onshore margin of southeast Brazil: Evidence from apatite (U-Th)/He and fission-track data. Earth and Planetary Science Letters, 309(1-2), 118-130.

Cogné, N., Gallagher, K., Cobbold, P. R., Riccomini, C. \& Gautheron, C. (2012). Post break-up tectonics in Southeast Brazil from thermochronological data and combined inverse-forward thermal history 105lippe105ng. Journal of Geophysical Research: Solid Earth, 117(B11).

Comin-Chiaramonti, P., Gomes, C. B., Piccirillo, E. M., Rivalenti, G. (1983). High TiO2 dikes in the coastline of São Paulo and Rio de Janeiro States. Neues Jahrbuch Mineralogie Abhandlungen, 146(2), 133-150.

Cordani, U.G. Civetta, L., Mantovani, M.S.M., Petrini, R., Kawashita, K., Hawkesworth, C.J., Taylor, P., Longinelli, A., Cavazzini, G. \& Piccirillo, E.M. (1988). Isotope geochemistry of flood basalts from the Paraná basin (Brazil). In: The Mesozoic flood volcanism of the Paraná basin: petrogenetic and geophysical aspects. Piccirillo E. M. \& Melfi A. J (eds). IAG, University of São Paulo, Brazil, 157-178.

Corval, A. (2009). Petrogênese e Contexto Geodinâmico das Suítes Basálticas Toleíticas (de alto-TiO2 e baixo-TiO2) do Cretáceo Inferior da Porção Centro-oriental do Enxame de Diques da Serra do Mar. Tese de Doutorado, Universidade do Estado do Rio de Janeiro, Rio de Janeiro.

Corval, A., Valente, S. C., Duarte, B. P., Famelli, N. \& Zanon, M. (2008). Dados petrológicos dos diabásios dos setores centro-norte e nordeste do Enxame de Diques da Serra do Mar. Geochimica Brasiliensis, 22(3), 159-177.

Cotta, A. J. B, Enzweiler, J. \& Nardy, A. J. R. (2008). Certificado de análise do material de referência BRP-1 (Basalto Ribeirão Preto). Geochimica Brasiliensis, 22(2), 113-118. 
Coutinho, J. M. V. (2008). Dyke Swarms of the Paraná Triple Junction, Southern Brazil. Revista do Instituto de Geociências, Universidade de São Paulo, 8, 29-52.

De La Roche, H., Leterrier, J., Grandclaude, P; Marchal, M. (1980). A classification of volcanic and plutonic rocks using R1-R2 diagram and major element analyses - its relationships with current nomenclature. Chemical Geology, 29, 183-210.

Deckart, K., Féraud, G., Marques, L. S., Bertrand, H. (1998). New time constraints on dyke swarms related to the Paraná-Etendeka magmatic province, and subsequent South Atlantic opening, southeastern Brazil. Journal of Volcanalogy and Geothermal Research, 80:7-83.

Deer, W. A., Howie, R. A. \& Zussman, J. (1982). Rock forming minerals. Volume 1AOrthosilicates.

DePaolo, D. J. (1981). Trace element and isotopic effects of combined wallrock assimilation and fractional crystallization. Earth and Planetary Science Letters, 53(2), 189-202.

Dutra T. (2006). Petrogênese dos basaltos de baixo-TiO2 do Enxame de Diques da Serra do Mar na Região dos Lagos, RJ. Dissertação de Mestrado, Universidade do Estado do Rio de Janeiro.

Dutra, T., Valente, S. Corval. A., Almeida, J.C.H., Monteiro, H. L. J., Wolfram Tetzner, W. \& Valladares, C.S. (2005). Diagramas Discriminantes para as suítes de baixo-TiO2 do Enxame de Diques da Serra do Mar a associações com a Província Paraná-Etendeka. X Congresso Brasileiro de Geoquímica, Porto de Galinhas, Pernambuco.

Dutra, T., Valente, S., Corval, A., Duarte, B. P. \& Heilbron, M. (2006). Geochemical modelling for the low-TiO2 basalts (the Costa Azul Suite) in the eastern portion of the Serra do Mar Dyke Swarm, Rio de Janeiro: Evidence for the contribution of a depleted mantle source. South American Symposium on Isotope Geology, 4, 355-357.

Eirado, L. G., Heilbron, M., \& de Almeida, J. C. H. (2016). Os terrenos tectônicos da Faixa Ribeira na Serra da Bocaina e na Baía da Ilha Grande, sudeste do Brasil. Revista Brasileira de Geociências, 36(3), 426-436.

Ernesto, M., Marques, L. S. \& Bucceroni, C. S. (2014). Atividade Ígnea filoniana ao longo da faixa costeira entre Santos-Cabo Frio: comparações geoquímicas, geocronológicas e paleomagnéticas. 47을 Congresso Brasileiro de Geologia, Salvador BA, CD-ROM. 
Ernesto, M., Marques, L. S., Piccirillo, E. M., Molina, E. C., Ussami, N., CominChiaramonti, P. \& Bellieni, G. (2002). Paraná Magmatic Province- Tristan da Cunha plume system: fixed versus mobile plume, petrogenetic considerations and alternative heat sources. Journal of Volcanology and Geothermal Research, 118, 15-36.

Ernesto, M., Raposo, M. I. B; Marques, L. S., Renne, P. R., Diogo, L. A. \& De Min, A. (1999). Paleomagnetism, geochemistry and 40Ar/39Ar dating of the North-eastern Paraná magmatic province: tectonic implications. Journal of Geodynamics, 28, 321-340.

Ernst, R. E. \& Buchan, K. L. (1997). Giant radiating dyke swarms: their use in identifying pre-Mesozoic large igneous provinces and mantle plumes. In: Mahoney J., Coffin M. Large Igneous Provinces: Continental, Oceanic, and Planetary Volcanism. AGU Geophysics Monograph Series, 100, 297-333

Ewart, A., Marsh, J.S., Milner, S. C., Duncan, A. R., Kamber, B. S. \& Armstrong, R. A. (2004). Petrology and geochemistry of Early Cretaceous bimodal continental volcanism of the NW Etendeka, Namibia. Journal of Petrology, 45, 59-105.

Faure, G. \& Mensing, T. M. (2005). Isotopes: principles and applications. Wiley, New Jersey, United States.

Figueiredo, A. M. G. \& Marques, L. S. (1989). Determination of Rare Earths and Other Trace Elements in the Brazilian Geological Standards BB-1 and GB-1 by Neutron Activation Analysis. Geochimica Brasiliensis, 3(1), 1-8.

Florisbal, L. M., Janasi, V. A., Bitencourt, M. F., Nardi, L. V. S. \& Marteleto, N. S. (2018). Geological, geochemical and isotope diversity of 134 Ma dykes from the Florianópolis Dyke Swarm, Paraná Magmatic Province: Geodynamic controls on petrogenesis. Journal of Volcanology and Geothermal Research, 355, 181-203.

Frank, H. T., Gomes, M. E. B. \& Formoso, M. L. L. (2009). Review of the areal extent and the volume of the Serra Geral Formation - Paraná Basin, South. Pesquisas em Geociências, 36(1), 49-57.

Freitas, V. A. D. (2009). A geração de magmas ácidos na Província Magmática Paraná, região de Piraju-Ourinhos (SP), uma contribuição da geoquímica isotópica e de elementos traço em rochas e minerais. Dissertação de Mestrado, Universidade de São Paulo. 
Gallagher, K., Hawkesworth, C. J. \& Mantovani, M. S. M. (1994). The denudation history of the onshore continental margin of SE Brazil inferred from apatite fission track data. Journal of Geophysical Research: Solid Earth, 99(B9), 18117-18145.

Garda, G. M. \& Schorscher, J. H. D. (1996). Os diques costeiros básicos e ultrabásicos adjacentes ao canal de São Sebastião (litoral norte do Estado de São Paulo). Revista do Instituto Geológico, 17(1/2), 7-31.

Garda, G. M. (1995). Os diques básicos e ultrabásicos da região costeira entre as cidades de São Sebastião e Ubatuba, Estado de São Paulo. Tese de Doutorado, Instituto de Geociências, Universidade de São Paulo.

Garland F., Hawkesworth C. J. \& Mantovani M. S. M. (1995). Description and petrogenesis of the Paraná rhyolites, Southern Brazil. Journal of Petrology, 36(5), 11931227.

Garland F., Turner, S. \& Hawkesworth, C. (1996). Shifts in the source of the Paraná basalts through time. Lithos, 37, 223-243.

Gibson, S. A., Thompson, R. N., Leonardos, O. H., Dickin, A. P. \& Mitchell, J. G. (1999). The limited extent of plume-lithosphere interactions during continental flood-basalt genesis: geochemical evidence from Cretaceous magmatism in southern Brazil. Contributions to Mineralogy and Petrology, 137, 147-169.

Gladczenko, T. P., Hinz, K., Eldholm, O., Meyer, H., Neben, S. \& Skogseid, J. (1997). South Atlantic volcanic margins. Journal of Geological Society, 154(3), 465-470.

Govindaraju, K. (1994). 1994 compilation of working values and sample description for 383 geostandards. Geostandards newsletter, 18, 1-158.

Guedes, E. (2007). O enxame de diques da Serra do Mar na região entre Resende e a Baía da Ilha Grande, RJ. Tese de Doutorado, Universidade do Estado do Rio de Janeiro.

Guedes, E., Heilbron, M., Valeriano, C. M., Almeida, J.C.H. \& Szatmari, P. (2016). Evidence of Gondwana early rifting process recorded by Resende-llha Grande Dike Swarm, southern Rio de Janeiro, Brazil. Journal of South American Earth Sciences, 67, 11-24.

Guedes, E., Heilbron, M., Vasconcelos, P., Valeriano, C.M., Almeida, J.C.H; Teixeira, W., Thomaz Filho, A. (2005). K-Ar and Ar-Ar ages of dikes emplaced in the onshore basement of Santos Basin, Resende Area, SE, Brazil: Implications for the South Atlantic 
opening and a Tertiary reactivation. Journal of South American Earth Sciences, 18, 145178.

Gündüz, M. \& Asan, K. (2021). PetroGram: An Excel-based petrology program for modeling of magmatic processes. Geoscience Frontiers, 12(1), 81-92.

Halls, H.C. (1982). The importance and potential of mafic dyke swarms in studies of geodynamic processes. Geoscience Canada, 9(3), 145-154

Hawkesworth, C. J., Gallagher, K., Kelley, S., Mantovani, M. S. M., Peate, D., Regelous, M. \& Rogers, N. (1992). Paraná magmatism and the opening of the South Atlantic. In: Storey, B., Alabaster, A., Pankhurst, R. Magmatism and the Causes of Continental Break-up. Geological Society Special Publication, 68, 221-240

Heilbron, M. \& Machado, N. (2003). Timing of terrane accretion in the Neoproterozoic-Eopaleozoic Ribeira orogen (SE Brazil). Precambrian Research, 125(12), 87-112.

Heilbron, M., Soares, A. C. P., Campos Neto, M., Silva, L. C., Trouw, R. \& Janasi, V. (2004). Província Mantiqueira. In: Mantesso-Neto, V., Bartorelli, A., Carneiro, C. D. R., Brito Neves, B. B. Geologia do Continente Sul Americano: Evolução da Obra de Fernando Flávio Marques de Almeida, Beca, 203-234.

Irvine, T.N. \& Baragar, W.R.A. (1971). A guide to the chemical classification of the commonvolcanic rocks. Canadian Journal of Earth Sciences, 8, 523-548.

ISO 13528 (2005). Statistical methods for use in proficiency testing by interlaboratory comparisons. First Edition, 29-30.

Janasi, V. A., Freitas, V. A. \& Heaman, L. H. (2011). The onset of flood basalt volcanism, Northern Paraná Basin, Brazil: A precise U-Pb baddeleyite/zircon age for a Chapecó-type dacite. Earth and Planetary Science Letters, 302(1-2), 147-153.

Jerram, D. A., \& Widdowson, M. (2005). The anatomy of Continental Flood Basalt Provinces: geological constraints on the processes and products of flood volcanism. Lithos, 79(3-4), 385-405.

Jourdan, F., Féraud, G., Bertrand, H. \& Watkeys, M. K. (2007). From flood basalts to the inception of oceanization: Example from the 40Ar/39Ar high-resolution picture of the Karoo large igneous province. Geochemistry, Geophysics, Geosystems, 8(2), 1-20.

Kawashita, K. (1972). O método Rb-Sr em rochas sedimentares. Tese de doutorado, Universidade de São Paulo. 
Knoll, G. F. (1999). Radiation Detection and Measurement, $3^{\text {rd }}$ ed Wiley.

Kuiper, K. F., Deino, A., Hilgen, F. J., Krijgsman, W., Renne, P. R. \& Wijbrans, A. J. (2008). Synchronizing rock clocks of Earth history. Science, 320(5875), 500-504.

Kuno, H. (1968). Differentiation of basalt magmas. In: Hess, H.H. \& Pol de- Vaart, A. Basalts, vol. II, Wiley Intersciences Publications, New York, United States.

Le Bas, M.J., Le Maitre, R.W., Streckeisen; A. \& Zanettin, B. (1986). A chemical classification of volcanic rocks based on the Total Alkali-Silica diagram. Journal of Petrology, 27(3), 745-750.

Lindstrom, R. M. \& Fleming, R. F. (1995). Dead time, pileup, and accurate gammaray spectrometry. Radioactivity \& Radiochemistry, 6(2), 20-27.

Lino, L. M. \& Vlach, S. R. F. (2021). Textural and Geochemical Evidence for Multiple, Sheet-like Magma Pulses in the Limeira Intrusion, Paraná Magmatic Province, Brazil. Journal of Petrology, 62(3), 1-38.

Ludka, I. P. (1997). Geoquímica do magmatismo básico na porção central do Cinturão Móvel Costeiro e regiões adjacentes aplicada ao estudo da composição do manto, SE-Brasil. Tese de Doutorado, Universidade Federal do Rio de Janeiro.

Lukens, H. R., Schlesinger, H. L. \& Bryan, D. (1974). Neutron activation analysis. Systematic Materials Analysis, 2, 45.

Machado, F. B., Nardy, A. J. R., De Melo, R. P., De Oliveira, M. A. F., \& Squisato, E. (2007). As rochas intrusivas da formação Serra Geral na porção leste da bacia do Paraná no estado de São Paulo: aspectos petrográficos e geoquímicos-resultados preliminares. Geociências (São Paulo), 24(1), 5-17.

Machado, F. B., Rocha-Júnior, E. R. V., Marques, L. S., Nardy, A. J. R., Zezzo, L. V., \& Marteleto, N. S. (2018). Geochemistry of the Northern Paraná Continental Flood Basalt (PCFB) province: implications for regional chemostratigraphy. Brazilian Journal of Geology, 48(2), 177-199.

Magdaleno, G. B., Petronilho, L. A., Silva, R. A., Ruiz; I. R., Babinski, M., Hollanda; M. H. B. M. \& Martins, V. T. S. (2017). Pb-Sr-Nd isotopic Characterization of USGS reference materials by Tims at CPGeo-USP. II-Workshop of Inorganic Mass Spectrometry.

Mantovani, M. S. M., Marques, L. S., Sousa, M. A. de; Atalla, L. T., Civetta, L. \& Inoccenti I. F. (1985). Trace element and strontium isotope constraints on the origin and 
evolution of the Paraná Continental flood basalts of Santa Catarina State (Southern Brazil). Journal of Petrology, 26, 187-209.

Marques, L. S. \& Ernesto, M. (2004). O magmatismo toleítico da Bacia do Paraná. Geologia do Continente Sul-Americano. In: Mantesso-Neto, V., Bartorelli, A., Carneiro, C. D. R., Brito Neves, B.B. Geologia do Continente Sul-Americano: Evolução da Obra de Fernando Flávio Marques de Almeida, Beca, 245-263.

Marques, L. S. (1988). Caracterização geoquímica das rochas vulcânicas da Bacia do Paraná: implicações petrogenéticas. Tese de Doutorado, Instituto de Astronomia, Geofísica e Ciências Atmosféricas, Universidade de São Paulo.

Marques, L. S. (2001). Geoquímica dos diques toleíticos da costa sul-sudeste do Brasil: contribuição ao conhecimento da Província Magmática do Paraná. Tese de Livre Docência, Universidade de São Paulo.

Marques, L. S., De Min, A., Rocha-Júnior, E. R. V., Babinski, M., Bellieni, G. \& Figueiredo, A. M. G. (2018). Elemental and Sr-Nd-Pb isotope geochemistry of the Florianópolis Dyke Swarm (Paraná Magmatic Province), crustal contamination and mantle source constraints. Journal of Volcanology and Geothermal Research, 355, 149164.

Marques, L. S., De Min, A., Babinski, M., Figueiredo, A. M. G., Andrade, L. L., Vicentini, C. M. \& Piccirillo, E. M. (2012). Genesis of the early Cretaceous tholeiites from Serra do Mar Dyke Swarm (Brazil), trace element and strontium, neodymium and lead isotopic constraints. South American Symposium on Isotope Geology, Medellín, Colombia, Anais, CD-ROM.

Marques, L. S., Dupré, B. \& Piccirillo, E. M. (1999). Mantle source compositions of the Paraná Magmatic Province (southern Brazil), evidence from trace element and Sr$\mathrm{Nd}-\mathrm{Pb}$ isotope geochemistry. Journal of Geodynamics, 28(4-5), 439-458.

Marques, L. S.; Ernesto, M.; Piccirillo, E. M.; Bellieni, G.; Figueiredo, A. M. G.; Min, A. (2005). Identificação de diferentes pulsos magmáticos no Enxame de Diques Toleíticos da Serra do Mar. Anais do III Simpósio de Vulcanismo e Ambientes Associados, 289-293.

Marques, L. S., Piccirilo, E. M., Melfi, A. J., Comin-Chiaramonti, P. \& Bellieni, G. (1989). Distribuição de terras raras e outros elementos traços em basaltos da Bacia do Paraná, Geochimica Brasilliensis, 3(1), 33-50. 
Marques, L. S., Rocha-Júnior, E. R. V., Babinski, M., Carvas, K. Z., Petronilho, L. A. \& De Min, A. (2016). Lead Isotope constraints on mantle sources involved in the genesis of Mesozoic high-Ti tholeiite dykes (Urubici type) from the São Francisco Craton (Southern Espinhaço). Journal of Brazilian Geology, 46, 105-122.

Marzoli, A., Melluso, L., Morra, V., Renne, P. R., Sgrosso, I., D’Antonio, M., Duarte Morais, L., Morais, E. A. A. \& Ricci, G. (1999). Geochronology and petrology of Cretaceous basaltic magmatism in the Kwanza basin (western Angola), and relationships with the Parana-Etendeka continental flood basalt province. Journal of Geodynamics 28(4-5), 341-356

McDonough, W. F. \& Sun, S. (1995). The composition of the Earth. Chemical Geology, 120, 223-253.

Milani, E. J., Melo, J. H. G., Souza P. A., Fernandes, L. A. \& França, A. B. (2007). Bacia do Paraná. Boletim de Geociências da Petrobrás, 15(2), 265-287.

Milner, S. C. \& Le Roex, A. P. (1996). Isotope characteristics of the Okenyenya igneous complex, northern Namibia: constraints on the composition of the early Tristan Plume and the origin of the EM1 mantle component. Earth and Planetary Science Letters, 141, 277-291.

Miyashiro, A. (1974). Volcanic rock series in island arcs and active continental margins. American journal of science, 274(4), 321-355.

Monteiro, H. L. J. \& Valente, S. C. (2003). Estudo petrológico comparativo das suítes de baixo-TiO2 do Enxame de Diques da Serra do Mar. In: Jornada De Iniciação Científica Da UFRuralRJ, 2003, Serpédica/RJ. Anais da Jornada de Iniciação Científica da UFRuralRJ, 54-55.

Nalimov, V. V. (1963). The application of mathematical statistics to chemical analysis. Williams, M. (trad.), Pergamon Press, 294.

Nardy A. J. R. (1996). Geologia e petrologia do vulcanismo mesozoico da região central da Bacia do Paraná. Tese de Doutorado, Instituto de Geociências e Ciências Exatas, Universidade Estadual Paulista.

Nardy, A. J. R., Machado, F. B. \& Oliveira, M. A. F. (2008). As rochas vulcânicas mesozoicas ácidas da Bacia do Paraná: litoestratigrafia e considerações geoquímicoestratigráficas. Revista Brasileira de Geociências, 38(1), 178-195. 
Peate, D. W. \& Hawkesworth, C. J. (1996). Lithospheric to asthenospheric transition in low-Ti flood basalts from southern Paraná, Brazil. Chemical Geology, 127, 1-24.

Peate, D. W. (1997). The Paraná-Etendeka Province. In: Mahoney, J.J., Coffin, M. Large Igneous Provinces, American Geophysical Union Geophysical Monograph Series, $100,217-246$.

Peate, D. W., Hawkesworth, C. J. \& Mantovani, M. S. M. (1992). Chemical stratigraphy of the Paraná lavas, South America: classification of magma types and their spatial distribution. Bulletin of Volcanology, 55, 119-139.

Peate, D. W., Hawkesworth, C. J., Mantovani, M. S. M., Rogers, N. W. \& Turner, S. P. (1999). Petrogenesis and stratigraphy of the high-Ti/Y Urubici magma type in the Paraná flood basalt province and implications for the nature of 'Dupal'- type mantle in the South Atlantic region. Journal of Petrology, 40(3), 451-473.

Peixoto, C. \& Heilbron, M. (2010). Geologia da 113lippe Italva na região entre Cantagalo e Itaocara, nordeste do Estado do Rio de Janeiro. Geociências (São Paulo), 29(3), 277-289.

Peixoto, C., Heilbron; M., Ragatky, D., Armstrong, R., Dantas, E., de Morisson Valeriano, C. \& Simonetti, A. (2017). Tectonic evolution of the Juvenile Tonian Serra da Prata magmatic arc in the Ribeira belt, SE Brazil: Implications for early west Gondwana amalgamation. Precambrian Research, 302, 221-254.

Petrini, R., Civetta, L., Piccirillo, E.M., Bellieni, B., Comin-Chiaramonti, P., Marques, L. S. \& Melfi, A. J. (1987). Mantle heterogeneity and crustal contamination in the genesis of low-Ti continental flood basalts from the Paraná plateau (Brazil), Sr-Nd isotope and geochemical evidence. Journal of Petrology, 28, 701-726.

Piccirillo, E. M \& Melfi, A. J. (1988). The Mesozoic flood volcanism of the Paraná Basin: petrogenetic and geophysical aspects. In: Santero, P., Zadro, M., Blitzkow, D., De Sá, N.C. Instituto Astronômico e Geofísico, Universidade de São Paulo.

Piccirillo, E. M., Bellieni, G., Cavazzini, G., Comin-Chiaramonti, P., Petrini, R., Melfi, A. J., Pinese, J. P. P., Zantadeschi, P. \& De Min, A. (1990). Lower Cretaceous tholeiitic dyke swarms from the Ponta Grossa Arch (southeast Brazil), Petrology, Sr-Nd isotopes and genetic relationships with the Paraná flood volcanics. Chemical Geology, 89(1), 1948. 
Piccirillo, E. M., Civetta, L., Petrini, R., Longinelli, A., Bellieni, G., CominChiaramonti, P., Marques, L. S. \& Melfi, A. J. (1989). Regional variations within the Paraná flood basalts (southern Brazil), Evidence for subcontinental mantle heterogeneity and crustal contamination. Chemical Geology, 75(1-2), 103-122.

Piccirillo, E. M., Comin-Chiaramonti, P., Bellieni, B., Civetta, L., Marques, L. S., Melfi, P., Petrini, R., Raposo, M. I. B. \& Stolfa, D. (1988). Petrogenetic aspects of continental flood basalt-rhyolite suites from the Paraná Basin. In: The Mesozoic flood volcanism of the Paraná Basin: petrogenetic and geophysical aspects. Piccirillo E. M. \& Melfi A. J. (eds.), IAG, University of São Paulo, Brazil, 179-205.

Piccirillo, E. M., Raposo, M. I. B., Melfi, A. J., Comin-Chiaramonti, P., Bellieni, B., Cordani, U. G. \& Kawashita, K. (1987). Bimodal fissural volcanlc suites from the Paraná Basin (Brazil), K-Ar age, Sr-tsotopes and geochemtstry. Geochimica Brasiliensis, 1: 53-69 Piccot, D. (1989). Comunicação Pessoal.

Polo, L. (2014). O vulcanismo ácido da Província Magmática Paraná-Etendeka na Região de Gramado Xavier, RS: Estratigrafia, estruturas, petrogênese e modelo eruptivo. Tese de Doutorado, Universidade de São Paulo.

Polo, L. A. \& Janasi, V. A. (2014). Volcanic stratigraphy of intermediate to acidic rocks in the southern Paraná Magmatic Province, Brazil. Geol USP-Ser Cient 14: 83-100.

Polo, L. A., Giordano, D., Janasi, V. A. \& Guimarães, L. F. (2018a). Effusive silicic volcanism in the Paraná Magmatic Province, South Brazil: Physico-chemical conditions of storage and eruption and considerations on the rheological behavior during emplacement. Journal of Volcanology and Geothermal Research, 355, 115-135.

Polo, L. A., Janasi, V. A., Giordano, D., Lima, E. F., Cañon-Tapia, E. \& Roverato, M. (2018b). Effusive silicic volcanism in the Paraná Magmatic Province, South Brazil: Evidence for locally-fed lava flows and domes from detailed field work. Journal of Volcanology and Geothermal Research, 355, 204-218.

Powell, R. (1984). Inversion of the assimilation and fractional crystallization (AFC) equations; characterization of contaminants from isotope and trace element relationships in volcanic suites. Journal of the Geological Society, 141(3), 447-452.

Raposo, M. I. B., Ernesto, M. \& Renne, P. R. (1998). Paleomagnetism and dating of the early Cretaceous Florianópolis dike swarm (Santa Catarina Island), Southern Brazil. Physics of the Earth and Planetary Interiors, 108(4), 275-290. 
Renne, P. R., Ernesto, M., Pacca, I. G., Col, R. S., Glen, J. M., Prevot, M. \& Perrin, M. (1992). The age of Paraná flood volcanism, rifting of Gondwanaland and JurassicCretaceous boundary. Science, 258, 975-979.

Renne, P. R., Glen, J. M., Milner, S. C. \& Duncan, A. R. (1996). Age of Etendeka flood volcanism and associated intrusions in southwestern Africa. Geology, 24, 659-662.

Rocha-Júnior, E. R. V. (2006). Comportamento de terras raras e outros elementostraço em soleiras e derrames da região norte-nordeste da província magmática do Paraná. Dissertação de Mestrado, Universidade de São Paulo.

Rocha-Júnior, E. R. V., Marques L. S., Babinski, M., Nardy, A. J. R., Figueiredo, A.M.G. \& Machado, F.B. (2013). Sr-Nd-Pb isotopic constraints on the nature of the mantle sources involved in the genesis of the high-Ti tholeiites from northern Paraná Continental Flood Basalts (Brazil). Journal of South American Earth Sciences, 46, 9-25.

Rocha-Júnior, E. R. V., Marques, L. S., Babinski, M., Machado, F. B., Petronilho, L. A., \& Nardy, A. J. R. (2020). A telltale signature of Archean lithospheric mantle in the Paraná continental flood basalts genesis. Lithos, 364, 105519.

Rollinson, H. R. (1993). Using geochemical data: evaluation, presentation, interpretation. Pearson, Prentice Hall, Essex, England.

Rudnick, R. L., Gao, S., Holland, H. D. \& Turekian, K. K. (2003). Composition of the continental crust. The crust, 3, 1-64.

Sarmento, C. C. T., Sommer, C. A., de Lima, E. F., Barreto, C. J. S., de Magalhães May Rossetti, L., \& Lafon, J. M. (2021). Mafic subvolcanic intrusions from the southern Paraná-Etendeka Large Igneous Province, Brazil: Insights from geochemistry and $\mathrm{Sr}-\mathrm{Nd}-$ $\mathrm{Pb}$ isotopes. Geological Journal, 56(2), 1143-1166.

Sato, K., Tassinari, C. G. C., Kawashita, K. \& Petronillo, L. (1995). O método geocronológico Sm-Nd no IG-USP e suas aplicações. Anais da Academia Brasileira de Ciências, 67, 313-336.

Sertek, J. P. (2010). Estudo das contaminações provenientes do processo de cominuição de amostras geológicas. Dissertação de Mestrado, Universidade de São Paulo.

Sertek, J. P., Andrade, S. \& Ulbrich, H. H. (2015). An Evaluation of the Effects of Primary and Cross-Contamination during the Preparation of Rock Powders for Chemical Determinations. Geostandards and Geoanalytical Research, 39(3), 381-397. 
Silva, L. R. \& Figueiredo, A. M. G. (1996). VISPECT program evaluation in gamma-ray spectra analysis of neutron-activated geological samples; Avaliação do programa VISPECT na análise de espectros de raios gama de amostras geológicas ativadas com nêutrons. Brasil.

Sparks, R. S. J. (1986). The role of crustal contamination in magma evolution through geological time. Earth and Planetary Science Letters, 78(2-3), 211-223.

Stormer Jr, J. C., \& Nicholls, J. (1978). XLFRAC: a program for the interactive testing of magmatic differentiation models. Computers \& Geosciences, 4(2), 143-159.

TECDOC, I. (1990). Practical aspects of operating a neutron activation analysis Laboratory. International Atomic Energy Agency IAEATEC DOC, 564.

Thiede, D. S. \& Vasconcelos, P. M. (2010). Parana flood basalts: Rapid extrusion hypothesis confirmed by new 40Ar/39Ar results. Geology, 38(8), 747-750.

Thompson, R. N., Morrison, M. A., Hendry, G. L. \& Parry, S. J. (1984). An assessment of the relative roles of crust and mantle in magma genesis: an elemental approach. Philosophical Transactions of the Royal Society of London, London, A310, 549-590.

Tupinambá, M., Heilbron, M., Oliveira, A., Pereira, A. J., Cunha, E. R. S. P., Fernandes, G. A., Ferreira, F. N., Castilho, J. G. \& Teixeira, W. (1996). Complexo Rio Negro - uma unidade estratigráfica relevante no entendimento da evolução da Faixa Ribeira. Congresso Brasileiro De Geologia, 39, Salvador, Sociedade Brasileira de Geologia. Anais, 6, 104-107.

Tupinambá, M., Teixeira, W. \& Heilbron, M. (2012). Evolução tectônica e magmática da Faixa Ribeira entre o Neoproterozoico e o Paleozoico Inferior na Região Serrana do Estado do Rio de Janeiro, Brasil. Anuário do Instituto de Geociências, 35(2), 140-151.

Turner, S., Regelous, M., Kelley, S., Hawkesworth, C. \& Mantovani, M. (1994). Magmatism and continental break-up in the South Atlantic: high precision 40Ar/39Ar geochronology. Earth and Planetary Science Letters, 121, 333-348.

Valente, S. C. (1997). Geochemical and isotopic constraints on the petrogenesis of the Cretaceous dykes of Rio de Janeiro, Brazil. Tese de Doutorado, The Queen's University of Belfast.

Valente, S. C., Corval, A., Duarte, B.P., Ellam, R.B., Fallick, A.E. \& Dutra, T. (2007). Tectonic boundaries, crustal weakness zones and plume-subcontinental lithospheric 
mantle interactions in the Serra do Mar Dyke Swarm, SE Brazil. Revista Brasileira de Geociências, 37(1), $194-201$.

Vanhaecke, F. (2012). Single-collector inductively coupled plasma mass spectrometry. In: Vanhaecke, F. \& Degryse, P. Isotopic Analysis. Wiley-VCH, Weinheim, Germany.

Vértes, A., Nagy, S., Klencsár, Z., Lovas, R. G. \& Rösch, F. (Eds.). (2010). Handbook of Nuclear Chemistry: Vol. 1: Basics of Nuclear Science; Vol. 2: Elements and Isotopes: Formation, Transformation, Distribution; Vol. 3: Chemical Applications of Nuclear Reactions and Radiation; Vol. 4: Radiochemistry and Radiopharmaceutical Chemistry in Life Sciences; Vol. 5: Instrumentation, Separation Techniques, Environmental Issues; Vol. 6: Nuclear Energy Production and Safety Issues. Springer Science \& Business Media.

Vicentini, C. M. (2015). Caracterização geoquímica e isotópica (Sr-Nd-Pb) dos litotipos subalcalinos diferenciados do Enxame da Serra do Mar. Dissertação de Mestrado, Universidade de São Paulo.

Wilson, M. (1989). Igneous petrogenesis. Unwin Hyman, London, England.

Winter, J. D. (2014). Principles of igneous and metamorphic petrology. Harlow, UK: Pearson education.

Yurimoto, H., Yamashita, A., Nishida, N. \& Sueno, S. (1989). Quantitative SIMS analysis of GSJ rock reference samples. Geochemical Journal, 23(5), 215-236.

Zanettin, B. (1984). Proposed new chemical classification of volcanic rocks. Episodes, 7, 19-20. 


\section{APÊNDICE A}

Tabela A.1. - Valores de $r_{\text {máx }}$ ou $r_{m i ́ n}$ para diferentes níveis de significâncias aplicados no teste de homogeneidade $r$ de Nalimov (1963).

\begin{tabular}{c|rrrr}
\hline $\begin{array}{c}N^{0} \text { de } \\
\text { graus de } \\
\text { liberdade }\end{array}$ & 0,10 & 0,05 & 0,025 & 0,01 \\
\cline { 2 - 5 }$(\mathrm{f})$ & & & & \\
\hline 1 & 1,406 & 1,412 & 1,414 & 1,414 \\
\hline 2 & 1,645 & 1,689 & 1,710 & 1,723 \\
\hline 3 & 1,791 & 1,869 & 1,917 & 1,955 \\
\hline 4 & 1,894 & 1,996 & 2,067 & 1,130 \\
\hline 5 & 1,974 & 2,093 & 2,182 & 2,265 \\
\hline 6 & 2,041 & 2,172 & 2,273 & 2,374 \\
\hline 7 & 2,097 & 2,237 & 2,349 & 2,464 \\
\hline 8 & 2,146 & 2,294 & 2,414 & 2,540 \\
\hline 9 & 2,190 & 2,343 & 2,470 & 2,606 \\
\hline 10 & 2,229 & 2,387 & 2,519 & 2,663 \\
\hline 11 & 2,264 & 2,426 & 2,562 & 2,714 \\
\hline 12 & 2,297 & 2,461 & 2,602 & 2,759 \\
\hline 13 & 2,326 & 2,493 & 2,638 & 2,800 \\
\hline 14 & 2,354 & 2,523 & 2,670 & 2,837 \\
\hline 15 & 2,380 & 2,551 & 2,701 & 2,871 \\
\hline 16 & 2,404 & 2,577 & 2,728 & 2,903 \\
\hline 17 & 2,426 & 2,600 & 2,754 & 2,932 \\
\hline 18 & 2,447 & 2,623 & 2,778 & 2,959 \\
\hline 19 & 2,467 & 2,644 & 2,801 & 2,984 \\
\hline 20 & 2,486 & 2,664 & 2,823 & 3,008 \\
\hline 21 & 2,504 & 2,683 & 2,843 & 3,030 \\
\hline 22 & 2,520 & 2,701 & 2,862 & 3,051 \\
\hline 23 & 2,537 & 2,717 & 2,880 & 3,071 \\
\hline & & & & \\
\hline
\end{tabular}




\section{APÊNDICE B}

Tabela B.1. - Resultados das análises por ativação neutrônica térmica realizadas no Centro do Reator de Pesquisas (CRPq) do Instituto de Pesquisas Energéticas (IPEN-CNEN/SP), em que $\overline{\mathbf{x}}$ consiste nas médias calculadas, $n$ é o número de determinações, $\sigma$ é a incerteza associada às medições e $r_{m i ́ n}$ e $r_{m a ́ x}$ para cada elemento de cada amostra.

\begin{tabular}{|c|c|c|c|c|c|c|c|c|c|c|c|c|c|c|c|c|c|c|}
\hline \multirow{2}{*}{$\begin{array}{l}\text { Amostra } \\
\text { Elemento }\end{array}$} & \multicolumn{6}{|c|}{ LMD-RJ-8018 } & \multicolumn{6}{|c|}{ LMD-RJ-8017 } & \multicolumn{6}{|c|}{ QT-SV-2D } \\
\hline & $\bar{x}$ & $1 \sigma$ & $1 \sigma(\%)$ & n & $r_{\min }$ & $r_{\text {máx }}$ & $\bar{x}$ & 10 & $1 \sigma(\%)$ & $\mathrm{n}$ & $r_{\min }$ & $r_{\text {máx }}$ & $\bar{x}$ & 10 & $1 \sigma(\%)$ & $\mathrm{n}$ & $r_{\min }$ & $r_{\text {máx }}$ \\
\hline Th & 3,64 & 0,12 & 3,3 & 3 & 1,257 & 1,190 & 4,23 & 0,14 & 3,3 & 3 & 1,257 & 1,190 & 2,83 & 0,09 & 3,2 & 6 & 1,432 & 1,879 \\
\hline Sc & 38,0 & 1,1 & 2,8 & 3 & 1,220 & 1,230 & 36,8 & 1,0 & 2,8 & 3 & 1,220 & 1,230 & 31,8 & 1,5 & 4,6 & 6 & 1,844 & 0,988 \\
\hline $\mathrm{Ba}$ & 321 & 8 & 2,5 & 2 & - & - & 207 & 5 & 2,5 & 2 & - & - & 325 & 40 & 12,2 & 6 & 1,289 & 1,132 \\
\hline Co & 42,0 & 0,1 & 0,1 & 2 & - & - & 41,5 & 0,1 & 0,1 & 2 & - & - & 45,8 & 1,9 & 4,1 & 6 & 1,383 & 1,717 \\
\hline Hf & 2,96 & 0,17 & 5,7 & 6 & 1,665 & 1,457 & 3,46 & 0,17 & 4,9 & 6 & 1,624 & 0,868 & 3,17 & 0,18 & 5,7 & 12 & 1,209 & 1,990 \\
\hline La & 16,3 & 0,3 & 2,0 & 9 & 1,864 & 1,390 & 19,9 & 0,4 & 1,8 & 9 & 1,567 & 1,198 & 18,5 & 1,1 & 5,9 & 18 & 1,091 & 1,514 \\
\hline $\mathrm{Ce}$ & 33,7 & 1,0 & 2,9 & 3 & 1,303 & 1,127 & 41,0 & 1,2 & 2,9 & 3 & 1,303 & 1,127 & 38,6 & 2,2 & 5,6 & 6 & 1,231 & 1,423 \\
\hline $\mathrm{Nd}$ & 21,2 & 0,2 & 0,9 & 2 & - & - & 30,9 & 0,3 & 0,9 & 2 & - & - & 14,5 & 1,2 & 8,5 & 5 & 1,160 & 1,498 \\
\hline Sm & 4,19 & 0,19 & 4,5 & 3 & 1,394 & 0,904 & 4,96 & 0,22 & 4,4 & 3 & 1,394 & 0,904 & 4,55 & 0,29 & 6,4 & 6 & 1,244 & 1,131 \\
\hline Eu & 1,28 & 0,08 & 6,3 & 12 & 1,295 & 1,821 & 1,39 & 0,11 & 7,9 & 12 & 1,544 & 1,396 & 1,55 & 0,11 & 7,1 & 22 & 1,452 & 2,104 \\
\hline $\mathrm{Tb}$ & 1,03 & 0,03 & 2,9 & 2 & - & - & 0,99 & 0,03 & 3,0 & 2 & - & - & 0,90 & 0,11 & 12,2 & 6 & 1,207 & 1,258 \\
\hline $\mathrm{Yb}$ & 2,22 & 0,16 & 7,2 & 8 & 1,937 & 1,096 & 2,54 & 0,07 & 2,8 & 7 & 1,632 & 1,300 & 2,78 & 0,35 & 12,6 & 18 & 1,622 & 2,393 \\
\hline Lu & 0,35 & 0,03 & 7,1 & 5 & 1,583 & 1,573 & 0,38 & 0,03 & 7,9 & 5 & 1,613 & 1,375 & 0,46 & 0,04 & 8,7 & 11 & 1,225 & 1,803 \\
\hline Ta & 0,66 & 0,01 & 1,5 & 2 & - & - & 0,74 & 0,04 & 5,4 & 2 & - & - & 0,80 & 0,14 & 17,5 & 8 & 1,011 & 1,503 \\
\hline
\end{tabular}


Tabela B.1. (Continuação) - Resultados das análises por ativação neutrônica térmica realizadas no Centro do Reator de Pesquisas (CRPq) do Instituto de Pesquisas Energéticas (IPEN-CNEN/SP), em que $\overline{\mathbf{x}}$ consiste nas médias calculadas, $n$ é o número de determinações, $\sigma$ é a incerteza associada às medições e $r_{m i ́ n}$ e $r_{m a ́ x}$ para cada elemento de cada amostra.

\begin{tabular}{|c|c|c|c|c|c|c|c|c|c|c|c|c|c|c|c|c|c|c|}
\hline \multirow{2}{*}{$\begin{array}{l}\text { Amostra } \\
\text { Elemento }\end{array}$} & \multicolumn{6}{|c|}{ LMD-RJ-8019C } & \multicolumn{6}{|c|}{ LMD-RJ-8019A } & \multicolumn{6}{|c|}{ QT-SV-1B } \\
\hline & $\bar{x}$ & $1 \sigma$ & $1 \sigma(\%)$ & $n$ & $r_{\min }$ & $r_{\text {máx }}$ & $\bar{x}$ & $1 \sigma$ & $10(\%)$ & $n$ & $r_{\min }$ & $r_{\text {máx }}$ & $\bar{x}$ & 10 & $1 \sigma(\%)$ & $n$ & $r_{\min }$ & $r_{\text {máx }}$ \\
\hline Th & 4,69 & 0,15 & 3,2 & 3 & 1,257 & 1,190 & 5,21 & 0,17 & 3,3 & 3 & 1,257 & 1,190 & 2,81 & 0,05 & 1,8 & 3 & 0,768 & 1,412 \\
\hline Sc & 35,7 & 1,0 & 2,8 & 3 & 1,220 & 1,230 & 37,0 & 1,0 & 2,8 & 3 & 1,220 & 1,230 & 30,0 & 0,4 & 1,3 & 3 & 1,014 & 1,361 \\
\hline $\mathrm{Ba}$ & 263 & 6 & 2,5 & 2 & - & - & 313 & 8 & 2,5 & 2 & - & - & 376 & 22 & 5,9 & 2 & - & - \\
\hline Co & 41,1 & 0,1 & 0,1 & 2 & - & - & 42,3 & 0,1 & 0,1 & 3 & - & - & 43,0 & 1,9 & 4,5 & 3 & 0,992 & 1,369 \\
\hline $\mathrm{Hf}$ & 3,67 & 0,17 & 4,6 & 6 & 1,361 & 1,584 & 3,87 & 0,19 & 4,9 & 6 & 1,658 & 1,391 & 5,57 & 0,15 & 2,7 & 6 & 1,477 & 1,082 \\
\hline La & 19,5 & 0,4 & 1,8 & 9 & 1,797 & 1,134 & 20,8 & 0,4 & 2,0 & 9 & 1,709 & 1,439 & 28,0 & 0,3 & 1,2 & 9 & 1,410 & 1,711 \\
\hline $\mathrm{Ce}$ & 40,4 & 1,2 & 2,9 & 3 & 1,303 & 1,127 & 42,1 & 1,2 & 2,9 & 3 & 1,303 & 1,127 & 60,4 & 1,5 & 2,5 & 3 & 1,404 & 0,848 \\
\hline $\mathrm{Nd}$ & 22,6 & 0,2 & 0,9 & 2 & - & - & 28,7 & 0,3 & 0,9 & 2 & - & - & 30,8 & 2,3 & 7,5 & 3 & 1,314 & 1,109 \\
\hline Sm & 5,11 & 0,23 & 4,5 & 3 & 1,394 & 0,904 & 5,37 & 0,24 & 4,5 & 3 & 1,394 & 0,904 & 8,15 & 0,25 & 3,1 & 3 & 1,412 & 0,771 \\
\hline Eu & 1,51 & 0,06 & 4,0 & 11 & 2,113 & 1,735 & 1,55 & 0,12 & 7,7 & 12 & 1,561 & 1,873 & 2,59 & 0,11 & 4,2 & 11 & 2,208 & 1,239 \\
\hline $\mathrm{Tb}$ & 1,16 & 0,03 & 2,6 & 2 & - & - & 1,37 & 0,04 & 2,9 & 2 & - & - & 1,20 & 0,06 & 5,0 & 3 & 1,398 & 0,882 \\
\hline $\mathrm{Yb}$ & 2,71 & 0,38 & 14,0 & 7 & 1,620 & 1,356 & 2,96 & 0,33 & 11,1 & 7 & 1,913 & 1,956 & 3,11 & 0,19 & 6,1 & 5 & 1,045 & 1,852 \\
\hline Lu & 0,44 & 0,04 & 9,1 & 5 & 1,377 & 1,133 & 0,48 & 0,05 & 10,4 & 5 & 1,391 & 1,600 & 0,47 & 0,04 & 8,5 & 5 & 1,135 & 1,445 \\
\hline $\mathrm{Ta}$ & 0,72 & 0,03 & 4,2 & 4 & 1,103 & 1,619 & 0,73 & 0,03 & 4,1 & 4 & 1,616 & 1,125 & 1,36 & 0,13 & 9,6 & 4 & 0,993 & 1,600 \\
\hline
\end{tabular}


Tabela B.1. (Continuação) - Resultados das análises por ativação neutrônica térmica realizadas no Centro do Reator de Pesquisas (CRPq) do Instituto de Pesquisas Energéticas (IPEN-CNEN/SP), em que $\overline{\mathbf{x}}$ consiste nas médias calculadas, $n$ é o número de determinações, $\sigma$ é a incerteza associada às medições e $r_{m i ́ n}$ e $r_{m a ́ x}$ para cada elemento de cada amostra.

\begin{tabular}{|c|c|c|c|c|c|c|c|c|c|c|c|c|c|c|c|c|c|c|}
\hline \multirow{2}{*}{$\begin{array}{l}\text { Amostra } \\
\text { Elemento }\end{array}$} & \multicolumn{6}{|c|}{ QT-SV-6A } & \multicolumn{6}{|c|}{ LMD-RJ-8005A } & \multicolumn{6}{|c|}{ LMD-RJ-8012 } \\
\hline & $\bar{x}$ & 10 & $1 \sigma(\%)$ & $n$ & $r_{\min }$ & $r_{\text {máx }}$ & $\bar{x}$ & $1 \sigma$ & $1 \sigma(\%)$ & $n$ & 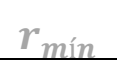 & & $\bar{x}$ & $1 \sigma$ & $1 \sigma(\%)$ & $n$ & $r_{\min }$ & $1 \mathrm{~m}$ \\
\hline Th & 3,04 & 0,06 & 2,0 & 3 & 0,768 & 1,412 & 5,37 & 0,14 & 2,6 & 3 & 1,060 & 1,341 & 5,17 & 0,17 & 3,3 & 3 & 1,257 & 1,190 \\
\hline Sc & 41,8 & 0,5 & 13 & 3 & 1,014 & 1,361 & 35,4 & 0,7 & & 3 & 0,889 & 1,397 & 37,44 & 1,04 & & 3 & 220 & 1,230 \\
\hline $\mathrm{Ba}$ & 379 & 35 & 9 & 2 & - & - & 379 & 17 & 4 & 3 & 1,050 & 1,345 & 380 & 9 & & 2 & - & - \\
\hline Co & 0,0 & 2,3 & 4,5 & 3 & 992 & 1,369 & 40,7 & 1,5 & & 3 & 0,820 & 1,408 & 44,1 & 0,1 & & 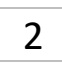 & - & - \\
\hline $\mathrm{Hf}$ & 34 & 0,12 & 3 & 6 & 1,572 & 90 & 4,52 & 0,17 & 3 & 6 & 2,040 & 0,884 & 4,54 & 0,21 & 4,6 & 6 & 1,551 & 1,229 \\
\hline La &, 3 & 0,4 & & 9 & & & 26,8 & 0,3 & & 9 & 1,428 & 86 & 27,3 & 0,5 & & 9 & 531 & 1,063 \\
\hline C & 2,5 & 1,1 & 2,5 & 3 & 1,404 & 0,848 & 55,4 & 1,5 & & 3 & 1,175 & 1,269 & 54,9 & 1 & & 3 & ,303 & 1,127 \\
\hline & ,8 & 1,6 & & 3 & 1,314 & 1,109 & 26,50 & 0,04 & & 2 & - & - & 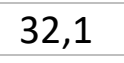 & 0 & & 2 & - & - \\
\hline $\mathrm{cm}$ & 01 & 0,16 & 3,2 & 3 & 1,412 & 0,771 & 6,14 & 0,01 & 0 , & 2 & - & - & 8 & 0,28 & 4,5 & 3 & ,394 & 0,904 \\
\hline$F_{H}$ & 1,59 & 0,08 & 5,0 & 11 & 1,484 & 1,494 & 1,76 & 0,08 & 4,5 & 12 & 1,731 & 1,374 & 1,82 & 0,08 & 4 & 12 & 1,698 & 1,924 \\
\hline $\mathrm{Tb}$ & 0,82 & 0,04 & 4,9 & 3 & 1,398 & 0,882 & 0,92 & 0,06 & 6,5 & 3 & 1,317 & 1,104 & 1,47 & 0,04 & 2 & 2 & - & - \\
\hline $\mathrm{Yb}$ & 2,99 & 0,20 & 6,7 & 5 & 1,067 & 1,823 & 3,10 & 0,35 & 11,3 & 10 & 1,837 & 1,507 & 3,22 & 0,19 & 8,0 & 7 & 639 & 1,579 \\
\hline Lu & 0,45 & 0,03 & 6,7 & 5 & 1,589 & 1,236 & 0,46 & 0,05 & 10,9 & 6 & 1,442 & 1,049 & 0,58 & 0,08 & 13,8 & 4 & 0,995 & 1,40 \\
\hline $\mathrm{Ta}$ & 0,84 & 0,12 & 4,3 & 4 & 1,026 & 1,447 & 0,97 & 0,08 & 8,2 & 4 & 1,457 & 1,242 & 1,03 & 0,05 & 4,9 & 4 & 1,111 & 1,607 \\
\hline
\end{tabular}


Tabela B.1. (Continuação) - Resultados das análises por ativação neutrônica térmica realizadas no Centro do Reator de Pesquisas (CRPq) do Instituto de Pesquisas Energéticas (IPEN-CNEN/SP), em que $\overline{\mathbf{x}}$ consiste nas médias calculadas, $n$ é o número de determinações, $\sigma$ é a incerteza associada às medições e $r_{m i ́ n}$ e $r_{m a ́ x}$ para cada elemento de cada amostra.

\begin{tabular}{|c|c|c|c|c|c|c|c|c|c|c|c|c|c|c|c|c|c|c|}
\hline Amostra & & & LMD-8 & 004 & & & & & QT-S & $/-6 B$ & & & & & LMD-RJ- & -801 & & \\
\hline Elemento & $\bar{x}$ & $1 \sigma$ & $1 \sigma(\%)$ & $n$ & $r_{\text {mín }}$ & $r_{\text {máx }}$ & $\bar{x}$ & $1 \sigma$ & $1 \sigma(\%)$ & $n$ & $r_{\min }$ & $r_{\text {máx }}$ & $\bar{x}$ & $1 \sigma$ & $1 \sigma(\%)$ & $n$ & $r_{\min }$ & $r_{\text {máx }}$ \\
\hline Th & 5,14 & 0,13 & 2,5 & 3 & 1,060 & 1,341 & 3,55 & 0,18 & 5,1 & 6 & 1,320 & 1,399 & 4,57 & 0,12 & 2,6 & 3 & 1,060 & 1,341 \\
\hline $\mathrm{Sc}$ & 35,7 & 0,7 & 2,0 & 3 & 0,889 & 1,397 & 39,5 & 1,5 & 3,7 & 6 & 1,602 & 1,657 & 37,0 & 0,8 & 2,0 & 3 & 0,889 & 1,397 \\
\hline $\mathrm{Ba}$ & 413 & 19 & 4,5 & 3 & 1,050 & 1,345 & 341 & 16 & 4,6 & 6 & 1,067 & 0,823 & 250 & 11 & 4,5 & 3 & 1,05 & 1,35 \\
\hline Co & 42,4 & 1,6 & 3,7 & 3 & 0,820 & 1,408 & 54,5 & 1,5 & 2,8 & 6 & 1,363 & 1,819 & 41,6 & 1,5 & 3,7 & 3 & 0,820 & 1,408 \\
\hline $\mathrm{Hf}$ & 4,39 & 0,15 & 3,4 & 6 & 1,925 & 0,915 & 3,71 & 0,24 & 6,5 & 12 & 1,743 & 1,096 & 4,76 & 0,17 & 3,6 & 6 & 1,422 & 1,340 \\
\hline La & 26,1 & 0,3 & 1,3 & 9 & 1,326 & 2,119 & 22,5 & 0,8 & 3,4 & 18 & 2,110 & 1,161 & 21,41 & 0,28 & 1,3 & 9 & 1,216 & 1,459 \\
\hline $\mathrm{Ce}$ & 53,1 & 1,4 & 2,7 & 3 & 1,175 & 1,269 & 47,0 & 3,6 & 7,6 & 6 & 1,239 & 1,590 & 46,25 & 1,25 & 2,7 & 3 & 1,175 & 1,269 \\
\hline $\mathrm{Nd}$ & 31,5 & 0,1 & 0,2 & 2 & - & - & 18,6 & 2,1 & 11,4 & 5 & 1,214 & 1,358 & 34,6 & 2,6 & 7,5 & 2 & - & - \\
\hline $\mathrm{Sm}$ & 6,07 & 0,01 & 0,2 & 2 & - & - & 5,67 & 0,09 & 1,6 & 6 & 1,779 & 1,230 & 6,45 & 0,22 & 3,4 & 2 & - & - \\
\hline Eu & 1,76 & 0,07 & 4,0 & 12 & 1,591 & 1,295 & 1,78 & 0,11 & 6,2 & 22 & 1,065 & 1,363 & 1,98 & 0,05 & 2,5 & 12 & 1,636 & 2,026 \\
\hline $\mathrm{Tb}$ & 0,79 & 0,05 & 6,3 & 3 & 1,317 & 1,104 & 0,91 & 0,09 & 9,9 & 6 & 1,512 & 1,582 & 0,97 & 0,06 & 6,2 & 3 & 1,317 & 1,104 \\
\hline $\mathrm{Yb}$ & 3,01 & 0,36 & 12,0 & 10 & 1,766 & 1,617 & 3,29 & 0,42 & 12,8 & 18 & 2,286 & 1,504 & 3,74 & 0,37 & 9,9 & 10 & 2,010 & 1,117 \\
\hline Lu & 0,45 & 0,01 & 2,2 & 5 & 1,617 & 1,389 & 0,52 & 0,05 & 9,6 & 11 & 1,486 & 1,423 & 0,56 & 0,05 & 8,9 & 6 & 1,504 & 1,019 \\
\hline $\mathrm{Ta}$ & 1,08 & 0,10 & 9,3 & 4 & 1,172 & 1,471 & 1,00 & 0,19 & 19,0 & 8 & 0,954 & 1,565 & 0,72 & 0,02 & 2,8 & 2 & - & - \\
\hline
\end{tabular}


Tabela B.1. (Continuação) - Resultados das análises por ativação neutrônica térmica realizadas no Centro do Reator de Pesquisas (CRPq) do Instituto de Pesquisas Energéticas (IPEN-CNEN/SP), em que $\overline{\mathbf{x}}$ consiste nas médias calculadas, $n$ é o número de determinações, $\sigma$ é a incerteza associada às medições e $r_{m i ́ n}$ e $r_{m a ́ x}$ para cada elemento de cada amostra.

\begin{tabular}{|c|c|c|c|c|c|c|c|c|c|c|c|c|c|c|c|c|c|c|}
\hline \multirow{2}{*}{$\begin{array}{l}\text { Amostra } \\
\text { Elemento } \\
\end{array}$} & \multicolumn{6}{|c|}{ QT-SV-2A } & \multicolumn{6}{|c|}{ LMD-RJ-8000A } & \multicolumn{6}{|c|}{ LMD-RJ-8014A } \\
\hline & $\bar{x}$ & $1 \sigma$ & $1 \sigma(\%)$ & $n$ & $r_{\min }$ & $r_{\text {máx }}$ & $\bar{x}$ & $1 \sigma$ & $1 \sigma(\%)$ & n & $r_{\min }$ & $r_{\text {máx }}$ & $\bar{x}$ & $1 \sigma$ & $1 \sigma(\%)$ & $n$ & $r_{\min }$ & $r_{\text {máx }}$ \\
\hline Th & 3,02 & 0,06 & 2,0 & 3 & 0,768 & 1,412 & 2,82 & 0,07 & 2,5 & 3 & 1,060 & 1,341 & 2,77 & 0,07 & 2,5 & 3 & 1,060 & 1,341 \\
\hline Sc & 30,5 & 0,4 & 1,3 & 3 & 1,014 & 1,361 & 33,5 & 0,2 & 0,4 & 2 & & - & 32,5 & 0,7 & 2,0 & 3 & 0,889 & 1,397 \\
\hline $\mathrm{Ba}$ & 366 & 34 & 9,2 & 2 & 1,349 & 1,472 & 386 & 17 & 4,5 & 3 & 1,050 & 1,345 & 352 & 16 & 4,5 & 2 & 1,050 & 1,345 \\
\hline Co & 44,5 & 2,0 & 4,5 & 3 & 0,992 & 1,369 & 47,1 & 1,7 & 3,7 & 3 & 0,820 & 1,408 & 43,7 & 1,6 & 3,7 & 3 & 0,820 & 1,408 \\
\hline $\mathrm{Hf}$ & 5,83 & 0,15 & 2,6 & 6 & 1,563 & 1,325 & 5,76 & 0,20 & 3,5 & 6 & 1,954 & 0,862 & 5,60 & 0,24 & 4,3 & 5 & 1,854 & 1,157 \\
\hline La & 29,59 & 0,35 & 1,2 & 9 & 1,072 & 2,464 & 28,3 & 0,4 & 1,3 & 9 & 1,658 & 1,693 & 28,3 & 0,4 & 1,3 & 9 & 1,601 & 1,855 \\
\hline $\mathrm{Ce}$ & 65,29 & 1,61 & 2,5 & 3 & 1,404 & 0,848 & 62,8 & 1,7 & 2,7 & 3 & 1,175 & 1,269 & 62,1 & 1,7 & 2,7 & 3 & 1,175 & 1,269 \\
\hline $\mathrm{Nd}$ & 38,9 & 2,9 & 7,5 & 3 & 1,314 & 1,109 & 37,8 & 0,1 & 0,2 & 2 & - & - & 38,4 & 0,1 & 0,2 & 2 & - & - \\
\hline Sm & 8,63 & 0,27 & 3,1 & 3 & 1,412 & 0,771 & 8,40 & 0,01 & 0,1 & 2 & - & - & 8,38 & 0,01 & 0,1 & 2 & - & - \\
\hline Eu & 2,75 & 0,14 & 5,1 & 11 & 2,238 & 1,709 & 2,71 & 0,11 & 4,1 & 12 & 1,468 & 1,655 & 2,63 & 0,09 & 3,4 & 12 & 1,414 & 1,837 \\
\hline $\mathrm{Tb}$ & 1,24 & 0,06 & 4,8 & 3 & 1,398 & 0,882 & 1,18 & 0,07 & 5,9 & 3 & 1,317 & 1,104 & 0,97 & 0,06 & 6,2 & 3 & 1,317 & 1,104 \\
\hline $\mathrm{Yb}$ & 3,23 & 0,11 & 3,4 & 5 & 1,271 & 1,774 & 2,86 & 0,30 & 10,5 & 10 & 1,555 & 1,499 & 2,91 & 0,22 & 7,6 & 7 & 2,003 & 1,556 \\
\hline Lu & 0,51 & 0,05 & 9,8 & 5 & 1,218 & 1,433 & 0,42 & 0,03 & 7,1 & 6 & 1,567 & 1,099 & 0,40 & 0,02 & 5,0 & 5 & 1,552 & 1,220 \\
\hline Ta & 1,35 & 0,13 & 9,6 & 4 & 0,999 & 1,585 & 1,26 & 0,07 & 5,6 & 4 & 1,169 & 1,594 & 1,33 & 0,07 & 5,3 & 4 & 1,12 & 1,60 \\
\hline
\end{tabular}


Tabela B.1. (Continuação) - Resultados das análises por ativação neutrônica térmica realizadas no Centro do Reator de Pesquisas (CRPq) do Instituto de Pesquisas Energéticas (IPEN-CNEN/SP), em que $\overline{\mathbf{x}}$ consiste nas médias calculadas, $n$ é o número de determinações, $\sigma$ é a incerteza associada às medições e $r_{m i ́ n}$ e $r_{m a ́ x}$ para cada elemento de cada amostra.

\begin{tabular}{|c|c|c|c|c|c|c|c|c|c|c|c|c|c|c|c|c|c|c|}
\hline \multirow{2}{*}{$\begin{array}{l}\text { Amostra } \\
\text { Elemento }\end{array}$} & \multicolumn{6}{|c|}{ QT-SV-3 } & \multicolumn{6}{|c|}{ LMD-RJ-8013A } & \multicolumn{6}{|c|}{ QT-SV-4A } \\
\hline & $\bar{x}$ & $1 \sigma$ & $1 \sigma(\%)$ & $n$ & $r_{\min }$ & $r_{\text {máx }}$ & $\bar{x}$ & $1 \sigma$ & $1 \sigma(\%)$ & $n$ & $r_{\min }$ & $r_{\text {máx }}$ & $\bar{x}$ & $1 \sigma$ & $1 \sigma(\%)$ & $n$ & $r_{\min }$ & $r_{\text {máx }}$ \\
\hline Th & 4,63 & 0,09 & 1,9 & 3 & 1,014 & 1,148 & 2,09 & 0,07 & 3,3 & 3 & 1,257 & 1,190 & 2,82 & 0,05 & 1,8 & 3 & 0,768 & 1,412 \\
\hline Sc & 36,0 & 0,5 & 1,3 & 3 & 1,014 & 1,361 & 22,16 & 0,62 & 2,8 & 3 & 1,220 & 1,230 & 31,2 & 0,4 & 1,3 & 3 & 1,014 & 1,361 \\
\hline $\mathrm{Ba}$ & 364 & 33 & 9,2 & 2 & - & - & 245 & 6 & 2,5 & 2 & - & - & 367 & 34 & 9,2 & 2 & - & - \\
\hline Co & 44,3 & 2,0 & 4,5 & 3 & 0,992 & 1,369 & 30,6 & 0,1 & 0,1 & 2 & - & - & 48,5 & 2,2 & 4,5 & 3 & 0,992 & 1,369 \\
\hline $\mathrm{Hf}$ & 3,91 & 0,10 & 2,6 & 6 & 1,259 & 1,187 & 4,11 & 0,18 & 4,4 & 6 & 1,403 & 1,299 & 5,53 & 0,14 & 2,5 & 6 & 1,588 & 1,353 \\
\hline La & 25,0 & 0,3 & 1,3 & 9 & 1,543 & 2,064 & 21,1 & 0,4 & 1,8 & 9 & 1,804 & 1,126 & 30,5 & 0,2 & 0,8 & 8 & 1,635 & 1,485 \\
\hline $\mathrm{Ce}$ & 51,5 & 1,3 & 2,5 & 3 & 1,404 & 0,848 & 45,5 & 1,3 & 2,9 & 3 & 1,303 & 1,127 & 64,6 & 1,6 & 2,5 & 3 & 1,404 & 0,848 \\
\hline $\mathrm{Nd}$ & 22,5 & 1,7 & 7,5 & 3 & 1,314 & 1,109 & 28,5 & 0,3 & 0,9 & 3 & - & - & 37,3 & 2,8 & 7,5 & 3 & 1,314 & 1,109 \\
\hline Sm & 5,97 & 0,19 & 3,2 & 3 & 1,412 & 0,771 & 6,02 & 0,27 & 4,5 & 3 & 1,394 & 0,904 & 8,98 & 0,28 & 3,1 & 3 & 1,412 & 0,771 \\
\hline $\mathrm{Eu}$ & 1,78 & 0,11 & 6,2 & 11 & 1,168 & 2,352 & 1,89 & 0,06 & 3,2 & 11 & 1,040 & 1,991 & 2,79 & 0,12 & 4,3 & 11 & 1,797 & 1,767 \\
\hline $\mathrm{Tb}$ & 1,13 & 0,06 & 5,3 & 3 & 1,398 & 0,882 & 1,19 & 0,04 & 3,4 & 2 & - & - & 1,44 & 0,07 & 4,9 & 3 & 1,398 & 0,882 \\
\hline $\mathrm{Yb}$ & 3,55 & 0,15 & 4,2 & 5 & 1,793 & 1,143 & 2,13 & 0,18 & 8,5 & 7 & 1,918 & 1,715 & 3,41 & 0,15 & 4,4 & 5 & 0,870 & 1,646 \\
\hline Lu & 0,59 & 0,05 & 8,5 & 5 & 1,209 & 1,436 & 0,35 & 0,03 & 8,6 & 5 & 1,613 & 1,524 & 0,49 & 0,03 & 6,1 & 5 & 1,762 & 1,014 \\
\hline $\mathrm{Ta}$ & 0,91 & 0,11 & 12,1 & 3 & 0,837 & 1,047 & 0,96 & 0,07 & 7,3 & 4 & 1,126 & 1,494 & 1,44 & 0,16 & 11,1 & 4 & 1,014 & 1,536 \\
\hline
\end{tabular}




\section{APÊNDICE C}

Tabela C.1. - Análises químicas de óxidos maiores e menores (\%) e elementos traço (mg/kg), obtidas através da Fluorescência de Raios-X (FRX), para o conjunto de amostras empregado nos diagramas e modelos petrogenéticos.

\begin{tabular}{|c|c|c|c|c|c|c|c|}
\hline Amostras & $\begin{array}{c}\text { LMD-RJ- } \\
8018\end{array}$ & $\begin{array}{c}\text { QT-SV- } \\
\text { 1B }\end{array}$ & $\begin{array}{c}\text { LMD-RJ- } \\
8017\end{array}$ & $\begin{array}{c}\text { QT-SV- } \\
6 B\end{array}$ & RJ-7512 & $\begin{array}{l}\text { LMD-RJ- } \\
8000 A\end{array}$ & $\begin{array}{c}\text { LMD-RJ- } \\
8014 A\end{array}$ \\
\hline Localização & Lumiar & Lumiar & Lumiar & Lumiar & Macuco & Lumiar & Frade \\
\hline $\mathrm{SiO}_{2}$ & 53,19 & 50,39 & 52,47 & 51,24 & 53,03 & 49,95 & 49,90 \\
\hline $\mathrm{TiO}_{2}$ & 1,16 & 1,49 & 1,35 & 1,98 & 1,08 & 2,90 & 2,92 \\
\hline $\mathrm{Al}_{2} \mathrm{O}_{3}$ & 14,25 & 13,60 & 14,04 & 13,03 & 15,91 & 12,11 & 12,70 \\
\hline $\mathrm{FeO}_{\mathrm{t}}$ & 10,41 & 11,94 & 10,74 & 13,14 & 9,55 & 14,02 & 13,21 \\
\hline $\mathrm{MnO}$ & 0,19 & 0,20 & 0,19 & 0,19 & 0,17 & 0,22 & 0,20 \\
\hline $\mathrm{MgO}$ & 6,18 & 5,99 & 5,66 & 5,58 & 5,49 & 5,41 & 5,13 \\
\hline $\mathrm{CaO}$ & 9,75 & 10,05 & 9,33 & 9,56 & 9,55 & 8,45 & 8,42 \\
\hline $\mathrm{Na}_{2} \mathrm{O}$ & 2,36 & 2,23 & 2,26 & 2,59 & 2,45 & 2,37 & 2,57 \\
\hline $\mathrm{K}_{2} \mathrm{O}$ & 1,23 & 0,73 & 1,21 & 0,93 & 0,90 & 1,20 & 1,26 \\
\hline $\mathrm{P}_{2} \mathrm{O}_{5}$ & 0,16 & 0,20 & 0,19 & 0,26 & 0,20 & 0,35 & 0,34 \\
\hline $\mathrm{Na}_{2} \mathrm{O}+\mathrm{K}_{2} \mathrm{O}$ & 3,58 & 2,96 & 3,47 & 3,52 & 3,35 & 3,57 & 3,83 \\
\hline LOI & 0,32 & 0,65 & 0,54 & - & 1,41 & 0,49 & 0,68 \\
\hline $\mathrm{Cr}$ & 68 & 53 & 62 & - & 43 & 79 & 72 \\
\hline $\mathrm{Ni}$ & 54 & 65 & 52 & - & 51 & 78 & 75 \\
\hline $\mathrm{Ba}$ & 250 & 306 & 277 & - & 226 & 358 & 360 \\
\hline $\mathrm{Rb}$ & 46 & 24 & 44 & - & 25 & 27 & 31 \\
\hline $\mathrm{Sr}$ & 230 & 273 & 231 & - & 233 & 423 & 493 \\
\hline La & - & - & - & - & 13 & 29 & 31 \\
\hline $\mathrm{Ce}$ & - & - & 56 & - & 24 & 63 & 66 \\
\hline $\mathrm{Nd}$ & 19 & 20 & 30 & - & 14 & 33 & 46 \\
\hline $\mathrm{Zr}$ & 113 & 122 & 135 & - & 107 & 212 & 211 \\
\hline$Y$ & 25 & 29 & 31 & - & 26 & 37 & 34 \\
\hline $\mathrm{Nb}$ & 13 & 15 & 14 & - & 7 & 21 & 21 \\
\hline
\end{tabular}


Tabela C.1. (Continuação) - Análises químicas de óxidos maiores e menores (\%) e elementos traço $(\mathrm{mg} / \mathrm{kg})$, obtidas através da Fluorescência de Raios-X (FRX), para o conjunto de amostras empregado nos diagramas e modelos petrogenéticos.

\begin{tabular}{|c|c|c|c|c|c|c|}
\hline Amostras & RJ-7502 & $\begin{array}{l}\text { LMD-RJ- } \\
8013 A\end{array}$ & $\begin{array}{l}\text { QT-SV- } \\
\text { 2D }\end{array}$ & $\begin{array}{c}\text { QT-SV- } \\
6 A\end{array}$ & $\begin{array}{c}\text { QT-SV- } \\
2 A\end{array}$ & RJ-7505 \\
\hline Localização & $\begin{array}{l}\text { S. Sebastião da } \\
\text { Paraíba }\end{array}$ & Glicério & Lumiar & Lumiar & Lumiar & $\begin{array}{c}\text { Valão do } \\
\text { Barro }\end{array}$ \\
\hline $\mathrm{SiO}_{2}$ & 49,76 & 50,58 & 52,16 & 52,64 & 51,13 & 52,62 \\
\hline $\mathrm{TiO}_{2}$ & 3,74 & 3,01 & 1,37 & 1,54 & 2,54 & 1,28 \\
\hline $\mathrm{Al}_{2} \mathrm{O}_{3}$ & 14,53 & 12,86 & 15,91 & 13,64 & 13,08 & 15,04 \\
\hline $\mathrm{FeO}_{\mathrm{t}}$ & 12,37 & 13,29 & 11,64 & 12,26 & 12,91 & 10,59 \\
\hline $\mathrm{MnO}$ & 0,17 & 0,21 & 0,17 & 0,20 & 0,19 & 0,17 \\
\hline $\mathrm{MgO}$ & 5,02 & 5,01 & 4,98 & 4,94 & 4,93 & 4,92 \\
\hline $\mathrm{CaO}$ & 7,21 & 8,28 & 9,74 & 8,48 & 8,45 & 9,06 \\
\hline $\mathrm{Na}_{2} \mathrm{O}$ & 3,18 & 2,48 & 2,86 & 2,61 & 2,60 & 2,41 \\
\hline $\mathrm{K}_{2} \mathrm{O}$ & 1,24 & 1,42 & 1,05 & 1,43 & 1,31 & 1,10 \\
\hline $\mathrm{P}_{2} \mathrm{O}_{5}$ & 0,63 & 0,34 & 0,21 & 0,21 & 0,37 & 0,24 \\
\hline $\mathrm{Na}_{2} \mathrm{O}+\mathrm{K}_{2} \mathrm{O}$ & 4,42 & 3,90 & 3,91 & 4,04 & 3,90 & 3,51 \\
\hline LOI & 2,17 & 0,57 & - & 0,64 & 0,5 & 1,56 \\
\hline $\mathrm{Cr}$ & 82 & 68 & - & 24 & 79 & 39 \\
\hline $\mathrm{Ni}$ & 77 & 73 & - & 48 & 72 & 45 \\
\hline $\mathrm{Ba}$ & 487 & 397 & - & 391 & 395 & 283 \\
\hline $\mathrm{Rb}$ & 25 & 36 & - & 52 & 30 & 27 \\
\hline $\mathrm{Sr}$ & 521 & 467 & - & 258 & 468 & 239 \\
\hline La & 36 & - & - & 31 & 30 & 17 \\
\hline $\mathrm{Ce}$ & 76 & 51 & - & - & 74 & 32 \\
\hline $\mathrm{Nd}$ & 51 & 31 & - & 16 & 50 & 16 \\
\hline $\mathrm{Zr}$ & 213 & 223 & - & 153 & 217 & 139 \\
\hline Y & 34 & 39 & - & 37 & 39 & 30 \\
\hline $\mathrm{Nb}$ & 20 & 21 & - & 18 & 21 & 9 \\
\hline
\end{tabular}


Tabela C.1. (Continuação) - Análises químicas de óxidos maiores e menores (\%) e elementos traço $(\mathrm{mg} / \mathrm{kg})$, obtidas através da Fluorescência de Raios-X (FRX), para o conjunto de amostras empregado nos diagramas e modelos petrogenéticos.

\begin{tabular}{|c|c|c|c|c|c|c|c|c|}
\hline Amostras & QT-SV-3 & $\begin{array}{c}\text { QT-SV- } \\
\text { 4A }\end{array}$ & RJ-7500 & $\begin{array}{c}\text { LMD-RJ- } \\
8012\end{array}$ & $\begin{array}{c}\text { LMD-RJ- } \\
8004\end{array}$ & $\begin{array}{c}\text { LMD-RJ- } \\
8006\end{array}$ & $\begin{array}{l}\text { LMD-RJ- } \\
8019 \mathrm{C}\end{array}$ & $\begin{array}{c}\text { LMD-RJ- } \\
\text { 8019A }\end{array}$ \\
\hline Localização & Lumiar & Lumiar & Murinel & Lumiar & Lumiar & Lumiar & Lumiar & Lumiar \\
\hline $\mathrm{SiO}_{2}$ & 49,97 & 49,98 & 49,63 & 52,95 & 52,27 & 52,83 & 53,30 & 53,44 \\
\hline $\mathrm{TiO}_{2}$ & 2,98 & 3,09 & 3,86 & 1,59 & 1,60 & 1,57 & 1,43 & 1,48 \\
\hline $\mathrm{Al}_{2} \mathrm{O}_{3}$ & 12,81 & 12,78 & 14,49 & 13,52 & 13,46 & 13,53 & 13,55 & 13,39 \\
\hline $\mathrm{FeO}_{\mathrm{t}}$ & 13,27 & 13,49 & 12,26 & 12,46 & 12,29 & 12,38 & 11,90 & 12,08 \\
\hline $\mathrm{MnO}$ & 0,20 & 0,20 & 0,17 & 0,21 & 0,21 & 0,22 & 0,20 & 0,20 \\
\hline $\mathrm{MgO}$ & 4,89 & 4,87 & 4,80 & 4,76 & 4,74 & 4,74 & 4,72 & 4,62 \\
\hline $\mathrm{CaO}$ & 8,56 & 8,30 & 8,21 & 8,50 & 8,70 & 8,45 & 8,53 & 8,18 \\
\hline $\mathrm{Na}_{2} \mathrm{O}$ & 2,36 & 2,52 & 2,61 & 2,48 & 2,45 & 2,45 & 2,45 & 2,53 \\
\hline $\mathrm{K}_{2} \mathrm{O}$ & 1,28 & 1,29 & 1,32 & 1,36 & 1,18 & 1,40 & 1,29 & 1,50 \\
\hline $\mathrm{P}_{2} \mathrm{O}_{5}$ & 0,37 & 0,35 & 0,76 & 0,23 & 0,22 & 0,22 & 0,19 & 0,20 \\
\hline $\mathrm{Na}_{2} \mathrm{O}+\mathrm{K}_{2} \mathrm{O}$ & 3,64 & 3,81 & 3,93 & 3,84 & 3,63 & 3,85 & 3,74 & 4,03 \\
\hline LOI & 0,72 & 0,54 & 2,19 & 0,54 & 0,46 & 0,51 & 0,65 & 0,65 \\
\hline $\mathrm{Cr}$ & 70 & 68 & 46 & 25 & 26 & 21 & 14 & - \\
\hline $\mathrm{Ni}$ & 71 & 69 & 43 & 46 & 47 & 47 & 38 & 39 \\
\hline $\mathrm{Ba}$ & 387 & 410 & 468 & 371 & 389 & 408 & 286 & 299 \\
\hline $\mathrm{Rb}$ & 30 & 31 & 19 & 41 & 39 & 45 & 48 & 59 \\
\hline $\mathrm{Sr}$ & 453 & 453 & 635 & 244 & 247 & 235 & 218 & 212 \\
\hline La & - & 28 & 42 & - & 31 & - & 31 & - \\
\hline $\mathrm{Ce}$ & 72 & 78 & 79 & 49 & 43 & 63 & - & - \\
\hline $\mathrm{Nd}$ & 36 & 41 & 50 & 27 & 24 & 30 & 32 & 23 \\
\hline $\mathrm{Zr}$ & 216 & 219 & 213 & 168 & 169 & 171 & 138 & 140 \\
\hline$Y$ & 39 & 39 & 36 & 35 & 34 & 33 & 30 & 31 \\
\hline $\mathrm{Nb}$ & 22 & 21 & 22 & 18 & 18 & 18 & 13 & 14 \\
\hline
\end{tabular}


Tabela C.1. (Continuação) - Análises químicas de óxidos maiores e menores (\%) e elementos traço $(\mathrm{mg} / \mathrm{kg})$, obtidas através da Fluorescência de Raios-X (FRX), para o conjunto de amostras empregado nos diagramas e modelos petrogenéticos.

\begin{tabular}{|c|c|c|c|c|c|c|}
\hline Amostras & $\begin{array}{c}\text { LMD-RJ- } \\
8005 A\end{array}$ & RJ-7513 & RJ-7511 & RJ-7508 & $\begin{array}{c}\text { LMD-RJ- } \\
8010\end{array}$ & RJ-7504 \\
\hline Localização & Lumiar & Macuco & $\begin{array}{l}\text { Bom } \\
\text { Jardim }\end{array}$ & $\begin{array}{l}\text { Bom } \\
\text { Jardim }\end{array}$ & Lumiar & $\begin{array}{c}\mathrm{P} . \\
\text { Marinho }\end{array}$ \\
\hline $\mathrm{SiO}_{2}$ & 52,88 & 53,83 & 53,33 & 50,22 & 51,81 & 51,38 \\
\hline $\mathrm{TiO}_{2}$ & 1,58 & 1,46 & 1,59 & 3,80 & 2,05 & 3,54 \\
\hline $\mathrm{Al}_{2} \mathrm{O}_{3}$ & 13,63 & 14,97 & 15,03 & 15,04 & 12,33 & 14,01 \\
\hline $\mathrm{FeO}_{\mathrm{t}}$ & 12,18 & 10,93 & 11,55 & 12,32 & 14,56 & 12,62 \\
\hline $\mathrm{MnO}$ & 0,20 & 0,17 & 0,18 & 0,19 & 0,22 & 0,17 \\
\hline MgO & 4,58 & 4,21 & 4,19 & 3,98 & 3,78 & 3,56 \\
\hline $\mathrm{CaO}$ & 7,89 & 8,17 & 8,20 & 7,54 & 7,91 & 6,77 \\
\hline $\mathrm{Na}_{2} \mathrm{O}$ & 2,97 & 2,45 & 2,37 & 2,84 & 2,59 & 2,97 \\
\hline $\mathrm{K}_{2} \mathrm{O}$ & 1,55 & 1,42 & 1,31 & 1,51 & 1,40 & 1,58 \\
\hline $\mathrm{P}_{2} \mathrm{O}_{5}$ & 0,23 & 0,30 & 0,30 & 0,67 & 0,25 & 0,50 \\
\hline $\mathrm{Na}_{2} \mathrm{O}+\mathrm{K}_{2} \mathrm{O}$ & 4,52 & 3,87 & 3,69 & 4,35 & 3,99 & 4,55 \\
\hline LOI & 0,62 & 1,85 & 1,79 & 1,61 & 0,56 & 1,88 \\
\hline $\mathrm{Cr}$ & 22 & 29 & 27 & 127 & - & 45 \\
\hline $\mathrm{Ni}$ & 43 & 35 & 34 & 88 & 38 & 55 \\
\hline $\mathrm{Ba}$ & 411 & 371 & 345 & 460 & 316 & 510 \\
\hline $\mathrm{Rb}$ & 57 & 38 & 34 & 26 & 53 & 29 \\
\hline $\mathrm{Sr}$ & 230 & 243 & 238 & 526 & 198 & 472 \\
\hline La & - & 26 & 32 & 41 & 31 & 37 \\
\hline $\mathrm{Ce}$ & 59 & 45 & 43 & 79 & 45 & 77 \\
\hline $\mathrm{Nd}$ & 33 & 23 & 28 & 50 & 27 & 48 \\
\hline $\mathrm{Zr}$ & 172 & 171 & 170 & 228 & 173 & 246 \\
\hline Y & 33 & 35 & 38 & 38 & 41 & 38 \\
\hline $\mathrm{Nb}$ & 19 & 11 & 11 & 21 & 15 & 21 \\
\hline
\end{tabular}


Tabela C.1. (Continuação) - Análises químicas de óxidos maiores e menores (\%) e elementos traço $(\mathrm{mg} / \mathrm{kg})$, obtidas através da Fluorescência de Raios-X (FRX), para o conjunto de amostras empregado nos diagramas e modelos petrogenéticos.

\begin{tabular}{|c|c|c|c|c|c|}
\hline Amostras & RJ-7506 & RJ-7501 & RJ-7510 & RJ-7507 & RJ-7509 \\
\hline Localização & $\begin{array}{c}\text { São Sebastião } \\
\text { Alto }\end{array}$ & Sumidouro & $\begin{array}{l}\text { Bom } \\
\text { Jardim }\end{array}$ & $\begin{array}{c}\text { São Sebastião } \\
\text { Alto }\end{array}$ & $\begin{array}{c}\text { Bom } \\
\text { Jardim }\end{array}$ \\
\hline $\mathrm{SiO}_{2}$ & 51,74 & 51,99 & 53,28 & 53,23 & 53,00 \\
\hline $\mathrm{TiO}_{2}$ & 3,17 & 3,42 & 1,53 & 2,85 & 3,08 \\
\hline $\mathrm{Al}_{2} \mathrm{O}_{3}$ & 13,66 & 14,46 & 15,76 & 14,23 & 14,50 \\
\hline $\mathrm{FeO}_{\mathrm{t}}$ & 12,90 & 12,55 & 11,01 & 12,37 & 12,46 \\
\hline $\mathrm{MnO}$ & 0,18 & 0,18 & 0,16 & 0,20 & 0,18 \\
\hline $\mathrm{MgO}$ & 3,48 & 3,27 & 3,13 & 2,95 & 2,63 \\
\hline $\mathrm{CaO}$ & 6,79 & 6,86 & 8,00 & 6,40 & 6,46 \\
\hline $\mathrm{Na}_{2} \mathrm{O}$ & 2,72 & 2,90 & 2,60 & 2,88 & 2,97 \\
\hline $\mathrm{K}_{2} \mathrm{O}$ & 1,83 & 1,69 & 1,47 & 2,01 & 2,11 \\
\hline $\mathrm{P}_{2} \mathrm{O}_{5}$ & 0,60 & 0,58 & 0,34 & 0,60 & 0,65 \\
\hline $\mathrm{Na}_{2} \mathrm{O}+\mathrm{K}_{2} \mathrm{O}$ & 4,55 & 4,59 & 4,07 & 4,90 & 5,08 \\
\hline LOI & 1,93 & 1,72 & 1,75 & 1,77 & 1,63 \\
\hline $\mathrm{Cr}$ & 12 & 49 & 18 & 5 & 8 \\
\hline $\mathrm{Ni}$ & 35 & 54 & 29 & 29 & 32 \\
\hline $\mathrm{Ba}$ & 555 & 501 & 396 & 603 & 594 \\
\hline $\mathrm{Rb}$ & 38 & 30 & 38 & 47 & 41 \\
\hline $\mathrm{Sr}$ & 445 & 498 & 262 & 446 & 465 \\
\hline La & 57 & 40 & 28 & 51 & 54 \\
\hline $\mathrm{Ce}$ & 94 & 76 & 46 & 95 & 94 \\
\hline $\mathrm{Nd}$ & 57 & 51 & 32 & 52 & 57 \\
\hline $\mathrm{Zr}$ & 280 & 245 & 189 & 296 & 289 \\
\hline Y & 42 & 41 & 39 & 46 & 43 \\
\hline $\mathrm{Nb}$ & 24 & 20 & 13 & 25 & 26 \\
\hline
\end{tabular}


Tabela C.2. - Análises químicas elementos traço $(\mathrm{mg} / \mathrm{kg})$, obtidas através da Análise por Ativação Neutrônica (INAA), e análises das razões isotópicas medidas de Sr e Nd, obtidas através da Espectrometria de Massa Termoiônica, para o conjunto de amostras empregado nos diagramas e modelos petrogenéticos.

\begin{tabular}{|c|c|c|c|c|c|c|c|}
\hline Amostras & $\begin{array}{l}\text { LMD-RJ- } \\
8018\end{array}$ & $\begin{array}{c}\text { QT-SV- } \\
\text { 1B }\end{array}$ & $\begin{array}{l}\text { LMD-RJ- } \\
8017\end{array}$ & $\begin{array}{c}\text { QT-SV- } \\
6 B\end{array}$ & RJ-7512 & $\begin{array}{c}\text { LMD-RJ- } \\
8000 \mathrm{~A}\end{array}$ & $\begin{array}{c}\text { LMD-RJ- } \\
8014 A\end{array}$ \\
\hline La & 16,3 & 28,0 & 19,9 & 22,2 & 16,0 & 28,3 & 28,3 \\
\hline $\mathrm{Ce}$ & 33,7 & 60,4 & 41,0 & 47,0 & 34,6 & 62,8 & 62,1 \\
\hline $\mathrm{Nd}$ & 21,2 & 30,8 & 30,9 & 18,6 & 15,0 & 37,8 & 38,4 \\
\hline $\mathrm{Sm}$ & 4,19 & 8,15 & 4,96 & 5,67 & 3,50 & 8,40 & 8,38 \\
\hline Eu & 1,28 & 2,59 & 1,39 & 1,78 & 1,17 & 2,71 & 2,63 \\
\hline Tb & 1,03 & 1,20 & 0,99 & 0,91 & 0,74 & 1,18 & 0,97 \\
\hline $\mathrm{Yb}$ & 2,22 & 3,11 & 2,54 & 3,29 & 2,50 & 2,86 & 2,91 \\
\hline Lu & 0,35 & 0,47 & 0,38 & 0,52 & 0,35 & 0,42 & 0,40 \\
\hline Ta & 0,66 & 1,36 & 0,74 & 1,00 & 0,58 & 1,26 & 1,33 \\
\hline Th & 3,64 & 2,81 & 4,23 & 3,55 & 3,39 & 2,82 & 2,77 \\
\hline U & - & - & - & - & 0,71 & - & - \\
\hline $\mathrm{Hf}$ & 2,96 & 5,57 & 3,46 & 3,71 & 2,27 & 5,76 & 5,60 \\
\hline $\mathrm{Ba}$ & 321 & 376 & 207 & 341 & 260 & 386 & 352 \\
\hline Sc & 38,0 & 30,0 & 36,8 & 39,5 & 34,0 & 33,5 & 32,5 \\
\hline Co & 42,0 & 43,0 & 41,5 & 54,5 & 45,0 & 47,1 & 43,7 \\
\hline${ }^{87} \mathrm{Sr} /{ }^{86} \mathrm{Sr}$ & 0,708016 & - & 0,710432 & - & 0,708828 & - & - \\
\hline${ }^{143} \mathrm{Nd} /{ }^{144} \mathrm{Nd}$ & 0,512311 & - & 0,512307 & - & 0,5123402 & - & - \\
\hline
\end{tabular}


Tabela C.2. (Continuação) - Análises químicas elementos traço $(\mathrm{mg} / \mathrm{kg})$, obtidas através da Análise por Ativação Neutrônica (INAA), e análises das razões isotópicas medidas de Sr e Nd, obtidas através da Espectrometria de Massa Termoiônica, para o conjunto de amostras empregado nos diagramas e modelos petrogenéticos.

\begin{tabular}{c|ccccccc}
\hline \multirow{2}{*}{ Amostras } & RJ-7502 & $\begin{array}{r}\text { LMD-RJ- } \\
8013 A\end{array}$ & $\begin{array}{c}\text { QT-SV- } \\
\text { 2D }\end{array}$ & $\begin{array}{r}\text { QT-SV- } \\
6 \text { A }\end{array}$ & $\begin{array}{c}\text { QT-SV- } \\
\text { 2A }\end{array}$ & RJ-7505 & QT-SV-3 \\
\hline La & 35,0 & 21,1 & 18,5 & 20,3 & 29,6 & 19,8 & 25,0 \\
\hline $\mathrm{Ce}$ & 81,0 & 45,5 & 38,6 & 42,5 & 65,3 & 39,6 & 51,5 \\
\hline $\mathrm{Nd}$ & 38,4 & 28,5 & 14,5 & 20,8 & 38,9 & 19,5 & 22,5 \\
\hline $\mathrm{Sm}$ & 7,91 & 6,02 & 4,55 & 5,01 & 8,63 & 4,44 & 5,97 \\
\hline $\mathrm{Eu}$ & 3,00 & 1,89 & 1,55 & 1,59 & 2,75 & 1,36 & 1,78 \\
\hline $\mathrm{Tb}$ & 1,23 & 1,19 & 0,90 & 0,82 & 1,24 & 0,84 & 1,13 \\
\hline $\mathrm{Yb}$ & 2,60 & 2,13 & 2,78 & 2,99 & 3,23 & 2,90 & 3,55 \\
\hline $\mathrm{Lu}$ & 0,36 & 0,35 & 0,46 & 0,45 & 0,51 & 0,36 & 0,59 \\
\hline $\mathrm{Ta}$ & 1,67 & 0,96 & 0,80 & 0,84 & 1,35 & 0,76 & 0,91 \\
\hline $\mathrm{Th}$ & 3,71 & 2,09 & 2,83 & 3,04 & 3,02 & 3,76 & 4,63 \\
\hline $\mathrm{U}$ & 0,81 & - & - & - & - & 1,04 & - \\
\hline $\mathrm{Hf}$ & 6,33 & 4,11 & 3,17 & 3,34 & 5,83 & 3,51 & 3,91 \\
\hline $\mathrm{Ba}$ & 466 & 245 & 325 & 379 & 366 & 300 & 364 \\
\hline $\mathrm{Sc}$ & 34,0 & 22,2 & 31,8 & 41,8 & 30,5 & 34,0 & 36,0 \\
\hline $\mathrm{Co}$ & 47,0 & 31,3 & 45,8 & 49,9 & 44,5 & 44,0 & 44,3 \\
\hline${ }^{87} \mathrm{Sr} /{ }^{86} \mathrm{Sr}$ & 0,706447 & - & - & - & - & 0,708682 & - \\
\hline${ }_{143} \mathrm{Nd} /{ }^{144} \mathrm{Nd}$ & 0,512392 & - & - & - & - & 0,512324 & - \\
\hline
\end{tabular}


Tabela C.2. (Continuação) - Análises químicas elementos traço $(\mathrm{mg} / \mathrm{kg})$, obtidas através da Análise por Ativação Neutrônica (INAA), e análises das razões isotópicas medidas de $\mathrm{Sr}$ e $\mathrm{Nd}$, obtidas através da Espectrometria de Massa Termoiônica, para o conjunto de amostras empregado nos diagramas e modelos petrogenéticos.

\begin{tabular}{c|ccccccc}
\hline \multirow{2}{*}{ Amostras } & $\begin{array}{c}\text { QT-SV- } \\
4 A\end{array}$ & RJ-7500 & $\begin{array}{c}\text { LMD-RJ- } \\
8012\end{array}$ & $\begin{array}{c}\text { LMD-RJ- } \\
8004\end{array}$ & $\begin{array}{c}\text { LMD-RJ- } \\
8019 \mathrm{C}\end{array}$ & $\begin{array}{c}\text { LMD-RJ- } \\
8019 A\end{array}$ & $\begin{array}{c}\text { LMD-RJ- } \\
8005 \mathrm{~A}\end{array}$ \\
\hline $\mathrm{La}$ & 30,5 & 29,5 & 27,3 & 26,1 & 19,5 & 20,8 & 26,8 \\
\hline $\mathrm{Ce}$ & 64,6 & 80,6 & 54,9 & 53,1 & 40,4 & 42,1 & 55,4 \\
\hline $\mathrm{Nd}$ & 37,3 & 48,0 & 32,1 & 31,5 & 22,6 & 28,7 & 26,5 \\
\hline $\mathrm{Sm}$ & 8,98 & 8,16 & 6,28 & 6,07 & 5,11 & 5,37 & 6,14 \\
\hline $\mathrm{Eu}$ & 2,79 & 3,12 & 1,82 & 1,76 & 1,51 & 1,55 & 1,76 \\
\hline $\mathrm{Tb}$ & 1,44 & 1,12 & 1,47 & 0,79 & 1,16 & 1,37 & 0,92 \\
\hline $\mathrm{Yb}$ & 3,41 & 2,22 & 3,22 & 3,01 & 2,71 & 2,96 & 3,10 \\
\hline $\mathrm{Lu}$ & 0,49 & 0,29 & 0,58 & 0,45 & 0,44 & 0,48 & 0,46 \\
\hline $\mathrm{Ta}$ & 1,44 & 1,67 & 1,03 & 1,08 & 0,72 & 0,73 & 0,97 \\
\hline $\mathrm{Th}$ & 2,82 & 3,33 & 5,17 & 5,14 & 4,69 & 5,21 & 5,37 \\
\hline $\mathrm{U}$ & - & 0,54 & - & - & - & - & - \\
\hline $\mathrm{Hf}$ & 5,53 & 6,06 & 4,54 & 4,39 & 3,67 & 3,87 & 4,52 \\
\hline $\mathrm{Ba}$ & 367 & 402 & 380 & 413 & 263 & 313 & 379 \\
\hline $\mathrm{Sc}$ & 31,2 & 27,9 & 37,4 & 35,7 & 35,7 & 37,0 & 35,4 \\
\hline $\mathrm{Co}$ & 48,5 & 44,4 & 44,1 & 42,4 & 41,1 & 43,2 & 40,7 \\
\hline${ }^{87} \mathrm{Sr} /{ }^{86} \mathrm{Sr}$ & - & - & - & - & - & 0,710819 & 0,711598 \\
\hline${ }^{143} \mathrm{Nd} /{ }^{144} \mathrm{Nd}$ & - & - & - & - & - & 0,512329 & 0,512218 \\
\hline
\end{tabular}


Tabela C.2. (Continuação) - Análises químicas elementos traço $(\mathrm{mg} / \mathrm{kg})$, obtidas através da Análise por Ativação Neutrônica (INAA), e análises das razões isotópicas medidas de $\mathrm{Sr}$ e $\mathrm{Nd}$, obtidas através da Espectrometria de Massa Termoiônica, para o conjunto de amostras empregado nos diagramas e modelos petrogenéticos.

\begin{tabular}{c|ccccccc}
\hline Amostras & RJ-7513 & RJ-7511 & RJ-7508 & $\begin{array}{c}\text { LMD-RJ- } \\
8010\end{array}$ & RJ-7504 & RJ-7506 & RJ-7501 \\
\hline La & 24,8 & 23,0 & 35,0 & 21,4 & 34,9 & 44,3 & 29,6 \\
\hline $\mathrm{Ce}$ & 47,5 & 49,5 & 75,0 & 46,3 & 71,6 & 86,3 & 71,0 \\
\hline $\mathrm{Nd}$ & 29,0 & 25,0 & 48,0 & 36,1 & 45,0 & 56,0 & 42,0 \\
\hline $\mathrm{Sm}$ & 5,90 & 5,60 & 9,40 & 6,57 & 8,90 & 10,10 & 7,80 \\
\hline $\mathrm{Eu}$ & 1,90 & 1,70 & 3,20 & 1,98 & 2,80 & 3,10 & 3,10 \\
\hline $\mathrm{Tb}$ & 1,10 & 1,00 & 1,41 & 0,97 & 1,50 & 1,60 & 1,35 \\
\hline $\mathrm{Yb}$ & 3,60 & 3,80 & 3,10 & 3,74 & 3,50 & 3,90 & 3,60 \\
\hline $\mathrm{Lu}$ & 0,55 & 0,48 & 0,41 & 0,56 & 0,40 & 0,46 & 0,42 \\
\hline $\mathrm{Ta}$ & 0,92 & 0,93 & 1,77 & 0,72 & 1,62 & 1,88 & 1,66 \\
\hline $\mathrm{Th}$ & 4,80 & 4,49 & 3,17 & 4,57 & 3,80 & 5,40 & 3,51 \\
\hline $\mathrm{U}$ & 1,04 & 1,04 & 0,67 & - & 0,87 & 1,26 & 0,76 \\
\hline $\mathrm{Hf}$ & 4,60 & 4,06 & 7,03 & 4,76 & 7,20 & 8,10 & 6,96 \\
\hline $\mathrm{Ba}$ & 364 & 328 & 437 & 250 & 522 & 571 & 478 \\
\hline $\mathrm{Sc}$ & 34,0 & 35,0 & 36,0 & 37,0 & 36,0 & 31,0 & 36,0 \\
\hline $\mathrm{Co}$ & 43,0 & 43,0 & 48,0 & 41,6 & 44,0 & 38,0 & 49,0 \\
\hline${ }^{87} \mathrm{Sr} /{ }^{86} \mathrm{Sr}$ & - & - & 0,705930 & 0,710045 & 0,706050 & - & 0,706010 \\
\hline${ }^{143} \mathrm{Nd} /{ }^{144} \mathrm{Nd}$ & - & - & 0,5124409 & 0,512393 & 0,5123825 & - & 0,5124463 \\
\hline
\end{tabular}


Tabela C.2. (Continuação) - Análises químicas elementos traço $(\mathrm{mg} / \mathrm{kg})$, obtidas através da Análise por Ativação Neutrônica (INAA), e análises das razões isotópicas medidas de $\mathrm{Sr}$ e $\mathrm{Nd}$, obtidas através da Espectrometria de Massa Termoiônica, para o conjunto de amostras empregado nos diagramas e modelos petrogenéticos.

\begin{tabular}{c|ccc}
\hline \multirow{2}{*}{ Amostras } & RJ-7510 & RJ-7507 & RJ-7509 \\
& & & \\
\hline La & 26,6 & 45,0 & 45,0 \\
\hline Ce & 51,8 & 95,0 & 88,0 \\
\hline Nd & 27,0 & 53,0 & 53,0 \\
\hline Sm & 6,10 & 10,20 & 9,10 \\
\hline Eu & 1,90 & 3,40 & 3,20 \\
\hline Tb & 1,10 & 1,52 & 1,55 \\
\hline Yb & 3,90 & 4,10 & 3,90 \\
\hline Lu & 0,53 & 0,51 & 0,50 \\
\hline Ta & 1,02 & 2,00 & 2,07 \\
\hline Th & 4,94 & 5,25 & 5,16 \\
\hline U & 1,21 & 1,20 & 1,28 \\
\hline Hf & 4,15 & 7,99 & 7,88 \\
\hline Ba & 379 & 579 & 571 \\
\hline Sc & 30,0 & 31,0 & 31,0 \\
\hline Co & 39,0 & 38,0 & 39,0 \\
\hline $87 \mathrm{Sr} / 86 \mathrm{Sr}$ & 0,708956 & 0,706818 & - \\
\hline $143 \mathrm{Nd} /{ }^{144} \mathrm{Nd}$ & 0,5123361 & 0,5124 & - \\
\hline
\end{tabular}




\section{APÊNDICE D}

Tabela D.1. - Valores representativos dos elementos maiores e menores nas fases minerais usadas nos cálculos de balanço de massa para o grupo BTi (Bellieni, dados não publicados).

\begin{tabular}{c|cccccccccc}
\hline Fases & $\mathrm{SiO}_{2}$ & $\mathrm{TiO}_{2}$ & $\mathrm{Al}_{2} \mathrm{O} 3$ & $\mathrm{FeO}_{\mathrm{t}}$ & $\mathrm{MnO}$ & $\mathrm{MgO}$ & $\mathrm{CaO}$ & $\mathrm{Na}_{2} \mathrm{O}$ & $\mathrm{K}_{2} \mathrm{O}$ & $\mathrm{P}_{2} \mathrm{O}_{5}$ \\
\hline Augita & 51,43 & 0,63 & 2,09 & 12,36 & 0,43 & 15,15 & 17,73 & 0,19 & 0 & 0 \\
\hline Pigeonita & 53,44 & 0,29 & 1,13 & 17,78 & 0,37 & 23,18 & 3,44 & 0,01 & 0 & 0 \\
\hline Plagioclásio & 53,41 & 0,07 & 29,22 & 0,66 & 0 & 0 & 11,65 & 4,68 & 0,33 & 0 \\
\hline Magnetita & 0,25 & 19,83 & 0,92 & 74,81 & 0,92 & 0,51 & 0,22 & 0 & 0 & 0 \\
\hline Olivina Fo-80 & 39,21 & 0 & 0 & 18,03 & 0,33 & 42,19 & 0,23 & 0 & 0 & 0 \\
\hline Olivina Fo-75 & 38,55 & 0 & 0 & 21,38 & 0,42 & 39,43 & 0,22 & 0 & 0 & 0 \\
\hline
\end{tabular}

Tabela D.2. - Valores representativos dos elementos maiores e menores nas fases minerais usadas nos cálculos de balanço de massa para o grupo ATi e ATi-Lumiar (Bellieni, dados não publicados).

\begin{tabular}{ccccccccccc}
\hline Fases & $\mathrm{SiO}_{2}$ & $\mathrm{TiO}_{2}$ & $\mathrm{Al}_{2} \mathrm{O}_{3}$ & $\mathrm{FeOt}$ & $\mathrm{MnO}$ & $\mathrm{MgO}$ & $\mathrm{CaO}$ & $\mathrm{Na}_{2} \mathrm{O}$ & $\mathrm{K} 2 \mathrm{O}$ & $\mathrm{P}_{2} \mathrm{O}_{5}$ \\
\hline Augita* & 51,81 & 1,01 & 2,17 & 11,3 & 0,37 & 13,82 & 19,14 & 0,36 & 0 & 0 \\
\hline Plagioclásio* & 56,84 & 0,06 & 26,92 & 0,60 & 0 & 0 & 8,97 & 5,99 & 0,72 & 0 \\
\hline Magnetita* & 0,26 & 29,39 & 0,60 & 65,90 & 0,8 & 0,16 & 0,32 & 0 & 0 & 0 \\
\hline Augita** & 51,18 & 1,01 & 1,70 & 14,00 & 0,36 & 14,52 & 16,95 & 0,25 & 0 & 0 \\
\hline Pigeonita** & 51,21 & 0,42 & 0,66 & 26,2 & 0,63 & 15,51 & 5,30 & 0,08 & 0 & 0 \\
\hline Plagioclásio** & 54,56 & 0,10 & 28,4 & 0,66 & 0 & 0 & 10,70 & 5,17 & 0,41 & 0 \\
\hline Magnetita** & 0,08 & 14,61 & 2,13 & 79,91 & 0,64 & 0,03 & 0 & 0 & 0 & 0 \\
\hline Olivina** & 33,50 & 0 & 0,01 & 48,58 & 0,68 & 17,07 & 0,16 & 0 & 0 & 0 \\
\hline Apatita & 0 & 0 & 0 & 0 & 0 & 0 & 61,04 & 0 & 0 & 38,96 \\
\hline
\end{tabular}

*MgO: $5-4 \%$

**MgO: 4 - 3\% 


\section{APÊNDICE E}

Tabela E.1. - Coeficientes de partição dos elementos traço (CF) para cada fase mineral no processo de cristalização fracionada (Marques, 1988).

\begin{tabular}{c|cccccc}
\hline CF & Olivina & Clinopiroxênio & Pigeonita & Plagioclásio & Magnetita & Apatita \\
\hline La & 0,008 & 0,11 & 0,024 & 0,180 & 0,24 & 8,20 \\
\hline Ce & 0,008 & 0,15 & 0,026 & 0,140 & 0,22 & 9,60 \\
\hline $\mathrm{Nd}$ & 0,008 & 0,30 & 0,039 & 0,100 & 0,23 & 10,00 \\
\hline $\mathrm{Sm}$ & 0,009 & 0,52 & 0,060 & 0,072 & 0,24 & 10,20 \\
\hline $\mathrm{Eu}$ & 0,009 & 0,50 & 0,051 & 0,400 & 0,22 & 6,90 \\
\hline $\mathrm{Tb}$ & 0,011 & 0,67 & 0,130 & 0,058 & 0,27 & 10,90 \\
\hline $\mathrm{Yb}$ & 0,017 & 0,65 & 0,290 & 0,040 & 0,28 & 6,40 \\
\hline $\mathrm{Lu}$ & 0,020 & 0,64 & 0,340 & 0,035 & 0,27 & 5,00 \\
\hline $\mathrm{Y}$ & 0,010 & 0,40 & 0,200 & 0,020 & 0,40 & 2,70 \\
\hline $\mathrm{Th}$ & 0,020 & 0,02 & 0,030 & 0,020 & 0,30 & 5,00 \\
\hline $\mathrm{U}$ & 0,010 & 0,03 & 0,010 & 0,030 & 0,10 & 4,00 \\
\hline $\mathrm{Hf}$ & 0,030 & 0,30 & 0,040 & 0,030 & 0,40 & 0,06 \\
\hline $\mathrm{Ba}$ & 0,010 & 0,05 & 0,030 & 0,400 & 0,20 & 0,05 \\
\hline $\mathrm{Rb}$ & 0,050 & 0,02 & 0,020 & 0,100 & 0,09 & 0,04 \\
\hline $\mathrm{Zr}$ & 0,040 & 0,20 & 0,080 & 0,070 & 0,30 & 0,30 \\
\hline $\mathrm{Sr}$ & 0,010 & 0,20 & 0,030 & 2,500 & 0,08 & 0,06 \\
\hline Sc & 0,300 & 4,00 & 2,000 & 0,040 & 1,50 & 0,05 \\
\hline $\mathrm{Co}$ & 4,000 & 2,00 & 4,000 & 0,050 & 7,00 & 0,05 \\
\hline
\end{tabular}




\section{APÊNDICE F}

Tabela F.1. - Resultados dos melhores ajustes obtidos na aplicação do modelo de cristalização fracionada nos diques BTi para o cálculo dos coeficientes de partição global dos elementos traço $\mathrm{Sr}, \mathrm{Nd}$, La, Th e $\mathrm{Zr}$ usados nas curvas do modelo AFC.

\begin{tabular}{|c|c|c|c|c|c|c|c|c|}
\hline \multicolumn{2}{|c|}{ Diferenciação } & \multicolumn{5}{|c|}{ Fases fracionadas } & \multirow[b]{2}{*}{ Mcristalizada (\%) } & \multirow[b]{2}{*}{ Eres ${ }^{2}$} \\
\hline $\begin{array}{l}\text { Magma } \\
\text { inicial }\end{array}$ & Magma final & $\begin{array}{c}\text { olivina } \\
(\%)\end{array}$ & augita (\%) & pigeonita (\%) & plagioclásio (\%) & magnetita (\%) & & \\
\hline $\begin{array}{l}\text { LMD-RJ-8018 } \\
\text { (MgO: 6,25\%) }\end{array}$ & $\begin{array}{c}\text { RJ-7510 } \\
\text { (MgO:3,22\%) }\end{array}$ & 3,916 & 49,016 & 12,954 & 34,114 & 0,000 & 34,151 & 0,065 \\
\hline $\begin{array}{c}\text { QT-SV-1B } \\
\text { (MgO: 6,19\%) }\end{array}$ & $\begin{array}{c}\mathrm{RJ}-7510 \\
\text { (MgO: } 3,22 \%)\end{array}$ & 5,239 & 55,296 & 0,000 & 32,201 & 7,275 & 39,694 & 0,089 \\
\hline $\begin{array}{c}\text { QT-SV-1B } \\
\text { (MgO: 6,19\%) }\end{array}$ & $\begin{array}{c}\mathrm{RJ}-7510 \\
\text { (MgO: } 3,22 \%)\end{array}$ & 0,000 & 46,825 & 10,811 & 35,358 & 7,004 & 46,281 & 0,044 \\
\hline
\end{tabular}

